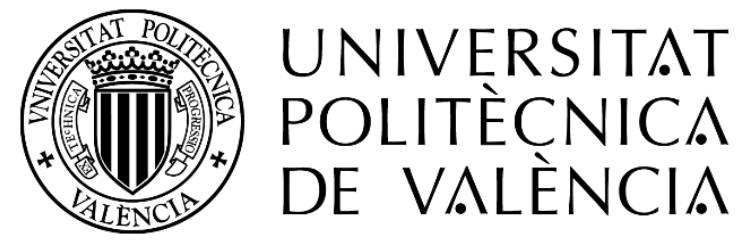

\title{
EMPLEO DE SUSTANCIAS TIPO HÚMICAS OBTENIDAS A PARTIR DE DIFERENTES RESIDUOS ORGÁNICOS EN LA ELIMINACIÓN DE CONTAMINANTES EMERGENTES
}

TESIS DOCTORAL

Autora:

Paula García Negueroles

Directores:

Ana María Amat Payá (U.P.V)

Antonio Arques Sanz (U.P.V)

Octubre 2021 

"Defiende tu derecho a pensar, porque incluso pensar de manera errónea es mejor que no pensar"

Hipatia de Alejandría 

1.1. Problemática derivada de la presencia de contaminantes emergentes ................. 3

1.2. Procesos de oxidación avanzada (POAs) ......................................................... 5

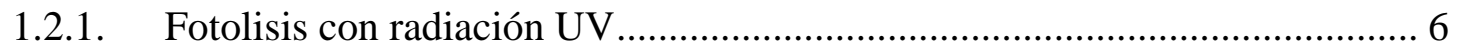

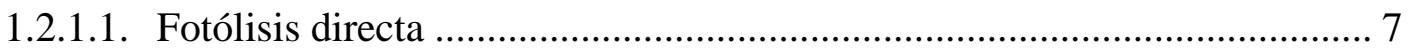

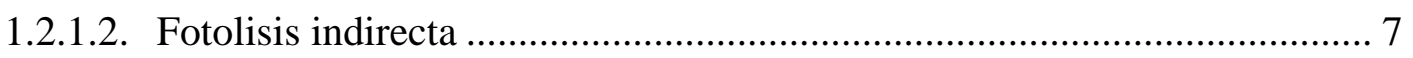

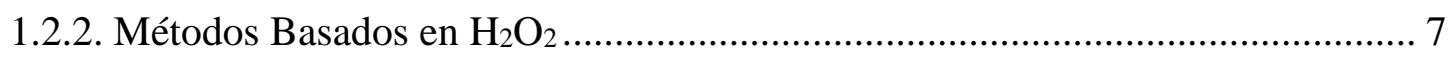

1.2.2.1. Proceso Fenton $\left(\mathrm{H}_{2} \mathrm{O}_{2}+\mathrm{Fe}^{2+}\right)$..................................................... 7

1.2.2.2. Proceso foto-Fenton $\left(\mathrm{Fe}^{2+}+\mathrm{H}_{2} \mathrm{O}_{2}+\right.$ radiación $\left.\mathrm{UV}\right)$................................ 8

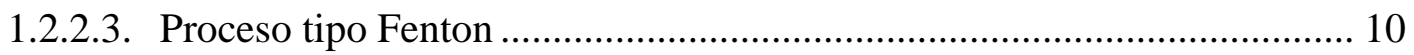

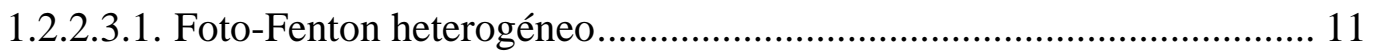

1.2.2.3.2. Adición de hierro a bajas concentraciones ......................................... 11

1.2.2.3.3. Uso de la matriz de agua para evitar la adición y desactivación del hierro ............................................................. 12

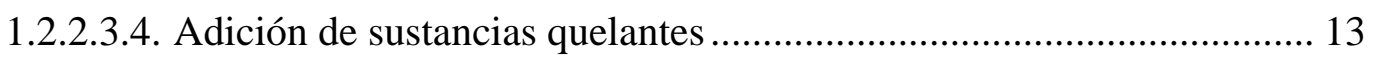

1.2.2.3.4.1. Diferentes agentes quelantes ................................................. 14

1.2.2.3.4.1.1.Ácido etilendiaminotetraacético (EDTA) .............................. 14

1.2.2.3.4.1.2.Ácido etilendiamino-N, N'-disuccinico (EDDS) .................... 16

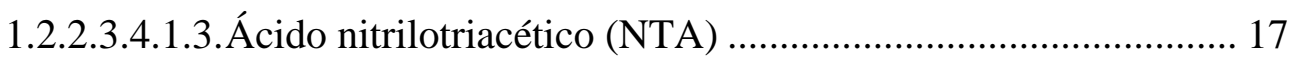

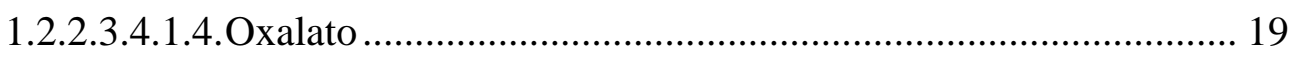

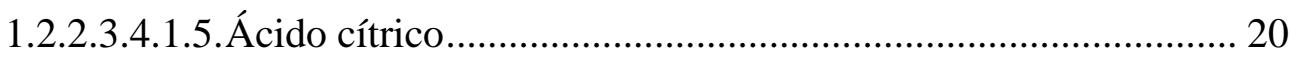

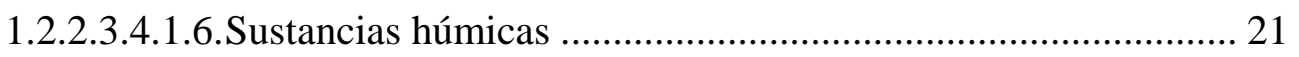

1.2.2.3.4.1.6.1. Formación de las $\mathrm{SH}$................................................... 23

1.2.2.3.4.1.6.2. Aislamiento de STH .................................................... 24

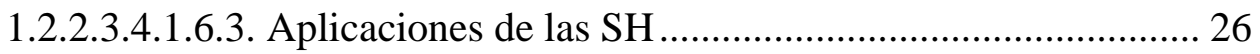

1.2.2.3.4.1.6.4. Aplicación como quelantes en proceso foto-Fenton........ 27

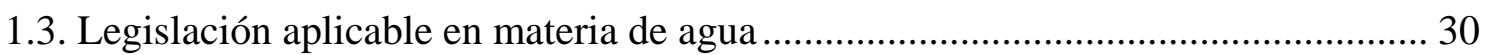

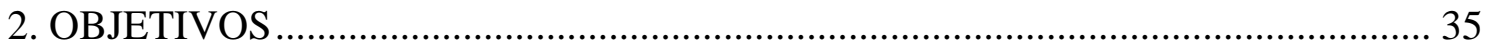

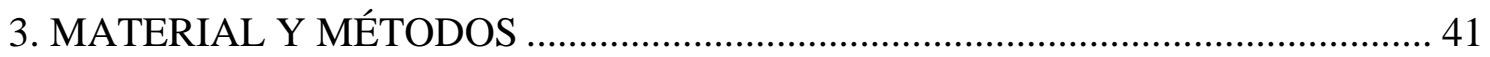

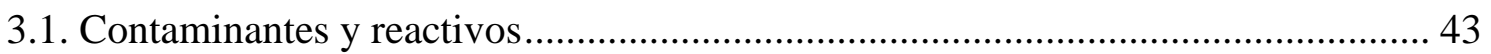




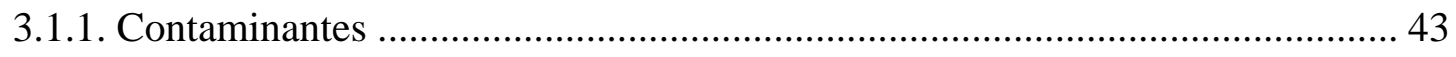

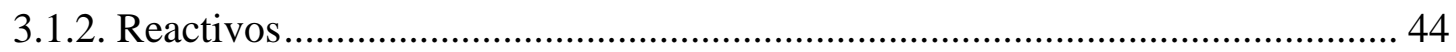

3.2. Proceso de extracción de las sustancias tipo húmicas (STH) ................................. 45

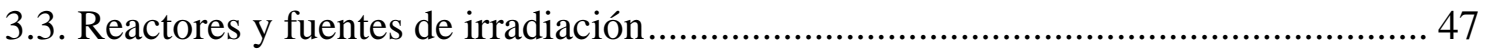

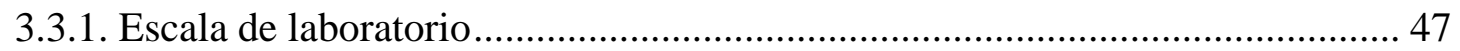

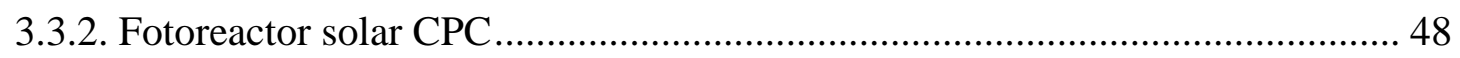

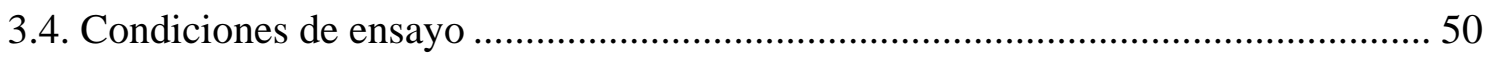

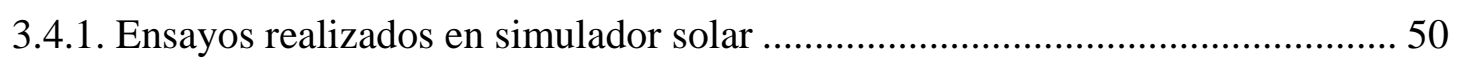

3.4.2. Ensayos realizados en la planta piloto ........................................................... 51

3.4.3. Método para la medición de la radicación solar ................................................ 51

3.4.4. Aplicación de STH en procesos de membrana ................................................ 51

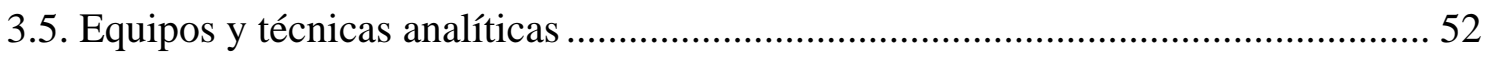

3.5.1. Medida del carbono orgánico disuelto (COD) ................................................. 52

3.5.2. Cromatografía líquida de ultra alta resolución (UHPLC) ................................. 54

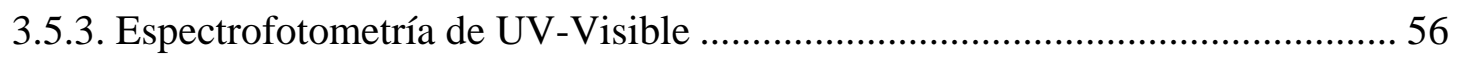

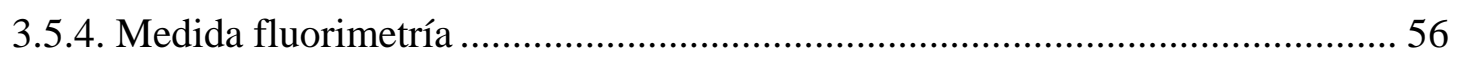

3.5.5. Método para la determinación del hierro en disolución (ISO 6332) ................. 56

3.5.6. Método para la determinación del peróxido de hidrogeno en disolución .......... 57

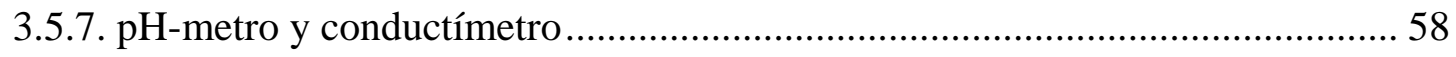

3.5.8. Medida demanda química de oxígeno (DQO) ................................................ 58

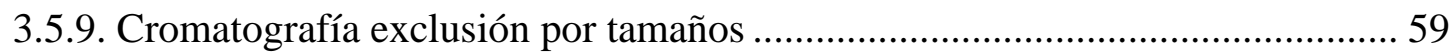

3.5.10. Cálculo \% humedad, sólidos totales y volátiles............................................... 60

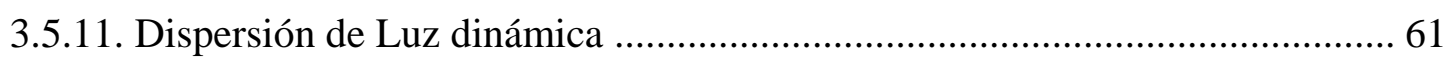

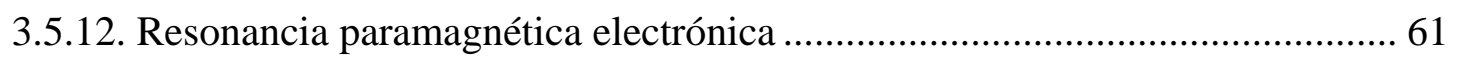

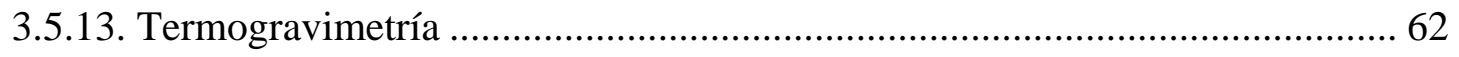

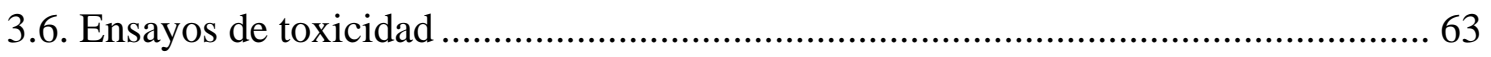

3.6.1. Bioensayo con la bacteria luminiscente Aliivibrio fischeri.............................. 63

3.6.2. Bioensayo con el alga Pseudokirchneriella subcapitata .................................. 64

3.5.3. Bioensayo de toxicidad con el microcrustáceo Daphnia magna ...................... 65

3.5.4. Ensayo toxicidad aguda lombriz de tierra Eisenia fetida ................................. 66

3.5.5. Ensayo citotoxicidad con las líneas celulares HEK y N2a ................................ 67 
3.5.6. Ensayo con levaduras recombinantes RYA (Recombinant Yeast Assay) para la evaluación de la actividad estrogénica.

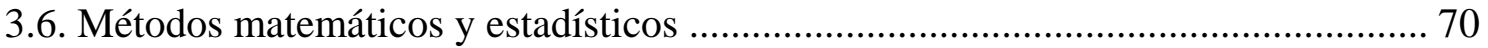

3.7.1. Análisis estadísticos de los bioensayos de toxicidad ...................................... 70

3.7.2. Análisis de matrices de excitación emisión de fluorescencia (EEM) y análisis paralelo de factores.

4.1. APLICACIÓN DE SUSTANCIAS TIPO HÚMICAS CON DIFERENTE TIEMPO DE FERMENTACIÓN PROCEDENTES DEL RESIDUO DE LA OLIVA PARA LA ELIMINACIÓN DE CONTAMINANTES EMERGENTES POR PROCESO TIPO FOTO-FENTON.

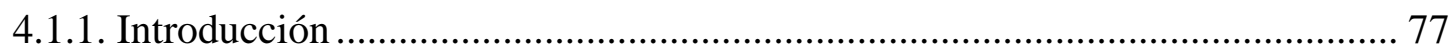

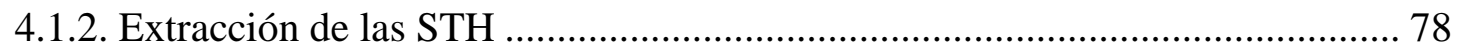

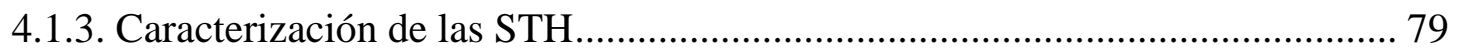

4.1.4. Aplicación de las STH en proceso foto-Fenton ............................................ 83

\subsection{EVALUACIÓN DE LA TOXICIDAD DE CUATRO CONTAMINANTES}

EMERGENTES CONTENIDOS EN LA DIRECTIVA 2013/39/CE TRATADOS POR PROCESO TIPO FOTO-FENTON EN CONDICIONES DE pH PRÓXIMAS A LA

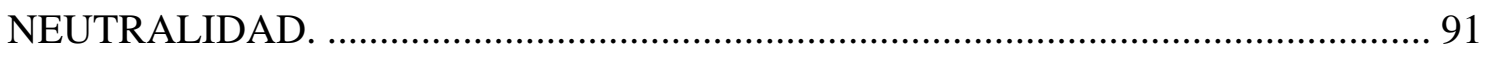

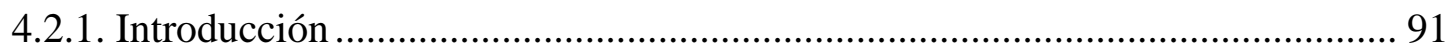

4.2.2. Extracción y caracterización de las STH .......................................................... 93

4.2.3. Aplicación de las STH en proceso foto-Fenton a pH más cercanos a la

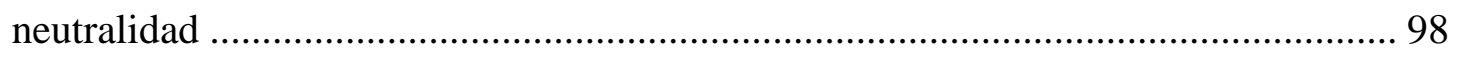

4.2.4. Experimentos en planta piloto y ensayos de toxicidad ................................ 103

4.2.4.1. Degradación en planta piloto.................................................................. 103

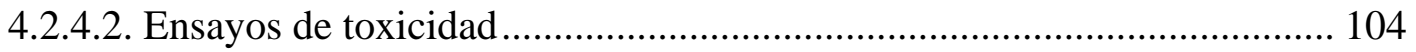

\subsection{GENERACIÓN DE RADICALES HIDROXILO CON LA UTILIZACIÓN DE}

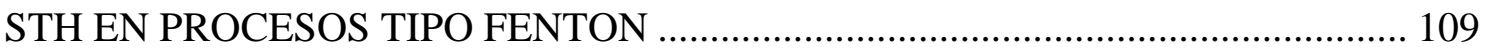

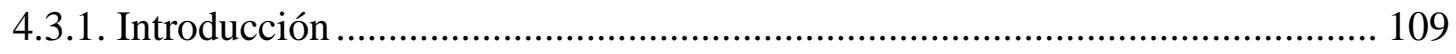


4.3.2. Generación de especies reactivas por los complejos Fe(II)-STH y Fe(III)-STH

4.3.3. Aplicación de diferentes concentraciones de STH

\subsection{ELIMINACIÓN DE CONSERVANTES COSMÉTICOS (PARABENOS)} PRESENTES EN AGUAS RESIDUALES DE LA INDUSTRIA COSMÉTICA POR PROCESO FOTO-FENTON Y EVALUACIÓN DE SU TOXICIDAD

4.4.1. Introducción

4.4.2. Selección de las STH a adicionar al proceso

4.4.3. Toxicidad aguda en organismos acuáticos

\subsection{UTILIZACIÓN DE SUSTANCIAS TIPO HÚMICAS PARA LA ELIMINACIÓN DE CONTAMINANTES POR SISTEMA DE MEMBRANAS ACOPLADO A UN PROCESO OXIDATIVO (FOTO-FENTON)}

4.5.1. Introducción

4.5.2. Extracción STH y selección del contaminante ............................................ 134

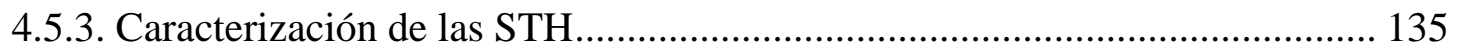

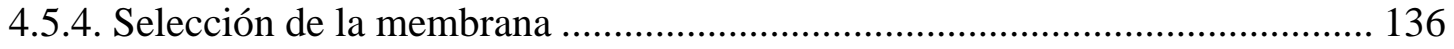

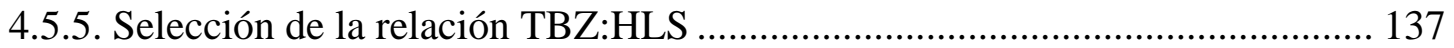

4.5.6. Selección de la presión de trabajo.................................................................... 138

4.5.7. Seguimiento del proceso por fluorescencia .................................................. 140

4.5.8. Ensayos foto-Fenton del RT obtenido al final del proceso de membranas..... 142

5. CONCLUSIONES

6. BIBLIOGRAFÍA 


\section{Índice de tablas:}

Tabla 1.1-1. Principales fuentes de entrada de microcontaminantes en el medio acuático. Fuente: Luo et al., 2014

Tabla 1.2-1 Clasificación distintos POAs de acuerdo con la fuente de generación de especies reactivas ..6

Tabla 3.1.1-1. Nombre, estructura química, porcentaje de pureza y peso molecular de cada uno de los contaminantes emergentes empleados

Tabla 3.1.2-1. Nombre, fórmula química, procedencia, riqueza y empleo experimental de los reactivos y disolventes de uso general 44

Tabla 3.5.2-1. Método cromatográfico para la determinación de la mezcla de contaminantes: TBT, DCF, CVF y PCP

Tabla 3.5.2-2. Método cromatográfico para la determinación de la mezcla de contaminantes: ACM, AMOX, CAF, ACP, CBZ y CLOF 55

Tabla 3.5.2-3. Método cromatográfico para la determinación del TBZ .55

Tabla 3.5.9-1. Método cromatográfico empleado en SEC .58

Tabla 3.5.9-2. Pesos moleculares, tiempos de retención y tiempos de elución de los diferentes patrones empleados

Tabla 4.2.2-1. Cantidad en gramos obtenida de cada fracción de STH

Tabla 4.2.2-2. Valores espectroscópicos obtenidos para cada una de las STH. Se muestran los valores $\mathrm{E}_{2} / \mathrm{E}_{3}, \mathrm{E}_{4} / \mathrm{E}_{6}$ y SUVA254 para cada fracción dializada y sin dializar, así como los valores para los AH comerciales de Sigma-Aldrich 96

Tabla 4.2.4.2-1. Valores LID y MID para las líneas celulares HEK y N2a y los organismos A. fischeri, P. subcapitata y D. magna para la mezcla de contaminantes [TBT, DCF, CVF y PCP $]_{0}$ a un $1 \mathrm{mg} \mathrm{L}^{-1}$ cada uno 106

Tabla 4.2.4.2-2. Valores LID y MID para las muestras tomadas a diferentes tiempos de tratamiento $(0,30,60$ y 180 minutos) para los diferentes organismos seleccionados. Condiciones experimentales: [Fe(III) $]_{0} 5 \mathrm{mg} \mathrm{L}^{-1},\left[\mathrm{H}_{2} \mathrm{O}_{2}\right]_{0} 10 \mathrm{mM}$, [STH $]_{0} 20 \mathrm{mg} \mathrm{L}^{-1}$, [CEs] $1 \mathrm{mg} \mathrm{L}^{-1}$ cada uno, $\mathrm{pH}_{0} 5 \mathrm{y}$ realizado en planta piloto .108 
Tabla 4.4.3-1. Valores LID y MID obtenidos para las diferentes muestras de agua para cada uno de los organismos acuáticos sobre los que se ha realizado ensayos ............126

Tabla 4.4.4-1. Toxicidad, factor de dilución Kd y actividad estrogénica (EEQs) obtenidas en el ensayo RYA para las diferentes muestras de agua estudiadas. Condiciones experimentales: [parabenos] $]_{0} \mathrm{mg} \mathrm{L}^{-1}$ cada uno, [Fe(III) $]_{0} 5 \mathrm{mg} \mathrm{L}^{-1},\left[\mathrm{H}_{2} \mathrm{O}_{2}\right]_{0} 12.59 \mathrm{mM}$,

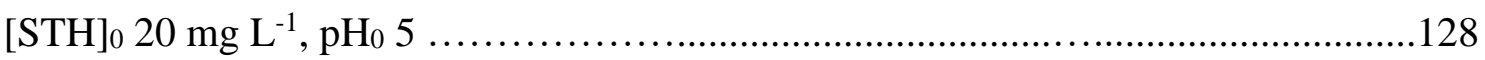




\section{Índice figuras:}

Figura 1.2.2.2-1. Especiación de los hidróxidos del Fe en función del pH para una disolución a una concentración $1.0^{*} 10^{-5} \mathrm{M}$ de Fe (III) a $25^{\circ} \mathrm{C}$. Fuente: Clarizia et al., 2017

Figura 1.2.2.3.4-1. Reacciones que tienen lugar por la complejación Fe-L. Fe(II)/Fe(III) representa todas las formas posibles de los complejos Fe-L. Fuente: Zhang \& Zhou, 2019 .13

Figura 1.2.2.3.4.1.1-1. Estructura molecular EDTA. Fuente: Sillanpää et al., 2011 .....15

Figura 1.2.2.3.4.1.1-2. Estructura octaedra del complejo metal-EDTA. Fuente: BucheliWitschel \& Egli, 2001 15

Figura 1.2.2.3.4.1.1-3. Diagrama de especiación del complejo Fe(III)-EDTA en función del pH en una disolución con una concentración de Fe(III) de $1.0^{*} 10^{-5} \mathrm{M}$ y $1.0^{*} 10^{-5} \mathrm{M}$ de EDTA a $25^{\circ} \mathrm{C}$ de temperatura. Fuente: Clarizia et al., 2017

Figura 1.2.2.3.4.1.2-1. Estructura molecular EDDS. Fuente: Bucheli-Witschel \& Egli, 2001 16

Figura 1.2.2.3.4.1.2-2. Diagrama de especiación del complejo Fe(III)-EDDS en función del $\mathrm{pH}$ en una disolución con una concentración de Fe(III) de $1.0^{*} 10^{-5} \mathrm{M}$ y $1.0^{*} 10^{-5} \mathrm{M}$ de EDDS a $25^{\circ} \mathrm{C}$ de temperatura. Fuente: Clarizia et al., 2017

Figura 1.2.2.3.4.1.3-1. Estructura molecular NTA. Fuente: Bucheli-Witschel \& Egli, 2001 .18

Figura 1.2.2.3.4.1.3-2. Estructura octaedra del complejo metal-NTA. Fuente: BucheliWitschel \& Egli, 2001 18

Figura 1.2.2.3.4.1.3-3. Diagrama de especiación del complejo Fe(III)-NTA en función del pH en una disolución con una concentración de Fe(III) de $1.0^{*} 10^{-5} \mathrm{M}$ y $1.0^{*} 10^{-5} \mathrm{M}$ de NTA a $25^{\circ} \mathrm{C}$ de temperatura. Fuente: Clarizia et al., 2017

Figura 1.2.2.3.4.1.4-1. Diagrama de especiación del complejo ferroxalato en función del $\mathrm{pH}$ en una disolución con una concentración de $\mathrm{Fe}(\mathrm{III}) \mathrm{de} 1.0^{*} 10^{-5} \mathrm{M}$ y $3.0^{*} 10^{-5} \mathrm{M}$ de oxalato a $25^{\circ} \mathrm{C}$ de temperatura. Fuente: Clarizia et al., 2017 
Figura 1.2.2.3.4.1.6-1. Propiedades fisicoquímicas de las SH. Fuente: Stevenson, 1994. 21

Figura 1.2.2.3.4.1.6-2. Ejemplo de estructura modelo de AH. Fuente: Stevenson,

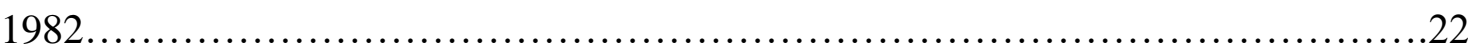

Figura 1.2.2.3.4.1.6-3. Ejemplo de estructura modelo de AF. Fuente: Buffle, 1977 .....22

Figura 1.2.2.3.4.1.6.1-1. Teoría de la lignina. Waksman, 1932 ......................23

Figura 1.2.2.3.4.1.6.1-2. Teoría del polifenol. Fuente: Stevenson, 1982 ................24

Figura 1.2.2.3.4.1.6.4-1. Principales reacciones que tienen lugar en aguas naturales por fotosensibilización de las SH. Fuente: Richard \& Canonica, 2005 .28

Figura 3.2-1. Proceso de digestión básica con $\mathrm{KOH}$ para la extracción de las STH .....46

Figura 3.3.1-1. Simulador solar utilizado en los experimentos a escala de laboratorio. ABET Sun 2000 ............................................................ 47

Figura 3.3.1-2. Espectro de irradiación de la lámpara del simulador solar empleado .....48

Figura 3.3.2-1. Geometría básica de un concentrador con receptor tubular. Fuente: Aguilar-Jiménez et al., 2016 ..............................................48

Figura 3.3.2-2. Planta piloto de fotocatálisis solar. SOLARDETOX ${ }^{\circledR}$ ACADUS$2005 / 0.25$ 49

Figura 3.4.4-1. Esquema del funcionamiento del sistema de filtración. Elaboración

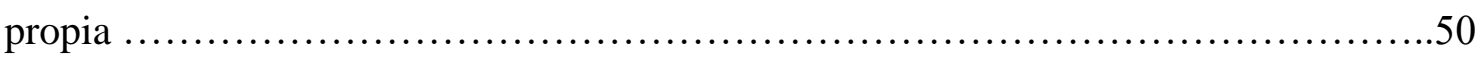

Figura 3.4.4-2. Sistema de filtración Likuid .....................................52

Figura 3.5.1-1. Analizador de Carbono Orgánico Total Shimadzu TOC-VCSH ........52

Figura 3.5.2-1. Equipo UHPLC Flexar FX-10 .................................53

Figura 3.5.3-1. Espectrofotómetro UH5300 ....................................54

Figura 3.5.4-1. Espectrofluorímetro PIT .................................... 56

Figura 3.5.7-1. pH-metro y conductímetro pHenomenal ${ }^{\circledR}$ MU6100L .................56

Figura 3.5.8-1. Termoreactor y fotómetro utilizado para la determinación de la DQO...57 
Figura 3.5.9-1. Equipo HPLC Hitachi Chromaster .57

Figura 3.5.10-1. Estufa y horno mufla empleados 58

Figura 3.5.11-1. Equipo ZETASIZER para la medición del DLS .61

Figura 3.5.12-1. Espectrómetro de resonancia paramagnética Bruker ESP 300E .....61

Figura 3.6.1-1. Módulo inyector de microplacas Tecan modelo Infinite M200 .62

Figura 3.6.2-1. Procedimiento de sembrado de las placas (izquierda) y placa a las $48 \mathrm{~h}$ de la siembra .64

Figura 3.6.3-1. Preparación del ensayo para D. magna 65

Figura 3.6.6-1. Concentración de las muestras .66

Figura 3.6.6-2. Ejemplo de siembra en las placas multipocillo para el ensayo RYA ......68

Figura 3.7.2-1. Flujo de trabajo de la aplicación EEMlab. Extraído de Micó et al., 2019 .69

Figura 4.1.3-1. Cromatograma de exclusión por tamaños obtenido para las diferentes STH. Muestras no dializadas en negro y dializadas en gris .72

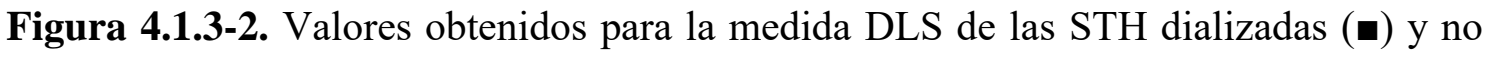
dializadas $(\diamond)$ .79

Figura 4.1.3-3. Espectro de absorbancia FTIR obtenido para las diferentes muestras de STH .80

Figura 4.1.3-4. TGA obtenido para las diferentes STH. Muestras no dializadas (negras) y dializadas (grises). Gráfica de la pérdida de peso $\left(\% /{ }^{\circ} \mathrm{C}\right)$ frente a la $\mathrm{T}\left({ }^{\circ} \mathrm{C}\right)$ . .81

Figura 4.1.3-5. EEM obtenidas para las diferentes STH. Arriba: no dializadas, abajo: dializadas 82

Figura 4.1.4-1. Degradación de la mezcla de contaminantes frente al tiempo sin la adición de STH. Condiciones experimentales: [CEs] $5 \mathrm{mg} \mathrm{L}^{-1}$ cada uno, $[\mathrm{Fe}(\mathrm{III})]_{0} 5 \mathrm{mg} \mathrm{L}^{-1}$, $\left[\mathrm{H}_{2} \mathrm{O}_{2}\right]_{0} 75 \mathrm{mg} \mathrm{L}^{-1}, \mathrm{pH}_{0} 5 . \operatorname{ACF}(\bullet), \operatorname{AMOX}(\bullet), \operatorname{CAF}(\bullet), \operatorname{ACP}(+), \operatorname{CBZ}(\mathrm{x}), \operatorname{CLOF}(\boldsymbol{\Delta})$ 
Figura 4.1.4-2. Degradación de la mezcla de contaminantes con la adición de las diferentes STH. A: MH, B: MHF, C: MHF-1A, D: MH-D, E: MHF-D, F: MHF-1A-D. Condiciones experimentales: [CEs] $5 \mathrm{mg} \mathrm{L}^{-1}$ cada uno, [Fe(III) $]_{0} 5 \mathrm{mg} \mathrm{L}^{-1}$, [H $\left.\mathrm{H}_{2} \mathrm{O}_{2}\right]_{0} 75$ $\mathrm{mg} \mathrm{L}^{-1},[\mathrm{STH}]_{0} 20 \mathrm{mg} \mathrm{L}^{-1}$. ACF (•), AMOX (•), CAF (•), ACP (+), CBZ (x), CLOF $(\boldsymbol{\Delta})$ .84

Figura 4.1.4-3. Degradación de la mezcla de contaminantes frente al tiempo. Condiciones experimentales: [CEs] $5 \mathrm{mg} \mathrm{L}^{-1}$ cada uno, [Fe(III) $]_{0} 5 \mathrm{mg} \mathrm{L}^{-1},\left[\mathrm{H}_{2} \mathrm{O}_{2}\right]_{0} 75$ $\mathrm{mg} \mathrm{L}^{-1}$, [STH $]_{0} 20 \mathrm{mg} \mathrm{L}^{-1}$ de C, $\mathrm{pH}_{0}$ 5. A: MHF, B: MHF-D. ACF (•), AMOX (घ), CAF $(\diamond), \operatorname{ACP}(+), \operatorname{CAR}(\times)$ and $\operatorname{CLOF}(\boldsymbol{\Delta})$

Figura 4.1.4-4. Huellas de los 3 componentes (C1, C2 y $\mathrm{C} 3$ respectivamente) obtenidos aplicando el método de análisis matemático PARAFAC para el conjunto de muestras de los experimentos foto-Fenton en presencia de STH. El eje X corresponde a las longitudes de onda de excitación (250-500 nm) y el eje Y a las longitudes de onda de emisión (300$600 \mathrm{~nm})$

Figura 4.1.4-5. Evolución de los componentes obtenidos por EEM-PARAFAC normalizados frente al tiempo. Foto-Fenton con $[\mathrm{MHF}]_{0} 20 \mathrm{mg} \mathrm{L}^{-1}(\bullet)$, foto-Fenton con [MHF-D]0 $20 \mathrm{mg} \mathrm{L}^{-1}(\mathbf{\square})$, foto-Fenton con $[\mathrm{MHF}]_{0} \mathrm{C} 20 \mathrm{mg} \mathrm{L}^{-1}$ (०), foto-Fenton con [MHF-D $]_{0} \mathrm{C} 20 \mathrm{mg} \mathrm{L}^{-1}(\square)$. Resto condiciones experimentales: [CEs] $5 \mathrm{mg} \mathrm{L}^{-1}$ cada uno, $[\mathrm{Fe}(\mathrm{III})]_{0} 5 \mathrm{mg} \mathrm{L}^{-1},\left[\mathrm{H}_{2} \mathrm{O}_{2}\right]_{0} 75 \mathrm{mg} \mathrm{L}^{-1}, \mathrm{pH}_{0} 5$

Figura 4.2.2-1. Cromatograma de exclusión por tamaños obtenido para las diferentes fracciones de STH dializadas y sin dializar y para los AH Sigma-Aldrich .88

Figura 4.2.2-2. Valores de DLS para las diferentes fracciones de STH dializadas (•) y sin dializar $(\boldsymbol{\Delta})$

Figura 4.4.2-3. EEMs para las tres fracciones no dializadas, la mezcla de las tres fracciones no dializadas y los AH comerciales de Sigma-Aldrich. El eje X corresponde a las longitudes de onda de excitación (250-500 nm) y el eje Y a las longitudes de onda de emisión (300-600 nm) .95

Figura 4.2.3-1. Degradación de la suma de los 4 CE (TBT, DCF, CVF y, PCP) frente al tiempo usando el simulador solar. Condiciones experimentales: [CEs] $1 \mathrm{mg} \mathrm{L}^{-1}$ cada uno, $[\mathrm{Fe}(\mathrm{III})]_{0} 5 \mathrm{mg} \mathrm{L}^{-1},\left[\mathrm{H}_{2} \mathrm{O}_{2}\right]_{0} 10 \mathrm{mM}, \mathrm{pH}_{0}$ 5. Sin adición de $\mathrm{STH}(\mathbf{A}, \mathbf{B}),>300 \mathrm{kDa}(\mathbf{C}, \mathbf{D})$, 
300-150 kDa (E, F), 150-50 kDa (G, H), mezcla de las tres fracciones de $\operatorname{STH}(\mathbf{I}, \mathbf{J})$. Agua MQ (A, C, E, G, I), agua del grifo $(\mathbf{B}, \mathbf{D}, \mathbf{F}, \mathbf{H}, \mathbf{J})$

Figura 4.2.3-2. Degradación de la suma de los 4 CEs (TBT, DCF, CVF y, PCP) vs el tiempo utilizando el simulador solar. Condiciones experimentales: [CEs] $1 \mathrm{mg} \mathrm{L}^{-1}$ cada uno, $[\mathrm{Fe}(\mathrm{III})]_{0} 5 \mathrm{mg} \mathrm{L}^{-1},\left[\mathrm{H}_{2} \mathrm{O}_{2}\right]_{0} 10 \mathrm{mM}, \mathrm{pH}_{0}$ 5. (•) sin adición de $\mathrm{STH}$, ( $\square$ ) mezcla de las tres fracciones de $[\mathrm{STH}]_{0} 20 \mathrm{mg} \mathrm{L}^{-1},(\Delta)$ [AH Sigma-Aldrich $]_{0} 20 \mathrm{mg} \mathrm{L}^{-1}$, (०) mezcla de las tres fracciones de $\left.\mathrm{STH}^{`}\right]_{0} 53.08 \mathrm{mg} \mathrm{L}^{-1},(\diamond)$ [AH Sigma-Aldrich $]_{0} 7.54 \mathrm{mg} \mathrm{L}^{-1} \ldots . .99$

Figura 4.2.3-3. Degradación de la suma de los 4 CEs (TBT, DCF, CVF y, PCP) vs el tiempo utilizando el simulador solar. Condiciones experimentales: [CEs] $1 \mathrm{mg} \mathrm{L}^{-1}$ cada uno, $[\mathrm{Fe}(\mathrm{III})]_{0} 5 \mathrm{mg} \mathrm{L}^{-1},\left[\mathrm{H}_{2} \mathrm{O}_{2}\right]_{0} 10 \mathrm{mM}, \mathrm{pH}_{0}$ 5. (匹) agua del grifo $\sin \mathrm{STH}$; (口) agua del grifo con $[\mathrm{STH}]_{0} 20 \mathrm{mg} \mathrm{L}^{-1}$; (•) agua de EDAR sin STH; (०) agua de EDAR con $[\mathrm{STH}]_{0}$ $20 \mathrm{mg} \mathrm{L}^{-1}$ 101

Figura 4.2.3-4. Fe (mg L-1) para cada uno de los experimentos a tiempo 30 minutos (gris oscuro), 60 minutos (gris claro) y 120 minutos (negro) 102

Figura 4.2.4.1-1. Degradación durante el proceso foto-Fenton a $\mathrm{pH}_{0} 5$ en ausencia de STH (A) y en presencia de STH (B). Condiciones experimentales: [CEs] $1 \mathrm{mg} \mathrm{L}^{-1}$ cada

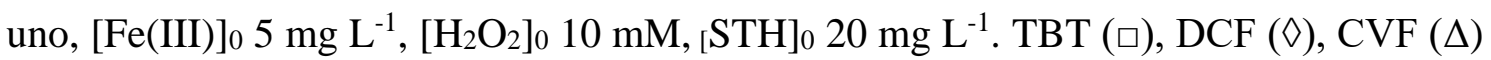
and PCP (०); Fe $\left(\mathrm{mg} \mathrm{L}^{-1}\right)(\bullet)$ y consumo de $\mathrm{H}_{2} \mathrm{O}_{2}(\bullet)$. Experimento realizado en planta piloto 102

Figura 4.2.4.2-1. Valores de $\mathrm{CE}_{50}\left(\mathrm{mg} \mathrm{L}^{-1}\right)$ para cada uno de los contaminantes seleccionados en cada ensayo toxicológico. A: citotoxicidad. HEK (gris claro), N2a (negro); B: A. fischeri; C: P. subcapitata; D: D. magna (48 h) .................... 104

Figura 4.2.4.2-2. Repulsión para los contaminantes TBT, DCF, CVF y, PCP para el organismo E. fétida. [TBT] $30 \mathrm{mg} \mathrm{L}^{-1},[\mathrm{DCF}]_{0} 30 \mathrm{mg} \mathrm{L}^{-1},[\mathrm{CVF}]_{0} 40 \mathrm{mg} \mathrm{L}^{-1},[\mathrm{PCP}]_{0} 15$ $\mathrm{mg} \mathrm{L}^{-1}$. Se muestran (A) los valores normalizados y (B) \% de respuesta 105

Figura 4.3.2-1. Espectro EPR del complejo DMPO-OH medido a pH 5 en presencia de $[\mathrm{STH}]_{0} 20 \mathrm{mg} \mathrm{L}^{-1} \mathrm{y}[\mathrm{Fe}(\mathrm{II})]_{0} 5 \mathrm{mg} \mathrm{L}^{-1}$ tras la adición de $\left[\mathrm{H}_{2} \mathrm{O}_{2}\right]_{0}\left(34 \mathrm{mg} \mathrm{L}^{-1}\right) \ldots$ 107

Figura 4.3.2-2. Variación de la señal del sistema DMPO-OH medida a pH 5 en presencia de $[\mathrm{STH}]_{0} 20 \mathrm{mg} \mathrm{L}^{-1},[\mathrm{Fe}(\mathrm{II})]_{0} 5 \mathrm{mg} \mathrm{L}^{-1}$ y $\left[\mathrm{H}_{2} \mathrm{O}_{2}\right]_{0} 34 \mathrm{mg} \mathrm{L}^{-1}$ 112 
Figura 4.3.2-3. Espectro EPR del complejo DMPO-OH medido a pH 5 en presencia de $[\mathrm{STH}]_{0} 20 \mathrm{mg} \mathrm{L}^{-1}$ y $[\mathrm{Fe}(\mathrm{III})]_{0} 5 \mathrm{mg} \mathrm{L}^{-1}$ tras la adición de $\left[\mathrm{H}_{2} \mathrm{O}_{2}\right]_{0} 34 \mathrm{mg} \mathrm{L}^{-1}$

Figura 4.3.2-4. Variación de la señal del sistema DMPO-OH medida a pH 5 en presencia de $[\mathrm{STH}]_{0} 20 \mathrm{mg} \mathrm{L}^{-1},[\mathrm{Fe}(\mathrm{III})]_{0} 5 \mathrm{mg} \mathrm{L}^{-1}$ y $\left[\mathrm{H}_{2} \mathrm{O}_{2}\right]_{0} 34 \mathrm{mg} \mathrm{L}^{-1}$

Figura 4.3.2-5. Degradación relativa de la cafeína frente al tiempo. (ロ) en presencia de $\mathrm{Fe}(\mathrm{II}) \mathrm{y}(\bullet)$ en presencia de $\mathrm{Fe}(\mathrm{III})$. Condiciones experimentales: $[\mathrm{CAF}]_{0} 5 \mathrm{mg} \mathrm{L}^{-1},[\mathrm{Fe}]_{0}$ $5 \mathrm{mg} \mathrm{L}^{-1},\left[\mathrm{H}_{2} \mathrm{O}_{2}\right]_{0} 60 \mathrm{mg} \mathrm{L}^{-1}$ y $\mathrm{pH}_{0} 5$

Figura 4.3.3-1. Señal del complejo DMPO-OH frente a diferentes concentraciones de STH a pHo 5 , [Fe(III) $]_{0} 5 \mathrm{mg} \mathrm{L}^{-1}$ y $\left[\mathrm{H}_{2} \mathrm{O}_{2}\right]_{0} 34 \mathrm{mg} \mathrm{L}^{-1}$

Figura 4.3.3-2. Porcentaje de degradación de la cafeína a los 60 minutos de tratamiento en proceso Fenton (negro) y foto-Fenton (gris). Condiciones experimentales [CAF] $]_{0} 5 \mathrm{mg}$ $\mathrm{L}^{-1},[\mathrm{Fe}(\mathrm{III})]_{0} 5 \mathrm{mg} \mathrm{L}^{-1},\left[\mathrm{H}_{2} \mathrm{O}_{2}\right]_{0} 60 \mathrm{mg} \mathrm{L}^{-1}, \mathrm{pH}_{0} 5 \mathrm{y}$ diferentes concentraciones de $[\mathrm{STH}]_{0}$ $0-40 \mathrm{mg} \mathrm{L}^{-1}$

Figura 4.3.3-3. Concentración de hierro total de acuerdo al método de la $o$-fenantrolina transcurridos 5 minutos (gris claro) y 60 minutos (gris oscuro) a pHo $5,[\mathrm{Fe}(\mathrm{III})]_{0} 5 \mathrm{mg} \mathrm{L}^{-}$ ${ }^{1}$ y diferentes concentraciones de STH $0-40 \mathrm{mg} \mathrm{L}^{-1}$. Se muestra también la medida de $[\mathrm{Fe}(\mathrm{II})]_{0} 5 \mathrm{mg} \mathrm{L}^{-1} \sin \mathrm{STH}$ a modo de control

Figura 4.3.3-4 Degradación relativa de la CAF en proceso foto-Fenton en ausencia de $\mathrm{STH}(\bullet)$ y con la adición de $30 \mathrm{mg} \mathrm{L}^{-1}$ de $[\mathrm{STH}]_{0}(\boldsymbol{\bullet})$ frente al tiempo. Condiciones experimentales: $[\mathrm{CAF}]_{0} 5 \mathrm{mg} \mathrm{L}^{-1}$, [Fe(III) $]_{0} 5 \mathrm{mg} \mathrm{L}^{-1}$, $\left[\mathrm{H}_{2} \mathrm{O}_{2}\right]_{0} 60 \mathrm{mg} \mathrm{L}^{-1}$ 118

Figura 4.4.1-1. Estructura de los diferentes parabenos (Sheskey et al., 2017) 119

Figura 4.4.2-1. Degradación relativa de los parabenos vs tiempo para el proceso fotoFenton. Condiciones experimentales: [parabenos $]_{0} 5 \mathrm{mg} \mathrm{L}^{-1}$ cada uno, [Fe(III) ]0 $5 \mathrm{mg} \mathrm{L}^{-}$ , $\left[\mathrm{H}_{2} \mathrm{O}_{2}\right]_{0} 6.29 \mathrm{mM}$ y, a $\mathrm{pH}_{0}$ 2.8. Experimento realizado en agua MQ

Figura 4.4.2-2. Diferentes componentes obtenidos para el análisis por PARAFAC de las diferentes STH extraídas (residuo de la oliva, café y lodo) a diferentes concentraciones (20-50 mg L ${ }^{-1}$ ), de los AH comerciales de Sigma-Aldrich y de las STH CVT-230 extraídas en Italia. El eje X corresponde a las longitudes d eonda de excitación (250-500 nm) y el eje Y a las longitudes de onda de emisión (300-600 nm) 122 
Figura 4.4.2-3. Peso de los diferentes componentes obtenidos por PARAFAC para las diferentes muestras de STH anañizadas. Componente C1 (blanco), componente C2 (gris claro), componente C3 (gris oscuro), componente C4 (negro)

Figura 4.4.2-4. Degradación de la suma de los parabenos a diferentes tiempos de tratamiento vs diferentes pHs $(2.8,5$ y 6$)$ y diferentes matrices de agua. $\mathbf{A}$ : agua destilada, B: agua del grifo a los 5 y 60 minutos de tratamiento (gris claro y gris oscuro respectivamente). Condiciones experimentales del proceso foto-Fenton: [parabenos] 5 $\mathrm{mg} \mathrm{L}^{-1}$ cada uno, [Fe (III) $]_{0} 5 \mathrm{mg} \mathrm{L}^{-1}$ y $\left[\mathrm{H}_{2} \mathrm{O}_{2}\right]_{0} 6.29 \mathrm{mM}$

Figura 4.4.2-3. Tiempo necesario para degradar el $60 \%$ de la suma de los parabenos vs diferentes tipos de HLS (residuo del café, residuo de la oliva y lodo de depuradora). FotoFenton con agua destilada. Condiciones experimentales: [parabenos] $5 \mathrm{mg} \mathrm{L}^{-1}$ cada uno, $[\mathrm{Fe}(\mathrm{III})]_{0} 5 \mathrm{mg} \mathrm{L}^{-1},\left[\mathrm{H}_{2} \mathrm{O}_{2}\right]_{0} 6.29 \mathrm{mM}(\mathbf{\square})$ y $12.59 \mathrm{mM}(\square),[\mathrm{STH}]_{0} 20 \mathrm{mg} \mathrm{L}^{-1}, \mathrm{pH}_{0} 5$ .125

Figura 4.4.3-1. Degradación de la mezcla de parabenos frente al tiempo expresado en t30w (min). Condiciones experimentales: parabenos $]_{0} 5 \mathrm{mg} \mathrm{L}^{-1}$ cada uno, [Fe(III) ]o $5 \mathrm{mg}$ $\mathrm{L}^{-1},\left[\mathrm{H}_{2} \mathrm{O}_{2}\right]_{0} 12.59 \mathrm{mM}$, [STH $]_{0}$ del café $20 \mathrm{mg} \mathrm{L}^{-1}, \mathrm{pH}_{0}$ 5. Experimento realizado con agua MQ. 125

Figura 4.4.4-1. Diferentes componentes presentes en la degradación obtenidos por PARAFAC para el experimento realizado en la planta piloto. El eje X corresponde a las longitudes d eonda de excitación (250-500 nm) y el eje Y a las longitudes de onda de emisión (300-600 nm). Condiciones experimentales: [parabenos]o $5 \mathrm{mg} \mathrm{L}^{-1}$ cada uno, $\left[\mathrm{Fe}(\mathrm{III})_{0} 5 \mathrm{mg} \mathrm{L}^{-1},\left[\mathrm{H}_{2} \mathrm{O}_{2}\right]_{0} 12.59 \mathrm{mM},[\mathrm{STH}]_{0} 20 \mathrm{mg} \mathrm{L}^{-1}, \mathrm{pH}_{0} 5\right.$

Figura 4.4.4-2. EEM obtenida para el tiempo 0 minutos de tratamiento. El eje $X$ corresponde a las longitudes d eonda de excitación (250-500 nm) y el eje Y a las longitudes de onda de emisión (300-600 nm). Condiciones experimentales: [parabenos] 0 $5 \mathrm{mg} \mathrm{L}^{-1}$ cada uno, [Fe(III) $\left.]_{0} 5 \mathrm{mg} \mathrm{L}^{-1}, \mathrm{H}_{2} \mathrm{O}_{2}\right]_{0} 12.59 \mathrm{mM}$, [STH] $]_{0} 20 \mathrm{mg} \mathrm{L}^{-1}, \mathrm{pH}_{0} 5$ 130

Figura 4.4.3-3. Evolución de los distintos componentes a lo largo del proceso de degradación. Experimento realizado en la planta piloto. Condiciones experimentales: [parabenos $]_{0} 5 \mathrm{mg} \mathrm{L}^{-1}$ cada uno, [Fe(III) $]_{0} 5 \mathrm{mg} \mathrm{L}^{-1},\left[\mathrm{H}_{2} \mathrm{O}_{2}\right]_{0} 12.59 \mathrm{mM}$, [STH $]_{0} 20 \mathrm{mg} \mathrm{L}^{-}$ ${ }^{1} \mathrm{pH}_{0} 5 . \mathrm{C} 1(\bullet), \mathrm{C} 2(\Delta), \mathrm{C} 3(\square), \mathrm{C} 4(+)$ 
Figura 4.5.3-1. Tensión superficial $\left(\mathrm{mN} \mathrm{m}^{-1}\right)$ para las STH extraídas de los lodos de EDAR a diferentes concentraciones $(\bullet)$ y para el agua $(\circ)$

Figura 4.5.3-2. Valores de tamaño medio obtenido $(\mathrm{nm})$ por DLS para diferentes concentraciones de STH

Figura 4.5.4-1. Relación cantidad de TBZ (mg) vs tiempo (min) para el PM (口), RT (ロ) y la suma de $\operatorname{ambos}(\Delta)$. [TBZ] $]_{0}\left(50 \mathrm{mg} \mathrm{L}^{-1}\right)_{0}, \mathrm{P}=2$ bar, $\mathrm{T}^{\mathrm{a}}$ ambiente, membrana de 50 $\mathrm{kDa}$

Figura 4.5.5-1. Cantidad de TBZ (mg) presente en el RT (gris claro) y PM (gris oscuro) al final del proceso de membranas (6 horas). [TBZ $]_{0} 50 \mathrm{mg} \mathrm{L}^{-1}$ y [STH $]_{0} 20 \mathrm{y} 40 \mathrm{~g} \mathrm{~L}^{-1}$

Figura 4.5.6-1. Relación cantidad de TBZ (mg) vs tiempo (min) para el PM ( $\square)$, RT (ロ) y la suma de ambos $(\Delta)$. Experimento relación TBZ: STH 1:40, pHo 7 y, (A) 2 bar, (B) 1 bar 139

Figura 4.5.6-2. Relación TOC (mg) vs tiempo (min) para el PM ( $\square$ ), RT (匹) y la suma de $\operatorname{ambos}(\Delta)$. Experimento relación TBZ: STH 1:40, pHo 7 y, (A) 2 bar, (B) 1 bar 140

Figura 4.5.7-1. Diferentes componentes obtenidos en el análisis por PARAFAC. El eje $\mathrm{X}$ corresponde a las longitudes d eonda de excitación $(250-500 \mathrm{~nm})$ y el eje Y a las longitudes de onda de emisión (300-600 nm). Set de datos compuesto por todas las muestras tomadas para el resto de los análisis. Incluye las muestras a diferentes tiempos de los experimentos para selección de la membrana, selección de la relación TBZ:STH y selección de la presión de trabajo, así como disoluciones de TBZ y STH por separado .141

Figura 4.5.8-1. Proceso foto-Fenton del RT obtenido en el proceso de membranas utilizando un tamaño de poro de $50 \mathrm{kDa}, 1$ bar de presión de trabajo y, una relación TBZ:STH 1:40. (•): RT filtrado con papel de filtro, (०): RT sedimentado. Condiciones experimentales: [TBZ 44.25] $\mathrm{mg} \mathrm{L}^{-1}$, [Fe(III) $]_{0} 5 \mathrm{mg} \mathrm{L}^{-1},\left[\mathrm{H}_{2} \mathrm{O}_{2}\right]_{0}(\bullet) 4.04 \mathrm{M}$, (०) $5.4 \mathrm{M}$, $\mathrm{pH}_{0} 5$ 
Índice de abreviaturas:

ACM: Acetaminofeno

ACP: Acetamiprid

AF: Ácidos Fúlvicos

AH: Ácidos Húmicos

AINEs: Antiinflamatorios No Esteroideos

AMOX: Amoxicilina

BP: Butilparabeno

BZP: Benzilparabeno

CBZ: Carbamazepina

CAF: Cafeína

CAFOs: Concentrated Animal Feeding Operations

CE: Contaminante Emergente

CE50: Concentración Efectiva

CI: carbono Inorgánico

CIT: Carbono Inorgánico Total

CLOF: Ácido Clofíbrico

COD: Carbono Orgánico Disuelto

COT: Carbono Orgánico Total

CPC: captadores Parabólicos Compuestos

CT: Carbono Total

CVF: Clorfenvinfos

DCF: Diclofenaco

DLS: Dispersión Luz Dinámica 
DMPO: 5,5-dimetil-1-pirrolina-N-oxido

DQO: Demanda Química de Oxígeno

EDAR: Estación Depuradora de Aguas Residuales

EDDS: Ácido Etilendiamino-N-N'-disuccinico

EDTA: Ácido Etilendiaminotetraacético

EEM: Excitation Emission Matrix (Matriz de Excitación Emisión)

EP: Etilparabeno

EPR: Resonancia Paramagnética de Electrones

FTIR: Fourier-Transformation Infrared Spectroscopy (Espectroscopía de Infrarrojo Transformada de Fourier)

HIX: Índice de Humificación

IF: Índice Fluorescencia

IP: Isopropyl parabeno

LID: Lowest Inhibition Dilution

MH: STH extraídas de la oliva sin fermentar

MH-D: STH extraídas de la oliva sin fermentar dializadas

MHF: STH extraídas de la oliva fermentadas un mes

MHF-D: STH extraídas de la oliva fermentadas un mes dializadas

MHF-1A: STH extraídas de la oliva fermentadas un año

MHF-1A-D: STH extraídas de la oliva fermentadas un año dializadas

MID: Medium Inhibition Dilution

MOD: Materia Orgánica Disuelta

MP: Metilparabeno

MQ: Agua Milli-Q

NTA: Ácido Nitrilotriacético 
PARAFAC: PARAllel Analysis FACtor (Análisis de factores Paralelos)

PCP: Pentaclorofenol

PM: Permeado

PP: Propilparabeno

POA: Procesos de Oxidación Avanzada

PPCPs: Pharmaceutical and Personal Care Products

RYA: Recombinant Yeast Assay (Ensayo con levaduras Recombinados)

RT: Retentato

SEC: Size Exclusion Chromatography (Cromatografía de Exclusión por Tamaños)

SH: Sustancias Húmicas

STH: Sustancias tipo húmicas

TBT: Terbutrina

TBZ: Tiabendazol

TGA: Termogravimetría

UHPLC: Ultra High Performance Liquid Chromatography (Cromatografía Líquida de Ultra Alta Resolución) 



\section{Agradecimientos}

En primer lugar, quiero agradecer al Ministerio de Economía, Industria y Competitividad la concesión de la beca FPI asociada a un proyecto del Plan Nacional de I+D+i (BES2016-077962) “Tecnologías eficientes para la eliminación de contaminantes de preocupación emergente, contenidos en Directiva 2013/39/CE o de riesgo significativo según Directiva 2008/105/CE" dentro del que se engloba el trabajo realizado en la presente tesis doctoral. Así como a la Unión Europea por la financiación para la realización de las estancias internacionales.

Agradecer también a mis directores de tesis, la Dra. Ana María Amat Payá y el Dr. Antonio Arques Sanz por el esfuerzo y dedicación.

Por último, agradecer al Departamento de Ingeniería Textil y Papelera, donde he realizado la mayoría de la investigación, y a toda la gente que conforma el grupo de investigación de Procesos de Oxidación Avanzada de la Escuela Politècnica Superior de Alcoy. Agradecer también al Departamento de Biotecnología de la Universitat Politècnica de València y, al INIFTA-CONICET-UNLP (Argentina). 



\section{Resumen}

La necesidad de reutilizar el agua para paliar escenarios de escasez de este recurso, es una preocupación mundial cada vez más extendida. Ello implica disponer de procesos de depuración eficientes y capaces de proporcionar agua de calidad sanitaria para su reuso. En los últimos años han adquirido especial importancia la presencia de microcontaminantes en aguas ya que las plantas de tratamientos convencionales no son capaces de eliminarlos y aparecen en aguas de salida suponiendo un grave problema medioambiental y para la salud humana. Los procesos de oxidación avanzada han demostrado su eficacia para la eliminación de estos contaminantes, y entre ellos, el proceso foto-Fenton es uno de los que mejores resultados ha proporcionado. Sin embargo, los requerimientos de $\mathrm{pH}$ ácido para mantener el hierro en disolución es uno de los mayores inconvenientes para la aplicación de este proceso a escala real.

En la presente tesis doctoral se ha estudiado la degradación de diferentes mezclas de contaminantes mediante el proceso de oxidación avanzada foto-Fenton solar, buscando alternativas que lo hagan más eficiente a un $\mathrm{pH}$ próximo a la neutralidad. Este proceso oxidativo se ha llevado a cabo a pH 5 mediante la adición de sustancias tipo húmicas (STH) extraídas de diferentes residuos orgánicos.

Las STH se han extraído del residuo de la producción del aceite de oliva, del residuo del café y de lodos de depuradora deshidratados del reactor anaerobio de EDAR. Estas STH se han caracterizado por diferentes técnicas analíticas y se han adicionado al proceso fotoFenton para comprobar su eficacia y eficiencia en el mismo.

En el caso del uso de las STH provenientes del residuo de la oliva se han obtenido diferentes tiempos de fermentación y diferentes tamaños de fracciones. El estudio sobre STH preparadas sobre residuos con diferentes tiempos de fermentación, demuestra que los mejores resultados de degradación se obtienen con las muestras fermentada un mes, pero en cualquier caso no son significativas las diferencias, por lo que no sería necesario someter al residuo a ningún tiempo de fermentación previo a la extracción de las STH.

En los ensayos con diferentes fracciones de STH, se determina que no es necesario el proceso de separación por membranas ya que las degradaciones obtenidas son muy similares, independientemente del uso de una u otra. Se ha probado su eficiencia en diferentes matrices de agua y se ha comprobado su capacidad para complejar el hierro manteniéndolo en disolución, obteniendo buenos resultados en todos los casos. Se han 
realizado ensayos de toxicidad sobre diferentes organismos para comprobar la detoxificación de las muestras tratadas. Los ensayos de toxicidad determinan que el compuesto clorfenvinfos es el más tóxico y que las muestras en presencia de las STH son más tóxicas antes de aplicar ningún tratamiento, debido a la capacidad surfactante de las mismas.

El tratamiento de una mezcla de parabenos con STH de diferente procedencia, mejora los resultados de degradación de contaminantes cuando el proceso se aplica a $\mathrm{pH}$ próximo a la neutralidad. Se determina que las STH extraídas del café aplicadas con una cantidad extra de peróxido de hidrógeno (doble de la estequiométrica) proporcionan mejores resultados de degradación de contaminantes que las STH obtenidas de la oliva y del lodo de depuradora. De los ensayos toxicológicos realizados y del de disrupción endocrina, se concluye que el tratamiento durante un t30w de 30 minutos, pese a que consigue la degradación de los parabenos, no resulta suficiente para detoxificar las muestras, ya que las disoluciones finales presentan mayor toxicidad que las intermedias, por lo que se considera prolongar los tratamientos.

Las STH extraídas del lodo de depuradora se han utilizado para el lavado de contaminantes cuando se quiere aumentar su concentración y tratar menores volumenes con mayor concentración. Se han acoplado procesos de membrana y procesos oxidativos. Se comprueba que las STH son capaces de atrapar el contaminante por la formación de micelas, impidiendo su paso por la membrana y facilitando el posterior tratamiento por proceso foto-Fenton del retentado obtenido. El análisis realizado por PARAFAC determina que existe una interacción entre las STH y el contaminante.

Por otro lado, se ha comprobado la capacidad de generar especies reactivas por parte de las STH en presencia de $\mathrm{Fe}(\mathrm{II})$ y $\mathrm{Fe}(\mathrm{III})$ obteniéndose una velocidad de reacción más lenta, aunque más estable a lo largo del tiempo con el uso del Fe(III).

Las STH extraídas de diferentes residuos han resultado eficientes para la degradación de contaminantes emergentes cuando se lleva el proceso foto-Fenton a $\mathrm{pH} 5$ debido a su capacidad por un lado de complejar el hierro manteniéndolo en disolución y por otro a la capacidad de generar especies reactivas durante el proceso. 


\section{Resum}

La necessitat de reutilitzar l'aigua per a pal-liar escenaris d'escassetat d'aquest recurs és una preocupació mundial cada vegada més estesa. Això implica disposar de processos de depuració eficients i capaces de proporcionar aigua de qualitat sanitària per al seu reús. En els últims anys han adquirit especial importància la presència de microcontaminants en aigües ja que les plantes de tractaments convencionals no poden eliminar-los $\mathrm{i}$ apareixen en aigües d'eixida suposant un greu problema mediambiental i per a la salut humana. Els processos d'oxidació avançada han demostrat la seua eficàcia per a l'eliminació d'aquests contaminants, i entre ells, el procés foto-Fenton és un dels quals millors resultats ha proporcionat. No obstant això, els requeriments de $\mathrm{pH}$ àcid per a mantindre el ferro en dissolució és un dels majors inconvenients per a l'aplicació d'aquest procés a escala real.

En la present tesi doctoral s'ha estudiat la degradació de diferents mescles de contaminants mitjançant el procés d'oxidació avançada foto-Fenton solar, buscant alternatives que ho facen més eficient a un $\mathrm{pH}$ pròxim a la neutralitat. Aquest procés oxidatiu s'ha dut a terme a pH 5 mitjançant l'addició de substàncies tipus húmiques (STH) extragudes de diferents tipus de residus orgànics.

Les STH s'han extret del residu de la producció de l'oli d'oliva, del residu del café i de lodes de depuradora deshidratats del reactor anaerobi d'EDAR. S'han caracteritzat per diferents tècniques analítiques i s'han addicionat al procés foto-Fenton per a comprovar la seua eficàcia i eficiència en el mateix.

En el cas de les STH provinents del residu de l'oliva s'han obtingut diferents temps de fermentació i diferents tamanys de fraccions. En l'ús de diferents temps de fermentació millors resultats de degradació s'observen en el cas de la mostra fermentada un mes, però, en qualsevol cas no son significatives les diferències, per el que no és necesari sotmetre al residu a cap temps de fermentació abans de l'extracció.

Respecte al assatjos en els diferents tamanys de fraccions es determina que no es necessari la separació per membranes, ja que, les degradacions obtenides son molt similars independentment de l'ús d'una fracció o altra. S'ha comprovat l'efectivitat en diferents matrius d'aigua i la capacitat de les mateixes per a complexar el ferro mantenint-lo en disolució, en bons resultats en tots els casos estudiats. Complementàriament s'han realitzat assajos de toxicitat sobre diferents organismes per tal de comprovar la 
detoxificació de les mostres tractades. Els assatjos de toxicitat determinen que el compost clorfenvinfos és el més tòxic i que les mostres en presència de les STH són més tòxiques, a causa de la capacitat surfactant d'aquestes.

El tractament d'una mescla de parabens en STH de diferent procedència milloren els resultats de degradació de contaminants quan es porta el procés a $\mathrm{pH}$ pròxim a la neutralitat. Es determina que les STH extragudes del residu del café quan s'adiciona al procés una quantitat extra de peròxid de hidrògen (doble de la quantitat estequiomètrica) milloren els resultats de degradació de contaminnats comparant en les STH obtingudes de l'oliva i del lodes de depuradora. Dels assatjos toxicològics realitzats i del de disrupció endocrina, es conclou que el tractamnet en una duració de $\mathrm{t}_{30 \mathrm{w}} 30$ minuts no és suficient per a detoxificar les mostres encara que, la degradació dels parabens es consegueix. Per lo que es considera prolongar el temps de tractament.

Les STH procedents del lodes de depuradora s'han utilitzat per al llavat de contaminants quan es troben a concentracions elevades. S'han acoplat processos de membrana i procesos oxidatius. Es comproba que les STH poden atrapar contaminnats per la formació de micel-les, bloquejant el pas del contaminant a través de la membrana i sent més fàcil el posterior tractament per foto-Fenton del retentat obtingut. L'anàlisi realitzat per PARAFAC determina que existeix una interacció entre les STH i el contaminant.

D'altra banda, s'ha estudiat el mecanisme de reacció de les STH i la seua capacitat per a generar espècies reactives en presència de Fe(II) i Fe(III), obtinguen una reacció més lenta encara que més estable al llarg del temps en el Fe(III).

Les STH extragudes de diferents residus han resultat eficients per a la degradció de contaminants emergents quan es porta el procés foto-Fenton a $\mathrm{pH} 5$ a causa de la seua capacitat per un costat de complexar el ferro mantenint-lo en dissolució i d'altra banda per la seua capacitat de genera espècies reactives durant el procés. 


\section{Abstract}

The need to reuse water to alleviate scenarios of scarcity is an increasingly widespread global concern, this implies having efficient purification processes able to provide sanitary and quality water for reuse. In recent years, micropollutants presence in water has acquired special importance since conventional wastewater treatment plants are not able to eliminate them, causing environmental and health problems. Advanced oxidation processes have proven effective in removing these pollutants, and among them, photoFenton process is one of most effective. However, the application requirements of acidic $\mathrm{pH}$ to remain the iron in solution is one of the major drawbacks for the full-scale process.

In the present doctoral thesis, degradation of different pollutant mixtures using the advanced oxidation process called photo-Fenton has been studied, gaining further insight in how this process would take place at circumneutral $\mathrm{pHs}$. Photo-Fenton was carried out at $\mathrm{pH} 5$ by adding humic like substances (HLS) isolated from different organic residues.

HLS have been isolated from olive mill wastes, coffee wastes and from wastewater treatment plant sludges. These HLS have been characterized by different analytical techniques and were added to photo-Fenton process to determine their efficacy and efficiency.

In the use of HLS isolated from olive mill wastes, different fermentation times and different sizes were obtained. For the HLS from different fermentation times slightly better degradation results were obtained with one month fermentation time, however differences were insignificant to take it into account, and the conclusion of no need of residue fermentation was achieved.

In the use of different sizes, the pollutant degradation kinetics were practically the same, concluding that the best option is to use a mixture of them all. Iron complexing ability were studied using different water matrixes with good results in all cases. Toxicity bioassays were carried out using different organisms to know which level of detoxification has achieved. Concluding that these HLS were able to act as iron complexing agents, and that chlorfenvinphos is the most toxic compound, and that water samples containing HLS seems to be more toxic at the end of the treatment time due to their surfactant capacity. 
A mixture of parabens was treated using different origin HLS at mild photo-Fenton process. HLS isolated from coffee were the most efficient when and extra amount of hydrogen peroxide were added (stoichiometric doble amount). The conclusion reached from toxicology bioassays and endocrine disruption is that the treatment time $t_{30 \mathrm{w}} 30$ minutes is not enough to eliminated toxicity, even when the parabens removal was obtained.

HLS from sludges were used for contaminant washing when pollutant concentration is high, fitting together membrane system and oxidative process. HLS formed micelles and can catch the pollutant inside, blocking the pass through the membrane. Thus, less volume is treated then by photo-Fenton making easier the process. PARAFAC analysis shows that exist an interaction between HLS and the pollutant.

Finally, mechanism reaction between HLS with $\mathrm{Fe}(\mathrm{II})$ and $\mathrm{Fe}(\mathrm{III})$ and their capacity of generate reactive species were studies. Obtaining that in presence of $\mathrm{Fe}(\mathrm{III})$ the reaction is slower but the complex is most stable.

HLS isolated from different residue types are useful when photo-Fenton process takes place at circumneutral conditions due to their ability to complex iron, remaining it in solution, and their ability to generate reactive species during the process.

Is possible to eliminate emerging pollutants present in wastewaters by photo-Fenton process at mild $\mathrm{pH}$ conditions by adding these substances, adding value to the process, and promoting circular economy. 


\section{INTRODUCCIÓN}


Introducción 


\subsection{Problemática derivada de la presencia de contaminantes emergentes}

En los últimos años en muchos de los países desarrollados y desde la Unión Europea, se han realizado grandes esfuerzos para reducir la presencia de ciertos contaminantes considerados "tradicionales" en las aguas. Estos contaminantes pueden ser nutrientes, metales o compuestos orgánicos persistentes (Solaun et al., 2021). Este esfuerzo ha dado como resultado su reducción en costas, ríos, estuarios y, en definitiva, en cualquier cauce de agua natural. Sin embargo y al mismo tiempo, la presencia de otro tipo de contaminantes ha ido ganando importancia y generando interés en la comunidad científica debido al poco conocimiento que se tiene respecto a su posible daño potencial en el medio ambiente y en la salud humana (Borja et al., 2020), son los llamados contaminantes emergentes.

El agua es un recurso esencial para la vida, y es imprescindible para numerosas actividades humanas como el desarrollo normal de actividades domésticas, agricultura e industria. Sin embargo, la presencia de estos contaminantes emergentes en aguas superficiales y subterráneas pone en riesgo su calidad (Barbosa et al., 2016). Se define como contaminantes emergentes (CE) aquellas sustancias de diferente origen y naturaleza que previamente eran desconocidas o no reconocidas como contaminantes, que entran de forma continua en el medio ambiente y para las que no existe una legislación específica. El principal problema de estas sustancias no es tanto su concentración (se encuentran en concentraciones de $\mathrm{n} \mathrm{L}^{-1}$ y $\mu \mathrm{g} \mathrm{L}^{-1}$ ) (Luo et al., 2014) sino los posibles efectos que puedan producir en el medio ambiente y, por tanto, en la salud humana ya que, generalmente no son eliminados por los medios convencionales de tratamientos de aguas (Planas et al., 1997; Kuster et al., 2008; Ahile et al., 2020). En los últimos años ha crecido la preocupación respecto a la presencia de estos contaminantes en los diferentes reservorios de agua y de sus efectos, ya que, aunque las concentraciones individuales presentes no son toxicas (Barbosa et al., 2016) el efecto sinérgico y acumulativo no está bien definido todavía. Entre los CEs más comúnmente detectados en las aguas se encuentran fármacos y productos de cuidado e higiene personal (PPCPs: pharmaceutical and personal care products) (Haman et al., 2015; Marta-Sánchez et al., 2018; Gmurek et al., 2019; Sadutto et al., 2021), pesticidas (Senka et al., 2008; Köck-Schulmeyer et al., 2013), antibióticos (Gracia-Lor et al., 2012), aditivos industriales (Terzic, et al., 2008; Clara et al., 2010) y/o disruptores endocrinos (Peng et al., 2008; Nie et al., 2012) entre otros. En la Tabla 1.1-1 se muestran los CE más frecuentes detectados en el medio ambiente y su posible entrada 
(Luo et al., 2014). La entrada de los CE en el medio ambiente se origina principalmente por la descarga del efluente secundario de las estaciones depuradoras de aguas residuales (EDARs), por los efluentes provenientes de los hospitales, industria química e industria agroalimentaria (De la Cruz et al., 2012). Una de las principales características de estos compuestos es que no necesitan ser persistentes en el medio ambiente para causar efectos negativos, ya que su posible alta transformación o degradación se compensa por su continua entrada (Petrovic et al., 2003).

Tabla 1.1-1. Principales fuentes de entrada de microcontaminantes en el medio acuático. Fuente: Luo et al., 2014.

\begin{tabular}{|c|c|c|c|}
\hline \multirow[t]{2}{*}{ Categoría } & \multirow[t]{2}{*}{ Subclase } & \multicolumn{2}{|c|}{ Fuentes principales } \\
\hline & & $\begin{array}{l}\text { Distintiva o } \\
\text { exclusiva }\end{array}$ & No exclusiva \\
\hline Fármacos & $\begin{array}{c}\text { AINEs, } \\
\text { reguladores } \\
\text { lipídicos, } \\
\text { anticonvulsivos, } \\
\text { antibióticos, } \beta \text { - } \\
\text { bloqueantes y } \\
\text { estimulantes. }\end{array}$ & $\begin{array}{l}\text { Aguas residuales } \\
\text { domésticas (por } \\
\text { excreción), } \\
\text { efluentes } \\
\text { hospitalarios, } \\
\text { escorrentía de } \\
\text { CAFOs } \\
\text { (concentrated } \\
\text { animal feeding } \\
\text { operations) y } \\
\text { acuicultura. }\end{array}$ & \multirow{6}{*}{$\begin{array}{l}\text { Aguas residuales } \\
\text { industriales } \\
\text { (derivadas de la } \\
\text { fabricación de los } \\
\text { productos) y } \\
\text { lixiviados de } \\
\text { vertederos (por } \\
\text { eliminación } \\
\text { inadecuada de } \\
\text { artículos usados, } \\
\text { defectuosos o } \\
\text { inservibles). }\end{array}$} \\
\hline PPCPs & $\begin{array}{l}\text { Fragancias, } \\
\text { desinfectantes, } \\
\text { filtros UV y } \\
\text { repelentes de } \\
\text { insectos. }\end{array}$ & $\begin{array}{l}\text { Aguas residuales } \\
\text { domésticas (ducha, } \\
\text { baño, afeitado, } \\
\text { piscinas, etc.) }\end{array}$ & \\
\hline $\begin{array}{l}\text { Hormonas } \\
\text { esteroideas }\end{array}$ & Estrógenos & $\begin{array}{l}\text { Aguas residuales } \\
\text { domésticas (por } \\
\text { excreción) y } \\
\text { escorrentía de } \\
\text { CAFOs y } \\
\text { acuicultura. }\end{array}$ & \\
\hline Surfactantes & $\begin{array}{l}\text { Surfactantes no } \\
\text { iónicos }\end{array}$ & $\begin{array}{l}\text { Aguas residuales } \\
\text { domésticas (baño, } \\
\text { colada, lavavajillas, } \\
\text { etc.) y vertidos de } \\
\text { aguas residuales de } \\
\text { limpieza industrial. }\end{array}$ & \\
\hline $\begin{array}{c}\text { Químicos } \\
\text { industriales }\end{array}$ & $\begin{array}{l}\text { Plastificantes y } \\
\text { retardadores del } \\
\text { fuego }\end{array}$ & $\begin{array}{l}\text { Aguas residuales } \\
\text { domésticas (por } \\
\text { lixiviación del } \\
\text { material). }\end{array}$ & \\
\hline Pesticidas & & $\begin{array}{l}\text { Aguas residuales } \\
\text { domésticas } \\
\text { (limpieza }\end{array}$ & \\
\hline
\end{tabular}




\begin{tabular}{cc}
\hline $\begin{array}{c}\text { Insecticidas, } \\
\text { herbicidas y } \\
\text { fungicidas. }\end{array}$ & $\begin{array}{c}\text { inadecuada, } \\
\text { escorrentía de } \\
\text { jardines, etc.) y } \\
\text { escorrentía agrícola. }\end{array}$ \\
\hline
\end{tabular}

*AINEs: antiinflamatorios no esteroideos.

*CAFO: concentrated animal feeding operation. Operaciones concentradas de alimentación de animales.

Las estaciones depuradoras de aguas residuales (EDARs) tienen como objetivo final minimizar el impacto ambiental de las aguas que descargan en los cauces naturales (Meneses et al., 2010). Están diseñadas para controlar un amplio rango de sustancias como partículas, nutrientes, o patógenos, pero mientras la eliminación de estas suele ser eficiente y suficiente, no ocurre lo mismo con los CE (Luo et al., 2014). La eficiencia de las EDARs convencionales depende de las características del contaminante y de los procesos empleados (Barbosa et al., 2016), y no están diseñadas para eliminar completamente compuestos orgánicos presentes a concentraciones bajas (Tijani et al., 2013), convirtiéndose así en una fuente de contaminación.

Existen procesos alternativos que pueden acoplarse a los tratamientos convencionales que sí son capaces de eliminar estos CE, como los procesos de oxidación avanzada (POAs). Estos pueden aplicarse como pretratamiento o postratamiento del proceso biológico de las EDARs. Como pretratamiento para conseguir un efluente más fácilmente biodegradable por los procesos biológicos tradicionales, y como postratamiento para la eliminación de CE y sus subproductos.

\subsection{Procesos de oxidación avanzada (POAs).}

Los POAs son procesos de tratamiento de agua muy eficientes que pueden considerarse una buena alternativa al tratamiento de aguas convencional. Los POAs se consideran procesos sostenibles con el medio ambiente, basados en procesos fisicoquímicos que inducen la descomposición o simplificación de la estructura molecular de moléculas orgánicas (Antonopoulou et al., 2021) pudiéndolas convertir en $\mathrm{H}_{2} \mathrm{O}, \mathrm{CO}_{2}$ y sales minerales bajo condiciones adecuadas (Augugliaro et al., 2006). Son procesos que involucran generación y uso de especies oxidantes transitorias, como el radical hidroxilo $(\mathrm{OH} \cdot)$, superóxido $\left(\mathrm{O}_{2} \cdot{ }^{-}\right)$, hidroperoxilo $\left(\mathrm{HO}_{2} \cdot\right)$, alcoxi $(\mathrm{RO} \cdot)$, sulfato $\left(\mathrm{SO}_{4} \cdot^{-}\right)$y cloro $(\mathrm{Cl} \cdot)$ dependiendo del catalizador o del oxidante utilizado, siendo el $\mathrm{OH} \cdot$ el más utilizado (Antonopoulou \& Konstantinou, 2016). El radical hidroxilo tiene un alto potencial de oxidación y puede oxidar gran cantidad de compuestos orgánicos, además de ser un 
proceso no selectivo. La eficiencia de la oxidación depende de aspectos como la naturaleza de los contaminantes a tratar o la matriz de agua (Wols et al., 2012). Los PAOs pueden utilizarse solos, combinándolos entre sí y/o en conjunto con otros tratamientos convencionales, para la eliminación de compuestos con alta estabilidad química y/o baja biodegradabilidad (Malato et al., 2007a).

Existen gran cantidad de PAOs, y la combinación entre ellos hace que puedan clasificarse de diferentes maneras. La Tabla 1.2-1 muestra su clasificación de acuerdo con la fuente de generación de especies reactivas:

Tabla 1.2-1. Clasificación distintos POAs de acuerdo con la fuente de generación de especies reactivas.

\begin{tabular}{|c|c|}
\hline $\begin{array}{l}\text { Método de generación } \\
\text { de especies reactivas }\end{array}$ & Procesos \\
\hline \multirow[t]{2}{*}{ Fotólisis con UV } & Fotólisis directa \\
\hline & Fotólisis indirecta \\
\hline \multirow{4}{*}{ Basados en $\mathrm{O}_{3}$} & $\mathrm{O}_{3}$ \\
\hline & $\mathrm{O}_{3}+\mathrm{UV}$ \\
\hline & $\mathrm{O}_{3}+\mathrm{H}_{2} \mathrm{O}_{2}$ \\
\hline & $\mathrm{O}_{3}+$ catalizador \\
\hline \multirow{3}{*}{ Procesos térmicos } & Oxidación húmeda \\
\hline & Oxidación húmeda supercrítica \\
\hline & Oxidación húmeda $+\mathrm{H}_{2} \mathrm{O}_{2}$ \\
\hline \multirow{3}{*}{$\begin{array}{c}\text { Procesos de alta } \\
\text { energía }\end{array}$} & Ultrasonidos \\
\hline & Tecnologías de haz de electrones \\
\hline & Tecnologías de microondas \\
\hline \multirow{5}{*}{ Basados en $\mathrm{H}_{2} \mathrm{O}_{2}$} & Fenton \\
\hline & Electro-Fenton \\
\hline & Foto-Fenton \\
\hline & Tipo-Fenton \\
\hline & $\mathrm{UV} / \mathrm{H}_{2} \mathrm{O}_{2}$ \\
\hline \multirow[t]{2}{*}{ Fotocatálisis } & Fotocatálisis heterogénea \\
\hline & Fotocatálisis homogénea \\
\hline
\end{tabular}

A continuación, se procede a la explicación de algunos de estos procesos, que han sido los utilizados principalmente en el presente trabajo:

\subsubsection{Fotolisis con radiación UV}

Este tratamiento se caracteriza porque la oxidación de los compuestos tiene lugar sin la adición de ningún reactivo químico, únicamente la exposición a la radiación. A pesar de la baja velocidad de reacción, es capaz de degradar contaminantes emergentes. La fotólisis puede producirse por dos vías: la directa y la indirecta. 


\subsubsection{Fotólisis directa}

La radiación directa promueve que las moléculas irradiadas promocionen de su estado fundamental a un estado excitado, desde el que posteriormente pueden experimentar otros procesos como: homólisis, heterólisis o fotoionización. En presencia de oxígeno se pueden producir reacciones adicionales con la generación del radical superóxido, aunque su potencial oxidativo es bajo. Este proceso presenta inconvenientes como baja eficiencia y es aplicable solo a compuestos que absorben entre 300-200 nm. Generalmente esta tecnología se combina con la adición de $\mathrm{H}_{2} \mathrm{O}_{2}$, aunque también puede combinarse con otras especies oxidantes como $\mathrm{S}_{2} \mathrm{O}_{8}{ }^{2-}$ o HSO$_{5}^{-}$. Shah et al., 2013 y Khan et al., 2014 estudiaron la degradación de endosulfan y atrazina respectivamente bajo fotolisis directa a $254 \mathrm{~nm}$ usando diferentes agentes oxidantes. En ambos casos se estudió la aplicación de $\mathrm{UV} / \mathrm{S}_{2} \mathrm{O}_{8}{ }^{2-}$, $\mathrm{UV} / \mathrm{HSO}_{5}{ }^{-}$y $\mathrm{UV} / \mathrm{H}_{2} \mathrm{O}_{2}$ obteniendo los mejores resultados de degradación con la combinación $\mathrm{UV} / \mathrm{S}_{2} \mathrm{O}_{8}{ }^{2-}$.

\subsubsection{Fotolisis indirecta}

En la fotolisis indirecta, otras sustancias fotosensibles presentes en la disolución generan por absorción de la luz un estado excitado y son capaces de transferir o ceder el exceso de energía a otra molécula, que a su vez puede reaccionar con otras especies químicas dando lugar a productos de reacción. En el caso de las aguas residuales, la materia orgánica disuelta puede interaccionar con la luz favoreciendo la degradación de microcontaminantes.

\subsubsection{Métodos Basados en $\mathrm{H}_{2} \mathrm{O}_{2}$}

\subsubsection{Proceso Fenton $\left(\mathrm{H}_{2} \mathrm{O}_{2}+\mathrm{Fe}^{2+}\right)$}

El proceso Fenton se basa en la utilización de iones ferrosos para la activación del peróxido de hidrógeno dando lugar a especies altamente oxidantes. Fue descubierto por H.J. Fenton que llevó a cabo la oxidación del ácido tartárico en presencia de $\mathrm{H}_{2} \mathrm{O}_{2}$ y sales de Fe (II) en 1894 (Fenton, 1894). Posteriormente, Haber y Weiss (Haber \& Weiss, 1934) propusieron que el oxidante activo que genera la reacción es el radical $\mathrm{OH} \cdot$.

El mecanismo exacto de degradación de los compuestos orgánicos por este proceso es complejo y aún hoy en día no se conoce totalmente, pero la mayoría de los autores están de acuerdo en las principales reacciones que tienen lugar, descritas a continuación según Neyers \& Baeyens, 2003 (Ecuaciones 1-7).

$$
\mathrm{Fe}^{2+}+\mathrm{H}_{2} \mathrm{O}_{2} \rightarrow \mathrm{Fe}^{3+}+\mathrm{OH}^{-}+\mathrm{OH}^{\cdot} \quad \text { (Ec. 1) }
$$




$$
\begin{gathered}
\mathrm{Fe}^{3+}+\mathrm{H}_{2} \mathrm{O}_{2} \rightarrow \mathrm{Fe}^{2+}+\mathrm{O}_{2} \mathrm{H}^{\cdot}+\mathrm{H}^{+} \quad(\text { Ec. 2) } \\
\mathrm{OH}+\mathrm{H}_{2} \mathrm{O}_{2} \rightarrow \mathrm{O}_{2} \mathrm{H}^{\cdot}+\mathrm{H}_{2} \mathrm{O} \quad(\text { Ec. 3) } \\
\mathrm{OH}+\mathrm{Fe}^{2+} \rightarrow \mathrm{Fe}^{3+}+\mathrm{OH}^{-} \quad \text { (Ec. 4) } \\
\mathrm{Fe}^{3+}+\mathrm{O}_{2} \mathrm{H}^{\cdot} \rightarrow \mathrm{Fe}^{2+}+\mathrm{O}_{2}+\mathrm{H}^{+} \quad \text { (Ec. 5) } \\
\mathrm{Fe}^{2+}+\mathrm{O}_{2} \mathrm{H}^{-}+\mathrm{H}^{+} \rightarrow \mathrm{Fe}^{3+}+\mathrm{H}_{2} \mathrm{O} \quad \text { (Ec. 6) } \\
\mathrm{O}_{2} \mathrm{H}^{-} \mathrm{O}_{2} \mathrm{H}^{\cdot} \rightarrow \mathrm{H}_{2} \mathrm{O}+\mathrm{O}_{2} \quad \text { (Ec. 7) }
\end{gathered}
$$

En ausencia de sales de hierro no se genera el radical $\mathrm{OH}$. pero con el aumento de la concentración de sales de hierro la degradación de los compuestos orgánicos aumenta, hasta un punto en que la adición de más sales de hierro resulta inefectiva.

Hay que tener en cuenta el $\mathrm{pH}$ al que se produce la reacción. El proceso Fenton es altamente dependiente del $\mathrm{pH}$, encontrándose su óptimo a pH 2.8-3. Esta dependencia con el pH se explica por la compleja química del hierro en disolución (Pignatello et al., 2006), que a pHs básicos o ligeramente ácidos precipita formando óxidos e hidróxidos de hierro, dejando de estar en disolución y, por lo tanto, provocando que se detenga la reacción. Estas especies coloidales de hierro descomponen el peróxido de hidrógeno en oxígeno y agua sin formar los radicales hidroxilo.

La concentración de $\mathrm{H}_{2} \mathrm{O}_{2}$ es otro de los parámetros a considerar, si la concentración es baja no se producirá la reacción y si es demasiado elevada atrapará los radicales hidroxilo generados dando lugar al "scavenging" y parando la reacción. Por último, hay que tener en cuenta la temperatura de reacción. Generalmente la velocidad de reacción aumenta con la temperatura, pero a temperaturas superiores a $40-50^{\circ} \mathrm{C}$ se pierde eficiencia en el proceso debido a la acelerada descomposición del $\mathrm{H}_{2} \mathrm{O}_{2}$ en $\mathrm{O}_{2}$ y $\mathrm{H}_{2} \mathrm{O}$.

La eficacia del proceso ha sido demostrada en gran cantidad de trabajos, degradando entre otros contaminantes, antibióticos (Türkay \& Kumbur, 2019; Gupta \& Garg, 2018; Wang et al., 2017), hidrocarburos aromáticos (Flotron et al., 2005) o, colorantes (Soon et al., 2011).

\subsubsection{Proceso foto-Fenton $\left(\mathrm{Fe}^{2+}+\mathrm{H}_{2} \mathrm{O}_{2}+\right.$ radiación $\left.\mathrm{UV}\right)$}

El proceso foto-Fenton es uno de los procesos de oxidación avanzada más estudiados y de los que mejores resultados muestran a la hora de purificar aguas residuales. En este proceso se combina la radiación UV o UV/luz visible con el proceso Fenton descrito 
anteriormente, consiguiendo una mejora en la eficiencia del proceso debido al aumento de la generación de radicales hidroxilo. Este aumento en la velocidad de degradación se debe a la fotoquímica del hierro y la descomposición del peróxido de hidrógeno (Ecuaciones 8-10).

$$
\begin{aligned}
& \mathrm{Fe}^{2+}+\mathrm{H}_{2} \mathrm{O}_{2} \rightarrow \mathrm{Fe}^{3+}+\mathrm{OH}^{-}+\mathrm{OH}^{\cdot} \quad(\text { Ec. 8) } \\
& \mathrm{Fe}^{3+}+\mathrm{H}_{2} \mathrm{O}+h v \rightarrow \mathrm{Fe}^{2+}+\mathrm{OH}^{\cdot}+\mathrm{H}^{+} \quad(\text { Ec. 9) } \\
& \mathrm{H}_{2} \mathrm{O}_{2}+h v \rightarrow 2 \mathrm{HO}^{\cdot} \quad(\lambda<400 \mathrm{~nm}) \quad(\text { Ec. 10 })
\end{aligned}
$$

Los complejos de $\mathrm{Fe}^{3+}$ sufren una transferencia de carga ligando-metal dando lugar a su disociación en $\mathrm{Fe}^{2+}$ y el ligando oxidado, Lox (Pignatelo et al., 2006). Ecuación 11.

$$
F e^{3+}+(L)_{n}+h v \rightarrow F e^{2+}+(L)_{n-1}+L_{o x} \quad(\text { Ec. 11) }
$$

Esta reducción del Fe(III) cierra el ciclo y genera a la vez nuevas especies reactivas. La oxidación de contaminantes orgánicos por el proceso Fenton y foto-Fenton se inhibe con la presencia de iones inorgánicos (sulfato, fosfato, cloruro, bromuro, fluoruro). El grado de inhibición depende de la concentración de estos iones, debido a que el hierro forma complejos insolubles y precipita (Pignatello et al., 2006).

Este proceso ha demostrado ser eficiente en la degradación de multitud de antibióticos (Amildon et al., 2018; Giraldo-Aguirre et al., 2018; Wang et al., 2019; Gou et al., 2021), plaguicidas (Carra et al., 2014; De la Cruz et al., 2012; Navarro et al., 2011; Gonçalves et al., 2020), efluentes de industria textil (Tarkwa et al., 2019; Visa \& Duta, 2013) y alimentaria (García-Ballesteros et al., 2016; Ioannou-Ttofa et al., 2017).

El requerimiento de un $\mathrm{pH}$ tan ácido para llevar a cabo el proceso foto-Fenton es uno de sus mayores inconvenientes, sobre todo si se considera el proceso a escala industrial, ya que harían falta gran cantidad de reactivos para bajar el $\mathrm{pH}$ (poder llevar el proceso a cabo) y para subirlo posteriormente en el momento de vertido de las aguas a los cauces naturales (Pérez et al., 2013). Existe una alta dependencia entre la reactividad y funcionamiento del sistema con el pH (Figura 1.2.2.2-1). A pH 1 la concentración libre de $\mathrm{Fe}(\mathrm{III})$ se reduce formando $\mathrm{FeOH}_{2}$ y $\mathrm{Fe}(\mathrm{OH})_{2}{ }^{+}$; a $\mathrm{pH}$ comprendidos entre 2 y 3 el $\mathrm{FeOH}_{2}$ alcanza su concentración más alta asegurando el máximo rendimiento. Conforme el valor de $\mathrm{pH}$ aumenta por encima de 3 la reactividad se desploma debido a la disminución de la disponibilidad de $\mathrm{FeOH}_{2}$ fotoactivo y hierro disuelto. A pHs superiores 
a 4 el hierro disuelto precipita en forma de óxidos e hidróxidos de hierro (Clarizia et al., 2017).

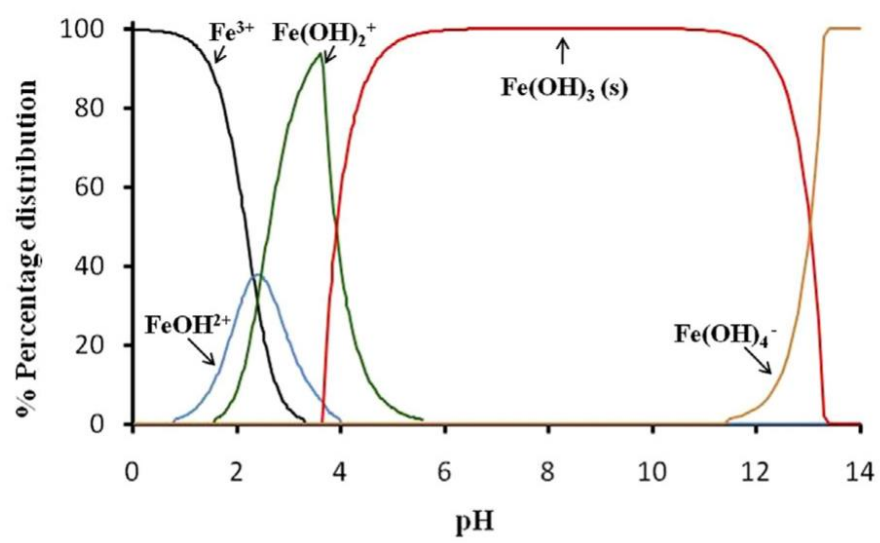

Figura 1.2.2.2-1. Especiación de los hidróxidos del $\mathrm{Fe}$ en función del $\mathrm{pH}$ para una disolución a una concentración $1.0 * 10^{-5} \mathrm{M}$ de $\mathrm{Fe}$ (III) a $25^{\circ} \mathrm{C}$. Fuente: Clarizia et al., 2017.

\subsubsection{Proceso tipo Fenton}

Los procesos tipo Fenton (Fento-like) son los procesos Fenton y foto-Fenton en los que se han producido variaciones con la finalidad de ampliar su rango de aplicación. De las primeras variaciones experimentadas fue la sustitución en el uso del $\mathrm{Fe}^{2+}$ por sales de $\mathrm{Fe}^{3+}$, cuyo precio es más asequible. $\mathrm{El}_{2} \mathrm{O}_{2}$ se descompone en radicales hidroxilo y el $\mathrm{Fe}(\mathrm{III})$ se reduce a $\mathrm{Fe}(\mathrm{II})$ (Ecuaciones 12-14) y los resultados finales obtenidos en las degradaciones son similares (Pignatello et al., 2006).

$$
\begin{aligned}
& \mathrm{Fe}^{3+}+\mathrm{H}_{2} \mathrm{O}_{2} \rightarrow \mathrm{Fe}^{2+}+\mathrm{OH}^{-}+\mathrm{OH} \quad(\text { Ec. 12) } \\
& \mathrm{Fe}^{3+}+\mathrm{H}_{2} \mathrm{O}_{2} \rightarrow \mathrm{H}^{+}+\mathrm{FeOOH}^{2+} \quad \text { (Ec. 13) } \\
& \mathrm{FeOOH}^{2+} \rightarrow \mathrm{HO}_{2}+\mathrm{Fe}^{2+} \quad(\text { Ec. 14) }
\end{aligned}
$$

Dentro de esta categoría entrarían también el conocido como Fenton-heterogéneo, donde el hierro empleado se encuentra fijado sobre algún soporte (Yeh et al., 2004; Babuponnusami \& Muthukumar, 2014; Lai et al., 2021). Otras alternativas son la sustitución de las sales de hierro por las sales de otros metales de transición como el cromo o el cobre (Santos-Juanes et al., 2008; Bokare \& Choi, 2014), la adición de hierro a bajas concentraciones (Miralles-Cuevas et al., 2015) o el uso de la matriz de agua para ampliar el rango de aplicación de pH (García-Ballesteros et al., 2016). También se engloban dentro de esta categoría los procesos en los que se adicionan complejantes del hierro para mantenerlo en disolución a pHs más neutros. De los agentes más empleados 
como quelantes están el ácido etilendiaminotetraacético, EDTA (De Luca et al., 2014; Clarizia et al., 2017); el ácido etilendiamino-N,N'-disuccinico, EDDS (Miralles-Cuevas et al., 2019; Lumbarque et al., 2019; Gonçalves et al., 2020); oxalato (Klamerth et al., 2011; Dias et al; 2014); ácido nitrilotriacético, NTA (De Luca et al., 2015; Dong et al., 2019; Ahile et al., 2020); ácido cítrico (Katsumata et al., 2006; Miralles-Cuevas et al., 2014); y ácidos húmicos y sustancias tipo húmicas (Gomis et al., 2014; Ballesteros et al., 2017; Caram et al., 2018).

Cuando se trata de la eliminación de CEs, al estar presentes en concentraciones tan bajas, se pueden asumir unos tiempos de tratamiento más largos sin que suponga una pérdida de eficiencia del proceso (Santos-Juanes et al., 2017) evitando la modificación del pH, de ahí que en los últimos años diferentes autores estén trabajando en el desarrollo de diferentes estrategias para lleva el proceso a pH más próximos a la neutralidad.

\subsection{Foto-Fenton heterogéneo}

Una de las estrategias para aplicar el proceso foto-Fenton a pHs más cercanos a la neutralidad es el conocido como proceso foto-Fenton heterogéneo, el cual se basa en la utilización de una fase sólida que contenga hierro activo, como pueden ser minerales a base de hierro, partículas recubiertas de hierro activo inmovilizado o especies de hierro fijadas a soportes sólidos (Santos-Juanes et al., 2017). La activación del $\mathrm{H}_{2} \mathrm{O}_{2}$ para generar especies oxidantes activas se produce principalmente en la interfaz del catalizador sólido (Zhu et al., 2019a). En los últimos años, estos procesos han ganado popularidad debido a las ventajas de usar catalizadores insolubles (Herney-Ramirez et al., 2010) ya que eliminan dificultades del proceso foto-Fenton homogéneo como son sus necesidades menos estrictas de $\mathrm{pH}$, que no hay generación de lodos por precipitación del hierro y que existe la posibilidad de recuperar el catalizador (Jain et al., 2018). Guo et al., 2021 compararon la degradación de fluoroquinolonas por foto-Fenton homogéneo y heterogéneo concluyendo que para su degradación se generaban más radicales $\mathrm{OH}$. mediante la utilización de catalizadores heterogéneos.

\subsection{Adición de hierro a bajas concentraciones}

De acuerdo con la Figura 1.2.2.2-1, la solubilidad del Fe(III) cae por encima de pH 3-4 y la especie predominante pasa a ser el $\mathrm{Fe}(\mathrm{OH})_{3}$ que precipita y deja de estar disponible en la reacción. Sin embargo, una pequeña fracción de hierro en forma de $\mathrm{Fe}(\mathrm{OH})^{2+}$ sigue permaneciendo soluble aun a $\mathrm{pH}$ próximos a la neutralidad. 
Con esta premisa se han realizado estudios añadiendo bajas concentraciones de hierro (1 mg $\mathrm{L}^{-1} \mathrm{o}$ inferiores) con la intención de que sea la cantidad mínima suficiente para mantenerse en disolución y que sea capaz de llevar a cabo la reacción. El objetivo es minimizar las pérdidas de hierro por precipitación. Esta técnica es útil cuando la concentración inicial de contaminantes a degradar es baja y la cantidad de hierro añadida es suficiente para actuar como catalizador, generando las especies reactivas necesarias para la eliminación de estos contaminantes (Santos-Juanes et al., 2017).

\subsection{Uso de la matriz de agua para evitar la adición y desactivación del hierro}

Según qué tipo de efluente vaya a tratarse, puede darse el caso de que no sea necesaria la adición de hierro o que el $\mathrm{pH}$ de aplicación del proceso pueda extenderse por encima de 3 debido a las características intrínsecas del efluente. García-Ballesteros et al., 2016 comprobaron que, en presencia de compuestos fenólicos, el pH óptimo del proceso fotoFenton aumentaba hasta 3.9 debido a la complejación del hierro por parte de los compuestos fenólicos. Este resultado es interesante teniendo en cuenta que estos compuestos están presentes en gran cantidad de efluentes provenientes de la industria alimentaria.

Moreno-Andrés et al., 2021 demostraron que en matrices de agua salina y ligeramente salina (30 y $1 \mathrm{~g} \mathrm{~L}^{-1}$ de $\mathrm{NaCl}$ respectivamente), el catecol es capaz de complejar el hierro manteniéndolo en disolución durante el proceso foto-Fenton a pHs más neutros. Por encima de $7 \mathrm{mg} \mathrm{L}^{-1}$ de catecol se eliminan el $90 \%$ de la mezcla de contaminantes estudiados en menos de una hora a cualquier $\mathrm{pH}$, siendo las condiciones experimentales óptimas $10-15 \mathrm{mg} \mathrm{L}^{-1}$ de catecol y pH 5.

Otro caso destacable serían las aguas residuales de la industria metalúrgica. Estas pueden contener a parte de hierro, otros metales como cobre o cromo, capaces de producir la complejación del hierro (Santos-Juanes et al., 2008).

La presencia de sustancias húmicas en el agua a tratar también puede ser útil en el proceso de estabilización del hierro en disolución. Katsumata et al., 2008 demostraron que la eliminación de estas sustancias mediante proceso foto-Fenton podía llevarse a cabo a pH de 4. Otros autores como Murray \& Parsons, 2004 o Georgi et al., 2007 aprovecharon la presencia de estas sustancias en el agua para llevar el proceso foto-Fenton a pH 5. 


\subsection{Adición de sustancias quelantes}

La idea de adicionar sustancias complejantes capaces de mantener el hierro activo a pH más próximos a la neutralidad resulta muy interesante teniendo en cuenta que pueden reducir la formación de lodos debido a la precipitación del hierro y que pueden llegar a reducir costes si se traslada el proceso a escala industrial.

Los agentes quelantes adicionados deben cumplir al menos dos condiciones, (i) tener más de dos grupos funcionales adecuados que sean donantes de electrones al átomo de metal procedentes de grupos como $\mathrm{NH}_{2} \mathrm{o}-\mathrm{COOH}$ (Figura 1.2.2.3.4-1) y, (ii) formar un anillo con el átomo de metal a través de estos grupos funcionales (Zhang \& Zhou, 2019).

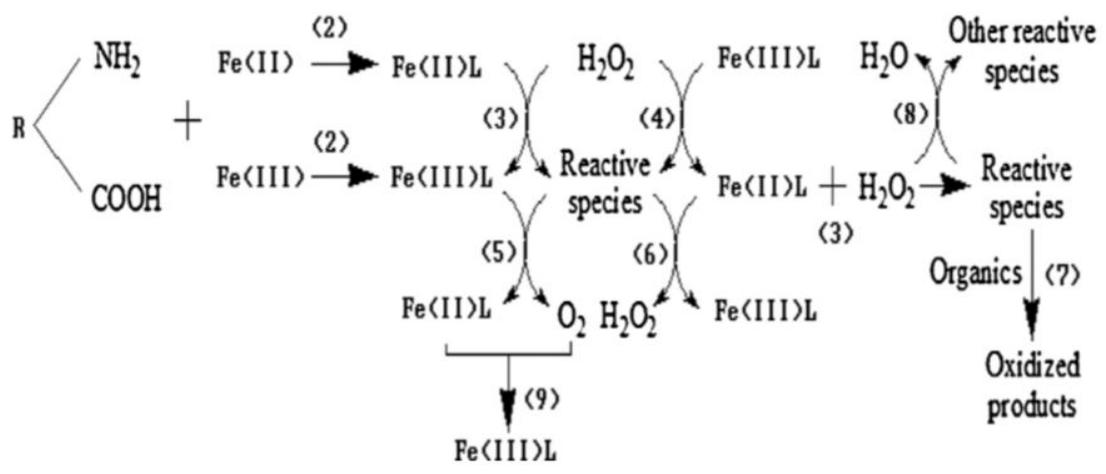

Figura 1.2.2.3.4- 1. Reacciones que tienen lugar por la complejación Fe-L. Fe(II)/Fe(III) representa todas las formas posibles de los complejos Fe-L. Fuente: Zhang \& Zhou, 2019.

La eficiencia de la reactividad de los complejos Fe-L puede venir de (i) el efecto de la sustancia quelante en las propiedades redox del $\mathrm{Fe}(\mathrm{III}) / \mathrm{Fe}(\mathrm{II})$, (ii) la inducción de la reacción del $\mathrm{H}_{2} \mathrm{O}_{2}$ con el $\mathrm{Fe} y$, (iii) la competición por las especies oxidantes en la reacción (Georgi et al., 2007; Santos-Juanes et al., 2017).

La capacidad de los iones metálicos para oxidarse/reducirse depende de los potenciales redox de las sustancias que se empleen (Rizvi et al., 2010). Los potenciales redox de los complejos Fe-L deben cumplir dos condiciones cuando se adicionan a los procesos fotoFenton, (i) debe ser inferior al del $\mathrm{H}_{2} \mathrm{O}_{2} / \mathrm{OH}^{-}$para permitir la oxidación del complejo $\mathrm{Fe}(\mathrm{II})-\mathrm{L}$ por parte del $\mathrm{H}_{2} \mathrm{O}_{2}$ y, (ii) ser lo suficientemente elevado para permitir la reducción de los complejos de Fe(III)-L a Fe(II)-L por las especies reactivas (Zhang \& Zhou, 2019). Cuanto mayores sean los potenciales redox de los complejos Fe-L más rápidas serán las reducciones de los complejos Fe(III)-L. La estabilidad del complejo es un parámetro importante y hay que considerarlo. Es la capacidad de interacción (mantenida en el tiempo) de los agentes quelantes y los iones metálicos; cuanto mayor 
sea la estabilidad del complejo mayor será la posibilidad de que se forme. Aunque el mecanismo de actuación del complejo Fe-L como catalizador en la reacción foto-Fenton no está descrita completamente, se sabe que el radical $\mathrm{OH}$ - desempeña un papel importante. Xue et al., 2009 describen la complejación del hierro por el quelante y el inicio de la reacción como se detalla a continuación (Ecuaciones 15-19):

$$
\begin{gathered}
\mathrm{Fe}^{3+}+\mathrm{L} \rightarrow \mathrm{Fe}(\mathrm{III}) \mathrm{L} \quad(\text { Ec. 15) } \\
\mathrm{Fe}(\mathrm{III}) \mathrm{L}+\mathrm{H}_{2} \mathrm{O}_{2} \rightarrow \mathrm{Fe}(I I) \mathrm{L}+\mathrm{H}^{+}+\mathrm{HO}_{2} \quad \text { (Ec. 16) } \\
\mathrm{Fe}(\mathrm{III}) \mathrm{L}+\mathrm{HO}_{2} \rightarrow \mathrm{Fe}(I I) \mathrm{L}+\mathrm{H}^{+}+\mathrm{O}_{2} \quad \text { (Ec. 17) } \\
\mathrm{Fe}(\mathrm{III}) \mathrm{L}+\mathrm{O}_{2}^{-} \cdot \rightarrow \mathrm{Fe}(I I) \mathrm{L}+\mathrm{O}_{2} \quad(\text { Ec. 18) } \\
\mathrm{Fe}(\mathrm{II}) \mathrm{L}+\mathrm{H}_{2} \mathrm{O}_{2} \rightarrow \mathrm{Fe}(I I I) \mathrm{L}+\mathrm{HO}^{\cdot}+\mathrm{OH}^{-} \quad \text { (Ec.19) }
\end{gathered}
$$

Del mismo modo que en el proceso foto-Fenton convencional la radiación juega un papel importante en la velocidad de la reacción (Ecuación 20), en este caso, la producción de especies reactivas también mejora.

$$
\mathrm{Fe}(I I I) L \rightarrow^{h v} \mathrm{Fe}^{2+}+L^{\cdot} \quad \text { (Ec. 20) }
$$

La utilización de agentes quelantes (i) promueve la generación de $\mathrm{OH} \cdot$ por la activación del $\mathrm{H}_{2} \mathrm{O}_{2}$, (ii) puede mejorar la solubilidad de compuestos no polares, (iii) tiene la capacidad de reducir el $\mathrm{Fe}$ (III) a $\mathrm{Fe}$ (II), (iv) los quelatos tienen mayor rendimiento cuántico y, (v) se amplía el rango de radiación al que puede producirse el proceso.

A la hora de seleccionar un compuesto quelante hay que tener en cuenta diversas consideraciones: (i) estabilidad del ligando libre y complejado (ii) relación molar L:Fe, ya que los quelantes generalmente no se encuentran de forma natural en las aguas, lo que supone un aumento del valor del COT (iii) biodegradabilidad y toxicidad del quelante.

\subsection{Diferentes agentes quelantes}

A continuación, se nombrarán algunos de los agentes quelantes más estudiados en la aplicación al proceso foto-Fenton a pHs más próximos a la neutralidad.

\subsection{1. Ácido etilendiaminotetraacético (EDTA)}

El ácido etilendiaminotetraacético es un ácido amino-policarboxílico que posee una alta capacidad complejante y que está presente en productos industriales y de limpieza doméstica (Ahile et al., 2020). Debido a su aplicación industrial y a su aplicabilidad en 
medio acuoso, este compuesto se encuentra con facilidad presente en los cauces de aguas naturales. También se encuentra presente en los suelos debido a su uso en fertilizantes agronómicos.

Es una molécula con cuatro grupos carboxílicos y dos amino, presenta seis átomos donantes que pueden formar hasta cinco anillos quelato-metal (Figura 1.2.2.3.4.1.1-1) formando idealmente un complejo octaédrico (Figura 1.2.2.3.4.1.1-2).

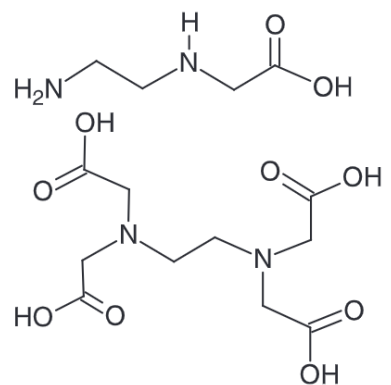

Figura 1.2.2.3.4.1.1- 1. Estructura molecular EDTA. Fuente: Sillanpää et al., 2011.

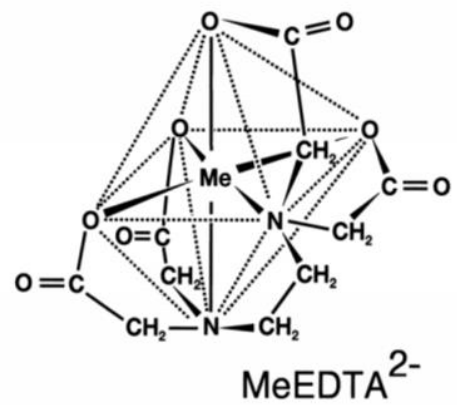

Figura 1.2.2.3.4.1.1 2. Estructura octaedra del complejo metal-EDTA. Fuente: Bucheli-Witschel \& Egli, 2001.

El rendimiento cuántico del complejo $\mathrm{Fe}(\mathrm{III})$-EDTA depende del $\mathrm{pH}$, de la longitud de onda de la radiación aplicada y de la cantidad de oxígeno disuelto presente en la disolución según Kocot et al., 2006. La degradación de CEs mediante la utilización de este complejo Fe(III)-EDTA ha sido demostrada por autores como De Luca et al., 2014 que demostraron que con una relación molar 1.5:1 EDTA:Fe(III) y a pH 7, el complejo es capaz de catalizar el $\mathrm{H}_{2} \mathrm{O}_{2}$ y degradar el antibiótico sulfametoxazol; Silva et al., 2021 degradaron naproxeno con una relación molar 2:1 EDTA:Fe(III) a pH 7 en presencia de $\mathrm{H}_{2} \mathrm{O}_{2}$ con buenos resultados de degradación; Ahile et al., 2020 demostraron la degradación del colorante azul de metileno a pH 7 y una relación EDTA:Fe(III) 1.5:1.

El principal problema que presenta la aplicación del EDTA es su baja tasa de biodegradabilidad (Yuan \& VanBriesen, 2013) convirtiéndolo en un contaminante emergente (Huang et al., 2013), así como la movilización de metales pesados presentes 
en el suelo o lodos (Kari and Giger, 1996) con el consiguiente paso a los cauces de agua y riesgo potencial para los ecosistemas acuáticos (Schmidt et al., 2004) ya que, el complejo EDTA-metal es hidrosoluble a un gran rango de pHs. En la Figura 1.2.2.3.1.1-3 se muestran las diferentes especies Fe-EDTA en función del pH.

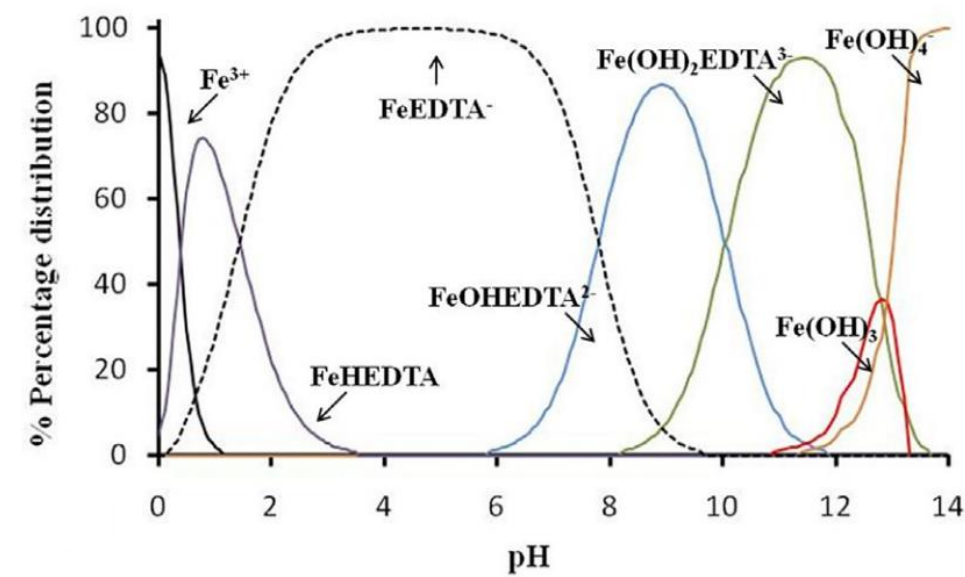

Figura 1.2.2.3.4.1.1 - 3. Diagrama de especiación del complejo Fe(III)-EDTA en función del pH en una disolución con una concentración de $\mathrm{Fe}(\mathrm{III})$ de $1.0^{*} 10^{-5} \mathrm{M}$ y $1.0^{*} 10^{-5} \mathrm{M}$ de EDTA a $25^{\circ} \mathrm{C}$ de temperatura. Fuente: Clarizia et al., 2017.

\subsection{2. Ácido etilendiamino- $N$, $N$ '-disuccinico (EDDS)}

El ácido etilendiamino- $N, N$ '-disuccinico (EDDS) ha sido el mayor sustituto del EDTA como complejante del hierro (Figura 1.2.2.3.4.1.2-1). Es un isómero estructural del EDTA pero con una mayor tasa de biodegradabilidad y que no presenta toxicidad en condiciones ambientales (Lumbaque et al., 2019). Ha demostrado ser eficiente en la solubilización de especies de hierro y otros metales en un amplio rango de pHs (Orama et al., 2002; Soriano-Molina et al., 2018).<smiles>O=C(O)CC(NCCNC(CC(=O)O)C(=O)O)C(=O)O</smiles>

Figura 1.2.2.3.4.1.2- 1. Estructura molecular EDDS. Fuente: Bucheli-Witschel \& Egli, 2001.

El mecanismo de reacción para la formación de Fe(II) a partir del complejo Fe(III)-EDDS en presencia de radiación ha sido descrita por $\mathrm{Wu}$ et al., 2014. Ellos calcularon los rendimientos cuánticos de reducción a Fe(II) por fotólisis por parte del complejo Fe(III)- 
EDDS entre 290 y 400 nm de radiación. Los autores asumen que la reducción de Fe(II) es igual a la degradación del complejo Fe(III)-EDDS (Ecuaciones 21-22).

$$
\begin{gathered}
F e^{3+}-E D D S+h v \rightarrow F e^{2+}+E D D S \quad(\text { Ec. 21) } \\
E D D S+O_{2} \rightarrow E D D S_{o x}+O_{2}^{--} \quad(\text { Ec. 22) }
\end{gathered}
$$

Li et al., 2010 calcularon el rendimiento cuántico del complejo a diferentes pH para la degradación del 17ß-estradiol obteniendo mayores rendimientos cuánticos conforme amentaba el pH, contrariamente a lo que ocurre en ausencia de complejo Fe(III)-EDDS. Las diferentes especies de Fe-EDDS en función del $\mathrm{pH}$ se muestran en la Figura 1.2.2.3.4.1.2-2.

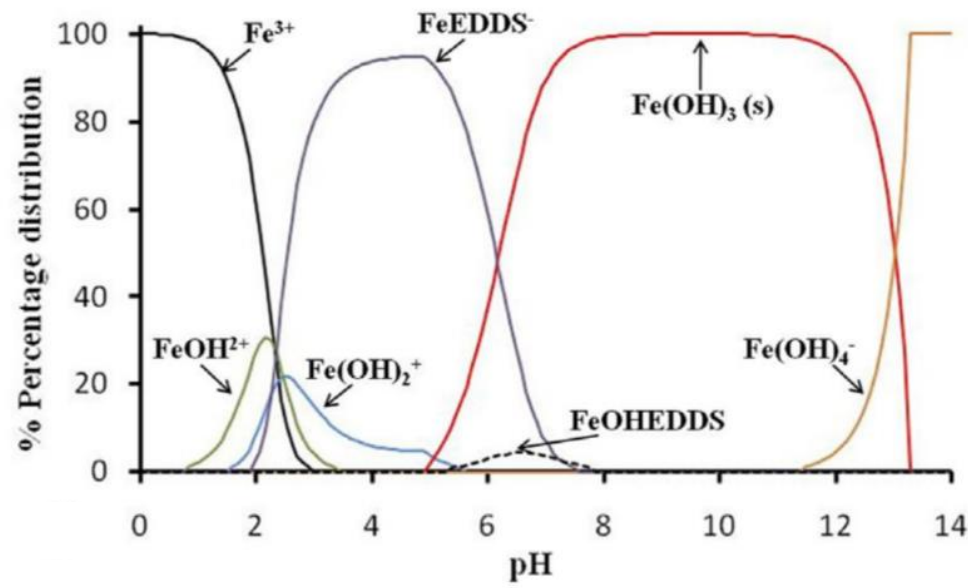

Figura 1.2. 2.3.4.1.2- 2. Diagrama de especiación del complejo Fe(III)-EDDS en función del pH en una disolución con una concentración de Fe(III) de $1.0^{*} 10^{-5} \mathrm{M}$ y $1.0^{*} 10^{-5} \mathrm{M}$ de EDDS a $25^{\circ} \mathrm{C}$ de temperatura. Fuente: Clarizia et al., 2017.

El EDDS ha demostrado por numerosos autores ser eficiente para llevar el proceso fotoFenton a pHs más neutros y ser capaz de complejar el hierro manteniéndolo en disolución. Papoutsakis et al., 2015 comprobaron en aguas reales de EDAR, la degradación de microcontaminantes a pHs de entre 5 y 8; Miralles-Cuevas et al., 2019 eliminaron el 90\% de una mezcla de microcontaminantes aplicando $2 \mathrm{~kJ} \mathrm{~L}^{-1}$ de energía solar y una relación molar 1:1 Fe:EDDS; Huang et al., 2012 demostraron que la presencia del complejo Fe:EDDS estimula la generación de $\mathrm{OH}$ y la degradación del bisfenol A a pHs neutros.

\subsection{3. Ácido nitrilotriacético (NTA)}

El ácido nitrilotriacético también pertenece a la familia de los ácidos aminopolicarboxílicos (Figura 1.2.2.3.4.1.3-1). Es un ligando trianiónico tetradentado tripodal 
que forma, al igual que el EDTA, un octaedro como estructura metal-NTA (Figura 1.2.2.3.4.1.3-2).<smiles>O=C(O)CN(CC(=O)O)CC(=O)O</smiles>

Figura 1.2.2.3.4.1.3- 1. Estructura molecular NTA. Fuente: Bucheli-Witschel \& Egli, 2001.

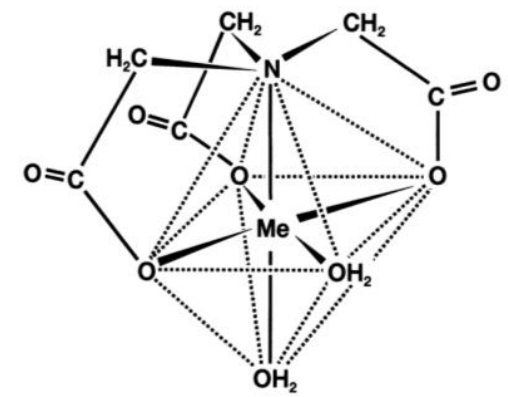

MeNTA $^{-}$

Figura 1.2.2.3.4.1.3- 2. Estructura octaedra del complejo metal-NTA. Fuente: Bucheli-Witschel \& Egli, 2001.

El complejo Fe(III)-NTA es capaz de fotolizarse a longitudes de onda por encima de 300 nm dando lugar a la formación de iones de Fe(II) (Clarizia et al., 2017). Pese a que su reactividad con los radicales hidroxilo es menor que la del complejo Fe(III)-EDDS, el complejo Fe(III)-NTA es capaz de degradar contaminantes en menores tiempos de tratamiento bajo las mismas condiciones y una radiación aplicada de 200 a $530 \mathrm{~nm}$ (Zhang et al., 2016). La estabilidad del complejo metal-NTA es menor que la del metal-EDTA (Bucheli-Witschel \& Egli, 2001), pero su alta biodegradabilidad y su baja toxicidad en el medio ambiente (Silva et al., 2021) lo convierten en una opción más respetuosa con el mismo. La Figura 1.2.2.3.4.1.3-3 muestra las diferentes especies de Fe(III)-NTA en función del $\mathrm{pH}$. 


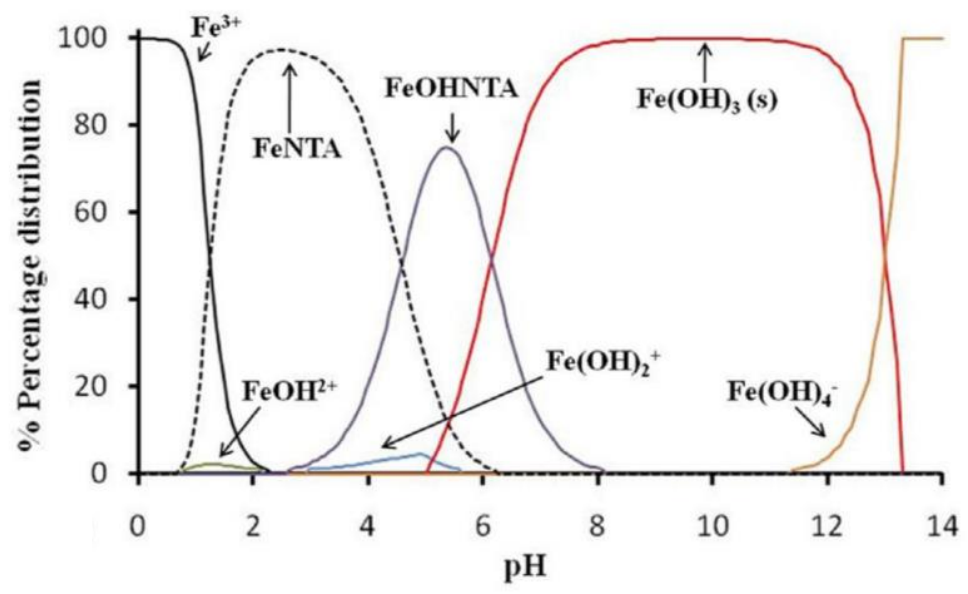

Figura 1.2.2.3.4.1.3- 3. Diagrama de especiación del complejo Fe(III)-NTA en función del pH en una disolución con una concentración de Fe(III) de $1.0^{*} 10^{-5} \mathrm{M}$ y $1.0^{*} 10^{-5} \mathrm{M}$ de NTA a $25^{\circ} \mathrm{C}$ de temperatura. Fuente: Clarizia et al., 2017.

De Luca et al., 2014 estudiaron la degradación del sulfametoxazol mediante la utilización de varios complejos Fe(III)-ligando concluyendo que, debido a su baja toxicidad, poca aportación al aumento del COT y alta estabilidad, el complejo más eficiente para llevar a cabo el proceso foto-Fenton era el NTA. Sun et al., 2013 estudiaron la degradación de la carbamazepina a pH 7 en presencia de este ligando metal, obteniendo una constante de degradación de $0.0419( \pm 0.002) \mathrm{min}^{-1}$.

\subsection{4. Oxalato}

El ácido oxálico es un ácido carboxílico cuya base conjugada, el oxalato, es un agente complejante de iones metálicos. Con el hierro forma el complejo ferroxalato, el cual es capaz de expandir el rango de aplicación del proceso foto-Fenton absorbiendo radiación por encima de $450 \mathrm{~nm}$ aumentando así la eficiencia oxidativa.

En la Figura 1.2.2.3.4.1.4-1 se muestra el diagrama de especiación del complejo ferroxalato. El Fe está en forma de Fe(III) di-oxalato férrico hasta valores de $\mathrm{pH}$ de 4, por encima de este valor de $\mathrm{pH}$ se forman $\mathrm{Fe}(\mathrm{OH})_{3}$. 


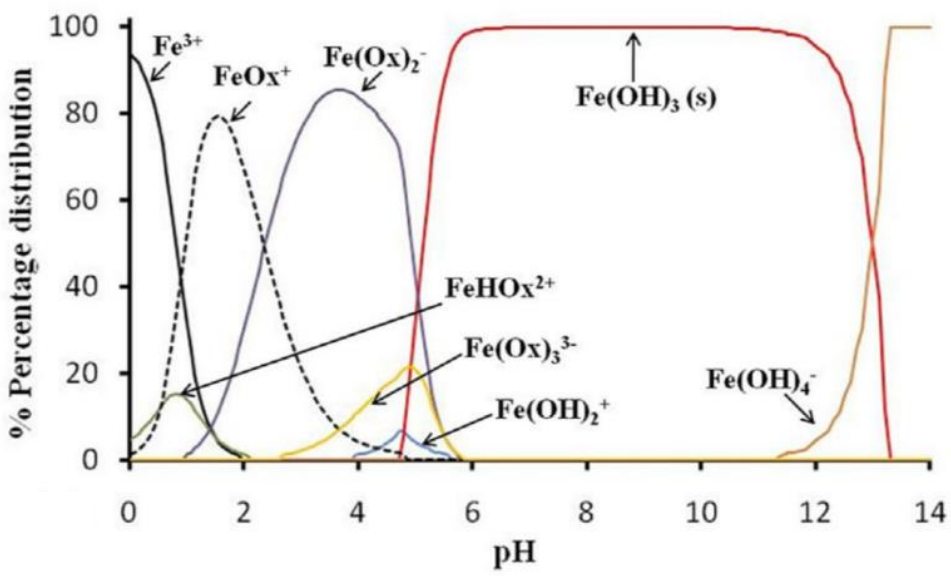

Figura 1.2.2.3.4.1.4-1. Diagrama de especiación del complejo ferroxalato en función del $\mathrm{pH}$ en una disolución con una concentración de $\mathrm{Fe}(\mathrm{III})$ de $1.0 * 10^{-5} \mathrm{M}$ y $3.0^{*} 10^{-5} \mathrm{M}$ de oxalato a $25^{\circ} \mathrm{C}$ de temperatura. Fuente: Clarizia et al., 2017.

El oxalato ha sido el ligando más utilizado para la degradación de compuestos orgánicos mediante proceso foto-Fenton, debido a su alta fotosensibilidad y a su alto rendimiento cuántico ( $\Phi=1.24$ a $300 \mathrm{~nm}$ y pH 2.0) (Silva et al., 2021). Aunque el oxalato es biodegradable y presenta baja toxicidad, el principal problema que presenta este complejo es la elevada relación molar necesaria para que se formen complejos estables, ya que es un complejante débil, lo que supone una adición demasiado alta de COT al sistema convirtiéndolo en un contaminante potencial. De Luca et al., 2014 probaron la relación molar Fe:oxalato 1:10, que era la usada generalmente en bibliografía, y 1:20 pasando de un $30 \%$ a un $70 \%$ de degradación de sulfametoxazol respectivamente.

Algunos autores que han demostrado la eficiencia de este complejo en el proceso fotoFenton han sido Klamerth et al., 2011; Pereira et al., 2014; Soares et al., 2015; Schenone et al., 2015.

\subsection{5. Ácido cítrico}

El ácido cítrico es ampliamente usado en la industria farmacéutica y alimentaria, por lo que una de sus principales ventajas es que se encuentra presente en numerosas ocasiones en las aguas. El complejo Fe(III)-citrato da lugar a una transferencia de carga ligando metal, después de la cual reaccionan para generar $\mathrm{Fe}(\mathrm{II})$ y especies reactivas como $\mathrm{OH}$, $\mathrm{HO}_{2} \cdot / \mathrm{O}_{2} \cdot-$ y $\mathrm{H}_{2} \mathrm{O}_{2}$ (Ahile et al., 2020).

El complejo Fe(III)-citrato ha demostrado ser eficiente en la degradación de atrazina en un rango de $\mathrm{pH}$ 3.5-8.6, donde a mayor concentración del ligando, mayor degradación del herbicida (Ou et al., 2008); Miralles-Cuevas et al., 2014 eliminaron el 90\% de los 
contaminantes presentes en la matriz de agua con una relación molar $\mathrm{Fe}$ (III)-citrato de 1:5 a un pH 6-7; la eliminación de alaclor en presencia de este ligando ha sido demostrada por Katsumata et al., 2006, entre otros.

\subsection{6. Sustancias húmicas}

Las sustancias húmicas $(\mathrm{SH})$ han sido consideradas como la parte estable de la materia orgánica de los suelos durante mucho tiempo (Gerke, 2018) y son uno de los reservorios más importantes de carbono en la biosfera (Ateia et al., 2017). Las SH son un conjunto de sustancias coloreadas de alto peso molecular formadas por procesos bioquímicos a partir de residuos de origen animal o vegetal, bastante resistentes a la degradación química y/o microbiológica. Están compuestas aproximadamente por 50\% de carbono, $35-45 \%$ de oxígeno, $5 \%$ de hidrógeno y 3\% de nitrógeno y azufre (Thurman et al., 1985; MacCarthy, 2001).

Las SH son sustancias amorfas de colores oscuros, polímeros tridimensionales de elevado peso molecular, de carácter ácido, constituidos por unos grupos funcionales: núcleo (grupos aromáticos nitrogenados y grupos bencénicos aromáticos), grupos reactivos (responsables de importantes propiedades de la materia orgánica: hidroxilo, carboxilo, amino, metoxilo, etc.), puentes de unión (nitrilo, amino, cetónicos, etc.) y cadenas alifáticas (Figura 1.2.2.3.4.1.6-1).

Sustancias húmicas

(polímeros pigmentados)

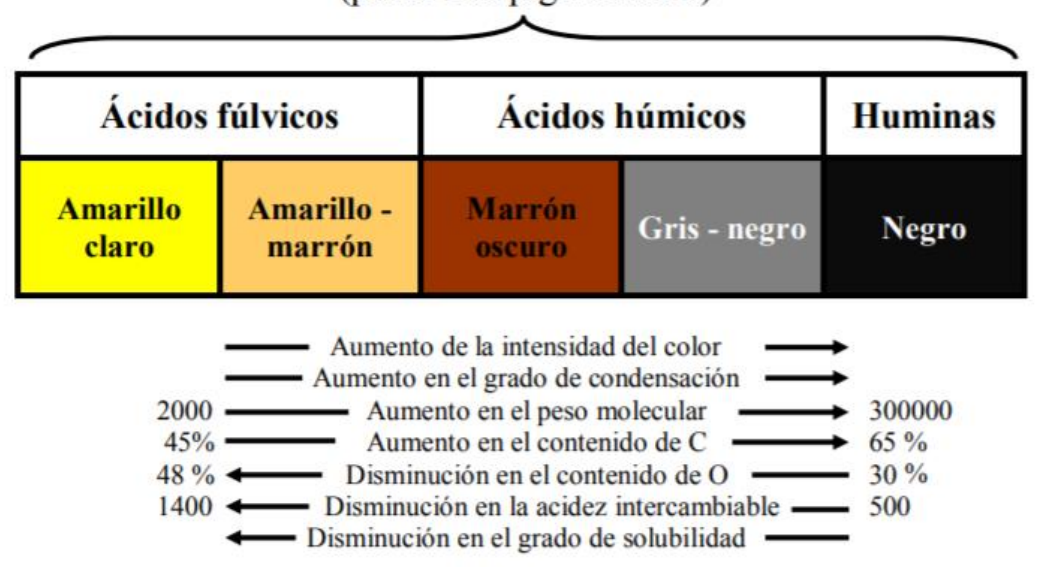

Figura 1.2.2.3.4.1.6- 1. Propiedades fisicoquímicas de las SH. Fuente: Stevenson, 1994.

Las sustancias húmicas pueden dividirse en tres grupos:

Ácidos húmicos (AH): sólidos amorfos de color marrón oscuro, insolubles en agua y en casi todos los disolventes no polares, pero fácilmente dispersables en las soluciones 
acuosas de los hidróxidos y sales básicas de los metales alcalinos, constituyendo un hidrosol que puede experimentar floculación mediante el tratamiento de los ácidos o los demás cationes. Figura 1.2.2.3.4.1.6-2.

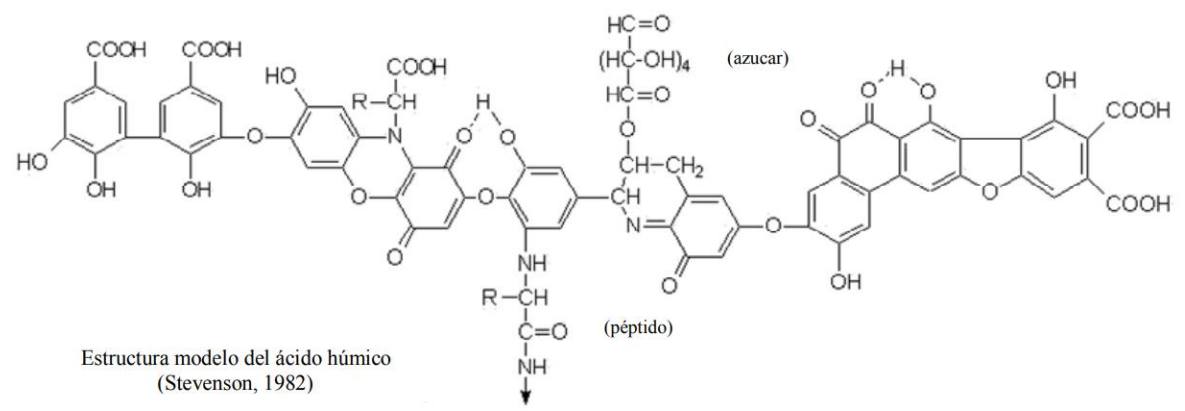

Figura 1.2.2.3.4.1.6- 2. Ejemplo de estructura modelo de AH. Fuente: Stevenson, 1982.

Ácidos fúlvicos (AF): constituyen una serie de compuestos sólidos o semisólidos, amorfos, de color amarillento y naturaleza coloidal, fácilmente dispersables en agua y no precipitables por los ácidos, pero susceptibles de experimentar floculación en determinadas condiciones de $\mathrm{pH}$ y concentración de las soluciones de cationes no alcalinos. Figura 1.2.2.3.4.1.6-3.

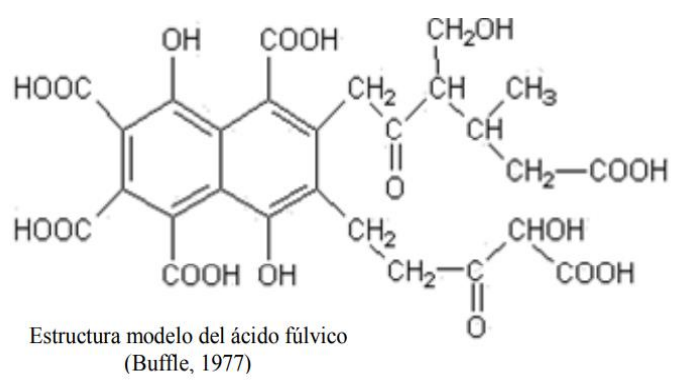

Figura 1.2.2.3.4.1.6- 3. Ejemplo de estructura modelo de AF. Fuente: Buffle, 1977.

Huminas: constituyen un grupo de sustancias muy diferentes entre sí, de color negro e insolubles en medio alcalino.

A pesar de la heterogeneidad de las $\mathrm{SH}$, existen similitudes entre muestras de distinto origen. La estructura molecular secundaria es clave para la asociación con compuestos orgánicos, y las variaciones en tamaño y forma dependen de las características fisicoquímicas de la matriz de agua en la que se encuentre (Ephraim et al., 1995). Así, a pHs básicos, baja concentración de materia orgánica disuelta y condiciones de baja fuerza iónica, se presentan como moléculas extendidas, lineales y de alto peso molecular, mientras que, a pHs ácidos, alta fuerza iónica y elevada concentración de MOD son moléculas con formas esféricas globulares compactas. La estructura secundaria es la 
responsable de la formación de pseudomicelas, que a su vez son las responsables de la interacción con compuestos orgánicos. Estas pseudomicelas son más grandes que las micelas y tienen un núcleo hidrofóbico (David Gara, 2008).

\subsection{6.1.Formación de las $\mathrm{SH}$}

La formación de las sustancias húmicas puede producirse por varios mecanismos conocidos como: (i) modificación de las ligninas, (ii) origen de los polifenoles y, (iii) condensación de azucares y aminas. Deben considerarse todos los mecanismos, y dependiendo de las condiciones ambientales del suelo prevalecerá la formación por una vía u otra.

\section{Teoría de la lignina:}

Descrita por Waksman \& Iyer, 1932 (Figura 1.2.2.3.4.1.6.1-1). La lignina es utilizada de forma incompleta por los microorganismos del suelo y el residuo pasa a formar parte del humus, posteriormente sufre otra serie de modificaciones para acabar generando primero AH y luego AF.

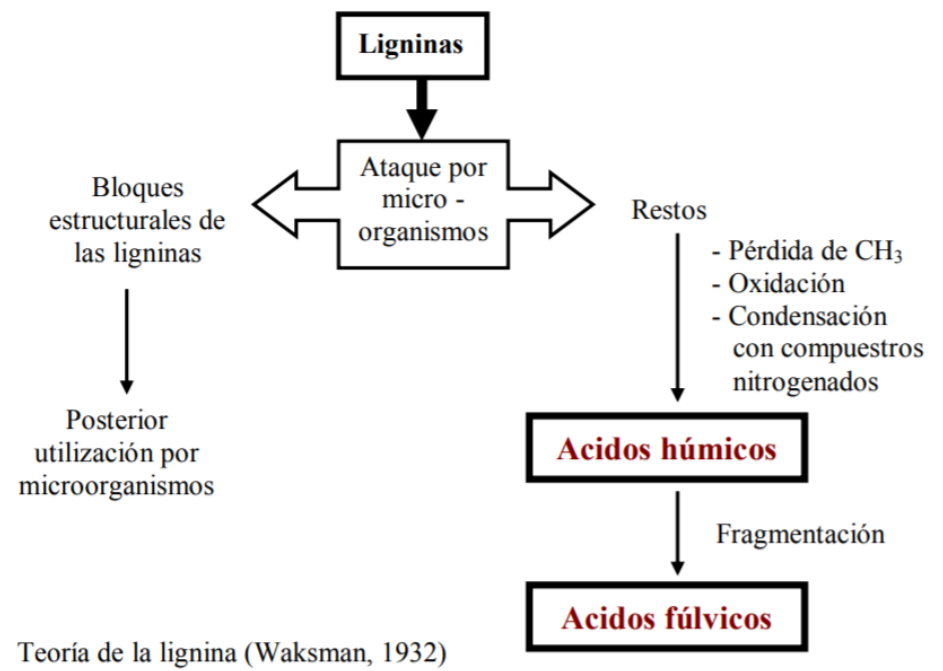

Figura 1.2.2.3.4.1.6.1- 1. Teoría de la lignina. Waksman, 1932 .

\section{Teoría del polifenol:}

Mecanismo descrito por Stevenson, 1982 (Figura 1.2.2.3.4.1.6.1-2). En una primera etapa, la lignina es degradada por los microorganismos en aldehídos y ácidos fenólicos que producen quinonas por reacciones enzimáticas que se polimerizan para formar $\mathrm{SH}$. En el segundo mecanismo los compuestos fenólicos son sintetizados a partir de sustratos 
distintos a la lignina (por ejemplo, celulosa), posteriormente son oxidados a quinonas y convertidas en $\mathrm{SH}$.

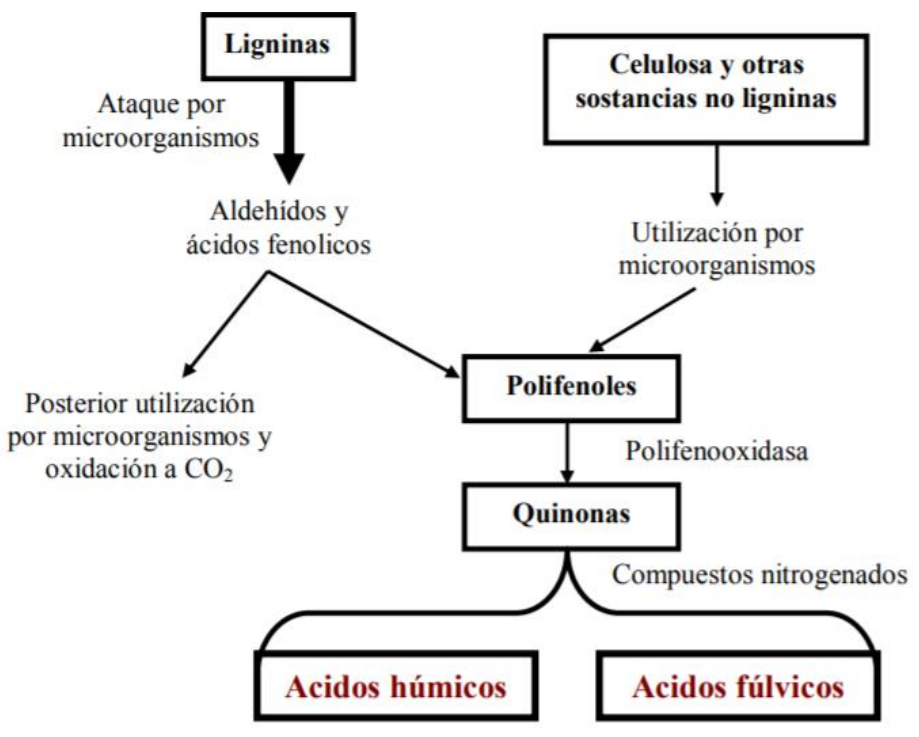

Teoria de los polifenoles (Stevenson, 1982)

Figura 1.2.2.3.4.1.6.1- 2. Teoría del polifenol. Fuente: Stevenson, 1982.

\section{Condensación de azúcares y aminas:}

Los azúcares y aminoácidos generados en el metabolismo microbiano se condensan para formar polímeros pardos por vía no enzimática y a temperaturas moderadas.

\subsection{6.2.Aislamiento de STH}

Las STH pueden sintetizarse y aprovecharse para diferentes usos. A continuación, se detalla su proceso de extracción.

\section{Extracción}

Es el primer paso para aislar y caracterizar SH y el más crítico, ya que deben extraerse de la forma menos alterada posible y evitando la extracción de otro tipo de sustancias con características no húmicas. El extractante utilizado debe solubilizar las $\mathrm{SH}$ sin producir cambios en su estructura molecular ni en sus propiedades (Schnitzer, 1978). Para que el método de extracción seleccionado sea considerado valido debe cumplir con una serie de objetivos (Stevenson, 1994):

- No debe alterar la materia orgánica que se aísla.

- En las SH obtenidas no debe haber presencia de impurezas orgánicas. 
- El peso molecular medio obtenido en la fracción extraída debe ser representativo de toda la muestra.

- El método seleccionado debe ser aplicable y universal para cualquier tipo de sustrato/material.

Según las características del material original del cual se van a extraer estas SH hay que adaptar el método de extracción, puesto que no existe un método universal aplicable a cualquier sustrato/material. Hay que considerar una serie de factores que influyen en la extracción de estas sustancias, como:

- Concentración y tipo de extractante: el tipo de extractante es un parámetro importante ya que de él depende la solubilidad de la materia orgánica. El más utilizado históricamente ha sido el $\mathrm{NaOH}$ y posteriormente el $\mathrm{KOH}$. En cualquier caso, deben ser extractantes alcalinos que son con los que se obtiene un mayor rendimiento debido a las características de las SH descritas anteriormente. Las concentraciones empleadas pueden variar dependiendo del caso, por ejemplo: Tomati et al., 2001 utilizaron $\mathrm{NaOH}$ a 0.1M, y Ouatmane, $2000 \mathrm{KOH} 1 \mathrm{M}$.

- Relación de extracción (p/v): influye en la concentración de material que se obtiene. Debe considerarse la posible saturación del extractante antes de que extraiga toda la materia orgánica.

- Tiempo de extracción: Según la Sociedad Internacional de Sustancias Húmicas (IHSS), el tiempo necesario es de 4 horas, pero este tiempo puede variar desde 1 a 24 horas dependiendo del estudio que se consulte.

- Temperatura de extracción: Se ha demostrado que el incremento de la temperatura resulta en un incremento del rendimiento del proceso de extracción.

\section{$\underline{\text { Fraccionamiento }}$}

El método más utilizado para el fraccionamiento de las $\mathrm{SH}$ se basa en la variación del pH, debido a las diferentes solubilidades de las sustancias (AH, AF y huminas). El principal objetivo del fraccionamiento es la disminución de la heterogeneidad de las sustancias para posteriormente facilitar su análisis. También se han utilizado cromatografía de elución sobre gel, ultrafiltración y ultracentrifugación y, electroforesis de isoelectroenfoque. 


\section{Purificación}

Se busca la eliminación de otro tipo de sustancias (carbohidratos, proteínas, lípidos, sales minerales, etc.) que son co-extraídas en el proceso. El método más ampliamente utilizado consiste en dializar la muestra obtenida con agua desionizada (García-Ballesteros et al., 2018).

\subsection{6.3.Aplicaciones de las $\mathrm{SH}$}

Debido a las propiedades de las $\mathrm{SH}$, éstas se pueden emplear en diferentes procesos o campos, siendo el campo de la agricultura el más destacado, no obstante, también están presentes en otros como procesos industriales, medicina y medio ambiente.

\section{Aplicaciones en la agricultura}

Las $\mathrm{SH}$ en el suelo son importantes porque mantienen los cationes disponibles para que puedan ser absorbidos por las raíces, además de ayudar a su transporte (Serrano et al., 2015). Por otro lado, ayudan a la mejora de las características químicas, fisicoquímicas y biológicas del suelo, por aumento en la retención de agua y nutrientes, favorecimiento la diversidad de microrganismos y la formación de complejos con micronutrientes como el $\mathrm{Fe}, \mathrm{Co}, \mathrm{Cu}$ y $\mathrm{Zn}$.

Numerosos estudios científicos se centran en la adición de estas sustancias como fertilizantes al suelo y estimuladores del crecimiento, para la elaboración de compost, para la reducción de enfermedades infecciosas en los cultivos, como quelantes de micronutrientes y como atrapadores de contaminantes (Guo et al., 2019; Cieschi et al., 2019; Luo et al., 2019; Olk et al., 2019; Ekin, 2019).

\section{$\underline{\text { Aplicaciones medioambientales }}$}

Se utilizan las $\mathrm{SH}$ en aplicaciones medioambientales principalmente para la eliminación de metales pesados como Cr, Cd, As, Pb, Cu y Zn (Bi et al., 2019; Piccolo et al., 2019; Lim et al., 2018; Pukalchik et al., 2018), y la eliminación de contaminantes orgánicos presentes en el suelo y en las aguas (Gomis et al., 2014; Sannino et al., 2013; Rebhun et al., 1996).

\section{$\underline{\text { Otras aplicaciones }}$}

Las SH se usan en diferentes sectores industriales como el de la cerámica (para mejorar las propiedades mecánicas), en la industria maderera y en la industria textil para su 
coloración, como endurecedores de espumas y plastificantes de PVC, como fuente de hidrocarburos, y para la formulación de detergentes ya que actúan como surfactantes.

\subsection{4.Aplicación como quelantes en proceso foto-Fenton}

Las sustancias húmicas pueden utilizarse también como agentes complejantes del hierro. Debido a su tamaño y alto peso molecular, poseen gran cantidad de sitios activos por molécula, por lo que se espera que sean más resistentes a la oxidación y que la perdida de eficiencia en el proceso foto-Fenton sea menor comparada con otros ligandos (SantosJuanes et al., 2017).

La habilidad de las SH de complejar metales es una de las funciones más importantes que presentan en el suelo, aunque el mecanismo de actuación no está bien descrito debido a (i) la variabilidad y compleja estructura de las $\mathrm{SH}$ en cuanto a composición de C (52$62 \%), \mathrm{H}(3-5.5 \%), \mathrm{N}(3.5-5 \%), \mathrm{O}(30-33 \%)$, grupos aromáticos, estructuras alifáticas, etc. (Kononova, 1966), (ii) pesos moleculares de entre 2000 a 50000 Da (Steelink, 2002) y, (iii) grado de humificación (Boguta \& Sokolowska, 2013). Estas características intrínsecas de cada SH hacen que la capacidad complejante para un mismo metal varíe (Dudare \& Klavins, 2013).

La capacidad complejante de las SH está condicionada por el $\mathrm{pH}$ como ha demostrado Wang et al., 2013 que investigó la capacidad coagulante de las SH a pH 2-10, o Boguta et al., 2019 que estudiaron la interacción entre las SH del suelo y iones ferrosos en función del $\mathrm{pH}$, la concentración de hierro y las características intrínsecas de las SH. Obtuvieron que la complejación del hierro es mayor a pH 7, aumentando conforme lo hacía la presencia de grupos carboxílicos y fenólicos presentes en las SH, así como, el grado de humificación. Por otro lado, la estabilidad del complejo Fe-SH era mayor a pH 5, debido a la formación de óxidos e hidróxidos de hierro por encima de este pH. García-Ballesteros et al., 2017 estudiaron por fluorescencia la complejación del Fe(III) por parte de STH extraídas de residuos sólidos urbanos a diferentes $\mathrm{pH}(3,5$ y 7). Obtuvieron que el complejo ligando metal más estable se producía a pH 5. Sometieron el complejo a proceso foto-Fenton y concluyeron que los resultados de degradación estaban de acuerdo con las medidas de fluorescencia efectuadas.

Químicamente las SH presentan similitudes con la materia orgánica disuelta (MOD) presente en aguas terrestres y suelos (Avetta et al., 2013). La MOD juega un papel fundamental en la autoremediación de aguas superficiales, ya que posee especies capaces 
de absorber radiación y generar especies reactivas (Canonica et al., 1995). La Figura 1.2. 2.3.1.6.4-1 muestra las principales reacciones que tienen lugar en aguas naturales por fotosensibilización de las SH. Las SH constituyen casi la mitad de la materia orgánica disuelta en las aguas naturales. Al ser fotosensibles, absorben la luz solar (UV-Vis) generando estados tripletes, reaccionando con otras especies presentes en el agua y dando lugar a diferentes intermedios reactivos como pueden ser oxígeno singlete $\left({ }^{1} \mathrm{O}_{2}\right)$, radicales alquilperóxido $\left(\mathrm{RO}_{2} \cdot\right)$, radicales hidroxilo $(\mathrm{OH} \cdot)$ y, radicales anión superóxido $\left(\mathrm{O}_{2} \cdot{ }^{-}\right)$. En aguas naturales se forman también otras especies reactivas como $\mathrm{HCO}_{3} \cdot{ }^{-}, \mathrm{Cl}_{2} \cdot{ }^{-}$y $\mathrm{Br}_{2} \cdot{ }^{-}$ debido a que las aguas contienen en disolución iones de $\mathrm{Fe}(\mathrm{III}), \mathrm{Cl}^{-}, \mathrm{Br}^{-}$y $\mathrm{HCO}_{3}{ }^{-}$. Estas especies reactivas son las responsables de la oxidación de contaminantes orgánicos presentes en las aguas y de la propia MOD. La MOD no puede considerarse viable a nivel industrial para el tratamiento de aguas debido a su baja presencia en suelos y aguas naturales $(<3 \%)$ (Avetta et al., 2013).

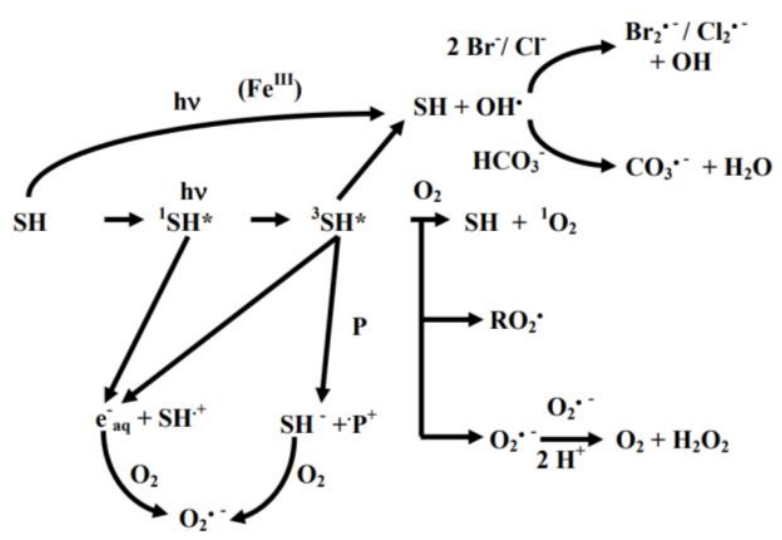

Figura 1.2.2.3.4.1.6.4- 1. Principales reacciones que tienen lugar en aguas naturales por fotosensibilización de las SH. Fuente: Richard \& Canonica, 2005.

Las SH tienen diferentes comportamientos, por un lado absorben radiación solar en el espectro UV-Vis hasta los $500 \mathrm{~nm}$ (Aguer \& Richard, 1999) dando lugar a estados excitados tripletes $\left({ }^{3} \mathrm{HS}^{*}\right)$, especies reactivas de oxígeno, radicales hidroxilo, oxígeno singlete y peróxido de hidrógeno, que pueden inducir la transformación de compuestos orgánicos (Zhan et al., 2006); contienen ácidos carboxílicos, fenólicos, quininas y, grupos amino, que las hace capaces de participar en procesos de intercambio iónico y redox para formar complejos; y también poseen radicales libres estables que pueden reaccionar con diferentes sustancias (Klamerth et al., 2011). Por otro lado, las SH son macromoléculas coloreadas que absorben radiación en el espectro UV-Vis, por lo que pueden ejercer la acción de filtro interno impidiendo que los fotones penetren y alcancen toda la disolución 
a tratar, lo que disminuiría la eficiencia del proceso (Carlos et al., 2012). Además, compiten por las especies reactivas con los contaminantes al tratarse de macromoléculas sensibles a la oxidación (Lipczynska-Kochany \& Kochani, 2008), lo que también supondría un descenso de la eficiencia de degradación conforme aumenta la concentración de SH presentes en la mezcla y haría necesaria el empleo de mayores cantidades de peróxido de hidrógeno. Con todo esto, la eficiencia del sistema $\mathrm{Fe}-\mathrm{SH}$ no está bien establecida ni descrita y es difícil de predecir (Gomis et al., 2015) por lo que hay que considerar todos los factores que intervienen en el proceso. Las SH interaccionan con los iones metálicos presentes, formando un complejo que inducido por la radiación solar generan especies oxidantes de acuerdo con las siguientes reacciones (Ecuaciones 23-30):

$$
\begin{aligned}
& \mathrm{Fe}^{3+}-\mathrm{SH}+h v \rightarrow \mathrm{Fe}^{2+}+\mathrm{SH}^{++} \quad(\text { Ec. 23) } \\
& S H+h v \rightarrow S H^{\cdot} \quad \text { (Ec. 24) } \\
& \mathrm{SH}^{++}, \mathrm{SH}^{\cdot}+\mathrm{O}_{2} \rightarrow \mathrm{P}+\mathrm{O}_{2}^{\cdot-}, \mathrm{HO}_{2}^{\cdot} \quad(\text { Ec. 25) } \\
& \mathrm{O}_{2}^{--} / \mathrm{HO}_{2}^{-} \rightarrow \mathrm{H}_{2} \mathrm{O}_{2} \quad(\text { Ec. 26) } \\
& \mathrm{Fe}^{3+}+\mathrm{O}_{2}^{--} \rightarrow \mathrm{Fe}^{2+}+\mathrm{O}_{2} \quad \text { (Ec. 27) } \\
& \mathrm{Fe}^{2+}+\mathrm{O}_{2} \rightarrow \mathrm{Fe}^{3+}+\mathrm{O}_{2}^{--} / \mathrm{HO}_{2} \quad \text { (Ec. 28) } \\
& \mathrm{Fe}^{2+}+\mathrm{H}_{2} \mathrm{O}_{2} \rightarrow \mathrm{Fe}^{3+}+\mathrm{OH}^{\cdot}+\mathrm{OH}^{-} \\
& \mathrm{C}+\mathrm{OH}^{\cdot} \rightarrow \mathrm{P} \quad(\text { Ec. 30) }
\end{aligned}
$$

Donde $C$ es contaminante y $P$ productos.

La aplicación de SH como agentes complejantes del hierro ha sido demostrada por diferentes autores. Klamerth et al., 2011 añadieron SH en concentraciones de 50, 25 y 10 $\mathrm{mg} \mathrm{L}^{-1}$, lo que equivale a una relación Fe(III)-SH 1:10, 1:5 y 1:2 respectivamente. La degradación de los contaminantes fue más lenta que con el uso de oxalato como complejante, y la eficiencia del proceso disminuyó conforme aumentaba la concentración de SH. No obstante, el pH a lo largo de todo el proceso se mantuvo estable, contrariamente a lo que ocurría con el oxalato que bajaba el $\mathrm{pH}$ hasta 3.3 con el consiguiente gasto de reactivos para subirlo en el caso de vertido a cauces naturales. Sakkas et al., 2002 estudiaron la influencia de la adición de diferentes cantidades de $\mathrm{SH}$ y $\mathrm{SF}$ en la degradación de irgarol 1051 por fotólisis. Los resultados obtenidos en agua destilada 
sugieren que estás sustancias ayudan a la degradación del compuesto. Zhan et al., 2006 concluyeron que las $\mathrm{SH}$ inducían la degradación del bisfenol A por oxidación con $\mathrm{OH}$. producidos por proceso tipo Fenton. Georgi et al., 2007 estudiaron la aplicación al proceso foto-Fenton de $\mathrm{SH}$ a concentraciones $50-100 \mathrm{mg} \mathrm{L}^{-1}$ y llevaron a cabo el proceso a pHs entre 5 y 7 , concluyendo que estas sustancias aumentaban la oxidación de compuestos orgánicos. Fan et al., 2011 demostraron que la adición de $10 \mathrm{mg} \mathrm{L}^{-1}$ de SH duplicaba la velocidad de degradación del paratión frente al proceso en ausencia de éstas.

Se ha visto que las SH son capaces de complejar el hierro y ayudan en la degradación de compuestos orgánicos por procesos fotocatalíticos, por lo que la investigación de su aplicación en estos procesos está justificada. Por otro lado, nace la idea de obtener estas sustancias a partir de residuos de distinto tipo, fomentando la revalorización de residuos y la economía circular, lo que estaría en concordancia con el Pacto Verde Europeo (COM 2019) que impulsa el uso eficiente de los recursos y fomenta la economía circular.

Montoneri et al., 2008 extrajeron y caracterizaron sustancias tipo húmicas (STH) de residuos domésticos vegetales. Gomis et al., 2013 estudiaron la aplicación de STH obtenidas de residuos sólidos urbanos para la eliminación del colorante cristal violeta por proceso tipo foto-Fenton obteniendo mejores resultados en presencia de estas STH que sin ellas. Gomis et al., 2014 aplicaron estas mismas sustancias para una mezcla de seis contaminantes emergentes en proceso foto-Fenton a $\mathrm{pH} 5.2$ con radiación solar, posteriormente en el 2015 estudiaron las variables experimentales concluyendo que el óptimo de adición de STH para evitar perdida de eficiencia en el proceso era de 19-22 mg $\mathrm{L}^{-1}$ para 4-5 mg L-1 de hierro. García-Ballesteros et al., 2018 degradaron cafeína a pH 5 con la adición de STH extraídas del residuo de la producción del aceite de oliva. Avetta et al., 2013 estudiaron la degradación de monoclorofenoles mediante la adición de STH a escala de laboratorio y a pH 7. Caram et al., 2018 estudiaron la capacidad de STH para aumentar la solubilidad del tiabendazol a la vez que se podía llevar el proceso oxidativo a pHs más próximos a la neutralidad.

\subsection{Legislación aplicable en materia de agua}

Para comprender el fin de toda la explicación anterior se debe considerar el marco legislativo actual en el que se enmarcan estos desarrollos tecnológicos

En octubre del año 2000 se aprueba la Directiva Europea 2000/60/CE Marco del Agua, por la que se establece un marco comunitario de actuación en el ámbito de la política de 
aguas (CE 2000). Se define un marco de protección para las aguas naturales y nace con la intención de promover un uso sostenible y responsable de la misma que garantice la disponibilidad de agua de calidad a largo plazo. La Directiva queda transpuesta al ordenamiento español por el Real Decreto Legislativo 1/2001.

Con la Directiva 2008/105/CE se ratifican los estándares de calidad para 33 sustancias/grupos de sustancias. La Directiva 2013/39/CE pone el foco en 45 sustancias y recomienda incluir en la primera lista de vigilancia el diclofenaco, el 17- $\alpha$-etinilestradiol y el $\beta$-estradiol que se aprobará con posterioridad. En el año 2015 se aprueba la llamada Watch List o lista de vigilancia (Decisión 2015/495/EU), una lista de diez grupos de sustancias de especial preocupación y sobre las cuales debe realizarse un control y monitoreo, así como el desarrollo de tecnologías capaces de garantizar su eliminación. Los diez grupos de sustancias incluidos en la Watch List se muestras a continuación:

1. 17- $\alpha$-etinilestradiol (EE2)

2. 17- $\beta$-estradiol (E1)

\section{Diclofenaco}

4. 2,6-di-ter-butil-4-metilfenol

5. 2-etilhexil-4-metoxicinamato

6. Antibióticos macrólidos: azitromicina, claritromicina, eritromicina

7. Metiocarb

8. Neonicotinoides: imidacloprid, tiacloprid, tiametoxam, clotianidina, acetamiprid

9. Oxadiazon

10. Triallate.

En el año 2018 a través de la Decisión de Ejecución 2018/840/UE se actualiza dicha lista de observación, se eliminan 5 sustancias y se añaden tres más.

Con la Directiva 2020/2184/CE se revisa la Directiva 98/83/CE relativa a la calidad de las aguas para el consumo humano. Dicha revisión nace de una iniciativa ciudadana, y 
parte de la base de garantizar el acceso por parte de toda la ciudadanía a un agua potable de calidad, cuyo consumo durante toda la vida no suponga ningún riesgo para la salud.

Por último, con la Directiva 2020/1161se establece una lista de observación de sustancias (C 2020) de conformidad con la Directiva 2008/105/CE, que modifica la Directiva 2000/60/CE y deroga la Decisión de Ejecución 2018/840/UE. Las sustancias que se incluyen son las siguientes:

- Metaflumizona

- Amoxicilina

- Ciprofloxacina

- Sulfametoxazol

- Trimetoprim

- Venlafaxina y O-desmetilvenlafaxina

- Compuestos azólicos: Clotrimazol, Fluconazol, Imazalil, Ipconazol, Metconazol, Miconazol, Penconazol, Procloraz, Tebuconazol, Tetraconazol.

- Dimoxistrobina

- Famoxadona

En cuanto a la normativa nacional, la legislación en materia de agua para tener en cuenta sería la siguiente:

- Real Decreto 849/1986 por el cual se aprueba el Reglamento del Dominio Público Hidráulico.

- Real Decreto Ley 11/1995 por el cual se establecen las normas aplicables al tratamiento de aguas residuales urbanas. Desarrollado posteriormente por el Real Decreto Ley 509/1996.

- Real Decreto Legislativo 1/2001 por el cual se aprueba el texto refundido de la ley de Aguas. 
- Real Decreto 1620/2007 por el cual se establece el régimen jurídico de la reutilización de las aguas depuradas.

- Real Decreto 817/2015 por el cual se establecen los criterios de seguimiento y evaluación del estado de las aguas superficiales y las normas de calidad ambiental. 
2. OBJETIVOS 
Objetivos 
La presente tesis doctoral se enmarca en los proyectos de investigación: "Tecnologías eficientes para la eliminación de contaminantes de preocupación emergente, contenidos en la Directiva 2013/39/CE o de riesgo significativo según la Directiva 2008/105/CE (TRICERATOPS)" financiado por el Ministerio de Economía, Industria y Competitividad, subproyecto CTQ2015-69832-C4-4-R; y el proyecto “Tecnologías avanzadas e híbridas para eliminación de contaminantes, microcontaminantes, reuso y revalorización en diferentes aguas residuales, incluyendo enfoques tecno-económicos (CalypSol)" financiado por el Ministerio de Ciencia, Innovación y Universidades, subproyecto RTI2018-097997-B-C31.

En el presente estudio se plantea la siguiente hipótesis:

Es posible eliminar contaminantes emergentes presentes en aguas de salida mediante la aplicación del proceso foto-Fenton solar a pHs más cercanos a la neutralidad que el óptimo del proceso (demasiado ácido para poder aplicarlo a gran escala). Este proceso puede realizarse dando valor añadido a residuos orgánicos colaborando a la consecución de una economía circular mediante la revalorización de residuos.

El objetivo general del presente trabajo es la eliminación de contaminantes emergentes y de riesgo significativo mediante aplicación de procesos de oxidación avanzada (fotoFenton solar) a pHs cercanos a la neutralidad, adicionando al proceso sustancias tipo húmicas extraídas de residuos orgánicos. Por tanto, se pretende encontrar alternativas para la aplicación del proceso foto-Fenton a escala real sin la necesidad de bruscas modificaciones de $\mathrm{pH}$.

Se plantea:

- Eliminación de contaminantes emergentes (CEs) prioritarios o recientemente incorporados a la normativa europea mediante el proceso de oxidación avanzada foto-Fenton.

- Revalorización de residuos a través de la extracción de sustancias tipo húmicas (STH) de diferentes tipos de residuos orgánicos, para facilitar la implementación del proceso foto-Fenton en condiciones más suaves de $\mathrm{pH}$. 
Para el desarrollo y cumplimiento de estos objetivos generales se plantean los siguientes específicos, cada uno desarrollado en un capítulo de la parte experimental y cuyos resultados se plasman en un artículo científico (ya publicado o en proceso de publicación):

1. Extracción y caracterización de sustancias tipo húmicas $(\mathrm{STH})$ evaluando la influencia de aplicación de diferentes tiempos de fermentación del residuo para comprobar su eficiencia en el proceso foto-Fenton. Este objetivo se desarrolla en el Capítulo 1: Aplicación de sustancias tipo húmicas con diferente tiempo de fermentación procedentes del residuo de la oliva para la eliminación de contaminantes emergentes por proceso tipo foto-Fenton.

2. Separación por diferente tamaño de fracciones de las STH extraídas mediante procesos de membranas y evaluación de su eficiencia en el proceso foto-Fenton, así como estudio de la evolución de la toxicidad. Objetivo desarrollado en el Capítulo 2: Evaluación de la toxicidad de cuatro contaminantes emergentes contenidos en la directiva 2013/39/CE tratados por proceso tipo foto-Fenton en condiciones de pH próximas a la neutralidad.

3. Determinación de los mecanismos de reacción de las STH. Objetivo desarrollado en el Capítulo 3: Generación de radicales hidroxilo con la utilización de STH en procesos tipo Fenton.

4. Comprobación de la eficacia de las STH de diferente naturaleza aplicadas a proceso foto-Fenton sobre una mezcla de parabenos como ejemplo de CEs y análisis de la evolución de la toxicidad en el proceso. Se desarrolla en el Capítulo 4: Eliminación de conservantes cosméticos (parabenos) presentes en aguas residuales de la industria cosmética por proceso foto-Fenton y evaluación de su toxicidad.

5. Investigación de otra posible aplicación de las STH para concentrar contaminantes por sistema de membrana reduciendo el volumen que se trata posteriormente por proceso foto-Fenton. Desarrollado en el Capítulo 5: Utilización de sustancias tipo húmicas para la eliminación de contaminantes por sistema de membranas acoplado a un proceso oxidativo (foto-Fenton).

6. Uso de herramientas informáticas y matemáticas que permitan conocer la composición de muestras complejas a partir de matrices de Excitación Emisión 
(EEM). Este objetivo se desarrolla a lo largo de varios capítulos: En el Capítulo 1 para caracterizar y comparar diferentes STH; en el Capítulo 2 para comparar fracciones de STH dializadas y sin dializar, en a el Capítulo 4 para separar diferentes componentes en la degradación de la mezcla de parabenos y, en el Capítulo 5 para comprobar la interacción entre las STH y el contaminante. 
3. MATERIAL Y
MÉTODOS 
Material y métodos 


\subsection{Contaminantes y reactivos}

\subsubsection{Contaminantes}

En la presente tesis doctoral se han utilizado diferentes mezclas de contaminantes para ampliar el espectro de aplicación de resultados. Por una parte se ha trabajado con una mezcla de contaminantes emergentes de características muy diferentes, que tienen en común que todos ellos están contenidos en la Directiva 2013/39/CE: terbutrina (TBT), diclofenaco (DCF), clorfenvinfos (CVF) y pentaclorofenol (PCP) y, otra mezcla de contaminantes emergentes algunos de los cuales también se encuentran recogidos en dicha Directiva, y otros que pese a no aparecer en dicha lista, su abundancia hace considerarlos de interés para nuestro estudio: amoxicilina (AMOX), acetaminofeno (ACM), cafeína (CAF), acetamiprid (ACP), carbamazepina (CBZ), ácido clofíbrico (CLOF) y tiabendazol (TBZ). En la Tabla 3.1.1-1 se muestra la estructura química, el porcentaje de pureza y el peso molecular de cada uno de los contaminantes modelo seleccionados. Los compuestos puros han sido suministrados por Sigma-Aldrich. El ACP utilizado ha sido el de uso comercial, suministrado por Sipcam.

Tabla 3.1.1-1. Nombre, estructura química, porcentaje de pureza y peso molecular de cada uno de los contaminantes emergentes empleados.

\begin{tabular}{|c|c|c|c|}
\hline Nombre compuesto & $\begin{array}{c}\text { Estructura } \\
\text { química }\end{array}$ & $\begin{array}{c}\% \\
\text { pureza }\end{array}$ & $\begin{array}{l}\text { Peso molecular } \\
\left(\mathrm{g} \mathrm{mol}^{-1}\right)\end{array}$ \\
\hline Terbutrina & & Analytical standard & 241.36 \\
\hline Diclofenaco & & $20.0 \%$ & 318.13 \\
\hline Clorfenvinfos & & Analytical standard & 359.57 \\
\hline Pentaclorofenol & & $97.0 \%$ & 266.34 \\
\hline Amoxicilina & & $99.0 \%$ & 365.40 \\
\hline Acetaminofeno & & $99.0 \%$ & 151.16 \\
\hline
\end{tabular}




Acetamiprid

\subsubsection{Reactivos}

Los reactivos y disolventes de uso general empleados en la presente tesis se recogen en la Tabla 3.1.2-1.

Tabla 3.1.2-1 1. Nombre, fórmula química, procedencia, riqueza y empleo experimental de los reactivos y disolventes de uso general.

\begin{tabular}{ccccc}
\hline Producto & $\begin{array}{c}\text { Fórmula } \\
\text { química }\end{array}$ & Procedencia & Riqueza & Empleo \\
\hline Acetonitrilo & $\mathrm{CH}_{3} \mathrm{CN}$ & Panreac & $\begin{array}{c}\text { Grado } \\
\text { HPLC }\end{array}$ & HPLC \\
\hline Metanol & $\mathrm{CH}_{3} \mathrm{OH}$ & Panreac & $\begin{array}{c}\text { Grado } \\
\text { HPLC }\end{array}$ & HPLC \\
\hline Ácido fórmico & $\mathrm{HCOOH}$ & Panreac & $85 \%$ & HPLC \\
\hline Hexano & $\mathrm{C}_{6} \mathrm{H}_{14}$ & Panreac & $99 \%$ & Toxicidad \\
\hline $\begin{array}{c}\text { Acetona } \\
\text { Diclorometano }\end{array}$ & $\mathrm{C}_{3} \mathrm{H}_{6} \mathrm{O}$ & Panreac & $99.5 \%$ & Toxicidad \\
\hline $\begin{array}{c}\text { Sulfato ferroso } \\
\mathrm{CH}_{2} \mathrm{Cl}_{2}\end{array}$ & $\mathrm{FeSO}_{4} \cdot 7 \mathrm{H}_{2} \mathrm{O}$ & Panreac & $99.8 \%$ & Toxicidad \\
\hline $\begin{array}{c}\text { Cloruro de } \\
\text { hierro }\end{array}$ & $\mathrm{FeCl}_{3} \cdot 6 \mathrm{H}_{2} \mathrm{O}$ & Panreac & $99 \%$ & Foto-Fenton \\
\hline $\begin{array}{c}\text { Peróxido de } \\
\text { hidrógeno }\end{array}$ & $\mathrm{H}_{2} \mathrm{O}_{2}$ & Panreac & $33 \%$ & Foto-Fenton \\
\hline $\begin{array}{c}\text { Ácido sulfúrico } \\
\text { Hidróxido de }\end{array}$ & $\mathrm{H}_{2} \mathrm{SO}_{4}$ & Panreac & $85 \%$ & Ajuste pH \\
\hline $\mathrm{NaOH}$ & Panreac & $99.9 \%$ & Ajuste pH \\
\hline
\end{tabular}




\begin{tabular}{|c|c|c|c|c|}
\hline $\begin{array}{l}\text { Tiras de } \\
\text { peróxido }\end{array}$ & - & M-Quant & - & Foto-Fenton \\
\hline Catalasa & - & $\begin{array}{l}\text { Sigma- } \\
\text { Aldrich }\end{array}$ & $\begin{array}{c}2-5 \\
\text { unidades } \\
\mathrm{mg}^{-1} \mathrm{de} \\
\text { proteína }\end{array}$ & Foto-Fenton \\
\hline 1,10-fenantrolina & $\mathrm{C}_{12} \mathrm{H}_{8} \mathrm{~N}_{2}$ & $\begin{array}{l}\text { Sigma- } \\
\text { Aldrich }\end{array}$ & $99 \%$ & $\begin{array}{c}\text { Determinación } \\
\text { hierro }\end{array}$ \\
\hline $\begin{array}{l}\text { Acetato de } \\
\text { amonio }\end{array}$ & $\mathrm{C}_{2} \mathrm{H}_{7} \mathrm{NO}_{2}$ & Merck & $99 \%$ & $\begin{array}{l}\text { Determinación } \\
\text { hierro }\end{array}$ \\
\hline Ácido acético & $\mathrm{CH}_{3} \mathrm{COOH}$ & Merck & $100 \%$ & $\begin{array}{c}\text { Determinación } \\
\text { hierro }\end{array}$ \\
\hline Ácido ascórbico & $\mathrm{C}_{6} \mathrm{H}_{8} \mathrm{O}_{6}$ & Merck & $99 \%$ & $\begin{array}{l}\text { Determinación } \\
\text { hierro }\end{array}$ \\
\hline $\begin{array}{l}\text { Metavanadato de } \\
\text { amonio }\end{array}$ & $\mathrm{NH}_{4} \mathrm{VO}_{3}$ & $\begin{array}{l}\text { Sigma- } \\
\text { Aldrich }\end{array}$ & $99.9 \%$ & $\begin{array}{c}\text { Determinación } \\
\mathrm{H}_{2} \mathrm{O}_{2}\end{array}$ \\
\hline DMPO & $\mathrm{C}_{6} \mathrm{H}_{11} \mathrm{NO}$ & $\begin{array}{l}\text { Sigma- } \\
\text { Aldrich }\end{array}$ & $\geq 97 \%$ & EPR \\
\hline Cloruro sódico & $\mathrm{NaCl}$ & Scharlau & $99 \%$ & Toxicidad \\
\hline $\begin{array}{l}\text { Medio de } \\
\text { reconstitución }\end{array}$ & - & $\begin{array}{l}\text { Preparado en } \\
\text { laboratorio }\end{array}$ & - & Toxicidad \\
\hline $\begin{array}{l}\text { Bold's Basal } \\
\text { medium }\end{array}$ & - & $\begin{array}{l}\text { Preparado en } \\
\text { laboratorio }\end{array}$ & - & Toxicidad \\
\hline DMEM & - & $\begin{array}{l}\text { Sigma- } \\
\text { Aldrich }\end{array}$ & - & Toxicidad \\
\hline $\begin{array}{l}\text { Medio de cultivo } \\
\text { selectivo }\end{array}$ & - & $\begin{array}{l}\text { Preparado en } \\
\text { laboratorio }\end{array}$ & - & Toxicidad \\
\hline YPER & - & $\begin{array}{l}\text { ThermoFish } \\
\text { er }\end{array}$ & - & Toxicidad \\
\hline MU-Gal & - & $\begin{array}{l}\text { Sigma- } \\
\text { Aldrich }\end{array}$ & $99 \%$ & Toxicidad \\
\hline
\end{tabular}

\subsection{Proceso de extracción de las sustancias tipo húmicas (STH)}

Se ha realizado la extracción de STH procedentes del residuo de la producción del aceite de oliva, de los residuos del café consumido en la cafetería de la universidad y de lodos deshidratados procedentes del reactor anaerobio de una EDAR (Cocentaina, Alicante). El residuo de oliva utilizado para la extracción de las STH se ha obtenido de la almazara de Millena, localidad perteneciente a la provincia de Alicante. El residuo proporcionado fue el alperujo, que es el subproducto de las almazaras, mezcla de partes sólidas de la aceituna (hueso, pieles) y restos grasos.

La extracción se realizó mediante una digestión con un reactivo alcalino $(\mathrm{KOH})$ para separar las huminas (que son insolubles) de los ácidos fúlvicos y húmicos, que si son solubles. Estos últimos se separan generalmente mediante tratamiento ácido. 
El residuo se almacena en congeladores en el laboratorio hasta su posterior uso. Para la extracción se utilizan $0.125 \mathrm{~kg}$ de residuo fresco para $1 \mathrm{~L}$ de solución (Figura 3.2-1). El peso del residuo utilizado se corrige con la humedad (se realiza por triplicado). Se introduce en $1 \mathrm{~L}$ de $\mathrm{KOH} 0.3 \mathrm{M}$ y se realiza una digestión básica durante 24 horas, a $65^{\circ} \mathrm{C}$ y 400 rpm. Una vez terminada la digestión, se lleva el volumen a 5 L con disolución de $\mathrm{KOH}$ a la misma molaridad a la que se ha realizado la digestión (se va comprobando el $\mathrm{pH}$ durante todo el proceso) para terminar de extraer las sustancias tipo húmicas. El volumen final se filtra con bomba de vacío y una membrana con un tamaño de poro de 100 micras para eliminar todos los sólidos suspendidos que puedan quedar en la mezcla. Posteriormente, se somete la mezcla a un proceso de membranas de ultrafiltración.

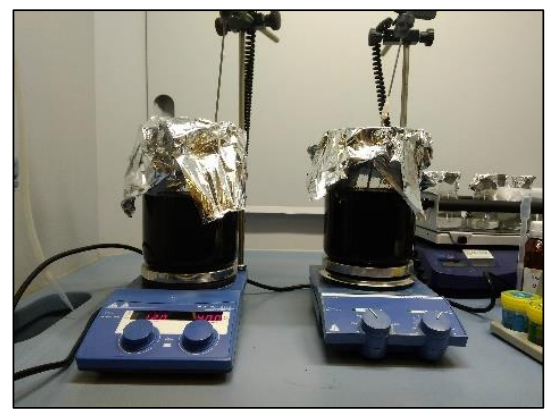

Figura 3.2-1. Proceso de digestión básica con $\mathrm{KOH}$ para la extracción de las STH.

Para el caso del residuo de la producción del aceite de oliva, se decidió utilizar diferentes tamaños de poro de membrana para separar fracciones de STH de diferente tamaño molecular y posteriormente poder utilizarlos en la aplicación del proceso foto-Fenton, con objeto de comprobar si existe alguna diferencia de comportamiento entre las diferentes fracciones. Las membranas seleccionadas fueron membranas cerámicas de la casa comercial Tami Industries con un tamaño de poro de 300, 150 y $50 \mathrm{kDa}$, obteniéndose así fracciones de STH con tamaños de > 300, entre 300-150, y entre 150$50 \mathrm{kDa}$. Con el proceso de membranas se busca concentrar las STH, es decir, se aprovecha el retentato y se desecha el permeado. El proceso de filtrado se lleva a cabo de la membrana de mayor tamaño a la de menor tamaño, y el permeado de cada uno de los procesos de filtración se utiliza como volumen de alimentación en el siguiente proceso de membrana. Los diferentes retentatos obtenidos para cada una de las membranas se secan en la estufa a $60^{\circ} \mathrm{C}$ hasta la total eliminación de la humedad. Por último, se tritura y se almacena para su posterior utilización (Figura 3.2-2). 


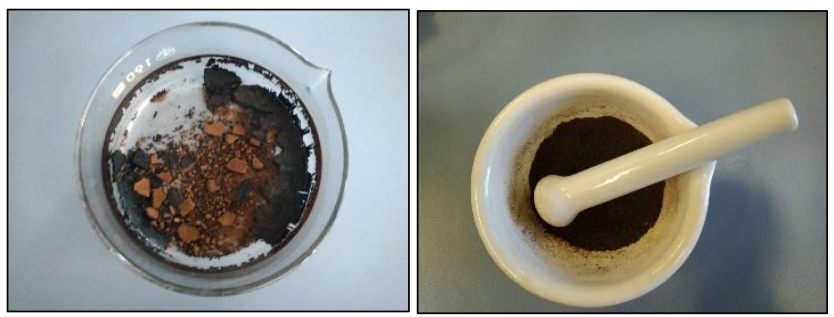

Figura 3.2-2. STH secadas en la estufa y trituradas para ser utilizadas.

Por otro lado, y también para el residuo de la producción del aceite de oliva, se obtuvieron STH de diferente tiempo de fermentación del residuo. MH (residuo fresco), MHF (residuo fermentado un mes) y MHF-1A (residuo fermentado un año).

En la extracción de STH del residuo del café y del lodo de reactor anaerobio, el procedimiento llevado a cabo fue el mismo a excepción del proceso de membranas, en el cual se utilizó una única membrana cerámica de tamaño de poro de $50 \mathrm{kDa}$ para concentrar las STH.

En todos los casos se procede a la dialización de una parte de las STH obtenidas para eliminar el exceso de sales con membranas Dialysis Sacks (Sigma-Aldrich) con un tamaño de poro de $12000 \mathrm{Da}$. Se introduce en estas membranas una disolución concentrada de las STH $\left(5 \mathrm{~g} 100 \mathrm{~mL}^{-1}\right)$ y se sumergen en agua destilada. Se va comprobando la conductividad eléctrica y cambiando el agua hasta que ya no aumenta más. Se secan en la estufa y se trituran del mismo modo que las no dializadas.

\subsection{Reactores y fuentes de irradiación}

\subsubsection{Escala de laboratorio}

En los experimentos realizados a escala de laboratorio se ha utilizado el simulador solar de la casa ABET Technologies (modelo 11014 Sun 2000 Solar Simulator), equipado con una lámpara de Xenón de $500 \mathrm{~W}$ (Figura 3.3.1-1). Esta lámpara genera un espectro uniforme que simula la radiación que llega del Sol a la Tierra, el espectro de irradiación de la lámpara se muestra en la Figura 3.3.1-2. El equipo cuenta con un reflector elipsoidal que recoge hasta un $70 \%$ de la radiación producida por la lámpara, la cual posteriormente se focaliza mediante un integrador óptico, consiguiendo un haz de luz divergente que es recogido por las lentes que lo unen en un área de 160x160 mm. 


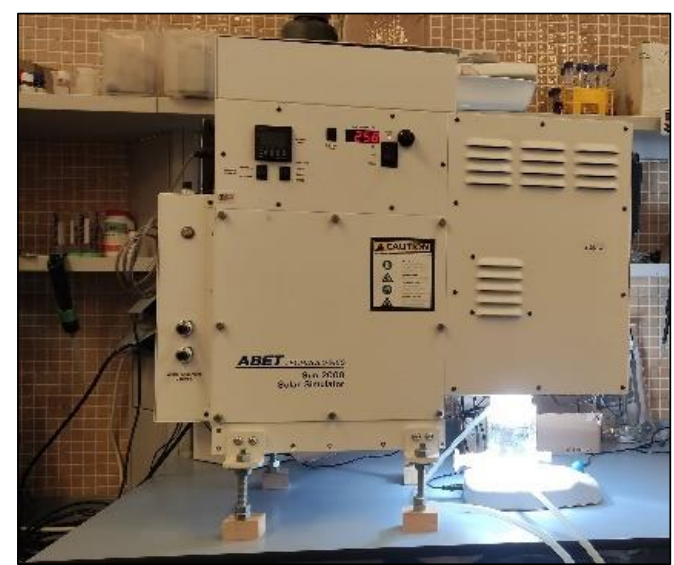

Figura 3.3.1-1. Simulador solar utilizado en los experimentos a escala de laboratorio. ABET Sun 2000.

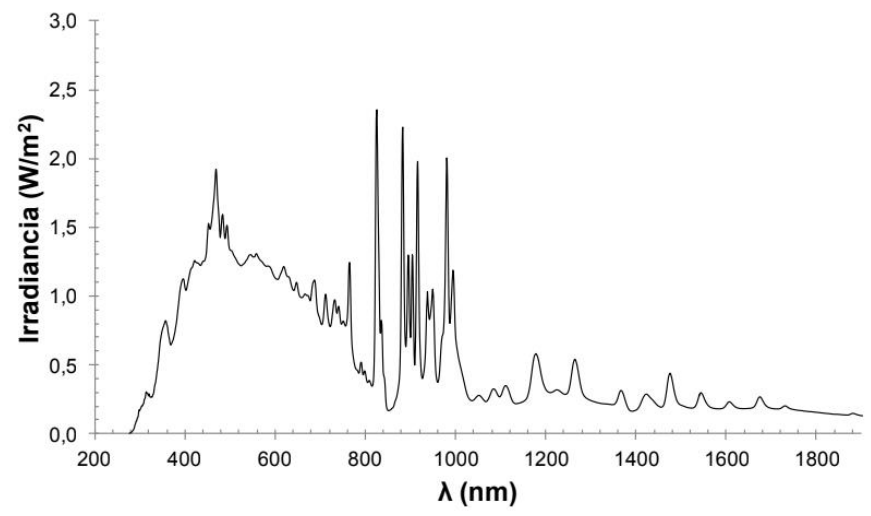

Figura 3.3.1-2. Espectro de irradiación de la lámpara del simulador solar empleado.

\subsubsection{Fotoreactor solar CPC}

Los captadores parabólicos compuestos (CPC) son dispositivos de concentración de la radiación solar de tipo estático, y son los reactores que con mayor frecuencia se usan en el tratamiento de aguas.

Están formados por reactores tubulares cilíndricos rodeados por una superficie de aluminio altamente anodizado. Los CPC pueden diseñarse con un rango de concentraciones cercano a uno $(\mathrm{FC})=1$, lo que le permite captar toda la radiación UV que llega al CPC (tanto la radiación directa como la difusa) y reconducirla. La radiación recogida se concentra y se distribuye por toda el área del tubo, llegando también a la parte trasera encontrándose así toda el área iluminada (Figura 3.3.2-1).

La configuración más extendida de estos reactores es la tubular, principalmente por la facilidad en el manejo que supone a la hora de trabajar. De entre los parámetros a tener en cuenta en el diseño de los CPC uno de los más importantes es el diámetro de los tubos, imprescindible para conseguir una correcta relación entre la distribución de la radiación, la concentración del catalizador y la eficiencia del proceso. Los diámetros que se 
encuentran más habitualmente están comprendidos entre 25 y $50 \mathrm{~mm}$, un diámetro menor supondría un aumento en la pérdida de carga y diámetros mayores dejarían zonas sin iluminar reduciendo la eficiencia del proceso.

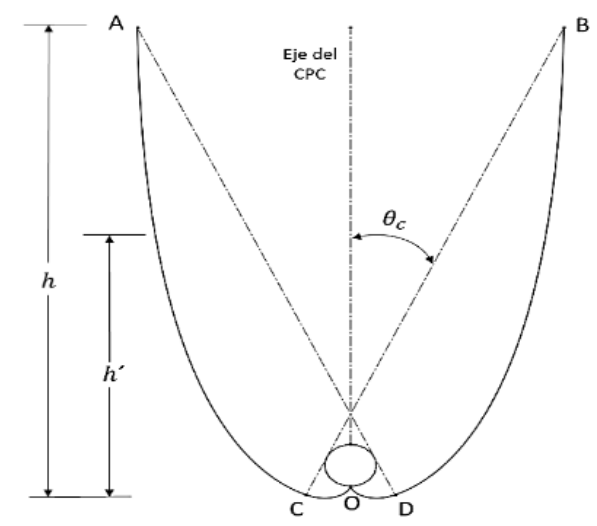

Figura 3.3.2-1. Geometría básica de un concentrador con receptor tubular. Fuente: Aguilar-Jiménez et al., 2016.

Para los experimentos con luz solar se emplea una planta piloto de fotocatálisis solar de 5 L de volumen, modelo SOLARDETOX ${ }^{\circledR}$ ACADUS-2005/0.25 de la casa comercial ECOSYSTEM (Figura 3.3.2-2). La planta piloto está compuesta de cuatro tubos de borosilicato de $32 \mathrm{~mm}$ de diámetro y $750 \mathrm{~mm}$ de longitud que dan lugar a un volumen total irradiado de $1.83 \mathrm{~L}$. Los tubos se encuentran dispuestos en una superficie de concentradores tipo CPC. La planta dispone de un tanque de alimentación desde el cual se impulsa el agua hacia los tubos por medio de una bomba centrífuga PanWorld 5PX-Z de propileno reforzado con fibra de vidrio y rotor cerrado, con una potencia de $11 \mathrm{~W}$. El volumen mínimo operativo para la planta piloto es de $3.5 \mathrm{~L}$ (para así evitar problemas de formación de burbujas) y el volumen máximo es de $5 \mathrm{~L}$. La superficie útil irradiada es de $0.257 \mathrm{~m}^{2}$. La estructura está instalada de acuerdo con la latitud local con una inclinación de $30^{\circ}$, y la temperatura máxima de trabajo es de $55^{\circ}$. La planta cuenta con un radiómetro ACADUS 85 para registrar la radiación instantánea $\left(\mathrm{W} \mathrm{m}^{2}\right)$ y la radiación acumulada (W h). 


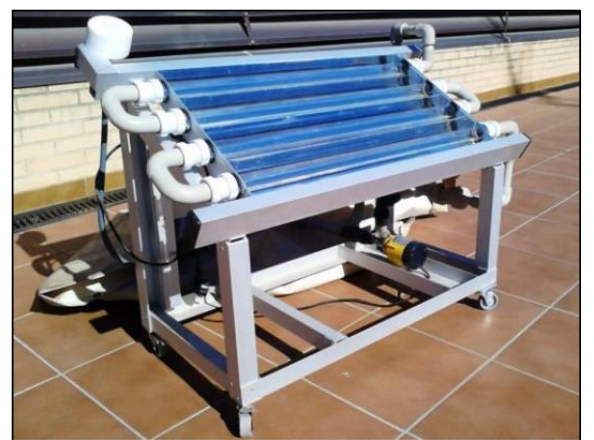

Figura 3.3.2-2. Planta piloto de fotocatálisis solar. SOLARDETOX ${ }^{\circledR}$ ACADUS-2005/0.25.

\subsection{Condiciones de ensayo}

\subsubsection{Ensayos realizados en simulador solar}

Para la realización de los ensayos se emplearon como reactores vasos de precipitado de vidrio de $250 \mathrm{~mL}$ de volumen con agitación magnética continua y refrigeración, para mantener la temperatura constante en $30-35^{\circ} \mathrm{C}$. Se utilizó un filtro de vidrio Pyrex para cortar la radiación que llega a la mezcla por debajo de los $300 \mathrm{~nm}$.

En el estudio de la degradación de los contaminantes emergentes contenidos en la Directiva 2019/39/CE (TBT, DCF, CVF y PCP) la concentración inicial de cada uno de los compuestos orgánicos fue de $1 \mathrm{mg} \mathrm{L}^{-1}$. La fuente de hierro utilizada fue $\mathrm{FeSO}_{4} \cdot 7 \mathrm{H}_{2} \mathrm{O}$ o $\mathrm{FeCl}_{3} \cdot 6 \mathrm{H}_{2} \mathrm{O}$ con una concentración inicial en todos los casos de $5 \mathrm{mg} \mathrm{L}^{-1}$. El pH fue ajustado mediante la adición de $\mathrm{H}_{2} \mathrm{SO}_{4}$ diluido o $\mathrm{NaOH}(0.01-1 \mathrm{M})$, y la cantidad adicionada de $\mathrm{H}_{2} \mathrm{O}_{2}$ fue de $0.14 \mathrm{mM}$, cantidad estequiométrica teórica para oxidar completamente la mezcla de contaminantes.

En el caso de la mezcla de seis contaminantes emergentes: AMOX, ACM, CAF, ACP, CBZ y CLOF la concentración inicial fue de $5 \mathrm{mg} \mathrm{L}^{-1}$ para cada uno de ellos, y se empleó en todos los experimentos una concentración de $\mathrm{FeCl}^{3} \cdot 6 \mathrm{H}_{2} \mathrm{O}$ de $5 \mathrm{mg} \mathrm{L}^{-1}$. La cantidad adicionada de $\mathrm{H}_{2} \mathrm{O}_{2}$ fue de $2.20 \mathrm{mM}$, que es la mitad de la cantidad estequiométrica teórica para oxidar completamente todos los contaminantes.

Por último, en los casos en los que se adiciono STH las condiciones experimentales de concentración de contaminantes y fuente de hierro fueron las mismas que las descritas anteriormente, utilizándose en todos los casos $\mathrm{FeCl}_{3} \cdot 6 \mathrm{H}_{2} \mathrm{O}$. Las concentraciones de $\mathrm{H}_{2} \mathrm{O}_{2}$ variaron dependiendo de la mezcla de contaminantes empleada de acuerdo con las descritas anteriormente, y las concentraciones empleadas de STH fueron desde 10 a 50 $\mathrm{mg} \mathrm{L} \mathrm{L}^{-1}$ dependiendo del experimento realizado. 


\subsubsection{Ensayos realizados en la planta piloto}

Del mismo modo que en los experimentos llevados a cabo en el simulador solar, para los ensayos en planta, la concentración inicial de los contaminantes emergentes fue de $1 \mathrm{mg}$ $\mathrm{L}^{-1}$, la fuente de hierro fue $\mathrm{FeCl}_{3} \cdot 6 \mathrm{H}_{2} \mathrm{O}$ y la cantidad de $\mathrm{H}_{2} \mathrm{O}_{2}$ de $0.14 \mathrm{mM}$. En los casos en los que se adicionaron STH se hizo a una concentración inicial de $20 \mathrm{mg} \mathrm{L}^{-1}$. La cantidad de peróxido se controló durante todo el proceso mediante el método para la determinación del peróxido de hidrógeno en disolución (Apartado 3.5.6). En las muestras tomadas para realizar los bioensayos de toxicidad, el exceso de $\mathrm{H}_{2} \mathrm{O}_{2}$ se elimina con catalasa para evitar la interferencia en los mismos.

\subsubsection{Método para la medición de la radicación solar}

Dada la variación de la radiación solar, es necesario normalizarla aplicando un parámetro que sea capaz de corregir este defecto. En este caso se ha utilizado el parámetro t30w, que se define como el tiempo necesario para alcanzar la radiación acumulada medida suponiendo que ha recibido una radiación constante de $30 \mathrm{~W}\left(\mathrm{~m}^{2}\right)^{-1}$. El parámetro t30w se ha calculado de acuerdo con la Ecuación 31.

$$
t_{30 w}=\frac{R_{a c} * 60\left(\min h^{-1}\right) * V_{i}}{R_{m} * A * V_{t}}
$$

donde, $\mathrm{R}_{\mathrm{ac}}$ es la radiación acumulada en $\mathrm{W}^{*} \mathrm{~h}, \mathrm{~V}_{\mathrm{i}}$ es el volumen irradiado el $\mathrm{L}, \mathrm{R}_{\mathrm{m}}$ es la radiación media considerada $\left(30 \mathrm{~W}\left(\mathrm{~m}^{2}\right)^{-1}\right.$ en este caso), A es el área irradiada en $\mathrm{m}^{2}, \mathrm{y}$ $\mathrm{V}_{\mathrm{T}}$ el volumen total en $\mathrm{L}$ tratado en la planta.

\subsubsection{Aplicación de STH en procesos de membrana}

Las membranas utilizadas han sido membranas cerámicas tubulares con soporte de $\mathrm{TiO}_{2}$, material biocompatible y de alta resistencia frente a gran cantidad de agentes químicos. Las membranas tienen un diámetro externo de $10 \mathrm{~mm}$ y 7 canales internos de $2 \mathrm{~mm}$ de diámetro cada uno. El equipo piloto de filtración utilizado ha sido suministrado por la casa comercial Likuid (Figura 3.4.4-1) cuyo sistema de funcionamiento se muestra en la Figura 3.4.4-2. Cuenta con un tanque de alimentación de 20 L y una bomba Grundfos modelo A-98394994-P3-1803 que puede trabajar a una presión máxima de 16 bar. Para evitar el aumento de temperatura durante el proceso de filtración se ha utilizado un refrigerador tipo dedo frío Julabo FT200 y se ha mantenido la temperatura constante a $25^{\circ} \mathrm{C}$. 
Para estos ensayos se utilizó como contaminante modelo el tiabendazol, seleccionado por su baja solubilidad. Se prepararon disoluciones de tiabendazol $\left(50 \mathrm{mg} \mathrm{L}^{-1}\right)$ y STH (de 1$2 \mathrm{~g} \mathrm{~L}^{-1}$ ), relación 1:20 o 1:40 para comprobar el paso del tiabendazol por la membrana y su posible atrapamiento por parte de las micelas formadas por las STH. Para la disolución de TBZ y puesto que se trabaja a concentraciones próximas al punto de saturación (50-75 $\mathrm{mg} \mathrm{L}^{-1}$ ), el TBZ se disuelve primero a $\mathrm{pH}$ ácido (2.8) y posteriormente se eleva el $\mathrm{pH}$ cuidadosamente mediante la adición de $\mathrm{NaOH}$ (0.1-1 M). Se han empleado membranas cerámicas de Tami Industries de $50 \mathrm{kDa}$ de tamaño de poro, y se ha trabajado a 2,1 y 0.5 bares de presión con aire a presión o bomba de vacío dependiendo del ensayo realizado. Se toman muestras del permeado (PM) y del retentato (RT) y se analizan por UHPLC, TOC y fluorescencia.

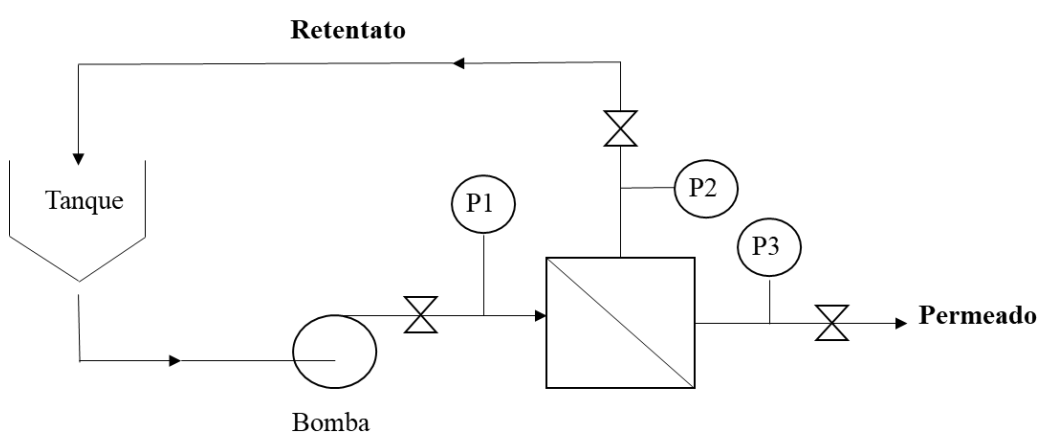

Figura 3.4.4-1. Esquema del funcionamiento del sistema de filtración. Elaboración propia.

Figura 3.4.4-2. Sistema de filtración Likuid.
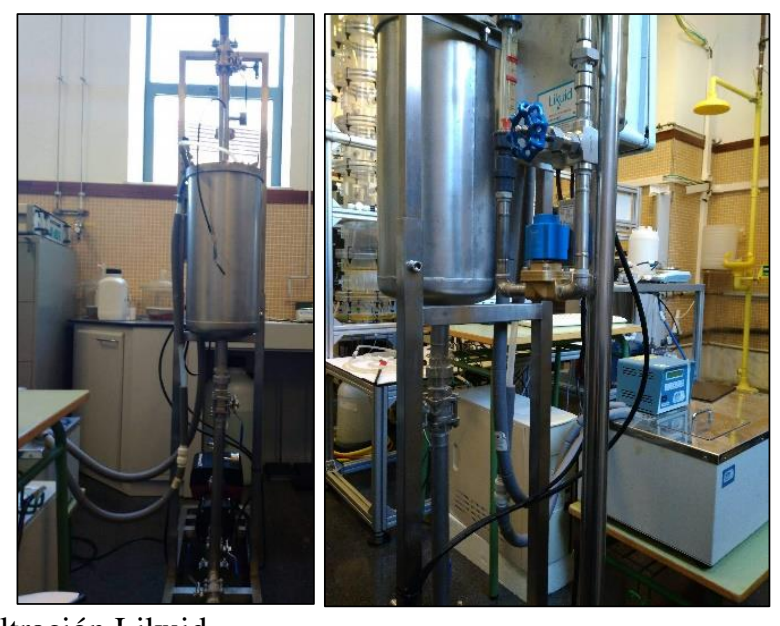

\subsection{Equipos y técnicas analíticas}

\subsubsection{Medida del carbono orgánico disuelto (COD)}

Una técnica para cuantificar la cantidad de materia orgánica presente en las muestras líquidas, así como el grado de mineralización alcanzado durante los procesos de reacción 
es la medida del carbono orgánico disuelto (COD). Se ha empleado un equipo de la marca Shimadzu modelo TOC-VCSH (Figura 3.5.1-1) que cuenta con un automuestreador modelo ASI-V. El equipo proporciona las medidas de Carbono total (CT) y Carbono Inorgánico Total (CIT), y por la diferencia de ambos valores se obtiene el Carbono Orgánico Disuelto (COD).

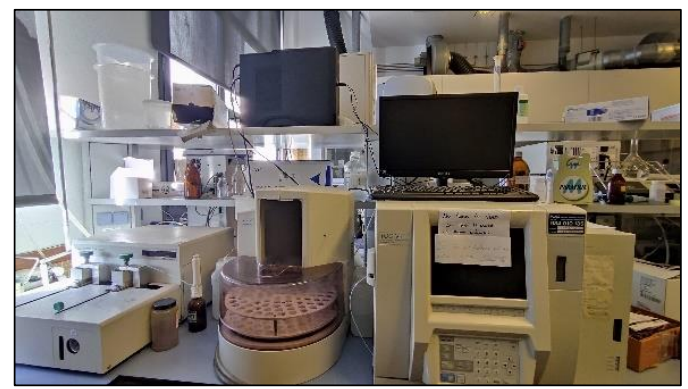

Figura 3.5.1-1. Analizador de Carbono Orgánico Total Shimadzu TOC-VCSH.

El equipo trabaja por combustión de las muestras a altas temperaturas $\left(680^{\circ} \mathrm{C}\right)$, empleando un catalizador de platino soportado por esferas de alúmina. El CT se oxida a $\mathrm{CO}_{2}$; este es arrastrado por el aire de alta pureza, enfriado y secado por un deshumificador. Mediante un detector de infrarrojo no dispersivo (NDIR) se mide el $\mathrm{CO}_{2}$ generado en la combustión y el equipo dibuja un pico con un área proporcional a la cantidad de carbono presente en la muestra.

Para el análisis y medida del Carbono Inorgánico (IC) la muestra es burbujeada con aire en un recipiente de reacción que contiene ácido fosfórico (25\% p/v). Se genera $\mathrm{CO}_{2}$ de la descomposición de los carbonatos y bicarbonatos que es procesado por el NDIR del mismo modo que ocurre en el caso del CT.

Para realizar esta medición es necesaria la eliminación de los posibles sólidos en suspensión; para ello las muestras se filtran por filtros de PTFE con un tamaño de poro de $0.45 \mu \mathrm{m}$ Chromafil ${ }^{\circledR}$ Xtra PTFE-45/25.

Este modelo cuenta también con un módulo para la medición del CT e IC en sólidos, Solid Sample module SSM-5000A. La muestra se combustiona a altas temperaturas para formar $\mathrm{CO}_{2}$. En el caso del CT se produce la oxidación por combustión catalítica a $900^{\circ} \mathrm{C}$ y en el caso del IC hay una pre-acidificación con $\mathrm{H}_{3} \mathrm{PO}_{4}$ y posterior combustión a $200^{\circ} \mathrm{C}$. El gas portador $\left(99.9 \% \mathrm{O}_{2}\right.$ a $\left.500 \mathrm{~mL} \mathrm{~min}^{-1}\right)$ conteniendo el $\mathrm{CO}_{2}$ y otros productos de la combustión es enfriado y deshidratado antes de llegar al detector NDIR. El equipo 
proporciona como respuesta un área que es proporcional a la cantidad de CT e IC presente en la muestra.

\subsubsection{Cromatografía líquida de ultra alta resolución (UHPLC)}

Para seguir la concentración de los contaminantes durante los procesos de degradación, se ha utilizado cromatografía líquida de ultra alta resolución (UHPLC). Esta técnica es ampliamente utilizada debido a la alta sensibilidad que presenta y a que es capaz de separar y cuantificar compuestos no volátiles y termolábiles.

El cromatógrafo empleado ha sido el modelo Flexar UHPLC FX-10 de la marca comercial Perkin-Elmer (Figura 3.5.2-1). El cromatógrafo cuenta con un automuestreador equipado con control de temperatura (S200 Autosampler Comm KIT-1022 PUS), dos bombas independientes (Flexar FX 10 UHP PUMP), un desgasificador de eluyentes (desgasificador de vacío de tres canales, FL) y un detector de UV (UV-Vis KIT-UHPLC Detector Tubing). El equipo trabaja en fase reversa con una columna C18 (Brownlee Analytical DB C18 $1.9 \mu \mathrm{m}$ 30x2.1 mm) termostatizada.

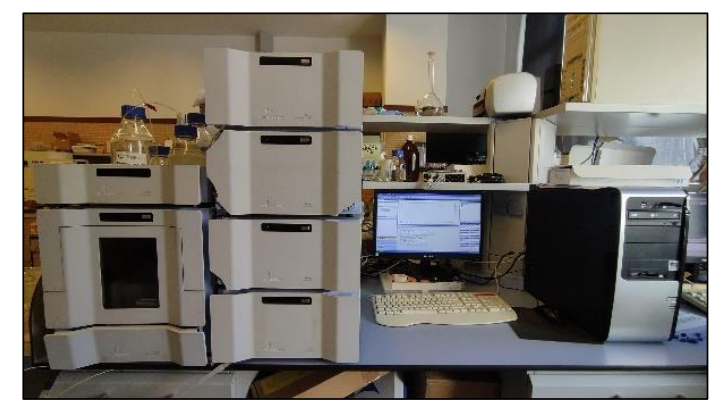

Figura 3.5.2-1. Equipo UHPLC Flexar FX-10.

Las condiciones de detección son específicas para cada contaminante, en la presente tesis se han utilizado los siguientes métodos mostrados en las Tablas 3.5.2-1, 3.5.2-2 y 3.5.23.

Tabla 3.5.2-1. Método cromatográfico para la determinación de la mezcla de contaminantes: TBT, DCF, CVF y PCP.

\begin{tabular}{cccccc}
\hline Etapa & Tipo de etapa & Tiempo & $\begin{array}{c}\text { \% } \\
\text { Acetonitrilo }\end{array}$ & $\begin{array}{c}\text { \% Ácido } \\
\text { sulfúrico } \\
(\mathbf{2 5} \mathbf{~ m M})\end{array}$ & $\begin{array}{c}\text { Flujo } \\
\left(\mathbf{m L} \mathbf{~ m i n}^{-\mathbf{1}}\right)\end{array}$ \\
\hline $\mathbf{1}$ & Equilibrado & 4 & 30 & 70 & 0.3 \\
\hline $\mathbf{2}$ & Gradiente & 10 & 95 & 5 & 0.3 \\
\hline $\mathbf{3}$ & Gradiente & 2 & 30 & 70 & 0.3 \\
\hline
\end{tabular}




\begin{tabular}{ccc}
\hline $\begin{array}{c}\text { Contaminante } \\
\text { emergente }\end{array}$ & $\begin{array}{c}\text { Longitud } \\
\text { de onda } \\
(\mathbf{n m})\end{array}$ & $\begin{array}{c}\text { Tiempo } \\
\text { de } \\
\text { retención } \\
(\mathbf{m i n})\end{array}$ \\
\hline Terbutrina & 230 & 3.50 \\
\hline Diclofenaco & 280 & 4.50 \\
\hline Clorfenvinfos & 240 & 5.31 \\
\hline Pentaclorofenol & 220 & 5.80 \\
\hline
\end{tabular}

Tabla 3.5.2-2. Método cromatográfico para la determinación de la mezcla de contaminantes: ACM, AMOX, CAF, ACP, CBZ y CLOF.

\begin{tabular}{cccccc} 
Etapa & $\begin{array}{c}\text { Tipo de } \\
\text { etapa }\end{array}$ & Tiempo & $\begin{array}{c}\text { \% } \\
\text { Acetonitrilo }\end{array}$ & $\begin{array}{c}\text { \% Ácido } \\
\text { fórmico } \\
(\mathbf{1 0 ~} \mathbf{~ m M})\end{array}$ & $\begin{array}{c}\text { Flujo } \\
(\mathbf{m L} \\
\left.\mathbf{m i n}^{-1}\right)\end{array}$ \\
\hline $\mathbf{1}$ & Equilibrado & 4 & 3 & 97 & 0.3 \\
\hline $\mathbf{2}$ & Gradiente & 3.5 & 10 & 90 & 0.3 \\
\hline $\mathbf{3}$ & Gradiente & 5 & 70 & 30 & 0.3 \\
\hline $\mathbf{4}$ & Gradiente & 1.5 & 3 & 97 & 0.3 \\
\hline
\end{tabular}

\begin{tabular}{ccc}
\hline $\begin{array}{c}\text { Contaminante } \\
\text { emergente }\end{array}$ & $\begin{array}{c}\text { Longitud } \\
\text { de onda } \\
(\mathbf{n m})\end{array}$ & $\begin{array}{c}\text { Tiempo } \\
\text { de } \\
\text { retención } \\
(\mathbf{m i n})\end{array}$ \\
\hline Amoxicilina & 205 & 1.79 \\
\hline Acetaminofeno & 205 & 1.97 \\
\hline Cafeína & 205 & 3.96 \\
\hline Acetamiprid & 245 & 4.99 \\
\hline Carbamazepina & 205 & 5.67 \\
\hline Ácido clofíbrico & 225 & 6.20 \\
\hline
\end{tabular}

Tabla 3.5.2-3. Método cromatográfico para la determinación del TBZ.

\begin{tabular}{cccccc}
\hline Etapa & $\begin{array}{c}\text { Tipo de } \\
\text { etapa }\end{array}$ & Tiempo & $\begin{array}{c}\text { \% } \\
\text { Acetonitrilo }\end{array}$ & $\begin{array}{c}\text { \% Ácido } \\
\text { fórmico } \\
(\mathbf{1 0 ~} \mathbf{~ m M})\end{array}$ & $\begin{array}{c}\text { Flujo } \\
\left(\mathbf{m L} \mathbf{~ m i n}^{-1}\right)\end{array}$ \\
\hline $\mathbf{1}$ & Equilibrado & 4 & 5 & 95 & \\
\hline $\mathbf{2}$ & Gradiente & 5 & 50 & 50 & 0.3 \\
\hline $\mathbf{3}$ & Gradiente & 2 & 100 & 0 & 0.3 \\
\hline $\mathbf{4}$ & Gradiente & 2 & 5 & 95 & 0.3 \\
\hline
\end{tabular}

\begin{tabular}{ccc}
\hline $\begin{array}{c}\text { Contaminante } \\
\text { emergente }\end{array}$ & $\begin{array}{c}\text { Longitud } \\
\text { de onda } \\
(\mathbf{n m})\end{array}$ & $\begin{array}{c}\text { Tiempo } \\
\text { de } \\
\text { retención } \\
\text { (min) }\end{array}$ \\
\hline Tiabendazol & 285 & 2.58 \\
\hline
\end{tabular}

Todas las muestras se filtran con un filtro de PTFE de $0.45 \mu \mathrm{m}$ Chromafil@ Xtra PTFE45/25 antes de ser analizadas para eliminar cualquier sólido en suspensión que pueda haber. En el caso de las muestras en las que ha intervenido el proceso foto-Fenton se les adiciona metanol con la finalidad de detener la reacción de degradación de los 
contaminantes orgánicos con los reactivos, además también disuelve los compuestos que puedan estar en fase sólida suspendida.

\subsubsection{Espectrofotometría de UV-Visible}

Se ha empleado el espectrofotómetro UV-visible (Figura 3.5.3-1) modelo UH5300 de la marca comercias Hitachi, provisto de una lámpara flash de Xenón y sistema óptico de doble haz.

Figura 3.5.3-1. Espectrofotómetro UH5300.

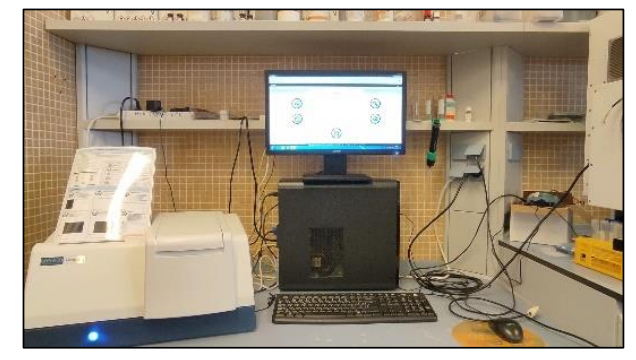

\section{Tigura 3.5.3-1. Espectrofotónetro UH5300.}

\subsubsection{Medida fluorimetría}

Se ha utilizado un espectrofluorímetro modular de la casa Photon Technology International (PIT) equipado con una lámpara de Xenón de 75 W y un detector de recuento de fotones individuales entre 200 y 900 nm (Figura 3.5.4-1).

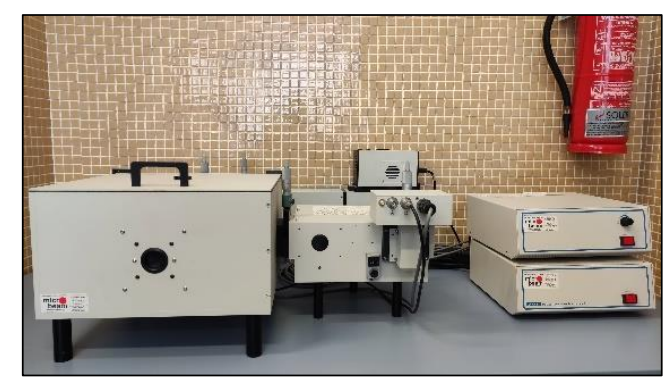

Figura 3.5.4-1. Espectrofluorímetro PIT.

\subsubsection{Método para la determinación del hierro en disolución (ISO 6332)}

El ion ferroso actúa como catalizador en la oxidación en fase homogénea con $\mathrm{H}_{2} \mathrm{O}_{2} / \mathrm{UV}$. La determinación de la cantidad de hierro y la forma en la que se encuentre, $\mathrm{Fe}$ (II) o Fe (III), durante la reacción es importante para determinar la eficiencia del proceso fotoFenton.

El ion ferroso disuelto forma un complejo de color rojo/anaranjado con tres moléculas de 1,10-fenantrolina que para valores de $\mathrm{pH}$ entre 2 y 9 absorbe a $510 \mathrm{~nm}$. El rango de $\mathrm{pH}$ es suficientemente amplio para asegurar la formación del complejo, pero para que éste se forme más rápidamente y sea cuantitativamente estable se utiliza una solución tampón 
(ácido acético) que mantiene la disolución en valores de $\mathrm{pH}$ de 3-3,5. La absorbancia del complejo Fe(II) y 1,10-fenantrolina es proporcional a la concentración de ion ferroso (APHA-AWWA-WEFF, 1998).

Hay que tener en cuenta la presencia de peróxido de hidrógeno en las muestras del proceso foto-Fenton, ya que puede oxidar el ion ferroso a férrico, el cual no formaría complejo con la 1,10-fenantrolina. Añadiendo ácido ascórbico en exceso se reduce todo el Fe(III) a Fe(II) y puede medirse el complejo, el valor obtenido, por tanto, hará referencia siempre al hierro total. Esta medida permite comprobar si la cantidad de catalizador añadida al inicio del proceso se mantiene constante o si ha precipitado.

Para la medida se toman $4 \mathrm{~mL}$ de muestra a la que se le añade $1 \mathrm{~mL}$ de disolución de 1,10-fenantrolina ( $0.1 \%$ p/v en agua destilada), $1 \mathrm{~mL}$ de la disolución tampón $\left(250 \mathrm{~g} \mathrm{~L}^{-1}\right.$ de acetato de amonio en $700 \mathrm{~mL} \mathrm{~L}^{-1}$ de ácido acético en agua destilada) y una punta de espátula de ácido ascórbico. Se agita la mezcla y transcurrido un minuto se mide la absorbancia a $510 \mathrm{~nm}$. Para la preparación del blanco se añaden $4 \mathrm{~mL}$ de agua en lugar de la muestra. Este procedimiento nos cuantifica la cantidad de hierro total.

A partir de los datos de absorbancia y con una recta de calibrado externa con un rango de concentraciones de entre 0 y $10 \mathrm{mgL}^{-1}$ de ion ferroso se calcula la cantidad de hierro total. En el caso de que la concentración sea superior a $10 \mathrm{mgL}^{-1}$ se procederá a la dilución de la muestra.

\subsubsection{Método para la determinación del peróxido de hidrogeno en disolución}

El peróxido de hidrógeno reacciona con el metavanadato de amonio dando lugar al ion $\mathrm{VO}_{2}{ }^{3+}$ cuya absorción a $450 \mathrm{~nm}$ es proporcional a la concentración de peróxido de hidrógeno. Este ion presenta un color amarillento y es muy estable a temperatura ambiente, siempre y cuando la concentración de peróxido de hidrógeno sea menor a 3 $\mathrm{mM}$.

Se toman $5 \mathrm{~mL}$ de muestra y se añaden $1.03 \mathrm{~mL}$ de metavanadato de amonio $(0.06 \mathrm{M}$ de metavanadato de amonio en $0.36 \mathrm{M}$ de ácido sulfúrico) y 3,97 $\mathrm{mL}$ de agua destilada. El blanco al igual que en el caso de la determinación del hierro se prepara añadiendo agua destilada en lugar de muestra. Se mide la absorbancia a $450 \mathrm{~nm}$ y mediante la Ecuación 32 (asumiendo que todo el metavanadato es oxidado) obtenemos la concentración de peróxido de hidrógeno. 


$$
C_{\mathrm{H}_{2} \mathrm{O}_{2}}\left(\mathrm{~mol} \mathrm{~L}^{-1}\right)=\frac{V_{t} * A b s}{V_{m} * 283} \quad(\text { Ec. 32) }
$$

donde $\mathrm{V}_{\mathrm{t}}$ son los $10 \mathrm{~mL}$ que suman los reactivos más la muestra, $\mathrm{V}_{\mathrm{m}}$ es el volumen de muestra añadida, Abs es el valor de absorbancia obtenido en cada caso a $450 \mathrm{~nm}$ y, 283 es el coeficiente de extinción molar en $\mathrm{mol} \mathrm{L}^{-1} \mathrm{~cm}^{-1}$ (Pupo Nogueira \& Guimarães, 2000).

\subsection{7. pH-metro y conductímetro}

Para las medidas de $\mathrm{pH}$ y conductividad se utilizó el pH-metro pHenomenal ${ }^{\circledR}$ MU6100L (Figura 3.5.7-1) de la casa comercial VWR.

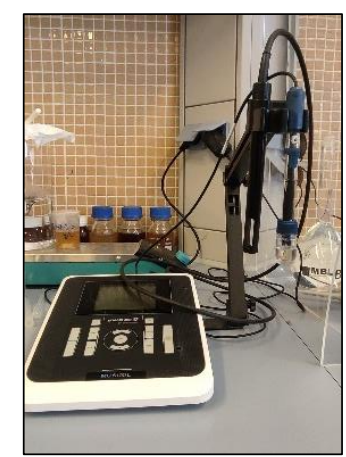

Figura 3.5.7-1. pH-metro y conductímetro pHenomenal ${ }^{\circledR}$ MU6100L.

\subsubsection{Medida demanda química de oxígeno (DQO)}

La DQO mide la cantidad de oxígeno necesario para oxidar toda la materia orgánica presente en una muestra líquida, bajo determinadas condiciones de agente oxidante, temperatura y tiempo. La metodología utilizada se basa en oxidación de las muestras mediante una disolución ácida con exceso de dicromato potásico en presencia de sulfato de plata (que actúa como catalizador). La muestra es digestada durante 2 horas a $148^{\circ} \mathrm{C}$ y posteriormente por espectrofotometría se determina la concentración de iones $\mathrm{Cr}$ (III).

Para esta determinación se toma un volumen $3 \mathrm{~mL}$ de muestra filtrada y se añade al tubo de reacción, se agita y se lleva al termoreactor. Una vez pasadas las dos horas se deja enfriar y se mide la concentración mediante el fotómetro (Figura 3.5.8-1) de Cr (III) obteniéndose directamente el valor en $\mathrm{mg} \mathrm{O}_{2} \mathrm{~L}^{-1}$. El rango utilizado en todas las medidas fue el de 10-150 $\mathrm{mg} \mathrm{O}_{2} \mathrm{~L}^{-1}$.

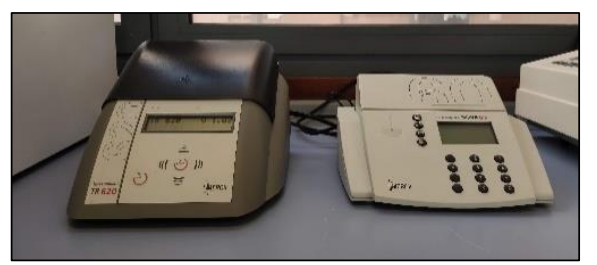

Figura 3.5.8-1. Termoreactor y fotómetro utilizado para la determinación de la DQO. 


\subsubsection{Cromatografía exclusión por tamaños}

La cromatografía de exclusión por tamaños se ha utilizado para la determinación del tamaño molecular de las distintas STH obtenidas. Consiste en un equipo de cromatografía líquida en el cual, la fase estacionaria es un material poroso que permite la elución diferencial de los solutos en función de su tamaño molecular.

El equipo utilizado ha sido un cromatógrafo Hitachi Chromaster de la casa comercial VWR (Figura 3.5.9-1) con una columna de metacrilato marca Shodex modelo OHpak SB-805 HQ termostatizada, un automuestreador Chromaster 5210, una bomba Chromaster 5110, un detector UV Chromaster 5410 y un detector de fluorescencia Chromaster 5440.

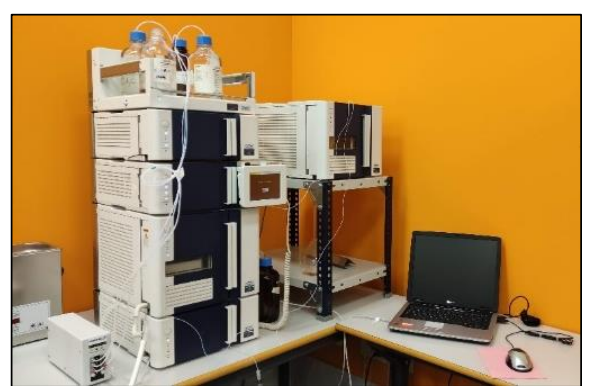

Figura 3.5.9-1. Equipo HPLC Hitachi Chromaster.

El programa isocrático empleado para la determinación de los tamaños moleculares se muestra en la Tabla 3.5.9-1.

Tabla 3.5.9-1. Método cromatográfico empleado en SEC.

\begin{tabular}{cc}
\hline \% Acetonitrilo & 30 \\
\hline $\begin{array}{c}\text { \% Tampón fosfato } \\
(\mathbf{p H ~ 7 . 2})\end{array}$ & 70 \\
\hline Flujo (mL min $\left.^{-1}\right)$ & 0.8 \\
\hline $\begin{array}{c}\text { Longitud de onda } \\
(\mathbf{n m})\end{array}$ & 260 \\
\hline
\end{tabular}

Se prepararon patrones a una concentración de $20 \mathrm{mg} \mathrm{L}^{-1}$ de PSS (Poli sodioestirensulfonato) con diferentes pesos moleculares $\left(\mathrm{M}_{\mathrm{w}}\right)$ y se midieron obteniendo los tiempos de elución ( $\mathrm{t}_{\mathrm{e}}$ ) para cada patrón. Se calculó también el tiempo total de la columna ( $\mathrm{t}_{\mathrm{T}}$ ) utilizando una concentración de $20 \mathrm{mg} \mathrm{L}^{-1}$ de $\mathrm{KNO}_{3}$ y el tiempo muerto ( $\mathrm{t}_{0}$ ) mediante una disolución acuosa de Pullulan a una concentración de $20 \mathrm{mg} \mathrm{L}^{-1}$ obteniéndose un tiempo de 6.07 minutos. Con todo esto se calculó el tiempo de retención $\left(t_{R}\right)$ para cada uno de los patrones mediante la Ecuación 33. En la Tabla 3.5.9-2 se muestran los pesos moleculares, tiempo de retención y tiempo de elución de los diferentes patrones. 


$$
t_{R}=\frac{t_{e}}{t_{0}} \quad(\text { Ec. 33) }
$$

Tabla 3.5.9-2. Pesos moleculares, tiempos de retención y tiempos de elución de los diferentes patrones empleados.

\begin{tabular}{cccc}
\hline PSS $\left(\mathbf{M}_{\mathbf{w}}\right)$ & $\log \mathbf{M}_{\mathbf{w}}$ & $\begin{array}{c}\mathbf{t}_{\mathbf{e}} \\
(\mathbf{m i n})\end{array}$ & $\mathbf{t}_{\mathbf{R}}$ \\
\hline $\mathbf{1 4 5 0 0 0}$ & 5.16 & 9.50 & 1.56 \\
\hline $\mathbf{7 7 4 0 0}$ & 4.89 & 10.21 & 1.68 \\
\hline $\mathbf{2 9 1 0 0}$ & 4.46 & 10.87 & 1.81 \\
\hline $\mathbf{9 6 8 0}$ & 3.99 & 11.50 & 1.89 \\
\hline $\mathbf{6 5 2 0}$ & 3.81 & 11.85 & 1.95 \\
\hline $\mathbf{4 2 3 0}$ & 3.62 & 12.43 & 2.05 \\
\hline
\end{tabular}

Con la recta de calibrado se calcularon los pesos moleculares $\left(\mathrm{M}_{\mathrm{w}}\right)$ de las distintas STH (Ecuación 34). La recta de calibrado se obtuvo mediante la representación del tiempo de retención frente al $\log \mathrm{M}_{\mathrm{w}}$ de cada uno de los patrones.

$$
\begin{gathered}
\log M_{w}=3.43 t_{R}+10.58 \quad(\text { Ec. 34) } \\
R^{2}=0.981
\end{gathered}
$$

Por último, se calcularon los pesos moleculares medios $\left(\mathrm{M}_{\mathrm{n}}\right)$, los pesos moleculares medios promedios $\left(\mathrm{M}_{\mathrm{i}}\right)$ y la polidispersidad $(\rho)$ de las muestras, mediante las Ecuaciones 35-37.

$$
\begin{aligned}
& M_{n}=\frac{\sum_{i=1}^{N} h_{i}}{\sum_{i=1}^{N} h_{i} / M_{i}} \quad(\text { Ec. 35) } \\
& M_{w}=\frac{\sum_{i=1}^{N} h_{i} M_{i}}{\sum_{i=1}^{N} h_{i}} \quad(\text { Ec. 36) } \\
& \rho=\frac{M_{w}}{M_{n}} \quad \text { (Ec. 37) }
\end{aligned}
$$

\subsubsection{Cálculo \% humedad, sólidos totales y volátiles}

Se pesaron las muestras frescas en crisoles de porcelana (cada muestra por triplicado) de acuerdo con el método normalizado 2540 (APHA-AWWA-WEFF, 1998). Para conocer el porcentaje de humedad se secan las muestras en la estufa marca BINDER durante 24 horas a una temperatura de $105^{\circ} \mathrm{C} \pm 5$ y se calcula por diferencia de pesada. Posteriormente se incineran las muestras en el horno mufla Nobertherm (Figura 3.5.10-1) a una temperatura de $550^{\circ} \mathrm{C} \pm 5$ durante dos horas, y por diferencia de pesada se calculan los sólidos volátiles y totales presentes en la muestra. 


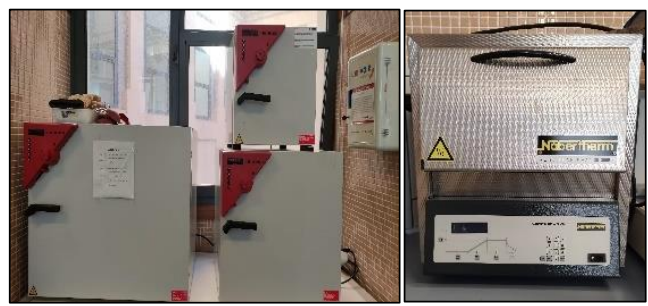

Figura 3.5.10-1. Estufa y horno mufla empleados.

\subsubsection{Dispersión de Luz dinámica}

La dispersión de luz dinámica o DLS es una técnica analítica fisicoquímica que sirve para la determinación de la distribución de tamaños de partículas en suspensión o macromoléculas en solución, cuantificando el movimiento por dispersión. Se basa en la velocidad con que las partículas se difunden en un solvente debido al movimiento Browniano (Figura 3.5.11-1). La velocidad de difusión browniana es inversamente proporcional al tamaño de partícula y se expresa como el radio hidrodinámico $\left(\mathrm{R}_{H}\right)$ de acuerdo con la ecuación de Einstein Ecuación 38.

$$
R_{H}=\frac{2 k T}{3 \pi \eta D} \quad(\text { Ec. 38) }
$$

donde $\mathrm{D}$ es el coeficiente de distribución translacional, $\mathrm{k}$ es la constante de Boltzman, $\mathrm{T}$ es la temperatura absoluta y, $\eta$ la viscosidad del solvente puro.

Se prepararon disoluciones de cada una de las STH a una concentración de $3 \mathrm{~g} \mathrm{~L}^{-1}$ y se miden diluciones de éstas hasta alcanzar una concentración de $20 \mathrm{mg} \mathrm{L}^{-1}$. Se realizan tres medidas por cada muestra. El equipo empleado ha sido un ZETASIZER Nano series (Nano-ZS) de la casa comercial Malvern. Nos proporciona el valor del radio hidrodinámico y anchura de las partículas, así como el grado de polidispersión (P.D.I) que es indicativo del grado de homogeneidad de la muestra.

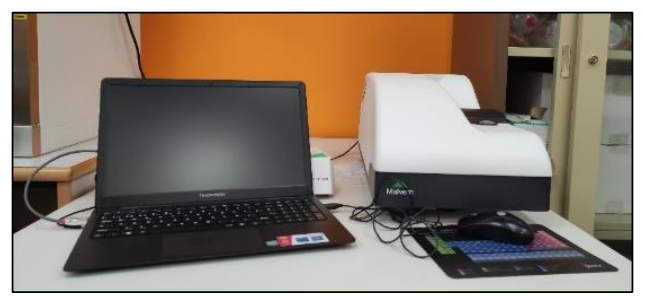

Figura 3.5.11-1. Equipo ZETASIZER para la medición del DLS.

\subsubsection{Resonancia paramagnética electrónica}

La resonancia paramagnética electrónica es una técnica espectroscópica que permite la detección de especies con electrones desapareados (Figura 3.5.12-1). Permite la detección directa de radicales libres en sistemas químicos o biológicos. Esta técnica 
permite obtener información estructural y dinámica que están ocurriendo al momento en el sistema sin perturbarlo. En este caso nos interesa el uso como trampa de espín (spin trap) usado para detectar radicales de vida corta como técnica analítica complementaria.

El espectrómetro utilizado ha sido el modelo Bruker ESP 300E que opera en la banda X y las medidas se han llevado a cabo en capilares de cuarzo. Los parámetros bajo los que se han realizado las medidas han sido los siguientes: frecuencia de microondas $9.78 \mathrm{GHz}$, potencia de microondas $5 \mathrm{~mW}$, la frecuencia de modulación $100 \mathrm{kHz}$ con una amplitud de modulación de 0.4 Gauss, y tiempo constante 40 ms. Como agente de captura (spin trap) se ha utilizado DMPO (5,5-dimetil-1-pirrolina-N-oxido).

La cantidad de STH para cada muestra se disuelve en agua MQ a pH 4.5, posteriormente se adicionan las sales de hierro a una concentración de $5 \mathrm{mg} \mathrm{L}^{-1}$ para $\mathrm{Fe}(\mathrm{II})$ y $\mathrm{Fe}(\mathrm{III})$, una vez disueltas se lleva cuidadosamente el $\mathrm{pH}$ a 5 mediante la adición de $\mathrm{NaOH}$. Seguidamente, se adiciona el DMPO a una concentración de $17 \mathrm{mM}$ y por último se adiciona el $\mathrm{H}_{2} \mathrm{O}_{2}$ a una concentración de $1 \mathrm{mM}$. Una vez se adiciona el $\mathrm{H}_{2} \mathrm{O}_{2}$ empieza la reacción, por eso es el último reactivo que se incorpora.

En el caso de las muestras con Fe(III) se acumulan una ganancia de 10 espectros debido a la baja señal, no así en el caso de las muestras con Fe(II) donde la señal es tan intensa que no es necesario. La intensidad de la señal se determina con la media de la altura de los espectros de DMPO-OH, que posteriormente es normalizada.

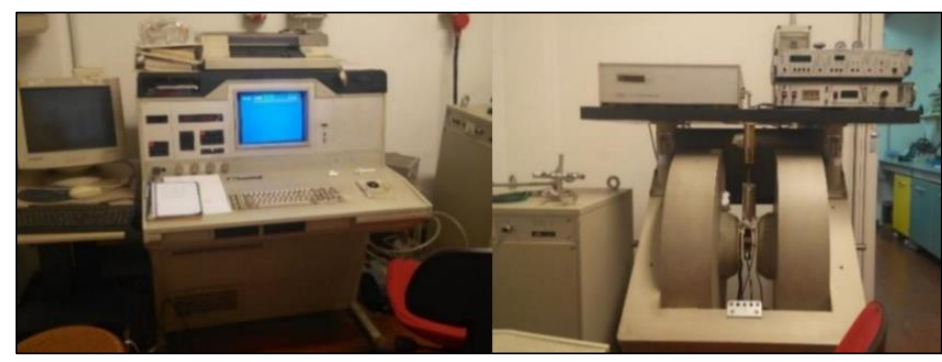

Figura 3.5.12-1. Espectrómetro de resonancia paramagnética Bruker ESP 300E.

\subsubsection{Termogravimetría}

El análisis termogravimétrico (TGA) es una técnica que se usa para caracterizar propiedades físicas y químicas de los materiales en función de la temperatura bajo una atmósfera controlada. Se mide la variación en la masa cuando las muestras son calentadas o enfriadas. 
Se ha usado un equipo TA Q600 (TA Instruments). El análisis se realiza con una rampa de temperatura desde temperatura ambiente hasta $\operatorname{los} 800^{\circ} \mathrm{C}$ en atmósfera de aire y aumento de ésta de $10^{\circ} \mathrm{C} \mathrm{min}^{-1}$.

\subsection{Ensayos de toxicidad}

Se han realizado diferentes ensayos de toxicidad: inhibición de la bioluminiscencia de la bacteria marina Allivibrio fischeri (ISO 11348-3:2007 adaptada), ensayo inhibición del crecimiento en el alga Pseudokirneriella subcapitata ( ISO 8692:2004 adaptada), inhibición movilidad del cladócero Daphnia magna (ISO 6341:2012), ensayo de repulsión con la lombriz de tierra Eisenia fétida (ISO 17512-1:2008), ensayos de citotoxicidad con las líneas celulares N2a y HEK (ISO 10993-5:2009 adaptada) y ensayos de disrupción endocrina RYA (recombinant yeast assay).

\subsubsection{Bioensayo con la bacteria luminiscente Aliivibrio fischeri}

El bioensayo con la bacteria $A$. fischeri es uno de los ensayos más utilizados para evaluar la toxicidad aguda de muestras de agua en presencia de contaminantes. A. fischeri es una bacteria anaerobia facultativa gram negativa, de la familia Vibrionaceae que presenta bioluminiscencia. Esta bioluminiscencia está ligada al sistema de transporte de electrones en la respiración celular, y es indicativa del estado metabólico de la célula, de modo que una disminución en la bioluminiscencia indica una disminución en la tasa de respiración celular. En presencia de agentes contaminantes, la bioluminiscencia disminuye y se puede expresar la toxicidad aguda como concentración efectiva 50 ( $\left.\mathrm{CE}_{50}\right)$, que es la concentración efectiva del contaminante que produce un 50\% de respuesta en la población estudiada.

Este ensayo se realiza de acuerdo con la ISO 11348-3:2007 con algunas adaptaciones. Las bacterias fueron suministradas por Fischer Scientific (Madrid, España). Con este bioensayo se mide la inhibición de la luminiscencia de la bacteria marina A. fischeri (cepa NRRL B-11177) que se pone en contacto con diferentes diluciones de las muestras. Este ensayo se realiza con la ayuda de un módulo inyector de microplacas Tecan modelo Infinite M200 (Figura 3.6.1-1). Primero, se les ajusta el pH a las muestras para asegurar las condiciones adecuadas para el crecimiento de las bacterias y se les adiciona $\mathrm{NaCl}$ para alcanzar una concentración del $2 \%$ de sal, y con ayuda del módulo inyector se siembran en la microplaca. Paralelamente, la bacteria liofilizada es reconstituida y sembrada manualmente en otra microplaca. Transcurridos 15 minutos, la bioluminiscencia de la 
microplaca que contiene las bacterias es medida. El contenido de la microplaca con las muestras se transfiere a la microplaca con las bacterias y se ponen en contacto durante 30 minutos, transcurrido este tiempo se mide la disminución en la bioluminiscencia de las bacterias. Todo el ensayo se lleva a cabo a una temperatura de $15^{\circ} \mathrm{C}$.

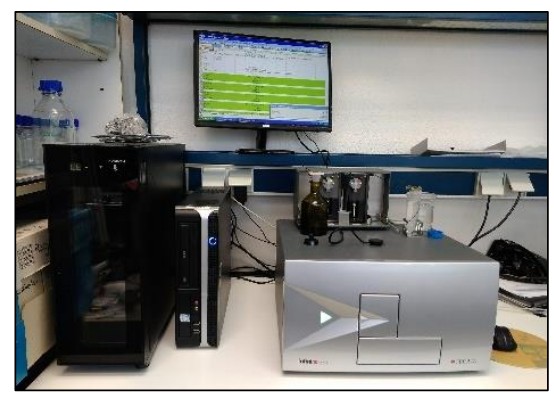

Figura 3.6.1-1. Módulo inyector de microplacas Tecan modelo Infinite M200.

\subsubsection{Bioensayo con el alga Pseudokirchneriella subcapitata}

$P$. subcapitata es un alga verde (clorófita) unicelular con forma de medialuna que puede encontrarse en sistemas acuáticos epicontinentales eutróficos u oligotróficos. La tasa de crecimiento se ve afectada y disminuye cuando son expuestas a muestras que contienen contaminantes tóxicos. Este ensayo de toxicidad aguda se realizó de acuerdo con la ISO 8692:2004 con algunas adaptaciones. La población de algas fue suministrada por ECOtest S.L. (Valencia, España).

El primer paso para la realización del ensayo consiste en la inmovilización del alga y cultivo de ésta hasta llegar a la fase exponencial de crecimiento. Para ello, el alga inmovilizada se agita y centrifuga varias veces en un medio de disolución (matrix disolving medium) y se resuspenden en medio de cultivo BBM (Bold's Basal Medium). La disolución obtenida se mantiene en cámara climática durante 12 horas a $22 \pm 2^{\circ} \mathrm{C}$ en agitación continua y bajo una intensidad luminosa de 1100 lux.

Todas las muestras a las que se les va a realizar este bioensayo deben tener ajustado el $\mathrm{pH}$ a valores de entre 7 y 8 . Una vez se ha alcanzado la fase de crecimiento exponencial de la población se procede al ensayo propiamente dicho (Figura 3.6.2-1). Para el sembrado de las microplacas (microplacas transparentes de 96 pocillos de fondo plano) se utiliza el Tecan Infinite M200. El Tecan realiza el llenado automático de las microplacas con las muestras problema y el cultivo de algas $\left(10^{4}\right.$ cél $\left.\mathrm{mL}^{-1}\right)$. 
Cada ensayo/muestra cuenta con ocho réplicas de control negativo (algas + medio de cultivo), ocho réplicas de cada dilución (algas + medio de cultivo + muestra problema) y ocho blancos (medio de cultivo), el volumen total sembrado en cada pocillo es de $300 \mu \mathrm{L}$.

Las microplacas se meten en bolsas de plástico, se saturan con $\mathrm{CO}_{2} \mathrm{al} 2 \%$, se sellan y se introducen en la cámara climática bajo las condiciones citadas anteriormente. El crecimiento de la población de $P$. subcapitata se mide a las 24,48 y 72 horas mediante la medición de la clorofila in vivo por fluorescencia (430 nm y $663 \mathrm{~nm}$ de excitación y emisión respectivamente). La toxicidad aguda se expresa como $\mathrm{CE}_{50}$.
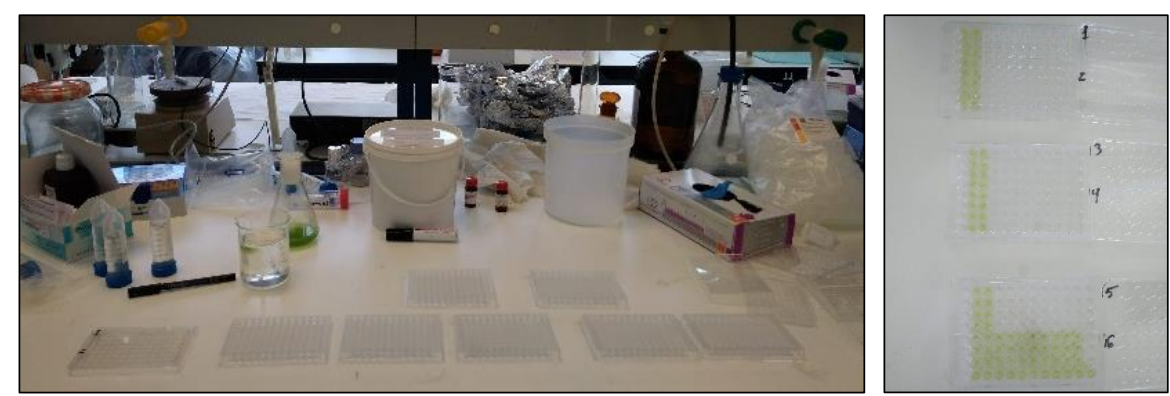

Figura 3.6.2-1. Procedimiento de sembrado de las placas (izquierda) y placa a las $48 \mathrm{~h}$ de la siembra.

\subsubsection{Bioensayo de toxicidad con el microcrustáceo Daphnia magna}

D.magna es un microcrustáceo planctónico ampliamente utilizado como indicador ambiental del estado de los efluentes dulceacuícolas. Es uno de los organismos más utilizados en ensayos toxicológicos debido a su ciclo de vida corto, a su reproducción partenogenética que garantiza la homogeneidad de los cultivos y a que es de fácil manejo. Las epifias de D. magna fueron suministradas por ECOtest S.L. y el ensayo se realizó de acuerdo con la ISO 6341:2012.

Tres días antes de la realización del ensayo se eclosionan los huevos de resistencia (epifias), vaciando el contenido de un vial en un tamiz y lavando abundantemente con agua. Las epifias se transfieren a una placa Petri de 9-10 cm de diámetro con $12 \mathrm{~mL}$ de medio reconstituyente. Para que los neonatos estén listos para su utilización se incuban durante 72 horas a $22 \pm 2^{\circ} \mathrm{C}$ bajo iluminación constante.

El pH de todas las muestras a analizar se ajusta a valores de entre 7-8. Se preparan por triplicado las diluciones en placas de fondo plano, así como el blanco, y se añaden $10 \mathrm{~mL}$ de medio con las correspondientes diluciones. Por último, se añaden 5 organismos a cada una de las placas (Figura 3.6.3-1), y se llevan a la incubadora dónde los organismos 
estarán en contacto con la muestra problema durante 48 horas. A las 24 y 48 horas se hace recuento de los organismos, muertos e inmóviles.

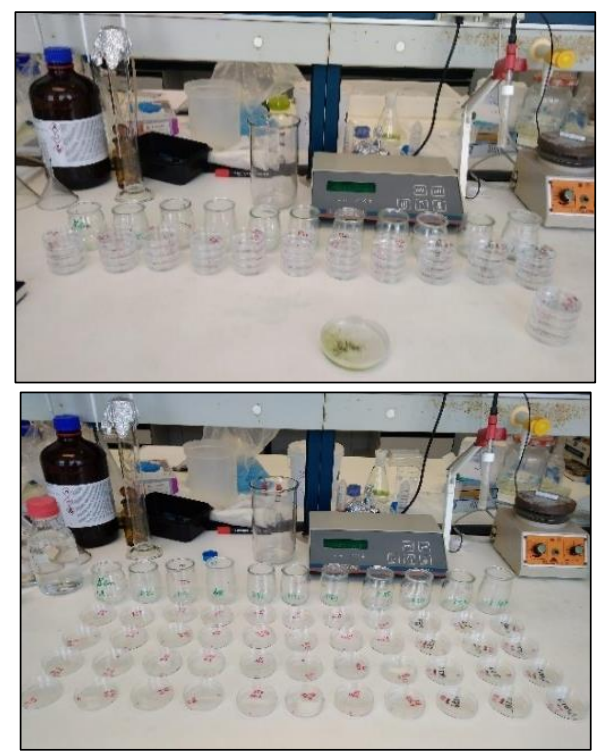

Figura 3.6.3-1. Preparación del ensayo para D. magna.

\subsubsection{Ensayo toxicidad aguda lombriz de tierra Eisenia fetida}

Las lombrices se usan como prueba para evaluar la toxicidad de las muestras problema en los suelos. El objetivo de este ensayo es determinar la repulsión que siente la lombriz de tierra por el sustrato que contiene las muestras problema. Las pruebas de repulsión se realizaron con organismos adultos con presencia de clitelo y con dos/tres meses de edad, siguiendo el protocolo establecido por la norma ISO 17512-1:2008. Los organismos fueron suministrados por el departamento de Ingeniería Hidráulica y Medio Ambiente de la Universitat Politècnica de València.

Primero se preparó y homogeneizó el sustrato, cuya composición fue:

- $69 \%$ de arena de cuarzo industrial

- $20 \%$ arcilla de caolinita (con un mínimo de $30 \%$ de caolinita)

- $10 \%$ de turba rubia

- $1 \%$ de carbonato cálcico

Una vez preparado se distribuye en los recipientes de vidrio, de $14 \mathrm{~cm}$ de diámetro y 6 $\mathrm{cm}$ de altura, una cantidad de $500 \mathrm{~g}$. Los recipientes se dividen en dos partes (una va a contener el sustrato con la muestra problema y la otra solo sustrato) es decir, $250 \mathrm{~g}$ para cada división. El sustrato se humecta para conseguir una humedad del 40\%. Con el 
sustrato preparado y dividido en el recipiente de ensayo se introducen los organismos en la división que queda entre los sustratos, los organismos fueron purgados previo al ensayo durante 24 horas. Los recipientes fueron tapados con film y agujereados para permitir la respiración. Transcurridas 48 horas a una temperatura $22 \pm 1^{\circ} \mathrm{C}$ e iluminación constante se procedió al recuento de los organismos en cada parte del sustrato. Cada muestra se preparó por triplicado, así como el blanco.

Los resultados se expresan como porcentaje de respuesta neta, de acuerdo con la siguiente Ecuación 39:

$$
N R=\frac{(C-T)}{N} * 100 \quad(\text { Ec. 39) }
$$

donde NR es el porcentaje de respuesta neta, $\mathrm{C}$ es el número de organismos en el lado control, $\mathrm{T}$ es el número de organismos en el lado con la muestra problema y $\mathrm{N}$ es el número total de organismos.

Si el valor de NR es positivo indica que ha habido repulsión, si es negativo que existe atracción por el compuesto y si es igual a cero quiere decir que no hay respuesta.

\subsubsection{Ensayo citotoxicidad con las líneas celulares HEK y N2a}

Los ensayos de viabilidad celular se realizan sobre dos líneas celulares, HEK (células embrionarias de riñón humano) y N2a (neuroblastoma de ratón). La viabilidad celular se evalúa usando resazurina. La resazurina es un indicador redox que permite detectar la viabilidad celular por la conversión de una tinción azul no fluorescente a un color rojo (resozurina) en respuesta a una reducción química.

Las células se mantienen en placas de cultivo de tejidos hasta su uso en medio Eagle modificado de Dulbecco (DMEM) suplementado con 1\% de L-glutamina, 2\% de penicilina-estreptomicina y $10 \%$ de suero bovino fetal. La incubación celular se realiza a $37^{\circ} \mathrm{C}$ y $5 \%$ de $\mathrm{CO}_{2}$ en atmósfera humidificada. Las células se recogen cuando alcanzan una confluencia del 70-90\% y se evalúa la viabilidad celular y densidad mediante Tryptan Blue con un hemocitómetro antes de su uso en el ensayo.

El ensayo se lleva a cabo en una placa de cultivo de tejidos de 96 pocillos. Cada pocillo se llena con $100 \mu \mathrm{L}$ de una de las suspensiones celulares $\left(1 * 10^{5}\right.$ cel $\left.\mathrm{mL}^{-1}\right)$ en DMEM suplementado. A las $24 \mathrm{~h}$, las muestras se siembran con diluciones en serie y se incuban otras $24 \mathrm{~h}$. Posteriormente se retira el medio y se añaden $100 \mu \mathrm{L}$ de solución de resazurina a una concentración de $15 \mu \mathrm{M}$. A las $4 \mathrm{~h}$ se procede a la lectura de la fluorescencia en el 
lector de placas del Tecan Infinite M200 a 560/590 nm Ex/Em. Se realizan controles negativos y blancos que se analizan simultáneamente con las muestras.

\subsubsection{Ensayo con levaduras recombinantes RYA (Recombinant Yeast Assay) para la evaluación de la actividad estrogénica}

El objetivo de este ensayo es comprobar la actividad estrogénica de los compuestos problema. Se basa en el uso de una cepa de levadura Saccharomices cerevisae modificada genéticamente, cepa BY4741 (ER).

Las muestras de agua se concentran utilizando un sistema de vacío (Extra Vac 12, Scharlab) mediante la utilización de cartuchos SPE (Solid Phase Extraction) de la misma marca comercial. Los cartuchos son previamente acondicionados con $10 \mathrm{~mL}$ hexano, 10 $\mathrm{mL}$ de diclorometano, $10 \mathrm{~mL}$ metanol y $15 \mathrm{~mL}$ de agua MQ para lavarlos con un flujo de $5 \mathrm{~mL} \min ^{-1}$. Se filtra un volumen de $0.5 \mathrm{~L}$ de muestra por cada cartucho. Una vez filtrada la muestra el cartucho se lava con $5 \mathrm{~mL}$ de agua MQ y se seca en la estufa. Una vez seco se procede a la elución de los parabenos del cartucho; para ello se hace pasar por éste 10 $\mathrm{mL}$ de diclorometano:hexano (1:1) y $10 \mathrm{~mL}$ de diclorometano:acetona (1:1). Los disolventes utilizados son evaporados por rotavapor (Figura 3.6.6-1), y el extracto seco es reconstituido con $500 \mu \mathrm{L}$ de metanol. Las muestras extraídas se almacenan a $-4^{\circ} \mathrm{C}$ hasta su análisis.

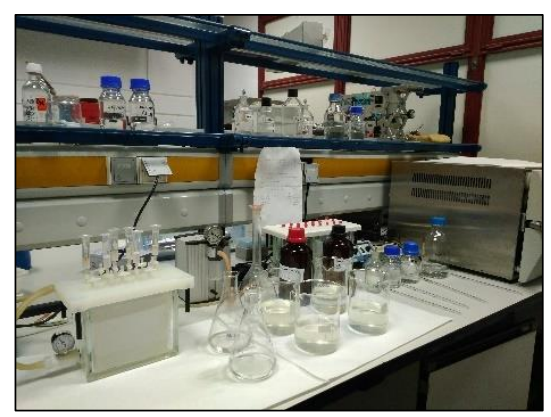

Figura 3.6.6-1. Concentración de las muestras.

El primer paso para realizar este ensayo es cultivar la levadura a partir de criocultivos. Se siembran placas a partir de estos criocultivos $\left(-80^{\circ} \mathrm{C}\right)$ y se incuban durante $24-48$ horas a $30^{\circ} \mathrm{C}$, obteniéndose lo que se conoce como cultivos stock. A partir de éstos, se siembran las placas con el medio de cultivo selectivo (YPD en este caso) según la cepa y se incuban 24 horas a $30^{\circ} \mathrm{C}$. Una vez transcurrido este tiempo, se inoculan en tubos de ensayo con medio de cultivo líquido y se incuban de nuevo a $30^{\circ} \mathrm{C}$ durante 17 horas y con agitación suave. Posteriormente se comprueba que volumen es el adecuado para que contenga la 
cantidad de células en fase exponencial de crecimiento necesaria para garantizar el ensayo, es necesario un cultivo con una densidad óptica de 0,08-0,15 a $600 \mathrm{~nm}$, y se inoculan en matraces Erlenmeyer de $50 \mathrm{~mL}$ con el medio de cultivo específico de la cepa.

El segundo paso consiste en el llenado de las placas multipocillo de polipropileno (NUNCTM, Thermo Scientific). La primera columna se llena con el cultivo de la levadura y la muestra preconcentrada a una dilución 1:20 v/v, y de esta se van realizando diluciones 1:2 sucesivas a lo largo de la placa hasta llegar a la columna 9. La columna 10 es el control de toxicidad, la 11 el control positivo y la 12 el control negativo (Figura 3.6.6-2). Las placas se incuban a $30^{\circ} \mathrm{C}$ con agitación orbital $(120 \mathrm{rpm})$ durante 6 horas.

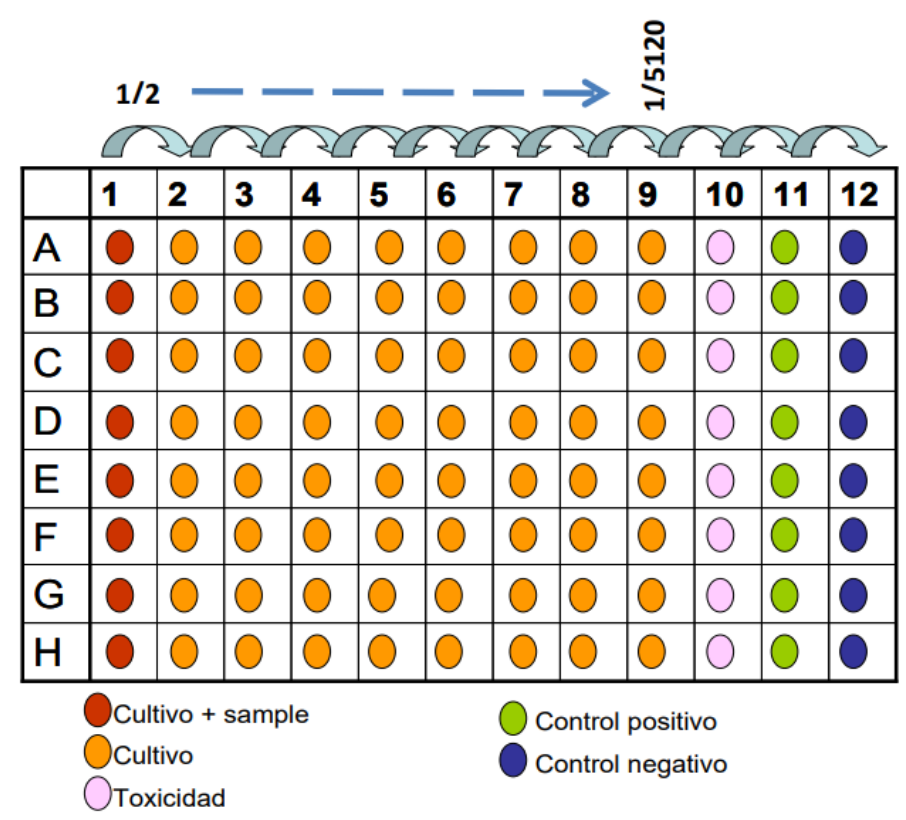

Figura 3.6.6-2. Ejemplo de siembra en las placas multipocillo para el ensayo RYA.

Una vez incubadas se añade a todos los pocillos el YPER (Yeast Protein Extraction Agent), que es un tampón de lisis, para permeabilizar la pared de la levadura y extraer las proteínas solubles. Se incuban de nuevo las placas 30 minutos a $30^{\circ} \mathrm{C}$.

Se añade el sustrato fluorescente MU-Gal para la detección de la $\beta$-galactosidasa a cada uno de los pocillos y se deja reposar la placa durante 5 minutos para asegurar que los restos celulares se depositen y se procede a la lectura de la placa.

Se mide la fluorescencia empleando el lector Tecan Infinite M200 a una longitud de onda de excitación de 360 nm y una longitud de onda de emisión de 460 nm cada 42 segundos durante 20 minutos. La intensidad de la fluorescencia registrada en ese tiempo 
corresponde con la actividad enzimática. Dicha cantidad es proporcional a la cantidad de enzima, que a su vez es proporcional a la cantidad de complejo ligando-receptor formado que active la transcripción del gen LacZ. La actividad máxima ha de ser la del control positivo y la actividad mínima la del control negativo.

La actividad de $\beta$-galactosidasa se calcula a partir de las pendientes de la recta de los valores de fluorescencia frente al tiempo. Para ello se asume que en la formación del complejo ligando-receptor nunca es limitante.

Este ensayo no proporciona una medida directa de los contaminantes potencialmente tóxicos o de sus actividades, por lo que los resultados se calculan como equivalentes E2 (EEQ). Los equivalentes son la concentración de los ligandos de referencia (ng L ${ }^{-1}$ ) que debería estar presente para obtener una respuesta similar a la observada (Noguerol et al., 2006)

\subsection{Métodos matemáticos y estadísticos}

\subsubsection{Análisis estadísticos de los bioensayos de toxicidad}

Para los diferentes ensayos de toxicidad realizados se ha calculado el valor MID, que es el factor de dilución requerido para producir un 50\% de efecto en la población estudiada, el LID, que es la dilución más baja que no produce efecto en la población estudiada, y la CE50 (Concentración Efectiva 50) que es la concentración requerida para causar el 50\% de respuesta en la población.

El valor MID se ha calculado mediante análisis Probit, utilizando el programa estadístico SPSS (versión 16.0), y el valor LID se ha calculado mediante el programa estadístico Statgraphics Plus (versión 5.1). Además, se ha aplicado análisis de la varianza ANOVA para conocer el efecto del tiempo de tratamiento en los procesos de degradación, tomando un $\rho<0.05$.

\subsubsection{Análisis de matrices de excitación emisión de fluorescencia (EEM) y análisis paralelo de factores.}

Las matrices de excitación emisión son una técnica analítica complementaria que proporciona gran cantidad de información que de otra manera sería complicada de conocer. Generalmente se han utilizado para obtener información acerca de la composición química de la materia orgánica disuelta (MOD) gracias a la alta sensibilidad que presenta esta técnica. En aplicaciones simples, la fluorescencia de un fluoróforo a una longitud de onda de excitación emisión concreta se utiliza para medir concentraciones. 
Sin embrago, generalmente se utilizan barridos de fluorescencia para medir una muestra combinada de fluoróforos conocidos y desconocidos (Bahram et al., 2006). Las técnicas de análisis multivalentes de datos se han utilizado para el estudio de señales de fluorescencia de muestras complejas (Stedmon et al., 2003), siendo de las más utilizadas PARAFAC.

El análisis paralelo de factores (PARAllel Analysis FACtor) proporciona un modelo tanto cuantitativo como cualitativo de los datos analizados, y separa la señal medida en señales individuales con espectros de Ex/Em específicos. Los datos de fluorescencia son multidireccionales, ya que dependen de tres factores: de la longitud de onda absorbida (excitación) y de la longitud de onda a la que presenta fluorescencia (emisión). Combinando los datos medidos de una serie de muestras se obtiene una matriz tridimensional definida por tres matrices bidireccionales A, B y C con elementos $\mathrm{a}_{\mathrm{ij}}, \mathrm{b}_{\mathrm{ij}} \mathrm{y}$ $\mathrm{c}_{\mathrm{ij}}$ (Ecuación 40), donde $\mathrm{x}_{\mathrm{ijk}}$ es la matriz tridimensional con dimensiones $I$, J y $K$. Es la intensidad de fluorescencia de la muestra $i$ medida a la longitud de onda de emisión $j$ y a longitud de onda de excitación $k$, $\varepsilon_{\mathrm{ijk}}$ es el error o residuo derivado del ruido o cualquier otra variación no modelada. Si hay fluoróforos F en la mezcla la señal medida es la suma de la contribución de cada uno de ellos.

$$
x_{i j k}=\sum_{f=1}^{F} a_{i f} b_{j f} c_{k f}+\varepsilon_{i j k}, i=1 ., . I ; j=1 ., . J ; k=1, ., K
$$

El resultado del modelo son los parámetros $a, b$ y $c$. Representan respectivamente la concentración, los espectros de emisión y los espectros de excitación de los fluoróforos.

En la presente tesis doctoral la representación y análisis por PARAFAC de las matrices medidas se ha realizado usando MATLAB2018b junto a la interfaz de usuario desarrollada por nuestro grupo de investigación en el proyecto al que está asociado mi contrato FPI (Micó et al., 2019) la cual emplea rutinas de drEEM toolbox para el pretratamiento y análisis de los datos. Los pasos seguidos para medir y obtener las EEMs y la representación y análisis de estas se muestran a continuación (Figura 3.7.2-1). 
Material y métodos

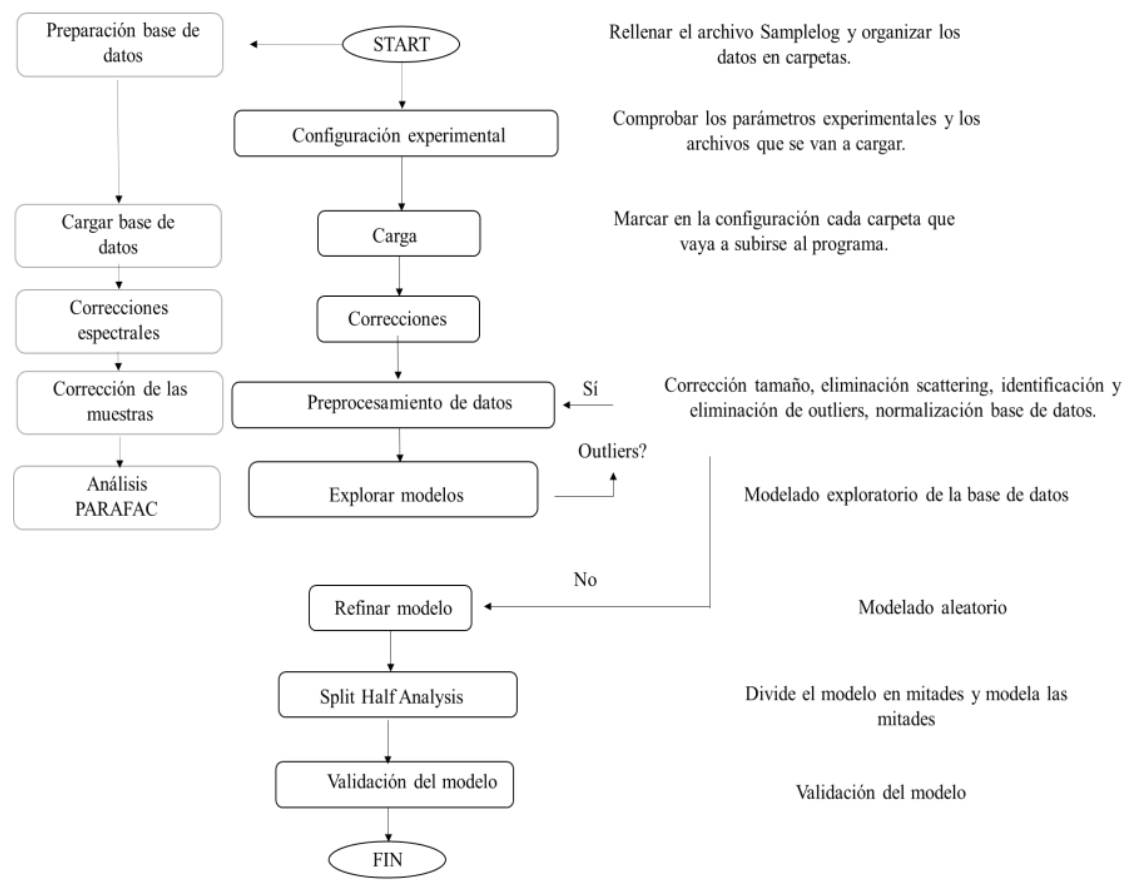

Figura 3.7.2-1. Flujo de trabajo de la aplicación EEMlab. Extraído de Micó et al., 2019. 
4. RESULTADOS Y DISCUSIÓN 
Resultados y discusión 
Esta parte de la tesis se va a dividir en 5 capítulos dirigidos a cumplir los objetivos específicos de la Tesis, y que se corresponden con 5 artículos científicos derivados de la misma (ya publicados o en fase de publicación).

\section{Capítulo 1}

En este capítulo se sintetizan las STH, se caracterizan y se platea la posibilidad de aplicar diferentes tiempos de fermentación del residuo de la producción del aceite de oliva para la extracción de STH y su aplicación al proceso foto-Fenton a pHs más próximos a la neutralidad. Se utilizan residuos a los que se les ha aplicado tres tiempos de fermentación diferentes y se caracterizan las STH obtenidas, posteriormente se aplican al proceso fotoFenton y se comprueba su eficiencia, determinando que no es necesario fermentar los residuos para mejorar la eficiencia de las STH obtenidas.

Artículo derivado: "Degradation of emerging polltants using different fermentation times olive mill wastes humic like substances at circumneutral photo-Fenton process". (artículo en fase de escritura)

\section{Capítulo 2}

Una vez comprobada la eficiencia de los diferentes tiempos de fermentación, se decide separar STH de diferente tamaño de partícula para comprobar el efecto que puede tener sobre el proceso foto-Fenton este factor. Se comprueba la eficiencia de tres fracciones de STH separadas mediante membranas y se evalua la toxicidad sobre varios organismos pertenecientes a diferentes niveles de la cadena trófica.

Artículo derivado: "Humic like substances isolated from olive mill wastes as iron complexants for the photo-Fenton treatment of emerging pollutants at mild conditions: toxicity assessment. 2021 ". Journal of Environmental Chemical Engineering (enviado).

\section{Capítulo 3}

Estudiada la influencia del tratamiento del residuo con diferentes condiciones de extracción y separación para su posterior aplicación al proceso foto-Fenton, así como su carcaterización y toxicidad, se evalúa el mecanismo de reacción de las STH en el proceso. Artículo derivado: "Unveiling the dependence between hydroxyl radical generation and performance of Fenton systems with complexed iron”. 2019. ACS Omega. 4, 2169821703. 


\section{Capítulo 4}

Una vez determinada la mejor metodología de extracción de las STH así como su mecanismo de reacción, se compara la aplicación en el proceso foto-Fenton de tres tipos diferentes de STH provenientes de tres tipos de residuos sobre una mezcla de parabenos, seleccionados como ejemplo de CE listados por la UE, y se evalua la toxicidad derivada. Artículo derivado: "Removal of pharmaceutical and personal care products (parabens) presents in cosmetic wastewaters by mild photo-Fenton process using humic like substances and their toxicity assessment". (En proceso de escritura).

\section{Capítulo 5}

Finalmente, estudiado el efecto de las STH en la mejora de la eficiencia del proceso oxidativo foto-Fenton a pHs más próximos a la neutralidad, se buscan otras posibles aplicaciones de las STH para el desarrollo de tecnologías más eficiencientes para la eliminación de contaminantes emergentes. Se estudia la capacidadde las STH para concentrar los contaminantes y de este modo, acoplar procesos de membrana seguidos de procesos foto-Fenton para descontaminar aguas con una elevada carga de contaminante.

Artículo derivado: "Use of membranes systems coupled with photo-Fenton process to remove emerging pollutants at high concentrations". (En proceso de escritura) 


\subsection{APLICACIÓN DE SUSTANCIAS TIPO HÚMICAS CON DIFERENTE TIEMPO DE FERMENTACIÓN PROCEDENTES DEL RESIDUO DE LA OLIVA PARA LA ELIMINACIÓN DE CONTAMINANTES EMERGENTES POR PROCESO TIPO FOTO-FENTON.}

\subsubsection{Introducción}

El uso de agentes quelantes capaces de complejar el hierro es una de las estrategias más prometedoras para llevar el proceso foto-Fenton a $\mathrm{pH}$ más próximos a la neutralidad. Estos compuestos son capaces de formar complejos fotoactivos y son estables durante el proceso (Santos-Juanes et al., 2017). Como hemos visto en el Apartado 1.2.2.3.4, en los últimos años se ha estudiado la aplicación de diferentes complejos como el EDTA (De Luca et al., 2014), el EDDS (Soriano-Molina et al., 2019; Miralles-Cuevas et al., 2019) o el NTA (Dong et al., 2019) entre otros.

A parte de agentes complejantes de origen químico, otro tipo de sustancias como las SH (Sustancias Húmicas) o STH (Sustancias Tipo Húmicas) han generado interés en cuanto a su uso como agentes complejantes del hierro. Son macromoléculas naturales originadas por transformaciones microbianas y químicas que tienen lugar en los suelos. En su estructura presentan quinonas (además de grupos - $\mathrm{OH}$ y - $\mathrm{COOH}$ ) que ayudan a reducir el $\mathrm{Fe}(\mathrm{III})$ a Fe(II) manteniendo el Fe en disolución y ampliando el rango de aplicación del proceso foto-Fenton, como ha demostrado (Georgi et al., 2007). Como se ha citado anteriormente, algunos autores de nuestro grupo de investigación han extraído STH de diferentes tipos de residuos como residuos sólidos urbanos (Gomis et al., 2014) o residuo de la producción del aceite de oliva (García-Ballesteros et al., 2018) y las han adicionado al proceso foto-Fenton consiguiendo buenos resultados de degradación de los contaminantes seleccionados en cada caso.

Considerando la importancia de la producción del aceite de oliva en los países mediterráneos, con los consiguientes residuos asociados al proceso, pone de manifiesto el creciente interés en la extracción de STH provenientes de este residuo y, en profundizar en el conocimiento de sus posibles aplicaciones.

Hay que considerar que los residuos generados en la producción del aceite de oliva son recalcitrantes y fitotóxicos (Roig et al., 2006) y necesitan de procedimientos especiales de gestión de residuos en la mayoría de los países. La revalorización de este residuo 
estaría de acuerdo con los objetivos de la Unión Europea respecto al fomento de la economía circular.

Para el presente trabajo, se han extraído STH procedentes del residuo de la producción del aceite de oliva de la almazara de Millena (Alicante) y se han sometido a diferentes tiempos de fermentación. Se ha empleado residuo fresco $(\mathrm{MH})$, residuo fermentado un mes (MHF) y residuo fermentado un año (MHF-1A) sin dializar y dializado respectivamente (MH-D, MHF-D y MHF-1A-D). Posteriormente, se ha estudiado su adición como agentes complejantes del Fe en el proceso foto-Fenton. Se han caracterizado las STH obtenidas mediante diferentes técnicas: espectroscopía UV-Vis, DLS, FTIR, TGA y fluorescencia. De entre las técnicas seleccionadas, las matrices de excitación emisión (EEMs) que se obtienen por fluorescencia, arrojan información acerca de la composición de las muestras mediante la identificación de fluoróforos que pueden ser asignados a diferentes familias de compuestos. Las EEMs combinadas con el análisis matemático PARAFAC nos permite conocer la tendencia de los diferentes componentes de las muestras a lo largo del tratamiento, evitando el uso de técnicas sofisticadas.

El objetivo final del estudio es determinar y comparar el papel de las STH sometidas a diferentes tiempos de fermentación como agentes complejantes del hierro en el proceso tipo foto-Fenton a $\mathrm{pH}$, prestando especial atención a los cambios en la composición de la materia orgánica medida por EEM-PARAFAC. Para los experimentos de degradación se han seleccionado seis contaminantes emergentes: acetaminofeno (ACF), amoxicilina (AMOX), acetamiprid (ACP), cafeína (CAF), carbamazepina (CAR) y ácido clofíbrico (CLOF).

\subsubsection{Extracción de las STH}

La extracción de STH se realiza a partir del residuo sólido de la producción del aceite de oliva (alperujo) obtenido de la Almazara de Millena (Alicante), al que se ha sometido a diferentes tiempos de fermentación. Se somete a digestión básica $0.125 \mathrm{~kg}$ del residuo fresco corregido por la humedad con $0.5 \mathrm{~L}$ de $\mathrm{KOH} 0.3 \mathrm{M}$ a $400 \mathrm{rpm}$ y 24 horas. Una vez transcurrido este tiempo, se lleva el volumen hasta $5 \mathrm{~L}$ con $\mathrm{KOH}$ a la misma concentración para acabar de extraer las STH que puedan quedar, y se filtra la muestra por un tamaño de poro de $100 \mu \mathrm{m}$ para eliminar toda la parte insoluble que pueda estar presente como piel o restos de hueso. Posteriormente se filtra toda la solución por membranas cerámicas de $\mathrm{TiO}_{2}$ de siete canales interiores con un tamaño de poro de 50 
kDa, así se obtienen tres tiempos de fermentación de STH: MH, MHF y MHF-1A. El retentato (RT) obtenido en cada filtración se seca en la estufa hasta la eliminación total de toda la humedad y se tritura, obteniendo así las STH. De cada tiempo de fermentación se toma una parte y se somete a diálisis con membranas de tamaño de poro $12000 \mathrm{Da}$ para eliminar todas las sales procedentes de la extracción. Posteriormente estas STH de diferentes tamaños se aplicarán al proceso foto-Fenton a $\mathrm{pH}$ más neutros; se busca determinar si el tiempo de fermentación del residuo de las STH condiciona el proceso.

\subsubsection{Caracterización de las STH}

El peso molecular de las diferentes STH se ha calculado por cromatografía de exclusión por tamaños (SEC); cuanto mayor sea la molécula, menor es el tiempo de retención. El tamaño y el peso molecular se especifica comparando los valores obtenidos con estándares de tamaños moleculares conocidos. Generalmente se utiliza el poliestireno de sulfonato como estándar (PSS) (Liu et al., 2010). Hay que tener en cuenta que la MOD o SH pueden presentar estructuras más ramificadas y entrecruzadas que el patrón PSS, por lo que los resultados obtenidos son aproximados (Sillanpää et al., 2015). Como puede observarse en la Figura 4.1.3-1 los tiempos de elución son prácticamente los mismos en todos los casos, indicando que todas las STH tienen pesos moleculares (Mw) similares. Las muestras dializadas presentan un mayor peso molecular, en torno a los $6400 \mathrm{kDa}$, mientras que las no dializadas se encuentran en los $4600 \mathrm{kDa}$. Estos valores están de acuerdo con los obtenidos por García-Ballesteros et al., 2018.

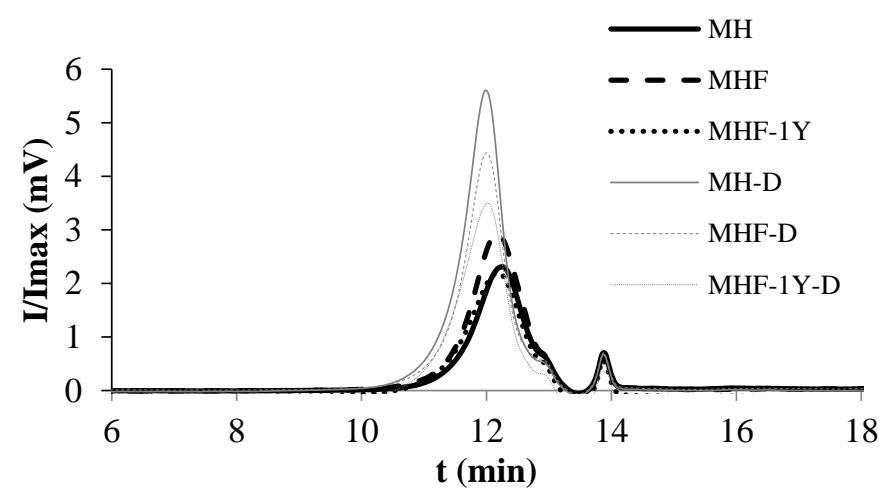

Figura 4.1.3-1. Cromatograma de exclusión por tamaños obtenido para las diferentes STH. Muestras no dializadas: MH, MHF, MHF-1A (negro) y dializadas: MH-D, MHF-D, MHF-1A-D (gris).

El tamaño de los agregados se ha determinado usando la técnica de dispersión de luz dinámica (DLS); esta técnica se utiliza para conocer el radio hidrodinámico de las 
partículas. Los resultados obtenidos (Figura 4.1.3-2) varían entre los diferentes tiempos de fermentación de las STH. En el caso de MH y MH-D se han obtenido valores en torno a los $400 \mathrm{~nm}$ (419.2 y $379.6 \mathrm{~nm}$ respectivamente) de acuerdo con los valores obtenidos por García-Ballesteros et al., 2018. El radio hidrodinámico obtenido para MHF (218.6 nm) es más similar a los obtenidos por Avetta et al., 2015 en la caracterización de STH extraídas de residuos sólidos urbanos, donde se obtuvieron valores de $135 \mathrm{~nm}$, lo cual tiene sentido ya que estas se obtuvieron del digestato de un digestor anerobio, es decir, estaban fermentadas. Los elevados valores obtenidos para MHF-D y MHF-1A-D podrían explicarse por la capacidad de las STH de formar agregados (Sutton et al., 2005).

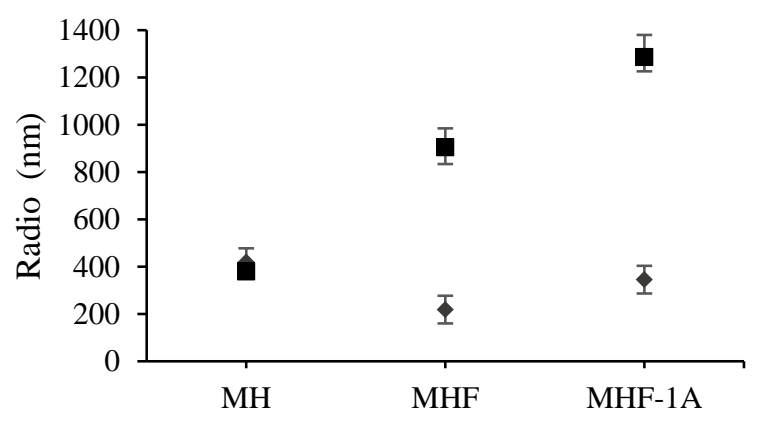

Figura 4.1.3-2. Valores obtenidos para la medida DLS de las STH dializadas ( $\mathbf{a})$ y no dializadas ( $\bullet$ ).

Respecto a la medida FTIR, las principales características son similares entre las diferentes STH indicando el origen común de las muestras, así como los mismos grupos funcionales, aunque, pueden observarse algunas diferencias entre las muestras dializadas y las no dializadas. El ancho pico registrado entre $3600-3000 \mathrm{~cm}^{-1}$ se asigna a las vibraciones de los grupos $\mathrm{O}-\mathrm{H}$ de fenoles, alcoholes y ácidos carboxílicos y, a vibraciones de los N-H de amidas y aminas (Andjelkovic et al., 2006). Es la banda de absorción IR más marcada en todas las muestras analizadas. La banda de absorción entre los 2960$2860 \mathrm{~cm}^{-1}$ se relaciona con cadenas alifáticas (C-H) (Krivácsy et al., 2001). Los picos de absorción medidos a $1800-1650 \mathrm{~cm}^{-1}$ muestran la presencia de dobles enlaces $(\mathrm{C}=\mathrm{O})$ de grupos ésteres y carboxílicos. El primer pico se relaciona con enlaces $\mathrm{C}=\mathrm{O}$ de $\mathrm{COOH}$ y otros grupos carboxílicos como cetonas y aldehídos (Duarte et al., 2007; Duarte et al., 2005). La segunda banda se relaciona con la presencia de deformaciones de los C-O y O$\mathrm{H}$ de $\mathrm{COOH}$ y enlaces fenólicos C-O. Alrededor de los $16212 \mathrm{~cm}^{-1}$ aparecen las bandas de absorción de los grupos carboxílicos ionizados; la región entre los 1620-1600 cm-1 también puede relacionarse con estiramientos $\mathrm{C}=\mathrm{C}$ de anillos aromáticos, estiramiento $\mathrm{C}=\mathrm{O}$ en quinonas, ácidos cetónicos y amidas primarias (Enev et al., 2014). El espectro de 
FTIR que se muestra en la Figura 4.1.3-3 está de acuerdo con los diferentes autores: Marques et al., 2005; Francioso et al., 2007; Enev et al., 2014; Kristensen et al., 2015. No se han observado grandes diferencias entre las medidas de las distintas muestras.

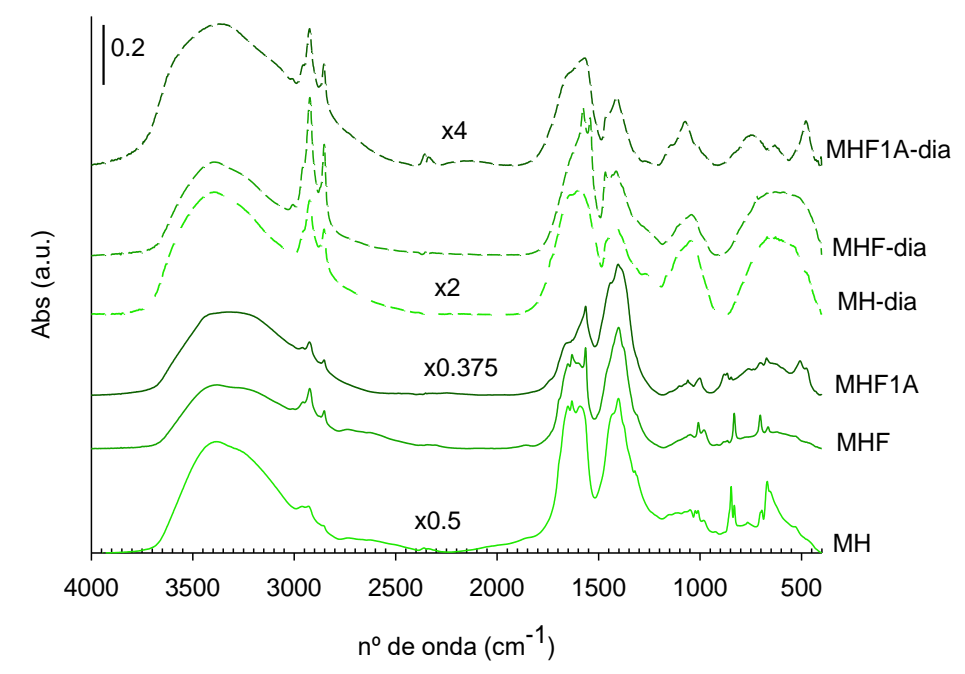

Figura 4.1.3-3. Espectro de absorbancia FTIR obtenido para las diferentes muestras de STH.

En la Figura 4.1.3-4 se muestra el análisis termogravimétrico. Esta técnica se usa normalmente para la caracterización de AH y para conocer su descomposición termal (Kucerik et al., 2004). Pueden observarse diferentes picos, que varían entre las muestras dializadas y no dializadas y entre los diferentes tiempos de fermentación de las STH. Generalmente, se registra una primera reacción exotérmica en torno a los $300^{\circ} \mathrm{C}$ debida a la descomposición de las proteínas y los grupos carboxílicos, y una segunda reacción exotérmica a $450^{\circ} \mathrm{C}$ aproximadamente que indica la descomposición del carbón refractario (Francioso et al., 2007). En las muestras dializadas, la pérdida de masa es mucho más acusada, se observa una fuerte pérdida de masa entre los $350-550^{\circ} \mathrm{C}$. La descomposición de proteínas, carbohidratos y ácidos grasos poliinsaturados tiene lugar a los $330^{\circ} \mathrm{C}$ (García-Ibañez et al., 2006), de acuerdo con la pérdida del núcleo aromático por la descomposición termal (Marques et al., 2005). 

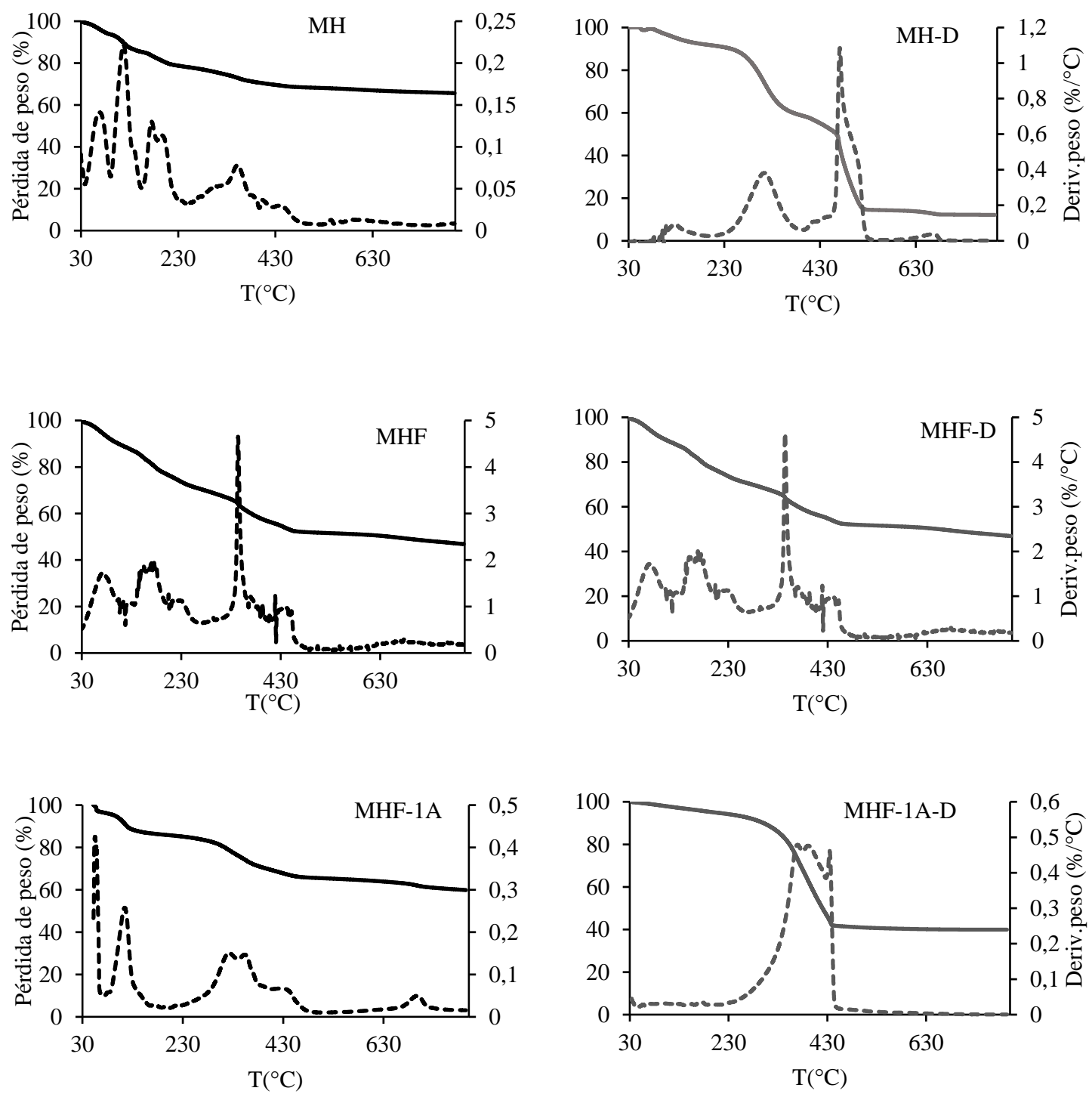

Figura 4.1.3-4. TGA obtenido para las diferentes STH. Muestras no dializadas (negras) y dializadas (grises). Gráfica de la pérdida de peso $\left(\% /{ }^{\circ} \mathrm{C}\right)$ frente a la $\mathrm{T}\left({ }^{\circ} \mathrm{C}\right)$.

La fluorescencia es una función de la estructura y de los diferentes grupos funcionales presentes, y es capaz de discriminar entre diferentes cromóforos (Valencia et al., 2013). Esta técnica espectroscópica es sensible y selectiva y no precisa de preparación de las muestras (Matilainen et al., 2011). La combinación entre la fluorescencia y la absorbancia a determinadas longitudes de onda características (como los valores $\mathrm{SUVA}_{254}, \mathrm{E}_{2} / \mathrm{E}_{3} \mathrm{o}$ $\mathrm{E}_{4} / \mathrm{E}_{6}$ ratios) son útiles para conocer los mecanismos de degradación y la eficiencia en procesos fotocatalíticos. Las matrices de excitación emisión son una herramienta muy útil para la caracterización de muestras complejas con presencia de MOD (Xiao et al., 2020; Her et al., 2003). En la Figura 4.1.3-5 se muestra las EEM obtenidas para las diferentes muestras de STH. Las muestras no dializadas presentan una señal muy intensa entre los 
400-500 nm, que corresponde con la región atribuible a las SH (Yang et al., 2015). En el caso de las muestras dializadas el área de emisión es mayor $(350-550 \mathrm{~nm})$ pero, en cualquier caso, entran dentro de la región característica de las SH (Coble, 1996; Henderson et al., 2009); el movimiento del área de emisión puede deberse a una mayor fuerza iónica en estas muestras.
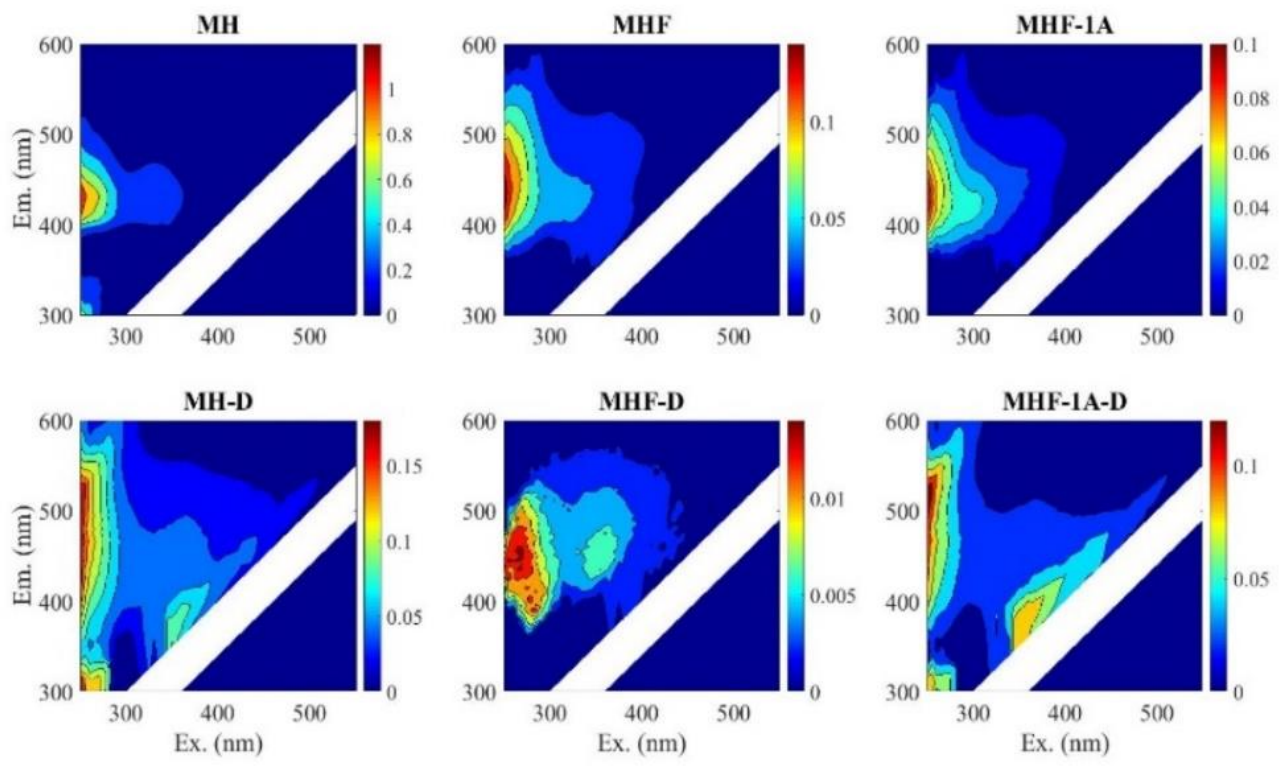

Figura 4.1.3-5. EEM obtenidas para las diferentes STH. Arriba: no dializadas, abajo: dializadas. El eje X corresponde a las longitudes de onda de excitación $(250-500 \mathrm{~nm})$ y el eje $\mathrm{Y}$ a las longitudes de onda de emisión (300-600 nm).

En el caso de valores específicos de emisión a determinadas longitudes de excitación como los índices FI (índice de fluorescencia) o HIX (índice de humificación) no se han obtenido conclusiones claras. Respecto al FI los valores entre las diferentes muestras son muy parecidos (entre 0.8-1.5) lo que indicaría que las muestras provienen del mismo origen, mientras que para el índice HIX los valores fueron muy dispares entre ellos, no obteniéndose una conclusión clara sobre el grado de humificación con esta técnica.

De acuerdo con los resultados obtenidos para la caracterización de las diferentes STH, se puede concluir que estas sustancias son tipo húmicas y que por lo tanto van a actuar como agentes complejantes del hierro en el proceso tipo foto-Fenton.

\subsubsection{Aplicación de las STH en proceso foto-Fenton}

Se ha estudiado la capacidad de estas sustancias para llevar a cabo el proceso foto-Fenton a pHs más próximos a la neutralidad sobre la degradación de una mezcla de seis contaminantes a una concentración de $5 \mathrm{mg} \mathrm{L}^{-1}$ cada uno. La Figura 4.1.4-1 muestra la degradación de los seis contaminantes seleccionados a pH 5 en ausencia de STH, donde 
se alcanza cierta degradación de estos. Sin embargo, si comparamos con la adición de 20 mg L ${ }^{-1}$ de STH (Figura 4.1.4-2), se alcanzan mejores resultados de degradación en el uso de cualquiera de los diferentes tiempos de fermentación a excepción de las sustancias fermentadas un año (MHF-1A y MHF-1A-D). La decisión de qué cantidad de STH adicionar al proceso para que sea eficiente, se ha hecho de acuerdo con los estudios de Gomis et al., 2015, quienes concluyeron para la misma mezcla de contaminantes, que la cantidad óptima de STH necesaria para complejar 4-5 mg L-1 de Fe era de 19-22 mg L-1 de STH.

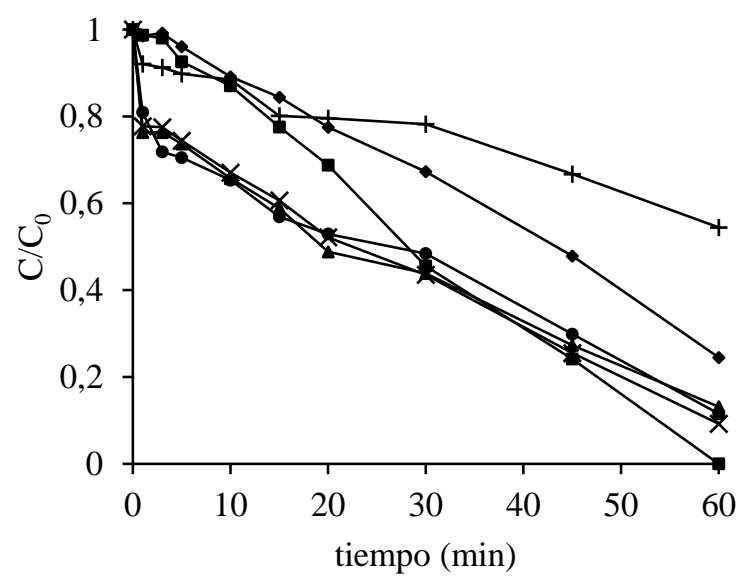

Figura 4.1.4-1. Degradación de la mezcla de contaminantes frente al tiempo sin la adición de STH. Condiciones experimentales: [CEs $]_{0} 5 \mathrm{mg} \mathrm{L}^{-1}$ cada uno, [Fe(III) $]_{0} 5 \mathrm{mg} \mathrm{L}^{-1}$, $\left[\mathrm{H}_{2} \mathrm{O}_{2}\right]_{0} 75 \mathrm{mg} \mathrm{L}^{-1}, \mathrm{pH}_{0} 5$. ACF $(\bullet), \operatorname{AMOX}(\bullet), \operatorname{CAF}(\bullet), \operatorname{ACP}(+), \operatorname{CBZ}(\mathrm{x}), \mathrm{CLOF}(\boldsymbol{\Delta})$. 

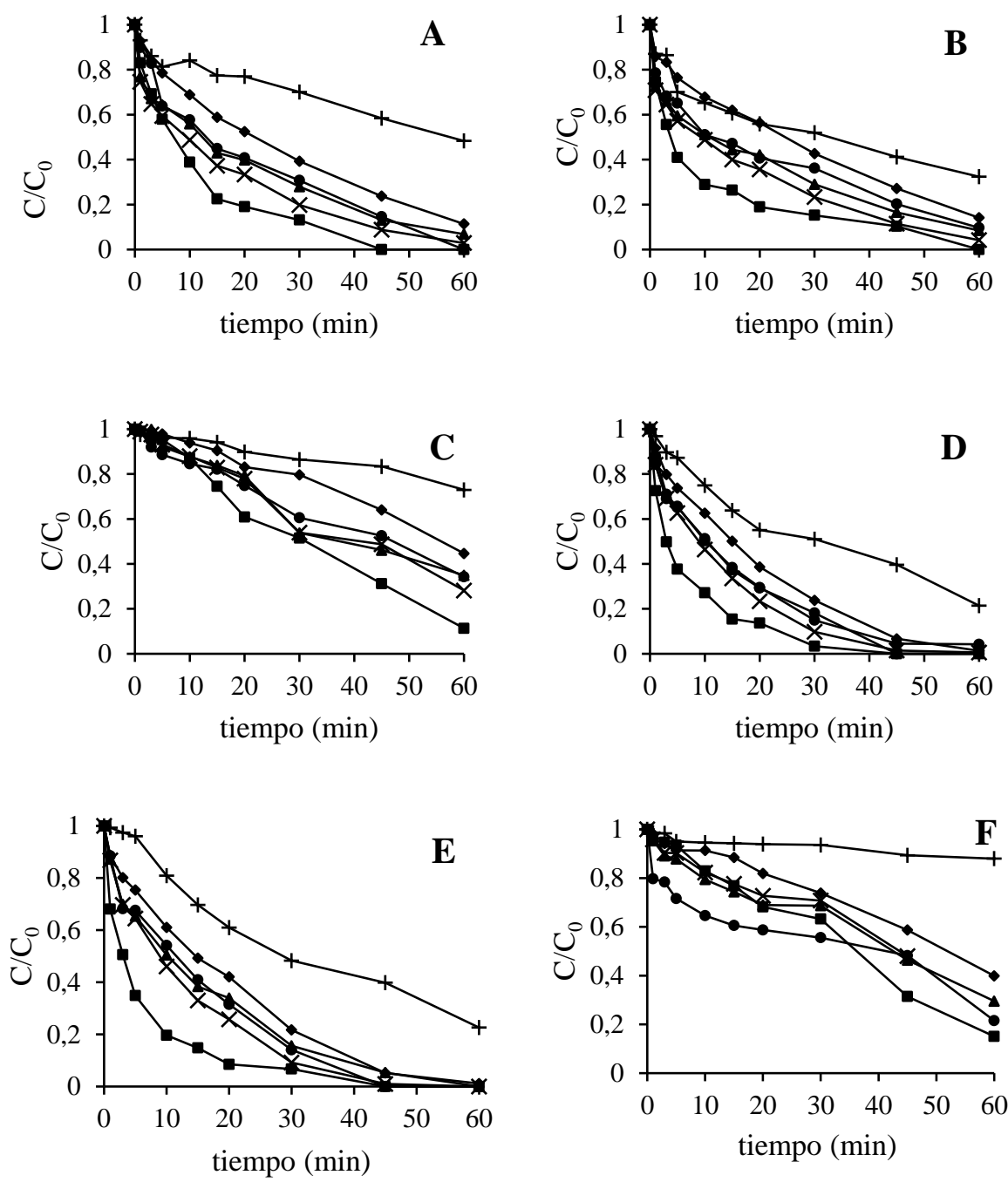

Figura 4.1.4-2. Degradación de la mezcla de contaminantes con la adición de las diferentes STH. A: MH, B: MHF, C: MHF-1A, D: MH-D, E: MHF-D, F: MHF-1A-D. Condiciones experimentales: [CEs] $5 \mathrm{mg}$

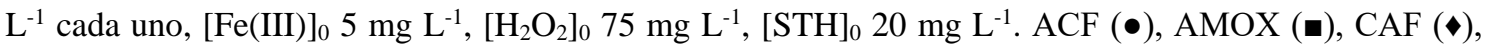
$\mathrm{ACP}(+), \operatorname{CBZ}(\mathrm{x}), \mathrm{CLOF}(\mathbf{\Lambda})$.

Se observa que mediante la adición de las STH (a excepción del residuo fermentado un año: MHF-1A y MHF-1A-D), tas 1 hora de tratamiento se eliminan todos los contaminantes excepto el ACP, quedando presente en la disolución aproximadamente un $20 \%$ de la cantidad inicial; estos resultados están de acuerdo con los porcentajes de degradación obtenidos por Gomis et al., 2014 y Gomis et al., 2015. El ACP se usa generalmente como contaminante modelo debido a que es un pesticida muy recalcitrante (Arzate et al., 2017). Klamerth et al., 2011 estudiaron diferentes agentes complejantes de Fe en proceso foto-Fenton para la degradación de una mezcla de contaminantes (entre los que se encontraban CBZ, CAF y ACF), concluyendo que la adición de $10 \mathrm{mg} \mathrm{L}^{-1}$ de SH a pH cercano a 5 conseguía degradar los contaminantes en tiempos de tratamiento 
razonables. Si se comparan los resultados de degradación obtenidos con el uso de las STH dializadas y no dializadas, se observan mejores tiempos de degradación en el caso de las STH dializadas (MH-D y MHF-D), contrariamente a lo obtenido en el trabajo de GarcíaBallesteros et al., 2018. Debido a estos resultados, se decide repetir los experimentos adicionando la misma cantidad de carbono en lugar de la misma cantidad de STH. La Figura 4.1.4-3 muestra las degradaciones para el uso de las STH fermentadas un mes (MHF y MHF-D) con la misma cantidad de carbono en ambos casos (20 $\mathrm{mg} \mathrm{L}^{-1}$ de C). Se observan mejores resultados de degradación para el uso de las STH no dializadas (A), por lo que se concluye que no es necesario realizar el proceso de diálisis para las STH.
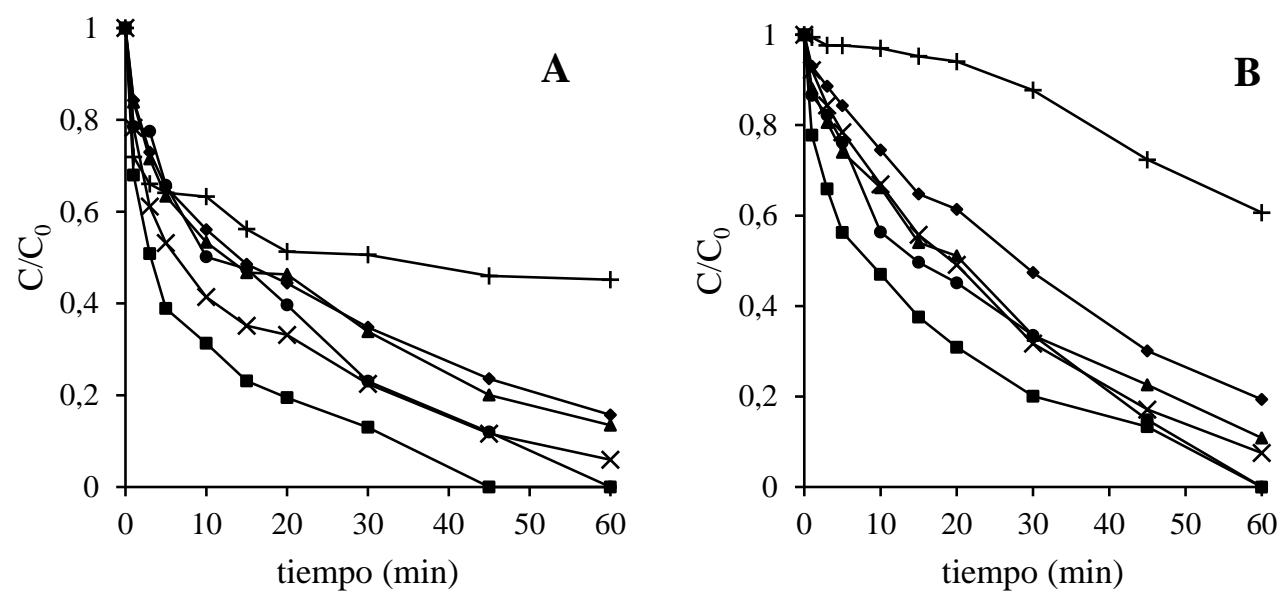

Figura 4.1.4-3. Degradación de la mezcla de contaminantes frente al tiempo. Condiciones experimentales: [CEs $]_{0} 5 \mathrm{mg} \mathrm{L}^{-1}$ cada uno, [Fe(III) $]_{0} 5 \mathrm{mg} \mathrm{L}^{-1},\left[\mathrm{H}_{2} \mathrm{O}_{2}\right]_{0} 75 \mathrm{mg} \mathrm{L}^{-1}$, [STH $]_{0} 20 \mathrm{mg} \mathrm{L}^{-1} \mathrm{de} \mathrm{C}, \mathrm{pH}_{0}$ 5. A: MHF, B: MHF-D. ACF $(\bullet), \operatorname{AMOX}(\bullet), \operatorname{CAF}(\bullet), \operatorname{ACP}(+), \operatorname{CAR}(\times), \operatorname{CLOF}(\boldsymbol{\bullet})$.

De forma complementaria a las medidas y seguimiento de la degradación de los contaminantes por HPLC, también se realizaron medidas de fluorescencia de las diferentes muestras tomadas durante los tratamientos. La fluorescencia es una técnica muy útil para estudiar químicamente muestras complejas que contengas MOD (Wünsch et al., 2019). Las matrices de excitación emisión (EEMs) se han combinado con PARAFAC para obtener más información del proceso de degradación de los contaminantes en presencia de las STH. EEM-PARAFAC se basa en la descomposición de las EEM medidas en sus diferentes componentes químicos, que pueden asociarse posteriormente con familias de compuestos y sus fluoróforos (García-Ballesteros et al., 2019). Sirve para obtener más información de la fracción orgánica contenida en matrices de agua complejas con presencia de MOD (McKnight et al., 2001; Stedmon et al., 2003; Stedmon \& Bro, 2008). Las EEM medidas nos facilitan las huellas de cada componente químico o cromóforo principal presente en la muestra. En el caso de las EEMs de 
muestras con contenido de materia orgánica los análisis publicados por otros autores suelen ser análisis de dos a cuatro componentes y, en ocasiones muestran espectros poco comunes (Bro et al., 2013).

El análisis por PARAFAC se realizó sobre una base de datos conteniendo diferentes tiempos de cada experimento realizado. Los tiempos analizados fueron 0, 15, 30 y 60. El modelo que mejor se adaptaba y que mayor sentido químico tenía respecto al contenido de las muestras fue un modelo de 3 componentes. La Figura 4.1.4-4 muestra las huellas características para cada uno de los componentes.

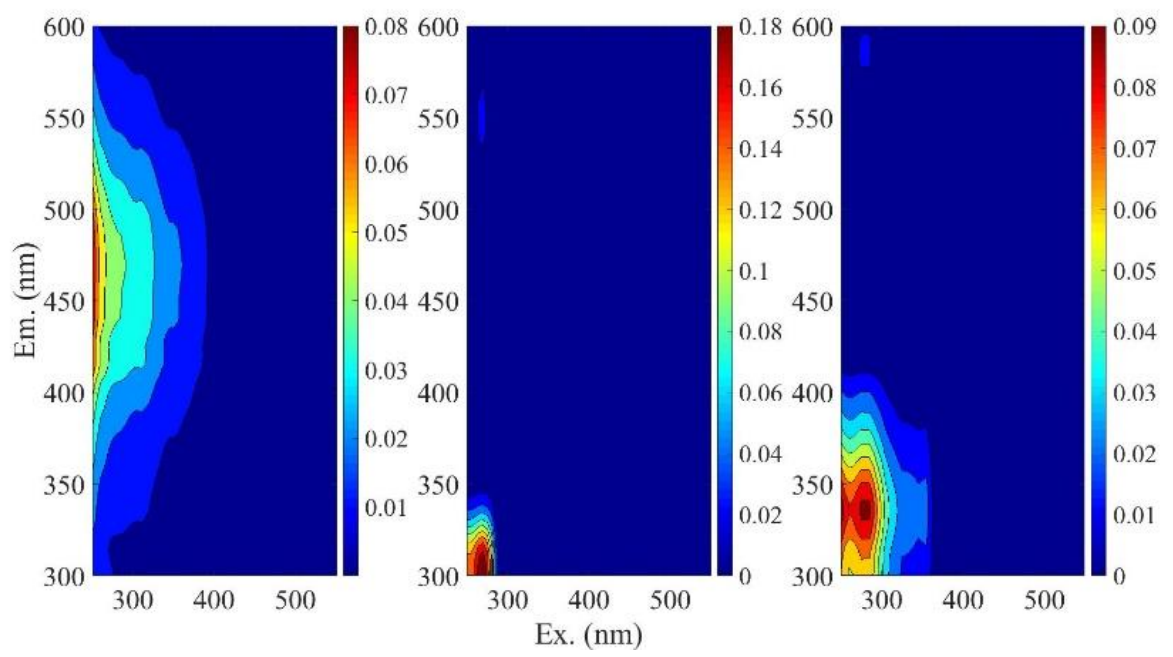

Figura 4.1.4-4. Huellas de los 3 componentes (C1, C2 y $\mathrm{C} 3$ respectivamente) obtenidos aplicando el método de análisis matemático PARAFAC para el conjunto de muestras de los experimentos foto-Fenton en presencia de STH. El eje X corresponde a las longitudes de onda de excitación (250-500 nm) y el eje Y a las longitudes de onda de emisión (300-600 nm).

La huella $\mathrm{C} 1$ se atribuye a las STH. Las señales de fluorescencia de las SH se detectan entre 237-260/400-500 nm, 300-370/400-500 nm y 290-325/370-430 nm de Ex/Em (Hudson et al., 2007; Henderson et al., 2009). En todos los casos los máximos de emisión de han detectado por encima de los $400 \mathrm{~nm}$, lo que indica el origen terrestre de estas STH (Yang et al., 2015) estando en concordancias con el origen del residuo utilizado. El componente $\mathrm{C} 2$ corresponde a la huella de la mezcla de los seis contaminantes emergentes estudiados. Los máximos de Ex/Em para la mezcla de contaminantes son 320/275 nm y concuerda con los máximos para el componente C2. En el caso del componente C3 los máximos de Ex/Em se encuentran entre 270-230/325-350 nm coincidiendo con las regiones de Ex/Em asociadas a las proteínas o moléculas similares al triptófano. Las moléculas similares al triptófano son generalmente las más detectadas de entre los compuestos tipo proteínas (Yang et al., 2015); teniendo en cuenta el origen de partida del 
residuo para la producción de las STH es coherente que haya presencia de proteínas. Em < $380 \mathrm{~nm}(\mathrm{C} 2$ y C3) se asocian generalmente con sustancias alifáticas con anillos aromáticos (Hao et al., 2021) y Em > 380 (C1) con fluoróforos de complejos aromáticos policíclicos y moléculas alicíclicas ricas en grupos carboxílicos (Carstea et al., 2016).
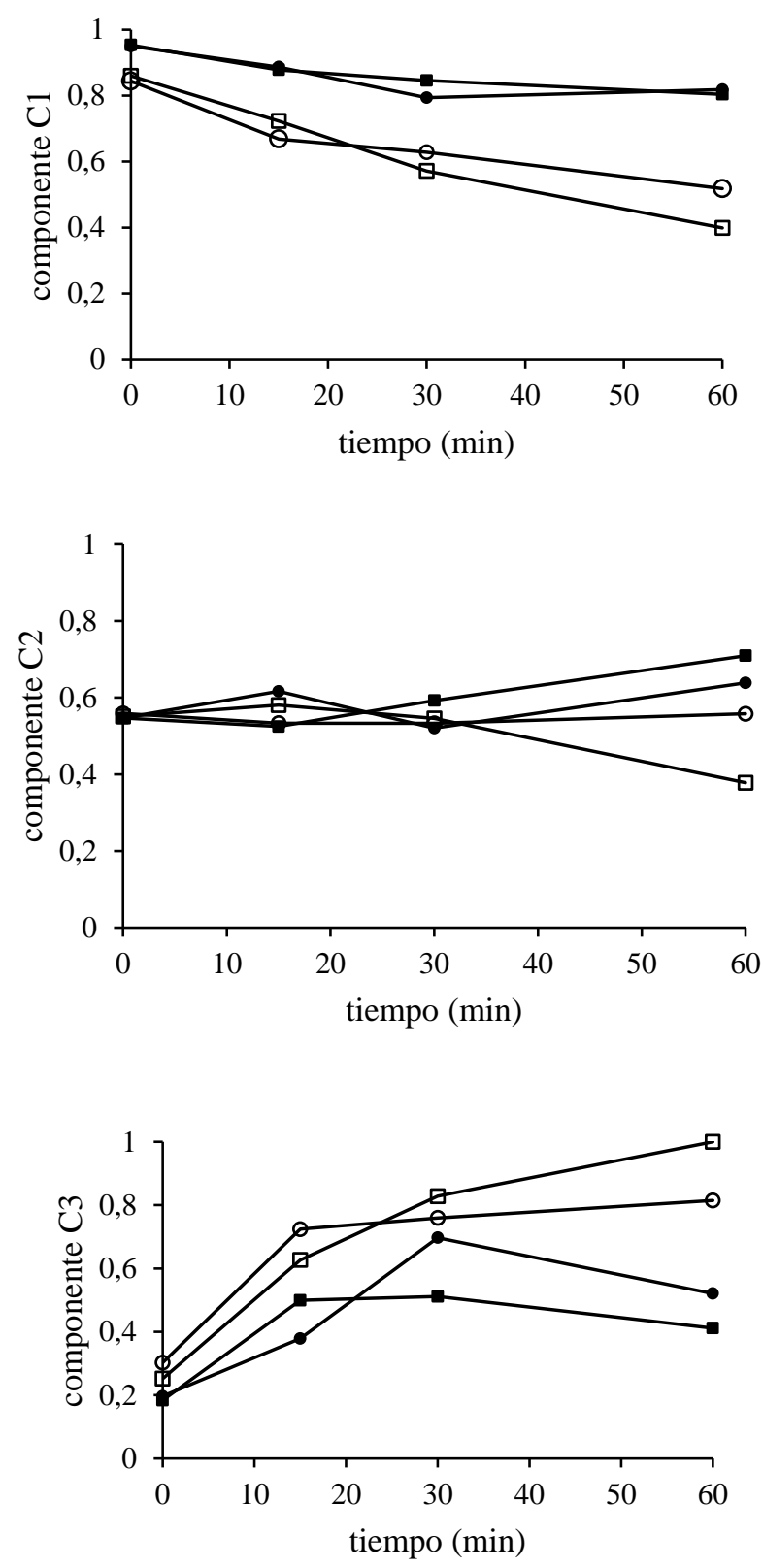

Figura 4.1.4-5. Evolución de los componentes obtenidos por EEM-PARAFAC normalizados frente al tiempo. Foto-Fenton con [MHF] $]_{0} 20 \mathrm{mg} \mathrm{L}^{-1}(\bullet)$, foto-Fenton con [MHF-D] $]_{0} 20 \mathrm{mg} \mathrm{L}^{-1}(\boldsymbol{\bullet})$, foto-Fenton con $[\mathrm{MHF}]_{0} \mathrm{C} 20 \mathrm{mg} \mathrm{L}^{-1}$ (०), foto-Fenton con [MHF-D $]_{0} \mathrm{C} 20 \mathrm{mg} \mathrm{L}^{-1}$ ( $\square$ ). Resto condiciones experimentales: [CEs $]_{0} 5 \mathrm{mg} \mathrm{L}^{-1}$ cada uno, [Fe(III)]0 $5 \mathrm{mg} \mathrm{L}^{-1},\left[\mathrm{H}_{2} \mathrm{O}_{2}\right]_{0} 75 \mathrm{mg} \mathrm{L}^{-1}, \mathrm{pH}_{0} 5$.

La Figura 4.1.4-5 muestra la evolución de los distintos componentes normalizados a lo largo del proceso tipo foto-Fenton para los experimentos realizados con la STH 
fermentada un mes, sustancia seleccionada, puesto que es con la que se han obtenido mejores resultados y con la que se ha estudiado la adición de la misma cantidad de carbono. En el caso del componente C1 no se observan grandes diferencias a lo largo del proceso, pero sí entre las STH dializadas y no dializadas. Las no dializadas sufren menos variaciones, manteniéndose estables. Esta tendencia nos indica que no experimentan oxidación durante el proceso y, por tanto, se encontrarían complejando el hierro. El componente $\mathrm{C} 2$ no sufre cambios a lo largos del proceso oxidativo; este componente hacía referencia a la mezcla de contaminantes. Aunque en el seguimiento por HPLC sí se observa la degradación de los compuestos de partida, es muy probable que los intermedios de reacción formados aún estén presentes en la disolución. Por último, el componente C3 experimenta un incremento conforme transcurre el tiempo de tratamiento, más acusado en el caso de las STH dializadas. Este componente está relacionado con aminoácidos y en el caso de las STH dializadas al no contener sales puede ser que estén presentes en mayor proporción.

Con las pruebas realizadas en este capítulo se concluye que no es necesario someter el residuo seleccionado para la extracción de las STH a ningún tiempo de fermentación. 
Resultados y discusión 


\subsection{EVALUACIÓN DE LA TOXICIDAD DE CUATRO CONTAMINANTES EMERGENTES CONTENIDOS EN LA DIRECTIVA 2013/39/CE TRATADOS POR PROCESO TIPO FOTO-FENTON EN CONDICIONES DE pH PRÓXIMAS A LA NEUTRALIDAD.}

\subsubsection{Introducción}

Los procesos de oxidación avanzada (POAs) se han utilizado para la eliminación de contaminantes presentes en las aguas residuales, especialmente para la eliminación de contaminantes de preocupación emergente, pesticidas o fármacos (García-Ballesteros et al., 20016; Ribeiro et al., 2015). El proceso foto-Fenton (Apartado 1.2.2.2) es uno de los PAOs más utilizados, basado en la utilización de sales de hierro que catalizan la descomposición del peróxido de hidrógeno dando lugar a los radicales hidroxilo, que son no selectivos y tienen un potencial de oxidación de $2.8 \mathrm{~V}$, que junto a la aplicación de radiación solar constituyen un buen sistema para la eliminación de compuestos orgánicos persistentes (Pignatello et al., 2006). Como se ha explicado, el principal inconveniente de este proceso es la necesidad de llevarlo a cabo a $\mathrm{pH}$ ácidos ( $\mathrm{pH}$ 2.8) para evitar la formación de especies no activas de hierro como óxidos e hidróxidos de hierro (SantosJuanes et al., 2017). Esta necesidad de pH ácido puede solventarse por la adición de sustancias químicas capaces de formar complejos fotoactivos con el hierro manteniéndolo en disolución y, por tanto, disponible para la reacción. La materia orgánica disuelta (MOD), como pueden ser los ácidos húmicos (AH) y los ácidos fúlvicos (AF), son capaces de formar bajo radiación especies reactivas y así oxidar contaminantes (Tixier et al., 2003; Guerard et al., 2009) y a su vez, han demostrado ser buenos complejantes de metales como el hierro (García-Ballesteros et al., 2017). Con estas premisas, el uso de otras macromoléculas con características similares como las sustancias tipo húmicas (STH) puede ayudar a la degradación de compuestos orgánicos aplicando proceso fotoFenton a pH más neutros (Gomis et al., 2014). Las STH como se ha mencionado anteriormente, pueden ser extraídas de diferentes tipos de residuos como los residuos sólidos urbanos o residuos agrícolas, fomentando su revalorización y la economía circular de acuerdo con los objetivos de la Unión Europea (COM/2017/033). En este contexto, García-Ballesteros et al., 2018 extrajeron STH del residuo de la producción del aceite de oliva, lo cual resulta muy interesante en los países mediterráneos donde se produce gran cantidad de aceite de oliva y por consiguiente gran cantidad de residuos derivados de esta actividad. Por otro lado, es importante conocer la biocompatibilidad de estos residuos en 
el tratamiento fotoquímico, por lo que el monitoreo de la toxicidad mediante diferentes ensayos toxicológicos resulta interesante, de acuerdo con los requerimientos europeos (Directiva 91/689/CEE).

En este capítulo se van a abordar por tanto dos objetivos, el primero es la capacidad complejante de STH de diferente tamaño molecular (> $300 \mathrm{kDa}, 300-150 \mathrm{kDa}$ y $150-50$ $\mathrm{kDa}$ ) extraídas del residuo de la producción del aceite de oliva y su acción en el proceso de degradación de los contaminantes seleccionados y por otro lado, se va a realizar el seguimiento y evaluación de la toxicidad y los cambios que en ella se producen durante el tratamiento, teniendo en cuenta la importancia en la selección del ensayo de toxicidad y los mecanismos de actuación de cada uno de los contaminantes sobre los diferentes organismos. De ahí la importancia de no confiar en los resultados toxicológicos de un único ensayo sino en la realización de ensayos de toxicidad sobre diferentes organismos pertenecientes a diferentes niveles de la cadena trófica. Para el presente caso de estudio se han seleccionado los siguientes: la bacteria Alivibrio fischeri, el alga Pseudokirchneriella subcapitata, el crustáceo Daphnia magna, la lombriz de tierra Eisenia fetida y, las dos líneas celulares HEK y N2a.

El objetivo final es la determinación de la actuación de las STH adicionadas en el proceso foto-Fenton como agentes complejantes del hierro y su capacidad para llevar el proceso a pHs más próximos a la neutralidad, prestando especial atención a la posible toxicidad derivada de su adición a la disolución y de la evolución del proceso. Para ello, se han seleccionado cuatro contaminantes emergentes contenidos en las Directivas europeas 2008/105/CE y 2013/39/CE como sustancias prioritarias para el desarrollo de tecnologías eficientes en su degradación. Los cuatro contaminantes diana pertenecen a diferentes familias: la terbutrina (TBT) es un herbicida perteneciente a la familia de las triazinas, el diclofenaco (DCF) es un antiinflamatorio, el clorfenvinfos (CVF) es un insecticida y el pentaclorofenol (PCP) es un desinfectante ampliamente utilizado en la industria textil y en el tratamiento de la madera, así como en otros sectores industriales (Ribeiro et al., 2015).

Estos contaminantes emergentes pueden afectar a diferentes organismos a muy bajas concentraciones, por lo que para los ensayos de toxicidad se han tomado muestras a distintos tiempos de tratamiento para comprobar si el proceso foto-Fenton es capaz de 
eliminar los compuestos seleccionados, así como sus intermedios de reacción sin causar daños en el medio ambiente en caso de descarga de las aguas.

\subsubsection{Extracción y caracterización de las STH}

La extracción de STH se realiza a partir del mismo tipo de residuo sólido que en el Capítulo 1 (alpechín procedente de almazara de Millena, Alicante) y de acuerdo con lo descrito en el Apartado 3.2, pero en este caso no se somete el residuo a ningún tiempo de fermentación, (a la vista de los resultados del capítulo anterior). Puesto que en esta ocasión se busca confirmar la influencia del tamaño de las STH en el proceso foto-Fenton, el residuo se filtra por membranas de diferente tamaño de poro: $300 \mathrm{kDa}, 150 \mathrm{kDa}$ y 50 kDa, obteniéndose así tres fracciones o tamaños de STH > 300 kDa, 300-150 kDa y 150$50 \mathrm{kDa}$. Se empieza el proceso de filtración de la membrana de mayor tamaño a la de menor tamaño, y el permeado (PM) de cada filtración pasa al tanque de alimentación del siguiente filtrado. De cada tamaño de STH se toma una parte y se somete a diálisis siguiendo el procedimiento descrito anteriormente. De la cantidad inicial de residuo fresco utilizada $(0.125 \mathrm{~kg})$ se obtuvieron un total de $53.22 \mathrm{~g}$ de STH de los tres tamaños (Tabla 4.2.2-1).

Tabla 4.2.2-1. Cantidad en gramos obtenida de cada fracción de STH.

\begin{tabular}{|c|c|}
\hline$>300 \mathrm{kDa}$ & $20.13 \mathrm{~g}$ \\
\hline $300-150 \mathrm{kDa}$ & $9.00 \mathrm{~g}$ \\
\hline 150-50 kDa & $24.09 \mathrm{~g}$ \\
\hline
\end{tabular}

El primer paso para saber si las sustancias extraídas pueden actuar como STH, es su caracterización usando en este caso, como técnicas analíticas: dispersión de luz dinámica (DLS), cromatografía de exclusión por tamaños (SEC), espectroscopía UV-Vis y fluorimetría. Los ácidos húmicos $(\mathrm{AH})$ comerciales de la casa Sigma-Aldrich fueron sometidos también a la caracterización con la finalidad de comparar las características de los STH obtenidos con este comercial.

El peso molecular se determinó por cromatografía de exclusión por tamaños a una concentración de cada una de las fracciones de 20 y $50 \mathrm{mg} \mathrm{L}^{-1}$. Los pesos moleculares se calcularon de acuerdo con los estándares utilizando los tiempos de retención de cada fracción de STH conforme se indica en el Apartado 3.5.9. En la Figura 4.2.2-1 se muestra el cromatograma obtenido, la distribución es similar para todas las STH exceptuando la muestra dializada de la mezcla de las tres fracciones que presenta un 
tiempo de elución mayor. Todas las STH presentan pesos máximos en torno a los 6000 Da, así como los AH de Sigma-Aldrich. La mezcla de las tres fracciones de STH dializadas muestran un peso molecular menor, de 4000 Da. Los valores obtenidos están de acuerdo con los obtenidos por Perminova et al., 2003 para sustancias húmicas acuáticas.

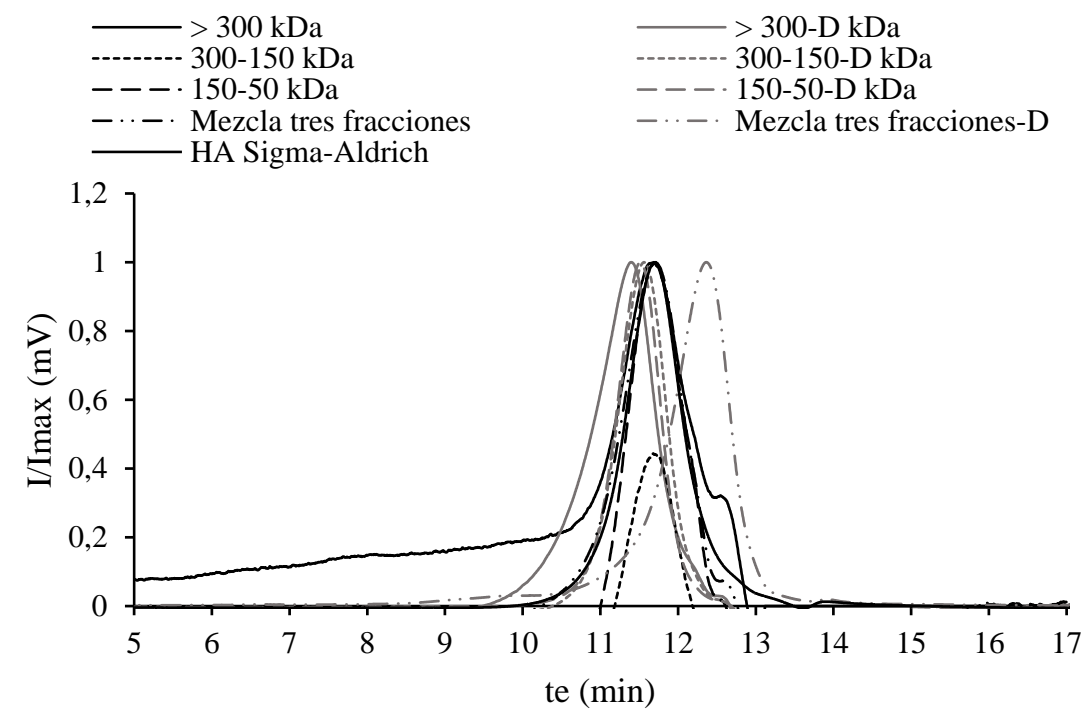

Figura 4.2.2-1. Cromatograma de exclusión por tamaños obtenido para las diferentes fracciones de STH dializadas y sin dializar y para los AH Sigma-Aldrich.

En la Figura 4.2.2-2 se muestran los valores obtenidos para la medida del DLS, que muestra el radio hidrodinámico de las partículas. Las medidas se realizaron a una concentración de sustancias de $3 \mathrm{~g} \mathrm{~L}^{-1}$ a $50 \mathrm{mg} \mathrm{L}^{-1}$ y se calculó la media de los valores. Todas las fracciones se encuentran entre los 290-450 nm. Avetta et al., 2015 obtuvieron valores más bajos en la caracterización por la misma técnica de STH provenientes de residuos sólidos urbanos $(135 \mathrm{~nm})$. Pero, en cualquier caso, estos valores están en concordancia con los obtenidos por García-Ballesteros et al., 2018 que obtuvieron valores de 420 y $380 \mathrm{~nm}$ para STH sin dializar y dializadas respectivamente trabajando con el mismo tipo de residuos de partida para la obtención de las STH. 


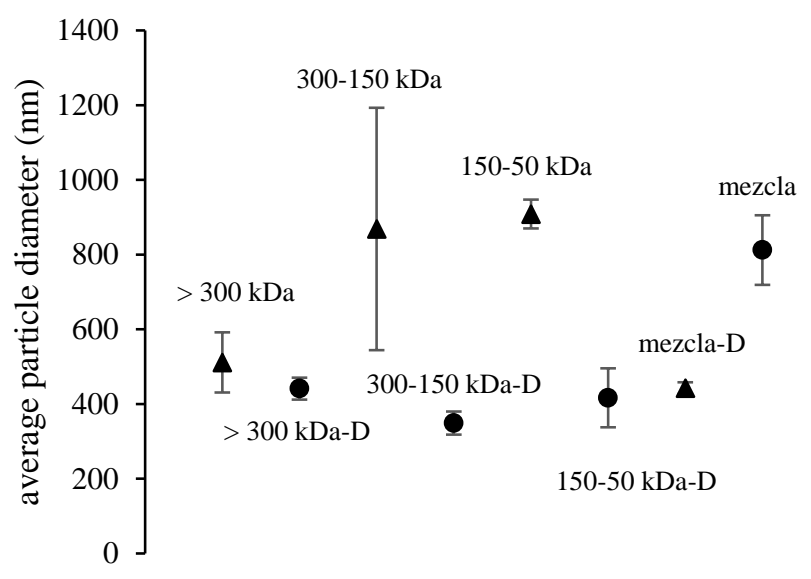

Figura 4.2.2-2. Valores de DLS para las diferentes fracciones de STH dializadas $(\bullet)$ y $\sin$ dializar $(\mathbf{\Lambda})$.

Se realizó caracterización espectroscópica con la finalidad de obtener más información sobre la naturaleza de las sustancias obtenidas. Para ello se prepararon disoluciones a $\mathrm{pH}$ 5 y a concentración $20 \mathrm{mg} \mathrm{L}^{-1}$ de cada una de ellas y se realizó un barrido de 200 a 700 $\mathrm{nm}$ cada $5 \mathrm{~nm}$. Del barrido obtenido se calcularon los valores $\mathrm{E}_{2} / \mathrm{E}_{3}\left(\mathrm{Abs}_{250} / \mathrm{Abs}_{365}\right), \mathrm{E}_{4} / \mathrm{E}_{6}$ (Abs465/Abs665) y SUVA254, parámetros ampliamente utilizados para la caracterización de materia orgánica (García et al., 2019; Matilainen et al., 2011). Tanto esos valores como los de absorbancia a longitudes de onda específicas (250, 254, 280, 300, 365, 400, 436 y, $465 \mathrm{~nm}$ ) son útiles para la caracterización de la MOD (Spencer et al., 2007; Hur et al., 2006; Korshin et al., 2009). Las diferentes longitudes de onda específicas se pueden asociar con diferentes cromóforos. Por ejemplo, la medida obtenida a $220 \mathrm{~nm}$ se atribuye a grupos aromáticos y carboxílicos, mientras que la absorbancia medida a $254 \mathrm{~nm}$ se relaciona solo con grupos aromáticos con diferentes grados de activación (Korshin et al., 2009). Los valores calculados se muestran en la Tabla 4.2.2-2. El ratio $\mathrm{E}_{2} / \mathrm{E}_{3}$ está relacionado con el peso molecular y con la aromaticidad, y se usa como índice de humificación, así como el ratio E4/E6 (Peauravori \& Pihlaja, 1997). Cuanto mayor es el valor $\mathrm{E}_{2} / \mathrm{E}_{3}$ obtenido, menor es la aromaticidad y peso molecular de la sustancia. 
Tabla 4.2.2-2. Valores espectroscópicos obtenidos para cada una de las STH. Se muestran los valores $\mathrm{E}_{2} / \mathrm{E}_{3}, \mathrm{E}_{4} / \mathrm{E}_{6}$ y SUVA 254 para cada fracción dializada y sin dializar, así como los valores para los AH comerciales de Sigma-Aldrich.

\begin{tabular}{|c|c|c|c|}
\hline & $\mathbf{E}_{4} / \mathbf{E}_{6}$ & $\mathbf{E}_{2} / \mathbf{E}_{3}$ & SUVA254 \\
\hline$>300 \mathrm{kDa}$ & 2.29 & 2.75 & 2.86 \\
\hline > 300-D kDa & 2.48 & 2.70 & 3.73 \\
\hline $300-150 \mathrm{kDa}$ & 2.78 & 3.13 & 2.40 \\
\hline 300-150-D kDa & 1.69 & 2.55 & 4.48 \\
\hline $150-50 \mathrm{kDa}$ & 3.14 & 3.21 & 1.60 \\
\hline 150-50-D kDa & 3.03 & 2.82 & 5.96 \\
\hline $\begin{array}{l}\text { Mezcla de las tres } \\
\text { fracciones }\end{array}$ & 2.67 & 3.23 & 2.17 \\
\hline HA (Sigma-Aldrich) & 5.57 & 2.72 & 7.22 \\
\hline
\end{tabular}

Los valores obtenidos para los ratios $\mathrm{E}_{2} / \mathrm{E}_{3}$ y $\mathrm{E}_{4} / \mathrm{E}_{6}$ no difieren mucho entre las distintas STH extraídas, pero sí con los valores obtenidos para los AH de Sigma-Aldrich que muestra valores más altos en el caso del ratio $\mathrm{E}_{4} / \mathrm{E}_{6}$, lo que indicaría un mayor peso molecular y mayor aromaticidad de las STH provenientes del residuo de la oliva. En cualquier caso, los valores obtenidos para estas STH están en concordancia con los obtenidos por Uyguner \& Bekbolet, 2005 que compararon espectroscópicamente diferentes tipos de AH. La absorbancia específica a $254 \mathrm{~nm}$ se usa para conocer la presencia de grupos aromáticos (Korshin et al., 2009). En el caso de las STH dializadas se obtienen valores más altos, lo que indicaría mayor grado de aromaticidad, aunque también puede ser debido a la presencia de sales en las no dializadas, que estarían interfiriendo en las transiciones electrónicas. Para poder comparar cuantitativamente este dato, se normaliza utilizando el valor de carbono orgánico disuelto (COD) y se obtiene así el valor SUVA254 (absorbancia UV A254 (1cm) $/ \mathrm{mg} \mathrm{C}^{-1} \mathrm{~L}^{-1}$ ). Este valor específico se relaciona con el origen de la materia orgánica en términos de hidrofobicidad e hidrofilicidad (Matilainen et al., 2011) y con la cantidad de carbono aromático presente (Jung \& Son, 2008). Valores de $\mathrm{SUVA}_{254}>4$ indicarían presencia de materiales aromáticos e hidrofobicidad, mientras que valores de SUVA $254<3$ hacen referencia a materiales principalmente hidrófilos (Edzwald \& Tobiason, 1999). Los valores obtenidos para las STH son diferentes a los de Sigma-Aldrich, indicando que las STH extraídas son principalmente hidrofílicas y las comerciales hidrofóbicas, lo cual estaría en concordancia con los valores $\mathrm{E}_{4} / \mathrm{E}_{6}$ obtenidos, que ponen de manifiesto mayor presencia de grupos aromáticos que en las comerciales, en las que predominan las cadenas alifáticas hidrofóbicas. Los grupos aromáticos son hidrofóbicos, pero al poseer grupos hidroxilo 
aumentan su hidrofília. De este valor podemos deducir que se puede usar una mayor cantidad de STH que de las comerciales sin problemas de solubilidad. Las STH son moléculas complejas y su estructura y características pueden variar entre ellas, pero en cualquier caso los valores obtenidos son similares a los obtenidos por Korshin et al., 1997.

Respecto a las matrices de excitación emisión (EEMs) se consideran una buena herramienta para el análisis de muestras de agua complejas que contengan materia orgánica (Her et al., 2003). Una de sus mayores ventajas es la buena sensibilidad de la técnica (Bieroza et al., 2009; Peiris et al., 2010). Permite obtener el índice de fluorescencia (IF) y el índice de humificación (HIX), que ayudan a identificar la contribución en la formación de las STH terrestre o microbiana (Cory et al., 2010; McKnight et al., 2001) y el grado de humificación respectivamente. En el caso del HIX, este índice se usa como indicador del contenido de SH y a mayores valores, mayor grado de humificación (Ohno, 2002). Los resultados que se obtuvieron para cada una de las STH preparadas y la comercial fueron muy similares, lo que no permitió sacar ninguna conclusión de estos valores.

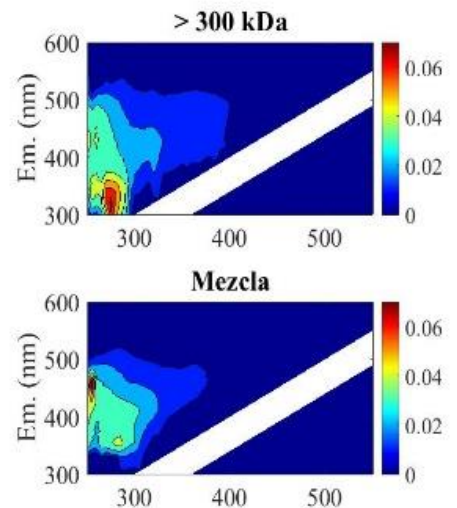

150-50 kDa-D

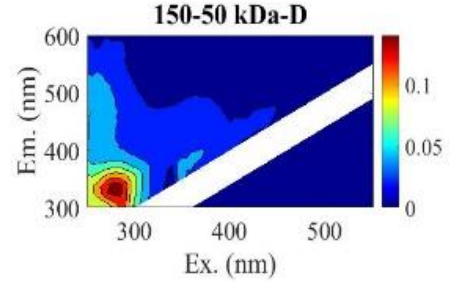

300-150 kDa
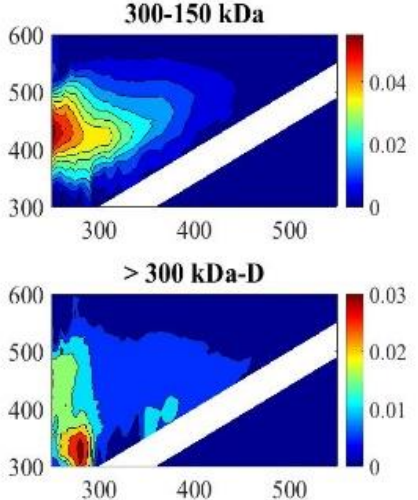

mezcla-D

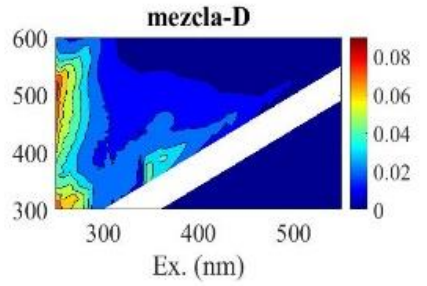

$150-50 \mathrm{kDa}$
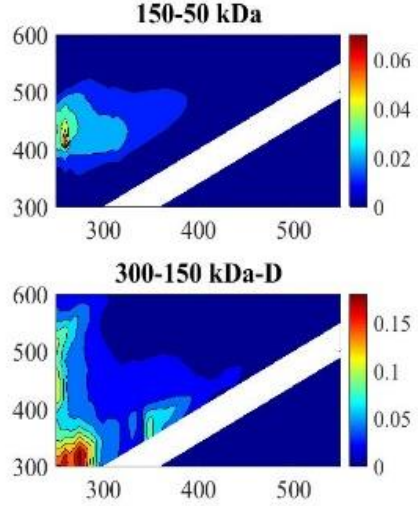

AH Sigma-Aldrich

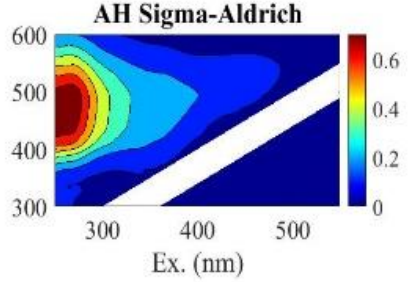

Figura 4.2.2-3. EEMs para las tres fracciones no dializadas, la mezcla de las tres fracciones no dializadas y los AH comerciales de Sigma-Aldrich. El eje X corresponde a las longitudes de onda de excitación (250$500 \mathrm{~nm})$ y el eje Y a las longitudes de onda de emisión (300-600 nm).

La Figura 4.4.2-3 muestra las EEMs medidas para las diferentes STH. Al igual que en el caso de la espectroscopia UV-Vis, no existe mucha diferencia en la señal para las STH 
extraídas, pero sí de éstas con la señal obtenida para los AH de Sigma-Aldrich donde la señal se expande más llegando a los 450-500 nm de excitación. Aunque las matrices obtenidas entre las STH extraídas y las de Sigma-Aldrich difieran, las áreas de máxima intensidad de fluorescencia corresponden con la región asignada a los ácidos húmicos y a las sustancias tipo húmicas en todos los casos, longitudes de onda de Ex/Em 250400/380-550 (Yang et al., 2015) de acuerdo con las obtenidas por García-Ballesteros et al., 2017.

En la matriz obtenida para los AH de Sigma-Aldrich no existe fluorescencia en la región Ex/Em 250-320/300-400 mientras que en las STH extraídas sí. Esta región se atribuye a la presencia de aminoácidos y proteínas (Yang et al., 2015); teniendo en cuenta que la extracción de STH se ha realizado a partir del residuo de la producción de aceite de oliva es coherente. La presencia de aminoácidos y proteínas no parece interferir en la capacidad complejante ya que, las intensidades obtenidas en esta región son diferentes para las distintas fracciones de STH, pero la aplicación en el proceso foto-Fenton de unas y otras no presenta grandes diferencias.

\subsubsection{Aplicación de las STH en proceso foto-Fenton a pH más cercanos a la neutralidad}

Se realizó una primera tanda de experimentos a escala de laboratorio utilizando el simulador solar. Se adicionaron todas las fracciones obtenidas (dializadas y sin dializar) y se comprobó su efecto en el proceso (Figura 4.2.3-1), así como la adición de los AH de Sigma-Aldrich. La concentración inicial de cada uno de los contaminantes fue de $1 \mathrm{mg}$ $\mathrm{L}^{-1}$, se utilizó Fe(III) como fuente de hierro a una concentración de $5 \mathrm{mg} \mathrm{L}^{-1}$, cantidad estequiométrica de peróxido de hidrógeno $\left(2.75 \mathrm{mg} \mathrm{L}^{-1}\right)$ y se adicionó cada una de las diferentes fracciones de STH obtenidas a una concentración inicial de $20 \mathrm{mg} \mathrm{L}^{-1}$. 

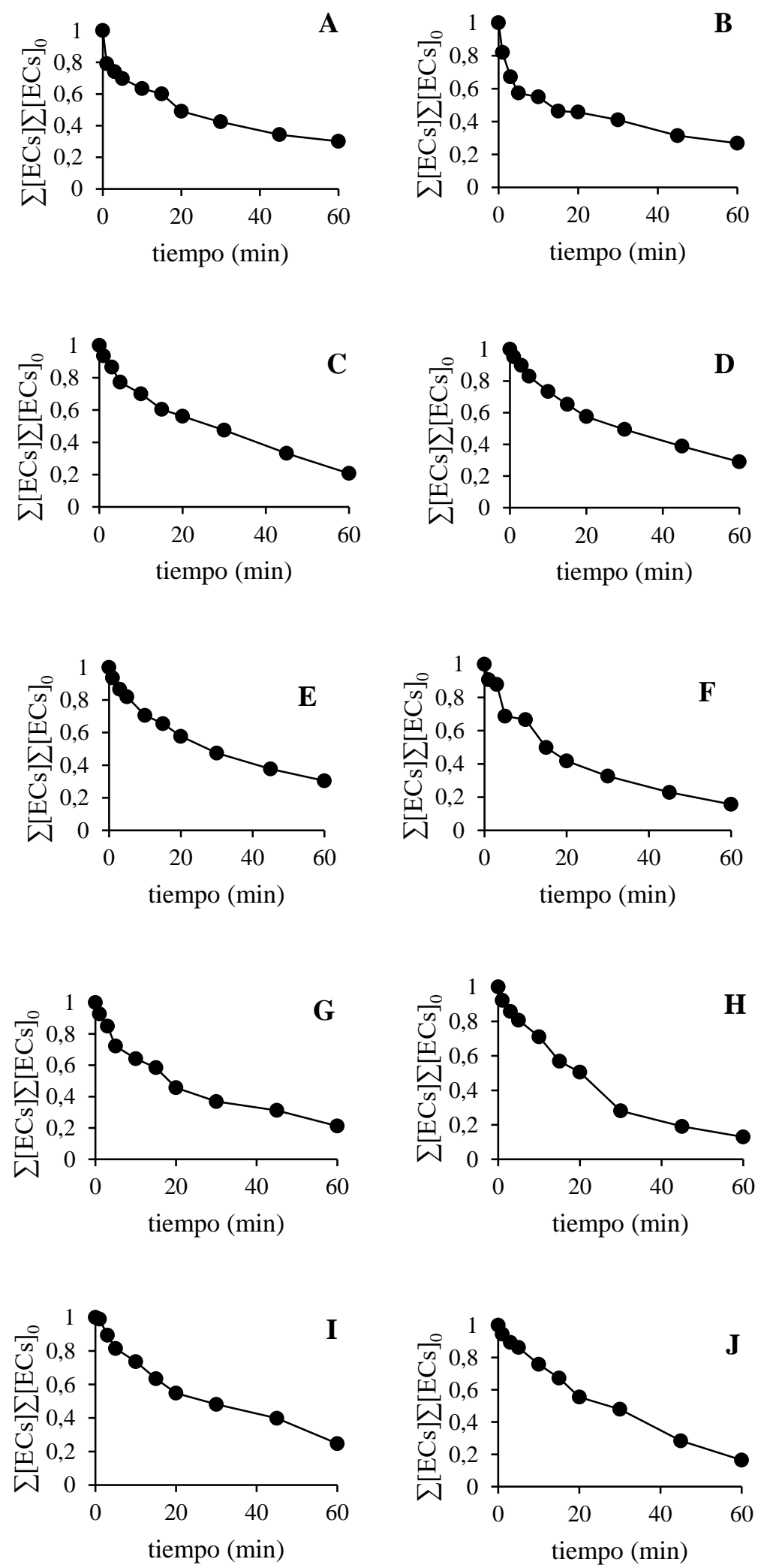

Figura 4.2.3-1. Degradación de la suma de los 4 CEs (TBT, DCF, CVF y, PCP) frente al tiempo usando el simulador solar. Condiciones experimentales: [CEs $]_{0} 1 \mathrm{mg} \mathrm{L}^{-1}$ cada uno, [Fe(III) $]_{0} 5 \mathrm{mg} \mathrm{L}^{-1}$, $\left[\mathrm{H}_{2} \mathrm{O}_{2}\right]_{0} 2.75$ ,g L ${ }^{-1}, \mathrm{pH}_{0}$ 5. Sin adición de $\mathrm{STH}(\mathbf{A}, \mathbf{B}),>300 \mathrm{kDa}(\mathbf{C}, \mathbf{D}), 300-150 \mathrm{kDa}(\mathbf{E}, \mathbf{F}), 150-50 \mathrm{kDa}(\mathbf{G}, \mathbf{H})$, mezcla de las tres fracciones de STH (I, J). Agua MQ (A, C, E, G, I), agua del grifo (B, D, F, H, J). 
Los resultados obtenidos, junto con los del Apartado 4.2.2, muestran que las diferentes fracciones de STH son similares y actúan de la misma manera en el proceso foto-Fenton. La utilización de membranas con diferente tamaño de poro no supone la obtención de STH diferentes, seguramente debido a la capacidad de estas sustancias de formar agregados, por lo que su peso molecular depende no solo del peso molecular de las macromoléculas individuales, sino, de más factores difíciles de controlar. Por ello, la utilización de la mezcla de las tres fracciones es la que va a utilizarse para el resto de los experimentos, ya que es la fracción más representativa.

Los resultados de degradación obtenidos en presencia y ausencia de las STH se muestran en la Figura 4.2.3-2. La comparación entre las STH obtenidas y las comerciales de Sigma-Aldrich no puede hacerse adicionando la misma cantidad total de producto $(20 \mathrm{mg}$ $\mathrm{L}^{-1}$ ), ya que cada una tiene diferentes cantidades de especies inorgánicas (por ejemplo, sales). Por ello se han realizado dos pares de experimentos adicionando la misma cantidad de carbono, a) $20 \mathrm{mg} \mathrm{L}^{-1}$ de AH de Sigma-Aldrich y $53.1 \mathrm{mg} \mathrm{L}^{-1}$ de la mezcla de STH y, b) $20 \mathrm{mg} \mathrm{L}^{-1}$ de la mezcla de STH y $7.6 \mathrm{mg} \mathrm{L}^{-1}$ de los AH de Sigma-Aldrich. Como puede observarse, en todos los casos en los que se han adicionado sustancias húmicas o STH, la eficiencia del proceso oxidativo foto-Fenton es mayor que en ausencia de estas, demostrando la capacidad de mantener el papel catalítico del hierro de todas ellas. Por otro lado, los resultados de degradación obtenidos son muy similares en el uso de unas sustancias u otras, independientemente de su origen y cantidad adicionada. 


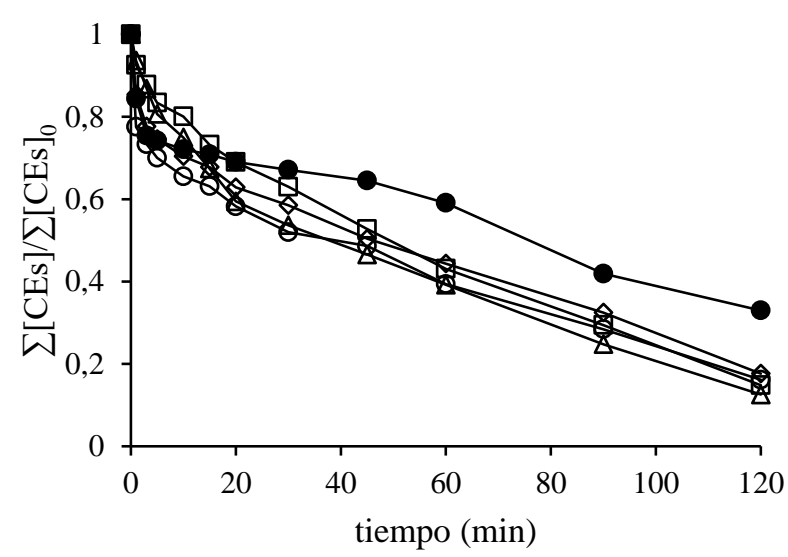

Figura 4.2.3-2. Degradación de la suma de los 4 CEs (TBT, DCF, CVF y, PCP) frente al tiempo utilizando el simulador solar. Condiciones experimentales: [CEs $]_{0} 1 \mathrm{mg} \mathrm{L}^{-1}$ cada uno, [Fe(III) $]_{0} 5 \mathrm{mg} \mathrm{L}^{-1},\left[\mathrm{H}_{2} \mathrm{O}_{2}\right]_{0} 2.75$ $\mathrm{mg} \mathrm{L}^{-1}, \mathrm{pH}_{0}$ 5. (•) sin adición de STH, (口) mezcla de las tres fracciones de $[\mathrm{STH}]_{0} 20 \mathrm{mg} \mathrm{L}^{-1},(\Delta)[\mathrm{AH}$ Sigma-Aldrich $]_{0} 20 \mathrm{mg} \mathrm{L}^{-1}$, (०) mezcla de las tres fracciones de $[\mathrm{STH}]_{0} 53.08 \mathrm{mg} \mathrm{L}^{-1},(\diamond)$ [AH SigmaAldrich $]_{0} 7.54 \mathrm{mg} \mathrm{L}^{-1}$.

Para completar la información acerca de cómo estas sustancias son capaces de complejar el hierro en el proceso foto-Fenton a pH más neutros, se llevaron a cabo experimentos en las mismas condiciones experimentales, pero utilizando agua del grifo y agua proveniente de una estación depuradora de aguas residuales (EDAR), en presencia y ausencia de STH (mezcla de las tres fracciones). En la Figura 4.2.3-3 puede observarse que la eficiencia del proceso en ambos casos es menor que con el uso de agua MQ, existiendo diferencias en el uso de una matriz u otra. En el caso del uso de agua del grifo se observa una mejora en el porcentaje de degradación de los contaminantes en presencia de las STH (40\%) frente al alcanzado en ausencia de estas (25\%), es decir, se observa en mejora en los dos casos, pero menor en el caso del agua del grifo. Este efecto es debido principalmente a que, aunque las STH tienen capacidad de complejar el hierro presente en la disolución, ésta se ve en parte mermada por la interferencia de aniones (por ejemplo, cloruros), disminuyendo la eficiencia del proceso por la formación de complejos menos activos $\left(\mathrm{FeCl}^{2+}\right)$. Por otro lado, en el caso del uso del agua de EDAR se obtiene el mismo porcentaje de degradación para ambos casos (presencia y ausencia de STH). Este efecto puede atribuirse a la presencia de materia orgánica disuelta capaz de complejar el hierro, haciendo innecesaria la adición de STH. La materia orgánica disuelta y las STH compiten por las especies reactivas, disminuyendo el efecto beneficioso de la adición de las STH. 


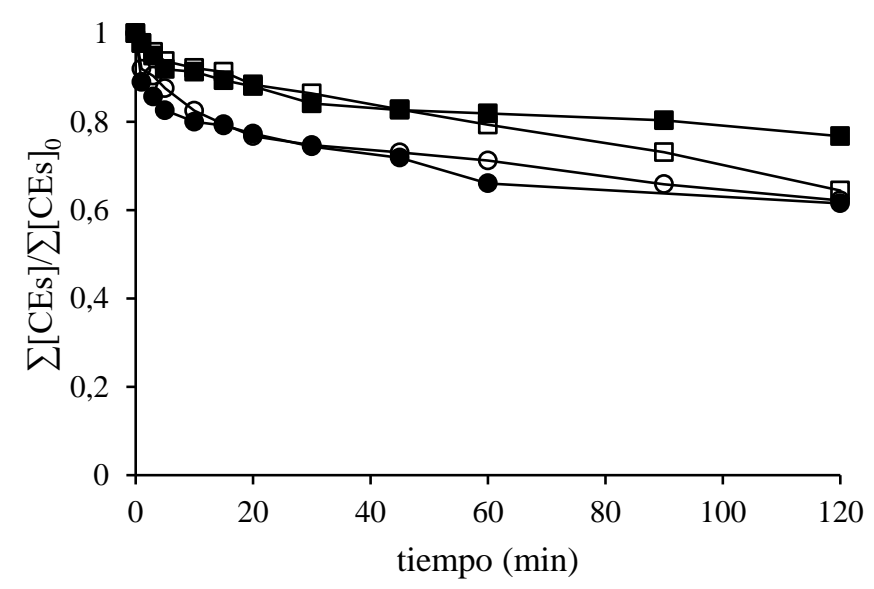

Figura 4.2.3-3. Degradación de la suma de los 4 CEs (TBT, DCF, CVF y, PCP) frente al tiempo utilizando el simulador solar. Condiciones experimentales: [CEs $]_{0} 1 \mathrm{mg} \mathrm{L}^{-1}$ cada uno, [Fe(III) $]_{0} 5 \mathrm{mg} \mathrm{L}^{-1}$, $\left[\mathrm{H}_{2} \mathrm{O}_{2}\right]_{0} 2.75$

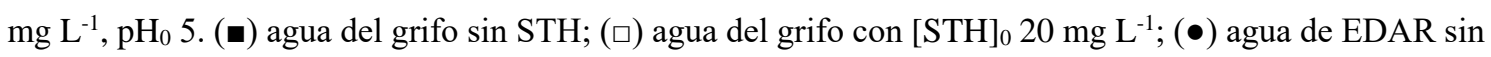
STH; (०) agua de EDAR con [STH $]_{0} 20 \mathrm{mg} \mathrm{L}^{-1}$.

Para comprobar la eficiencia complejante de estas sustancias, se determinó el hierro presente mediante el método normalizado de la o-fenantrolina (ISO 6332) a los tiempos 0, 30, 60 y 120 para cada uno de los experimentos (Figura 4.2.3-4).

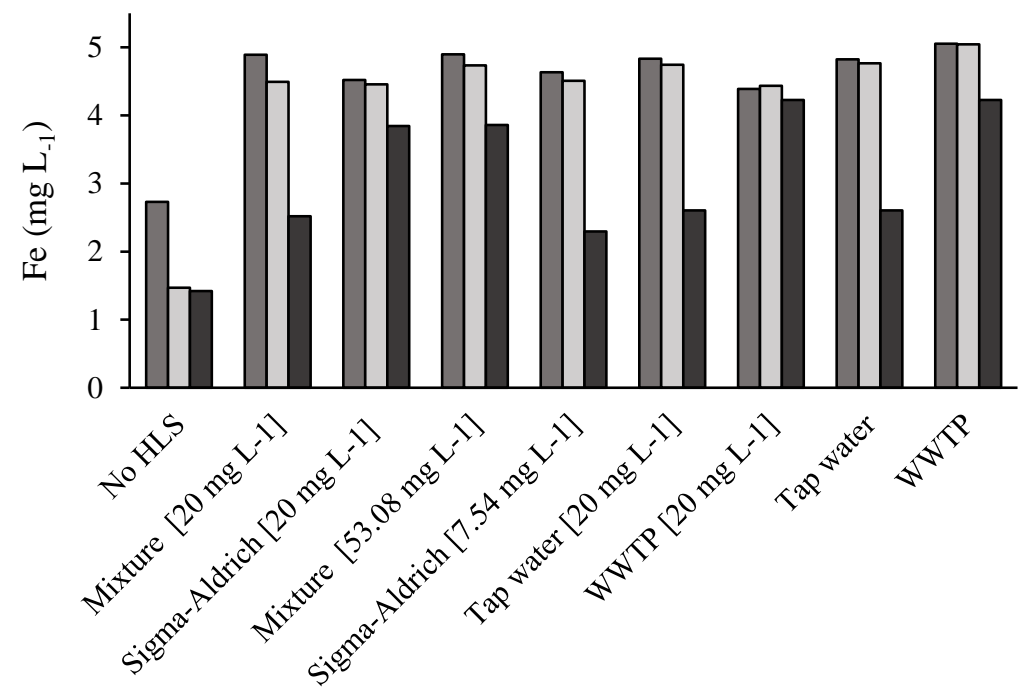

Figura 4.2.3-4. Fe (mg L-1) para cada uno de los experimentos a tiempo 30 minutos (gris oscuro), 60 minutos (gris claro) y 120 minutos (negro).

En todos los casos en que se han adicionado STH, se comprueba que permanece más hierro disponible para la reacción al final del proceso, lo que demuestra la capacidad complejante de estas sustancias en el proceso foto-Fenton a $\mathrm{pHs}$ más próximos a la neutralidad. Cuando la misma cantidad de carbono es adicionada al proceso, no existen diferencias entre la adición de las STH extraídas del residuo de la oliva y los AH 
comerciales de Sigma-Aldrich, lo que estaría en concordancia con los resultados obtenidos en la caracterización. En el caso del uso de agua de EDAR permanece más hierro en disolución al final del proceso comparando con los otros supuestos, lo que se explicaría teniendo en cuenta la presencia de materia orgánica disuelta.

\subsubsection{Experimentos en planta piloto y ensayos de toxicidad}

\subsubsection{Degradación en planta piloto}

Una vez realizados los experimentos a escala de laboratorio y sabiendo que las STH extraídas del residuo de la oliva actúan como agentes complejantes del hierro, se trasladó el proceso a planta piloto (Figura 4.2.4.1-1). Se realizaron ensayos en las condiciones óptimas del proceso foto-Fenton y a pH 5 en presencia y ausencia de las STH. El volumen total de mezcla tratada fue de $5 \mathrm{~L}$ y las condiciones experimentales restantes fueron las mismas que en el caso de los experimentos realizados a escala de laboratorio. Los resultados obtenidos muestran la mejora en la degradación para todos los contaminantes en presencia de las STH, aunque el orden de eliminación se mantiene: $\mathrm{DCF}>\mathrm{PCP} \geq \mathrm{TBT}$ $>$ CVF. Cuando se alcanza un t30w de 90 minutos, el CVF es el único contaminante que permanece en disolución (20\% de la cantidad inicial adicionada) frente al 50\% de CVF y $20 \%$ de TBT que permanece en el experimento llevado a cabo sin adición de STH para la misma radiación.

Esta mejora en la eficiencia del proceso se puede explicar por la capacidad estabilizadora de los complejos formados entre las STH y el Fe, capaces de mejorar su rendimiento. En ausencia de las STH, se forman especies no solubles del hierro como óxidos e hidróxidos, pero por otro lado en presencia de éstas, el consumo de peróxido de hidrógeno es mayor ya que compiten con los contaminantes por las especies reactivas. De hecho, se observa que el consumo de este reactivo se produce a los t30w 30 minutos cuando se han adicionado las STH.

Como puede observarse, el uso de este tipo de sustancias en el proceso tipo foto-Fenton, permite llevar el proceso a pHs más próximos a la neutralidad. Sin la adición de estas STH no se alcanzan los mismos resultados de detoxificación de la muestra de agua. Sin la adición de STH, se consigue la degradación del DCF y del PCP, pero no de la TBT y el CVF, de los cuales se consigue un porcentaje de degradación del 78\% y 57\% respectivamente frente al $100 \%$ y $81 \%$ que se alcanza respectivamente cuando se adicionan las STH extraídas del residuo de la producción del aceite de oliva. 

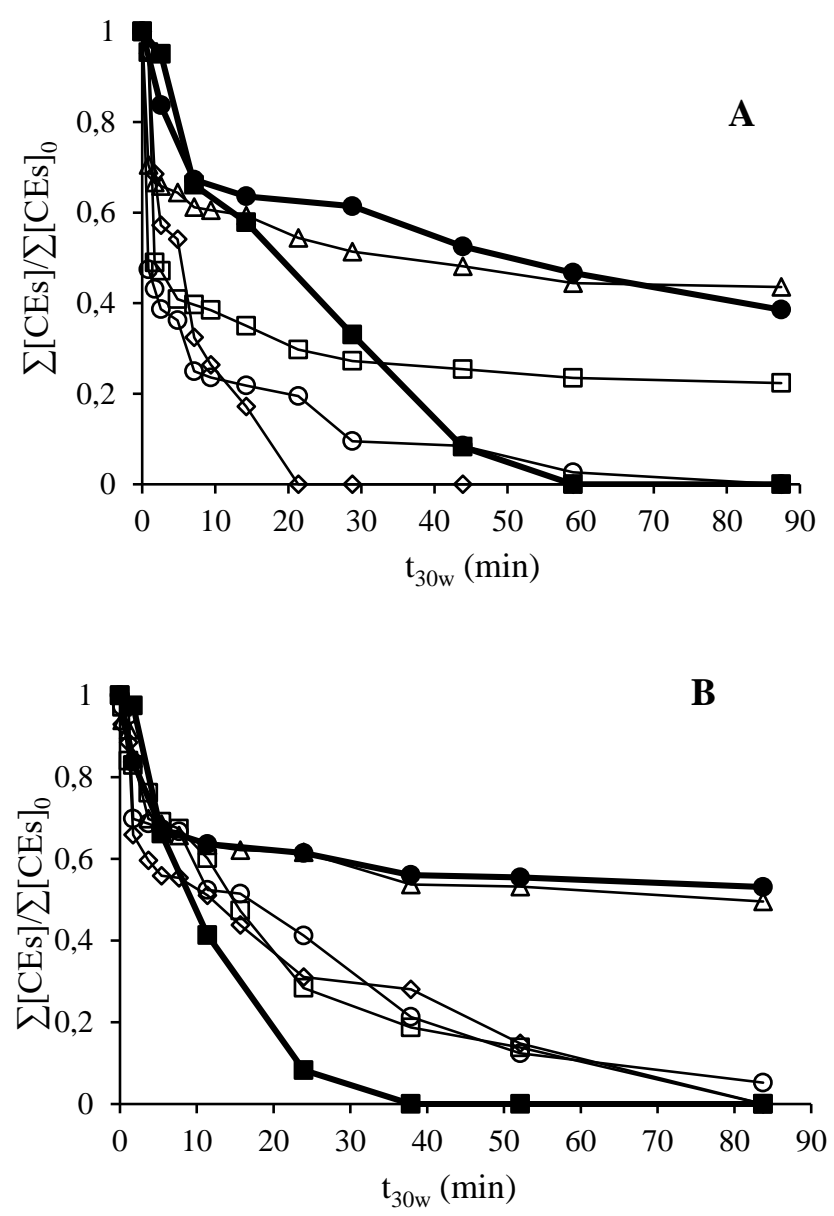

Figura 4.2.4.1-1. Degradación durante el proceso foto-Fenton a $\mathrm{pH}_{0} 5$ en ausencia de $\mathrm{STH}(\mathbf{A})$ y en presencia de STH (B). Condiciones experimentales: [CEs $]_{0} 1 \mathrm{mg} \mathrm{L}^{-1}$ cada uno, $[\mathrm{Fe}(\mathrm{III})]_{0} 5 \mathrm{mg} \mathrm{L}^{-1},\left[\mathrm{H}_{2} \mathrm{O}_{2}\right]_{0}$ $2.75 \mathrm{mg} \mathrm{L}^{-1}$, $[\mathrm{STH}]_{0} 20 \mathrm{mg} \mathrm{L}^{-1}$. TBT $(\square)$, DCF $(\diamond), \operatorname{CVF}(\Delta)$ and PCP $(\circ) ; \mathrm{Fe}\left(\mathrm{mg} \mathrm{L}^{-1}\right)(\bullet)$ y consumo de $\mathrm{H}_{2} \mathrm{O}_{2}(\boldsymbol{\bullet})$. Experimento realizado en planta piloto.

\subsubsection{Ensayos de toxicidad}

Como hemos visto, el uso de este tipo de sustancias como agentes complejantes del hierro ha sido estudiada anteriormente por autores como Gomis et al., 2013; Gomis et al., 2015a; Gomis et al., 2015b; García-Ballesteros et al., 2018 y Caram et al., 2018. Sin embargo, existe una falta de bibliografía en cuanto a la toxicidad derivada de la aplicación de estas sustancias en el proceso foto-Fenton y si este proceso es suficiente para garantizar una buena detoxificación de las muestras sin causar daños ambientales derivados de la posible descarga de las aguas a los cauces naturales.

En primer lugar, se realizaron los ensayos de toxicidad para los compuestos de forma individual y para la mezcla de los cuatro contaminantes, con el fin de determinar si existe un efecto sinérgico o antagónico entre ellos (Figura 4.2.4.2-1). Los resultados se expresan como $\mathrm{CE}_{50}\left(\mathrm{mg} \mathrm{L}^{-1}\right)$, concentración media necesaria para causar respuesta en el 
50\% de la población. Los organismos ensayados han sido: A. fischeri, P. subcapitata, D. magna y, las líneas celulares HEK y N2a.
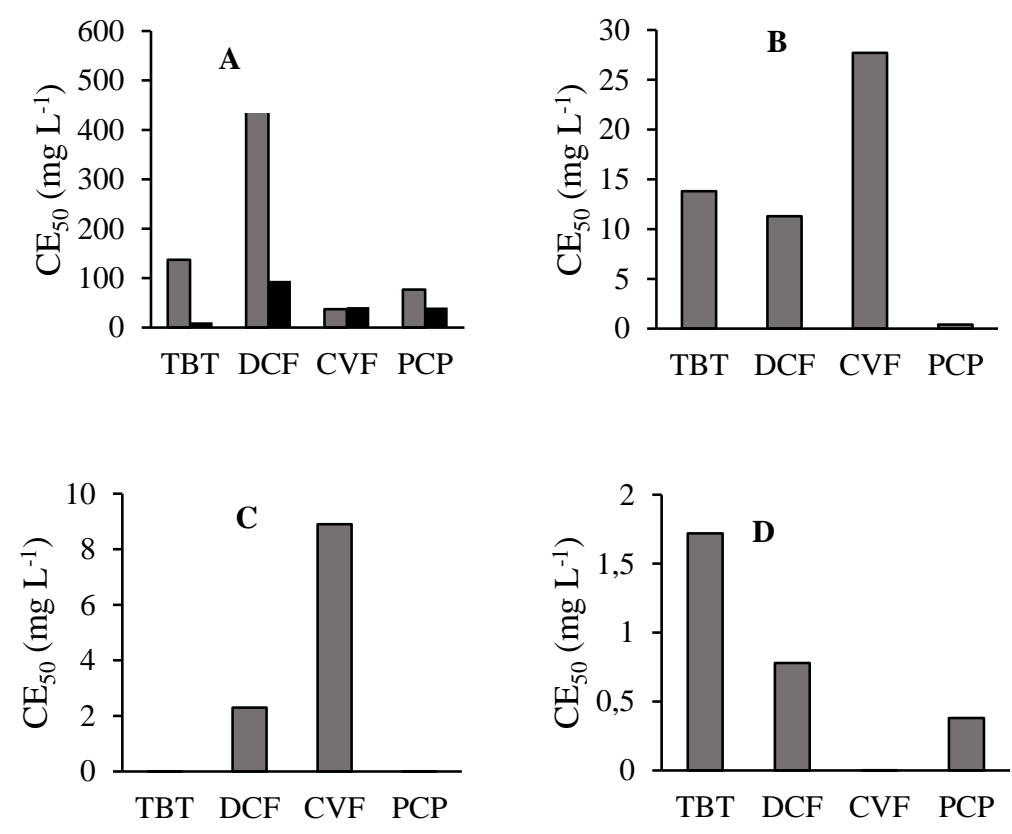

Figura 4.2.4.2-1. Valores de $\mathrm{CE}_{50}\left(\mathrm{mg} \mathrm{L}^{-1}\right)$ para cada uno de los contaminantes seleccionados en cada ensayo toxicológico. A: citotoxicidad. HEK (gris claro), N2a (negro); B: A. fischeri; C: P. subcapitata; D: D. magna (48 h).

El ensayo toxicológico de la bacteria marina A. fischeri es un buen método para evaluar la toxicidad derivada del metabolismo celular (Acevedo-Barrios et al., 2018). El PCP es el compuesto más tóxico para este organismo, con un $\mathrm{CE}_{50}$ de $0.4 \mathrm{mg} \mathrm{L}^{-1}$, aunque se observa una disminución de la bioluminiscencia en todos los contaminantes, $\mathrm{CE}_{50}$ de $13.8,11.3$ y $27.7 \mathrm{mg} \mathrm{L}^{-1}$ para la TBT, DCF y CVF respectivamente.

En el caso del alga $P$. subcapita se observa una alta sensibilidad para el PCP (CE50 $8.90 * 10^{-4} \mathrm{mg} \mathrm{L}^{-1}$ ) seguida de la TBT (CE50 2.10*10 ${ }^{-3} \mathrm{mg} \mathrm{L}^{-1}$ ). Algunos autores (Smith et al., 2004; Cáceres et al., 2008; Fu et al., 2017) han destacado que este organismo presenta una alta sensibilidad a la exposición a xenobióticos, pudiendo ocasionar efectos adversos en la cadena alimenticia, ya que las algas son productores primarios. La TBT es un herbicida, por lo que la elevada toxicidad que presenta estaría justificada.

En el caso del cladócero D. magna, el CVF es el compuesto que presenta mayor toxicidad con diferencia (CE50 3.2*10 $10^{-4} \mathrm{mg} \mathrm{L}^{-1}$ ) comparado con los otros compuestos. El CVF es un insecticida organofosforado neurotóxico que afecta a la enzima acetilcolinesterasa 
(Walker et al., 2001), de entre todos los organismos ensayados D. magna es el único que cuenta con esta enzima, de ahí que los insecticidas pueden afectar más a los vertebrados que a otros organismos.

Para los ensayos de viabilidad celular, todos los compuestos muestran toxicidad. La línea celular HEK es más sensible para el CVF, mientras que la línea celular N2a para la TBT. El DCF muestra una CE50 muy elevada para la línea celular HEK (551 $\left.\mathrm{mg} \mathrm{L}^{-1}\right)$, lo cual puede explicarse teniendo en cuenta que el DCF es un antiinflamatorio usado en humanos y la línea celular HEK proviene de células humanas.

Respecto a la toxicidad observada par la mezcla de contaminantes (Tabla 4.2.4.2-1) $D$. magna muestra los valores más altos de toxicidad seguido del alga $P$. subcapitata. En el caso de la citotoxicidad y de la bacteria A. fischeri los valores obtenidos fueron menores a diluciones 1:1, lo que indica que no habría toxicidad en este caso concreto.

Tabla 4.2.4.2-1. Valores LID y MID para las líneas celulares HEK y N2a y los organismos A. fischeri, $P$. subcapitata y D. magna para la mezcla de contaminantes TBT, DCF, CVF y PCP a una $\left[1 \mathrm{mg} \mathrm{L}^{-1}\right] \mathrm{cada}^{-}$ uno.

\begin{tabular}{ccc}
\hline & LID & MID \\
\hline HEK & $<1: 1$ & $<1: 1$ \\
N2a & $<1: 1$ & $<1: 1$ \\
\hline A. fischeri & $1: 2$ & $1: 2[1: 1-1: 2]$ \\
\hline P. subcapitata & $<1: 32$ & $1: 10[1: 8-1: 11]$ \\
\hline D. magna (24 h) & $1: 512$ & $1: 38[1: 30-1: 48]$ \\
\hline D. magna (48h) & $1: 512$ & $1: 90[1: 85-1: 100]$ \\
\hline
\end{tabular}

Paralelamente, también se han realizado ensayos de toxicidad para la lombriz de tierra $E$. fétida. En este caso las concentraciones iniciales de cada contaminante se han seleccionado de acuerdo con valores bibliográficos: TBT (30 mg L-1), DCF (30 mg L-1), CVF (40 mg L $\left.{ }^{-1}\right)$ y PCP (15 mg L $\mathrm{m}^{-1}$ ), por lo que, para expresar los resultados, éstos se han normalizado para poder compararlos entre ellos. E. fétida muestra repulsión para todos los compuestos (Figura 4.2.4.2-2) sin embrago, generalmente para considerar la respuesta positiva a toxicidad se necesita encontrar al $80 \%$ de los organismos en el compartimento con el suelo control al final del ensayo (Sánchez-Hernández et al., 2006). Este porcentaje solo se ha alcanzado para el caso del herbicida TBT, y para la mezcla de los cuatro compuestos que con una concentración mucho menor teniendo en cuenta las 
iniciales de los compuestos individuales, ha alcanzado el $100 \%$ de repulsión. Esto demostraría el efecto sinérgico de la mezcla. Los porcentajes de respuesta y los valores normalizados se muestran a continuación.
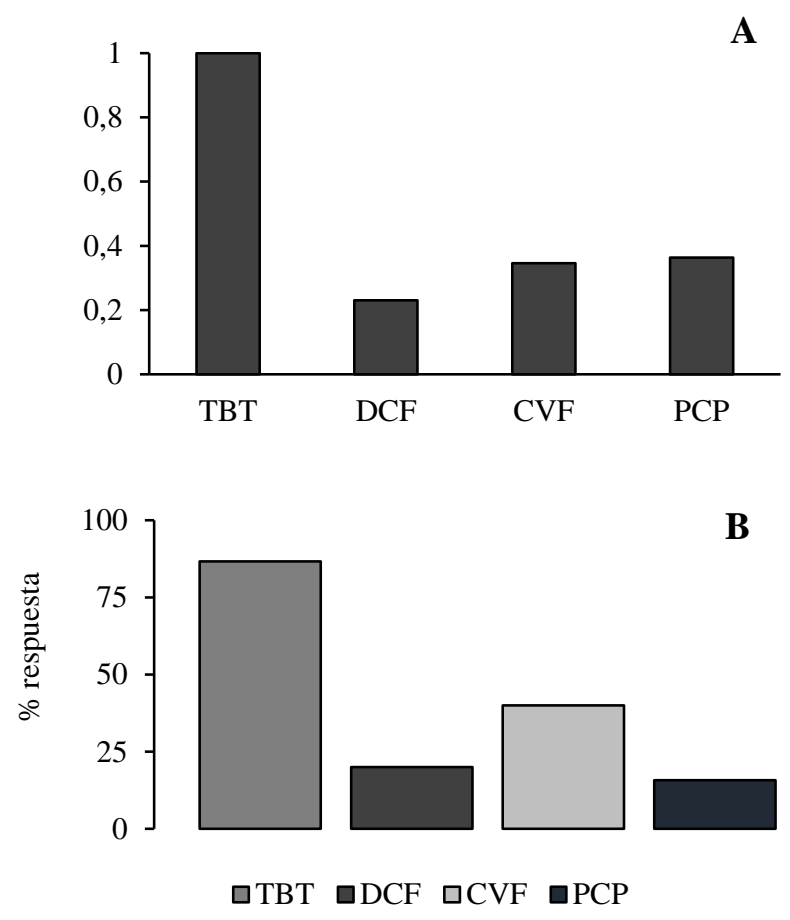

Figura 4.2.4.2-2. Repulsión para los contaminantes TBT, DCF, CVF y, PCP para el organismo E. fétida. $[\mathrm{TBT}]_{0} 30 \mathrm{mg} \mathrm{L}^{-1}$, $[\mathrm{DCF}]_{0} 30 \mathrm{mg} \mathrm{L}^{-1}$, $[\mathrm{CVF}]_{0} 40 \mathrm{mg} \mathrm{L}^{-1}$, [PCP $]_{0} 15 \mathrm{mg} \mathrm{L}^{-1}$. Se muestran (A) los valores normalizados y (B) \% de respuesta.

Los resultados obtenidos para los ensayos toxicológicos a diferentes tiempos de tratamiento y en presencia de las STH se muestran en la Tabla 4.2.4.2-2.

Respecto a ambas líneas celulares y a A. fischeri, no se observa toxicidad al final del tratamiento (valores LID y MID < 1:1). D. magna, en cambio, sí presenta toxicidaden este punto, lo cual es de esperar ya que el insecticida CVF no es degradado del todo al final de el proceso. Si nos fijamos en la tabla, el organismo más comprometido al final del tratamiento es el alga $P$. subcapitata. Rizzo et al., 2009b sugirieron que $P$. subcapitata es más sensible que D. magna cuando se analizan toxicidades de soluciones tratadas fotocatalíticamente. Esta característica de P. subcapitata y el hecho de que quede sin degradar una pequeña parte de PCP al final del proceso lo convierte en el organismo más afectado.

Tabla 4.2.4.2-2. Valores LID y MID para las muestras tomadas a diferentes tiempos de tratamiento $(0,20,50$ y 90 minutos $\mathrm{t}_{30 \mathrm{w}}$ ) para los diferentes organismos seleccionados. Condiciones experimentales: [Fe(III) $]_{0} 5$ 
$\mathrm{mg} \mathrm{L}{ }^{-1},\left[\mathrm{H}_{2} \mathrm{O}_{2}\right]_{0} 2.75 \mathrm{mg} \mathrm{L}^{-1}$, [STH $]_{0} 20 \mathrm{mg} \mathrm{L}^{-1}$, [CEs $]_{0} 1 \mathrm{mg} \mathrm{L}^{-1}$ cada uno, $\mathrm{pH}_{0} 5$ y realizado en planta piloto.

\begin{tabular}{|c|c|c|c|c|c|c|c|c|c|}
\hline & & \multicolumn{4}{|c|}{ Tratamiento sin STH } & \multicolumn{4}{|c|}{ Tratamiento con STH } \\
\hline & & $\mathbf{0}$ & 20 & 50 & 90 & $\mathbf{0}$ & 20 & 50 & 90 \\
\hline & & t30w & t30w & t30w & t30w & t30w & t30w & t30w & t30w \\
\hline \multirow[t]{2}{*}{ HEK } & LID & $<1: 1$ & $<1: 1$ & $<1: 1$ & $<1: 1$ & $1: 3$ & $1: 3$ & $<1: 1$ & $<1: 1$ \\
\hline & MID & $<1: 1$ & $<1: 1$ & $<1: 1$ & $<1: 1$ & $<1: 1$ & $<1: 1$ & $<1: 1$ & $<1: 1$ \\
\hline \multirow[t]{2}{*}{$\mathbf{N} 2 \mathbf{a}$} & LID & $<1: 1$ & $<1: 1$ & $<1: 1$ & $<1: 1$ & $1: 6$ & $1: 6$ & $1: 2$ & $<1: 1$ \\
\hline & MID & $<1: 1$ & $<1: 1$ & $<1: 1$ & $<1: 1$ & $<1: 1$ & $<1: 1$ & $<1: 1$ & $<1: 1$ \\
\hline \multirow[t]{2}{*}{ A. fischeri } & LID & $1: 2$ & $<1: 1$ & $<1: 1$ & $<1: 1$ & $1: 5$ & $1: 8$ & $1: 3$ & $1: 3$ \\
\hline & MID & $1: 2$ & $<1: 1$ & $<1: 1$ & $<1: 1$ & $1: 1.8$ & $1: 0.8$ & $<1: 1$ & $<1: 1$ \\
\hline \multirow{2}{*}{$\begin{array}{c}P . \\
\text { subcapitata }\end{array}$} & LID & $1: 32$ & $1: 8$ & $<1: 1$ & $<1: 1$ & $1: 360$ & $1: 240$ & $1: 240$ & $1: 180$ \\
\hline & MID & $1: 10$ & $1: 2$ & $<1: 1$ & $<1: 1$ & $1: 125$ & $1: 100$ & $1: 100$ & $1: 91$ \\
\hline D. magna & LID & $1: 512$ & $1: 128$ & $1: 128$ & $1: 54$ & $1: 512$ & $1: 256$ & $1: 128$ & $1: 128$ \\
\hline
\end{tabular}

$(24 \mathrm{~h})$

\begin{tabular}{cccccccccc} 
& MID & $1: 38$ & $<1: 1$ & $<1: 1$ & $<1: 1$ & $1: 56$ & $1: 43$ & $1: 32$ & $1: 17$ \\
\hline $\begin{array}{c}\text { D. magna } \\
(48 \text { h) }\end{array}$ & LID & $1: 512$ & $1: 256$ & $1: 128$ & $1: 128$ & $1: 512$ & $1: 256$ & $1: 256$ & $1: 128$ \\
& & & & & & & & & \\
\cline { 2 - 9 } & MID & $1: 90$ & $<1: 1$ & $<1: 1$ & $<1: 1$ & $1: 83$ & $1: 32$ & $1: 14$ & $1: 7$
\end{tabular}

La concentración inicial de contaminantes estudiada es mayor a las que suelen encontrarse en aguas naturales, pero estos resultados ayudan a comprender mejor como pueden afectar diferentes contaminantes si entran al medio ambiente. Teniendo en cuenta que $P$. subcapitata se encuentra en la base de la cadena trófica serían necesarios tiempos de tratamiento más largos, así como, un mayor conocimiento de cómo pueden afectar estas STH a los diferentes organismos presentes en el medio ambiente. 


\subsection{GENERACIÓN DE RADICALES HIDROXILO CON LA UTILIZACIÓN DE SUSTANCIAS TIPO HÚMICAS EN PROCESOS TIPO FENTON}

\subsubsection{Introducción}

Como se ha explicado anteriormente, el proceso Fenton consiste en la aplicación de la combinación de sales de hierro y peróxido de hidrógeno, y ha sido ampliamente utilizado para el tratamiento de aguas residuales debido a su capacidad para oxidar materia orgánica (Pignatello et al., 2006). Aunque el mecanismo de reacción es complejo, se sabe que los radicales $\mathrm{OH}$. juegan un papel fundamental. El proceso Fenton mejora su eficiencia en presencia de radiación en el rango UV-Vis $(\lambda<540 \mathrm{~nm})$ pudiendo así utilizar la radiación solar para acelerar el proceso. En el proceso foto-Fenton hay que tener en cuenta la necesidad de llevar el proceso a pH ácido si se busca el óptimo del proceso foto-Fenton. A pHs por encima de 4 se produce la inactivación del hierro por la formación de óxidos e hidróxidos férricos.

Para evitar esta acidificación y posterior alcalinización del proceso y hacerlo así más fácilmente escalable a escala industrial, a la vez que más económico y sostenible (Pérez et al., 2013) se han propuesto diferentes estrategias que permitan desarrollar el proceso a pHs más cercanos a la neutralidad (Santos-Juanes et al., 2017; Zhang et al., 2019). En particular, el uso de sustancias auxiliares capaces de complejar el hierro cambiando su esfera de activación y mantenerlo en disolución, están ganando atención (Lee \& Sedlack, 2009). Se ha estudiado el uso de diferentes sustancias (Apartado 1.2.2.3.4) como EDTA, EDDS o NTA (Chen et al., 2011; Huang et al., 2012; Klamerth et al., 2012; De Luca et al., 2014) con distintos grados de efectividad. También pueden usarse como agentes complejantes macromoléculas con características químicas similares a las SH (Gomis et al., 2014; Zingaretti et al., 2018). Estas sustancias, están formadas por diferentes grupos funcionales como ácidos carboxílicos, aminas, hidróxilos o amidas, capaces de complejar metales y, en este caso concreto el hierro, de forma eficiente (García-Ballesteros et al., 2017; Sukekava et al., 2018).

Las STH pueden extraerse a partir de diferentes tipos de fuentes como residuos sólidos urbanos o residuos de la producción del aceite de oliva (Montoneri et al., 2011; GarcíaBallesteros et al., 2018). Estas sustancias han demostrado no ser tóxicas para el medio ambiente y capaces de llevar el proceso foto-Fenton a condiciones de $\mathrm{pH}$ más cercanas a la neutralidad (Gomis et al., 2015). Sin embargo, la eficiencia en el tratamiento de este 
complejo Fe-STH no está completamente definida debido a la existencia e intervención de mecanismos con efectos opuestos (Gomis et al., 2015).

Por un lado, las STH son moléculas fotoactivas capaces de generar especies reactivas como oxígeno singlete y radicales hidroxilo (Bianco Prevot et al., 2011) aunque el proceso no es muy eficiente, y solo la adición de grandes cantidades de STH son capaces de alcanzar una considerable degradación de contaminantes (Avetta et al., 2013). No obstante, el complejo Fe-STH ha demostrado ser capaz de incrementar la eficiencia del proceso foto-Fenton a pHs más cercanos a la neutralidad, seguramente debido a su capacidad para generar especies altamente oxidantes como el OH· (García-Ballesteros et al., 2018).

Las STH son moléculas con color, cuya absorbancia en el rango UV-Vis no se puede despreciar. Pueden actuar como filtro para la penetración de la radiación, disminuyendo el número de fotones capaces de llegar a las partes más profundas del reactor. Este hecho va a disminuir previsiblemente la degradación por fotólisis directa de los contaminantes, como también se ha observado con la presencia de ácidos húmicos (Carlos et al., 2012), disminuyendo y limitando la eficiencia del complejo Fe-STH.

Al ser las STH macromoléculas orgánicas, van a interactuar con las especies reactivas que se generan durante el proceso tipo foto-Fenton. De hecho, Gomis et al., 2015 demostraron que estas sustancias sufren oxidación cuando son sometidas a proceso fotoFenton en condiciones cercanas a la neutralidad cambiando su estructura molecular. Por lo tanto, va a existir un proceso competitivo por las especies reactivas por parte de los contaminantes y de las STH, lo que supone un descenso en el porcentaje de degradación de contaminantes conforme se aumenta la concentración de STH presente; además de la necesidad de adicionar mayores cantidades de peróxido de hidrógeno al sistema. Por último, las STH son capaces de mejorar la degradación por proceso foto-Fenton de contaminantes que se encuentran en concentraciones cercanas a su límite de solubilidad (Caram et al., 2018). Esta característica puede ser debida a la capacidad de las STH de formar micelas, atrapando los contaminantes en el interior de las mismas.

Es interesante conocer las especies reactivas que se generan en el sistema Fenton-STH, particularmente la generación del radical $\mathrm{OH}$. Para ello, se usan métodos indirectos de detección de especies reactivas que se formar por reacción del $\mathrm{OH}$. cuando se le aplica radiación (Zhang et al., 2018). Una de estas técnicas es la resonancia paramagnética 
electrónica (EPR), en la cual el complejo que se forma entre el radical OH· y el DMPO registra una señal específica. La EPR se ha utilizado, por ejemplo, en sistemas biológicos para determinar la capacidad de diferentes sustancias de generar radicales $\mathrm{OH} \cdot$ (Hirata \& Fujii, 2006). También se ha empleado para detectar la generación de radicales en procesos de tratamiento de aguas residuales (Su et al., 2017; Liu et al., 2019), particularmente en el sistema foto-Fenton (Fontmorin, et al., 2016; García-Ballesteros et al., 2018; Rutely et al., 2018).

Con todo lo anterior, el objetivo del presente capítulo es estudiar la cantidad de radicales $\mathrm{OH}$ - que pueden generarse y por tanto reaccionar con STH en diferentes condiciones de ensayo. Los experimentos se han realizado en oscuridad para evitar la fotolisis y el efecto de filtro interno por parte de las STH. Posteriormente, los resultados obtenidos por EPR se han trasladado y se ha llevado a cabo experimentos tipo foto-Fenton con la adición de las STH (provenientes de residuos sólidos urbanos) y usando la cafeína (CAF) como contaminante modelo para las degradaciones. Se ha elegido la cafeína porque se sabe que su degradación por fotolisis es despreciable y porque al estar su consumo altamente extendido se encuentra con facilidad en las aguas como contaminante presente (Buerge, et al., 2003).

\subsubsection{Generación de especies reactivas por los complejos Fe(II)-STH y Fe(III)-STH} En primer lugar, se realizaron una serie de experimentos para comprobar la capacidad del $\mathrm{Fe}$ (II) de formar DMPO-OH en presencia de $\mathrm{H}_{2} \mathrm{O}_{2}$, así como la variación en la señal atribuible a este complejo en el tiempo. El pH al cual se realizó el experimento fue pH 5, ya que es el pH más próximo a la neutralidad, determinado en trabajos previos del grupo de investigación, para llevar el proceso foto-Fenton en presencia de STH sin que se pierda mucha eficiencia en el proceso (Santos-Juanes et al., 2017). La cantidad de STH adicionada fue de $20 \mathrm{mg} \mathrm{L}^{-1}$, la de $\mathrm{Fe}$ (II) de $5 \mathrm{mg} \mathrm{L}^{-1}$ y la de $\mathrm{H}_{2} \mathrm{O}_{2}$ de $34 \mathrm{mg} \mathrm{L}^{-1}$, que correspondería a una relación molar $\mathrm{Fe}: \mathrm{H}_{2} \mathrm{O}_{2}$ de 1:10 que según Rutely et al., 2018 es la relación óptima para la generación de radicales hidroxilo por parte de este sistema. La señal obtenida es alta (Figura 4.3.2-1), lo que supone una eficiente generación de radicales hidroxilo bajo estas condiciones. Para comprobar la estabilidad del sistema con el tiempo, se midieron los espectros a diferentes tiempos tras la adición del peróxido de hidrógeno. La intensidad de la señal se normalizó como la media de la altura de los cuatro picos característicos del espectro; las intensidades relativas obtenidas se representaron 
respecto al tiempo. Como se observa en la Figura 4.3.2-2, hay un rápido descenso en la señal, que sería compatible con la inactivación del sistema Fenton.

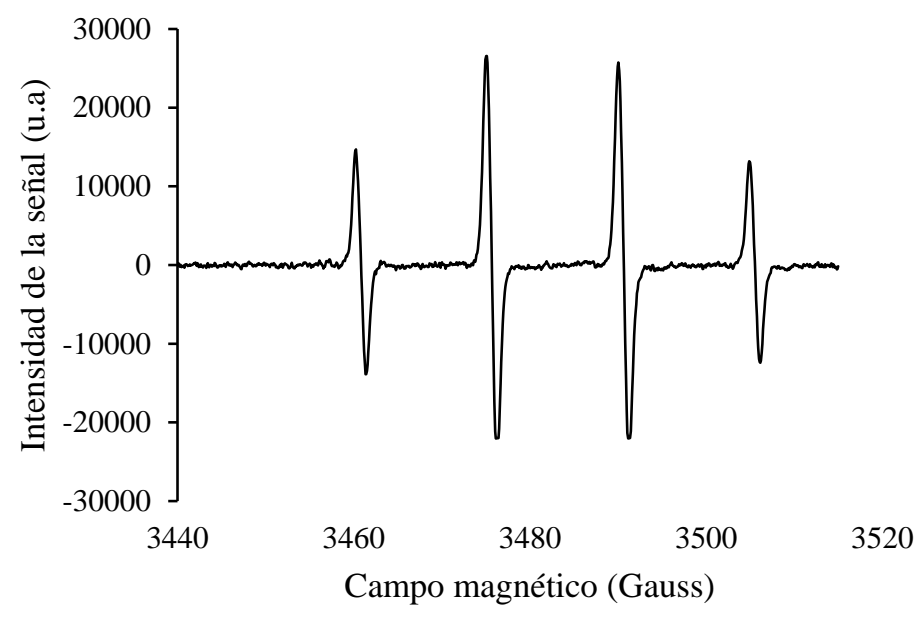

Figura 4.3.2-1. Espectro EPR del complejo DMPO-OH medido a pH 5 en presencia de $[\mathrm{STH}]_{0} 20 \mathrm{mg} \mathrm{L}^{-1}$ y $[\mathrm{Fe}(\mathrm{II})]_{0} 5 \mathrm{mg} \mathrm{L}^{-1}$ tras la adición de $\left[\mathrm{H}_{2} \mathrm{O}_{2}\right]_{0} 34 \mathrm{mg} \mathrm{L}^{-1}$.

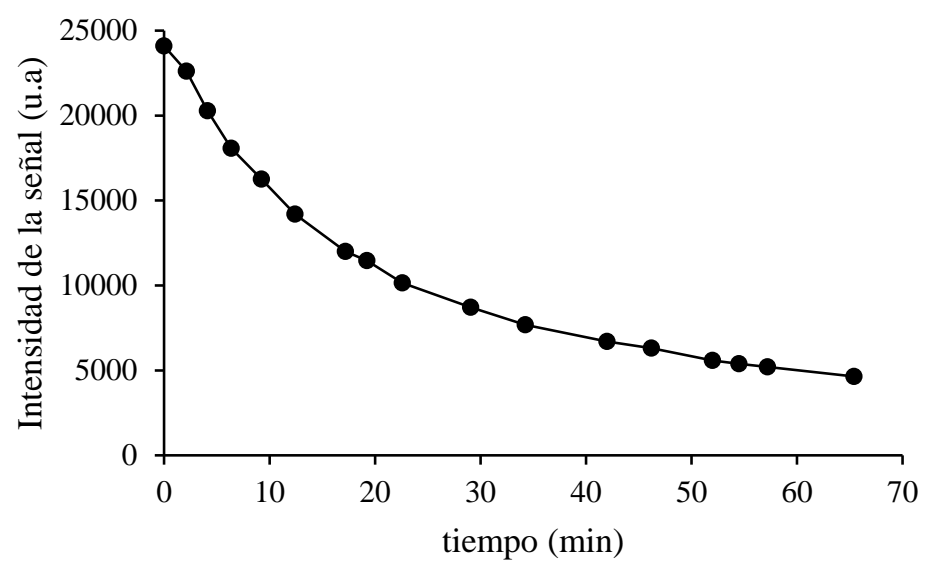

Figura 4.3.2-2. Variación de la señal del sistema DMPO-OH medida a pH 5 en presencia de $[\mathrm{STH}]_{0} 20 \mathrm{mg}$ $\mathrm{L}^{-1},[\mathrm{Fe}(\mathrm{II})]_{0} 5 \mathrm{mg} \mathrm{L}^{-1}$ y $\left[\mathrm{H}_{2} \mathrm{O}_{2}\right]_{0} 34 \mathrm{mg} \mathrm{L}^{-1}$.

En el proceso Fenton (Apartado 1.2.2.1) se producen dos reacciones principales (Ecuaciones 41-42):

$$
\begin{aligned}
& \mathrm{Fe}^{2+}+\mathrm{H}_{2} \mathrm{O}_{2} \rightarrow \mathrm{Fe}^{3+}+\mathrm{OH}^{\cdot}+\mathrm{OH}^{-} \\
& \mathrm{Fe}^{3+}+\mathrm{H}_{2} \mathrm{O}_{2} \rightarrow \mathrm{Fe}^{2+}+\mathrm{OOH}^{\cdot}+\mathrm{H}^{+}
\end{aligned}
$$

La primera reacción es muy rápida, pero cuando el $\mathrm{Fe}(\mathrm{II})$ ha sido oxidado a $\mathrm{Fe}(\mathrm{III})$ la reducción de este a Fe(II) es muy lenta (Pereira et al., 2012), por lo que una vez oxidada la cantidad inicial de Fe(II) la concentración disminuye en el sistema y se observa una pérdida de eficiencia en la generación de $\mathrm{OH} \cdot$. A la vista de estos resultados, se decidió 
adicionar como fuente de hierro, el Fe(III), y comprobar la eficiencia del sistema bajo las mismas condiciones experimentales. La intensidad de la señal obtenida en este caso es menor (Figura 4.3.2-3), indicando que bajo estas condiciones la generación de $\mathrm{OH}$ - es más baja. Sin embargo, si se observa la Figura 4.3.2-4 donde se muestra la evolución de la señal normalizada frente al tiempo vemos que ésta permanece prácticamente constante con el paso del tiempo, lo que supone que, aunque la generación de radicales hidroxilo es menor, la eficiencia en su generación es la misma con el paso del tiempo. Esto puede explicarse a partir de la Ecuación 42 que es la limitante en caso anterior. Cuando se empieza la reacción con $\mathrm{Fe}(\mathrm{III})$ en lugar de $\mathrm{Fe}(\mathrm{II})$ la especiación $\mathrm{Fe}(\mathrm{II}) / \mathrm{Fe}(\mathrm{III})$ se alcanza rápidamente y por tanto se obtiene una señal estable. A efectos prácticos y para el presente estudio se va a usar Fe(III) para el resto de experimentos y medidas EPR.

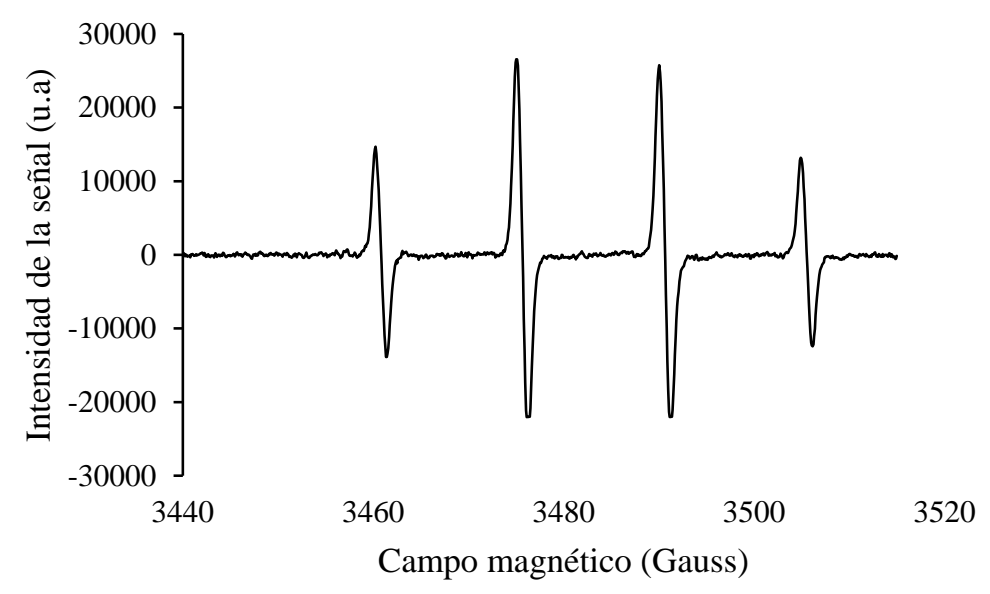

Figura 4.3.2-3. Espectro EPR del complejo DMPO-OH medido a pH 5 en presencia de $[\mathrm{STH}]_{0} 20 \mathrm{mg} \mathrm{L}^{-1}$ y $[\mathrm{Fe}(\mathrm{III})]_{0} 5 \mathrm{mg} \mathrm{L}^{-1}{ }_{0}$ tras la adición de $\left[\mathrm{H}_{2} \mathrm{O}_{2}\right]_{0} 34 \mathrm{mg} \mathrm{L}^{-1}$.

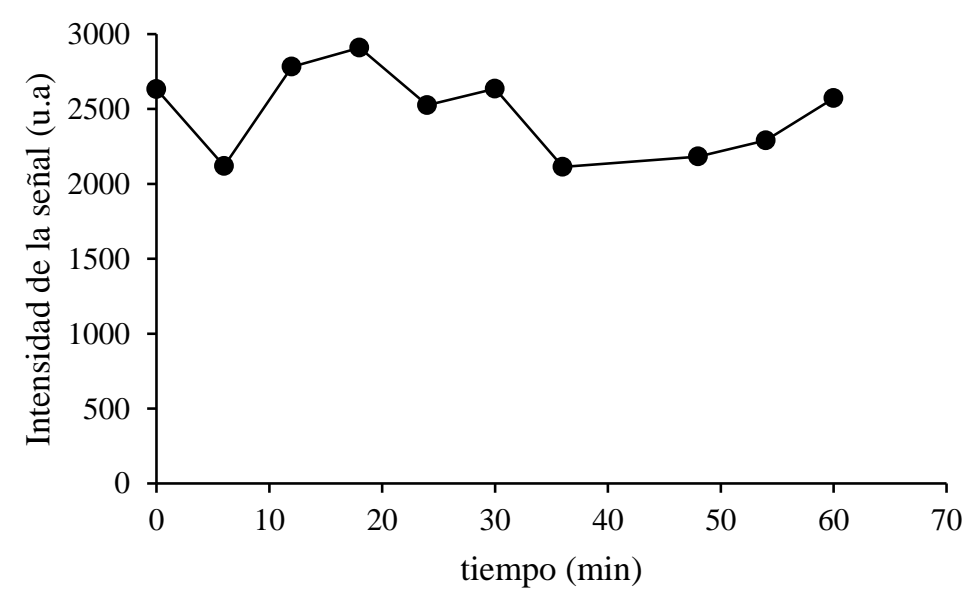

Figura 4.3.2-4. Variación de la señal del sistema DMPO-OH medida a pH 5 en presencia de $[\mathrm{STH}]_{0} 20 \mathrm{mg}$ $\mathrm{L}^{-1},[\mathrm{Fe}(\mathrm{III})]_{0} 5 \mathrm{mg} \mathrm{L}^{-1}$ y $\left[\mathrm{H}_{2} \mathrm{O}_{2}\right]_{0} 34 \mathrm{mg} \mathrm{L}^{-1}$. 
De forma complementaria, se investigó la degradación de la cafeína por proceso Fenton con ambas fuentes de hierro a pH 5. En la Figura 4.3.2-5 se observa que con el uso de Fe(II) la degradación al inicio de la reacción es muy rápida, pero se ralentiza con el paso del tiempo. Cuando la fuente de hierro que se adiciona es Fe(III), la velocidad de reacción es más lenta, pero se mantiene constante a lo largo del todo el proceso, de acuerdo a los resultados obtenidos para la generación de radicales hidroxilo con ambos sistemas.

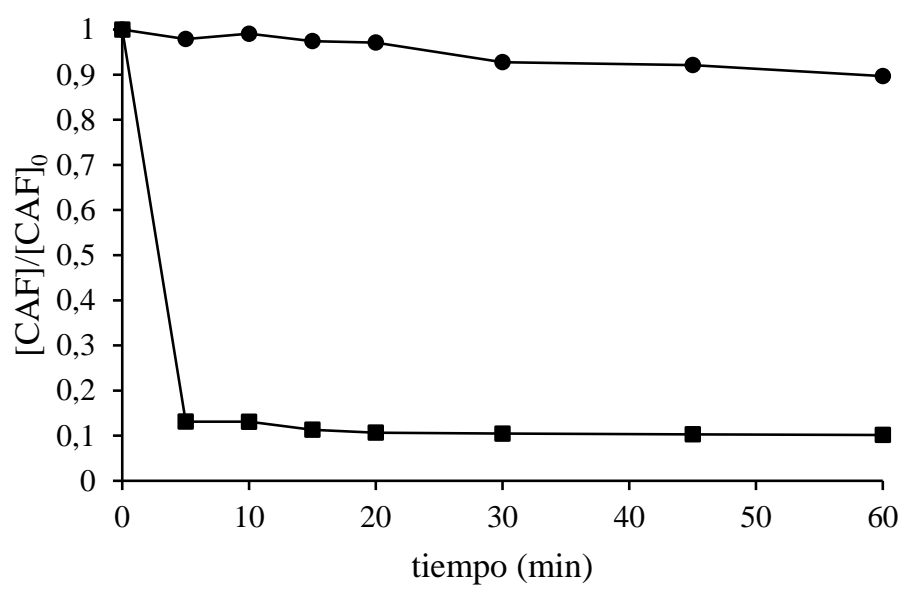

Figura 4.3.2-5. Degradación relativa de la cafeína frente al tiempo mediante proceso Fenton. (-) en presencia de $\mathrm{Fe}(\mathrm{II})$ y $(\bullet)$ en presencia de $\mathrm{Fe}(\mathrm{III})$. Condiciones experimentales: $[\mathrm{CAF}]_{0} 5 \mathrm{mg} \mathrm{L}^{-1}$, $[\mathrm{Fe}]_{0} 5 \mathrm{mg}$ $\mathrm{L}^{-1},\left[\mathrm{H}_{2} \mathrm{O}_{2}\right]_{0} 60 \mathrm{mg} \mathrm{L}^{-1}$ y $\mathrm{pH}_{0} 5$.

\subsubsection{Aplicación de diferentes concentraciones de STH}

La señal de EPR del complejo DMPO-OH se ha medido en presencia de diferentes concentraciones de STH (Figura 4.3.3-1). Puede observarse que, aunque en ausencia de las STH como agentes complejantes se produce generación de radicales $\mathrm{OH} \cdot$, su cantidad es baja, lo que puede deberse a la pequeña fracción de hierro que queda sin desactivar en el sistema. Como se ha explicado en el Apartado 1.2.2.3.2, la adición de bajas concentraciones de hierro es una de las estrategias usadas para llevar a cabo procesos tipo foto-Fenton a pHs más neutros, cuando debido a la baja concentración de contaminantes a degradar, se pueden asumir tiempos de degradación más largos. De hecho, se ha demostrado que la presencia en agua de bajas concentraciones de hierro es suficiente para degradar contaminantes en algunas situaciones (Serra-Clausellas et al., 2018). 


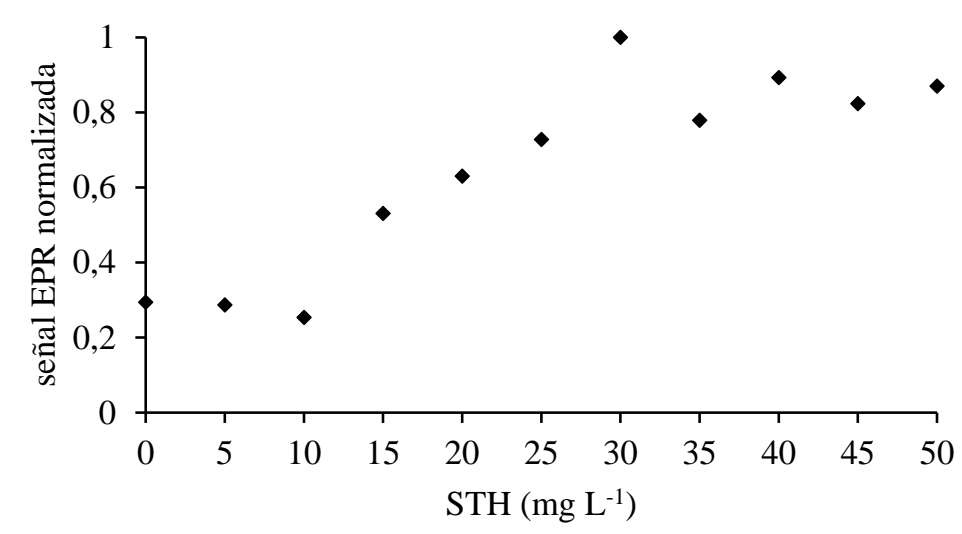

Figura 4.3.3-1. Señal del complejo DMPO-OH frente a diferentes concentraciones de $\mathrm{STH}$ a $\mathrm{pH}_{0} 5$, $[\mathrm{Fe}(\mathrm{III})]_{0} 5 \mathrm{mg} \mathrm{L}^{-1} \mathrm{y}\left[\mathrm{H}_{2} \mathrm{O}_{2}\right]_{0} 34 \mathrm{mg} \mathrm{L}^{-1}$.

La adición de bajas concentraciones de STH (por debajo de $10 \mathrm{mg} \mathrm{L}^{-1}$ ) no resulta en la generación de una cantidad significativa de radicales $\mathrm{OH} \cdot$, lo cual podría deberse a que no hay cantidad suficiente de STH para complejar la cantidad total de hierro presente en la disolución. Sin embargo, conforme se aumenta la concentración de STH presente en la disolución, se observa una mayor eficiencia en la generación de estos radicales. Por otro lado, por encima de $30 \mathrm{mg} \mathrm{L}^{-1}$ de STH la adición de las mismas no supone un incremento en la intensidad de la señal del EPR. Este hecho puede ser debido a dos causas principales (i) la mayoría del hierro ya está formando el complejo Fe-STH y, (ii) el exceso de STH reacciona con los radicales $\mathrm{OH}$ - generados dando lugar a la perdida de eficiencia del complejo.

El efecto del complejo Fe-STH hay que considerarlo también aplicado a la eliminación real de contaminantes. Para ello, se ha seleccionado la cafeína como contaminante modelo y se han realizado experimentos Fenton a escala de laboratorio. Las condiciones experimentales han sido las siguientes: $[\mathrm{CAF}]_{0} 5 \mathrm{mg} \mathrm{L}^{-1}$, [ $\left.\mathrm{Fe}(\mathrm{III})\right]_{0} 5 \mathrm{mg} \mathrm{L}^{-1} \mathrm{y},\left[\mathrm{H}_{2} \mathrm{O}_{2}\right]_{0}$ $60 \mathrm{mg} \mathrm{L}^{-1}$ para la eliminación de la CAF. En la Figura 4.3.3-2 se muestran los resultados obtenidos para proceso Fenton y proceso foto-Fenton tras una hora de tratamiento. Como puede observarse, la eficiencia del proceso Fenton es muy baja, alcanzándose degradaciones menores al $20 \%$ tras 1 hora de tratamiento, resultados que están de acuerdo con la baja eficiencia del proceso a $\mathrm{pH}$ 5. Sin embargo, existen diferencias en los resultados obtenidos dependiendo de la concentración de STH adicionada. La degradación de la cafeína con la presencia de $10 \mathrm{mg} \mathrm{L}^{-1}$ de STH es menor que en ausencia de estas sustancias en el caso del proceso Fenton, pero para concentraciones de STH comprendidas entre $20-40 \mathrm{mg} \mathrm{L}^{-1}$ se obtienen mejores porcentajes de degradación. Esta 
tendencia estaría de acuerdo con los resultados obtenidos en la generación de radicales $\mathrm{OH} \cdot$

La aplicación del complejo Fe-STH también se ha estudiado en el proceso foto-Fenton (realizando el proceso con luz solar). Las condiciones experimentales seleccionadas han sido las mismas que en el caso de las degradaciones por Fenton (oscuridad). Los valores de degradación obtenidos en este caso son siempre superiores al 65\%, de acuerdo con la mayor eficiencia del proceso foto-Fenton respecto al Fenton. Bajo las condiciones aplicadas en este caso, los resultados obtenidos coinciden más con los datos obtenidos para la EPR. La degradación de la cafeína es muy parecida en ausencia de las STH y en presencia de una concentración de $10 \mathrm{mg} \mathrm{L}^{-1}$, pero para la adición de STH a una concentración de 20-40 mg L $\mathrm{m}^{-1}$ se observa una clara mejora del proceso de acuerdo con una mayor generación de radicales $\mathrm{OH}$. Los mejores resultados de degradación se obtienen con la adición de $30 \mathrm{mg} \mathrm{L}^{-1}$ de STH; a mayores concentraciones no se observa una mejora en la eficiencia del proceso relacionada con una mayor producción de radicales $\mathrm{OH} \cdot$.

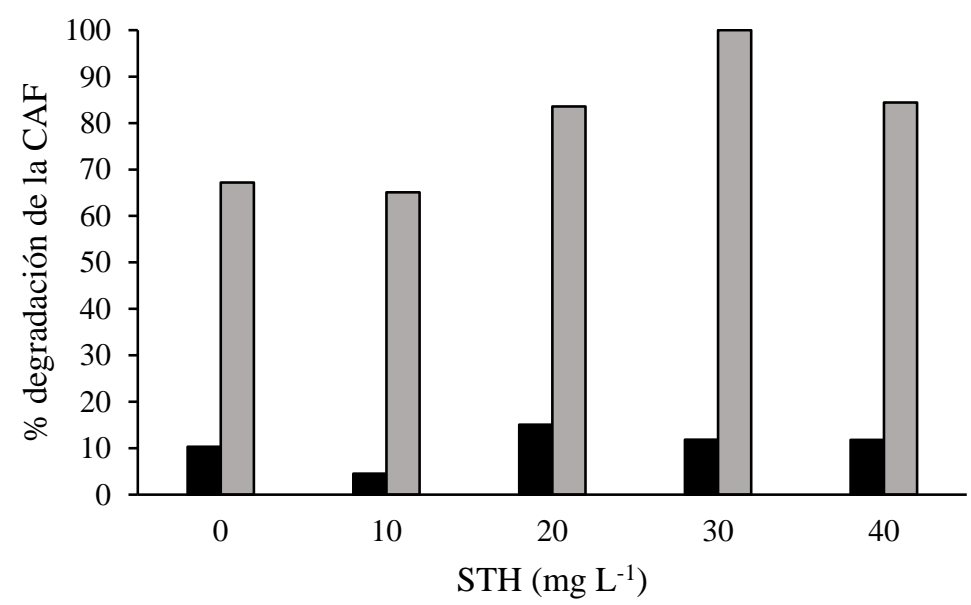

Figura 4.3.3-2. Porcentaje de degradación de la cafeína a los 60 minutos de tratamiento en proceso Fenton (negro) y foto-Fenton (gris). Condiciones experimentales $[\mathrm{CAF}]_{0} 5 \mathrm{mg} \mathrm{L}^{-1}$, [Fe(III) $]_{0} 5 \mathrm{mg} \mathrm{L}^{-1},\left[\mathrm{H}_{2} \mathrm{O}_{2}\right]_{0} 60$ $\mathrm{mg} \mathrm{L}^{-1}, \mathrm{pH}_{0} 5$ y diferentes concentraciones de $[\mathrm{STH}]_{0} 0-40 \mathrm{mg} \mathrm{L}^{-1}$.

Para completar y facilitar la comprensión del proceso, se determina la concentración de hierro transcurridos 15 y 60 minutos en ausencia y en presencia de STH en un rango de 0-40 mg L $\mathrm{m}^{-1}$ (Figura 4.3.3-3). Los resultados obtenidos están de acuerdo con los observados, tanto en la generación de especies oxidantes, como en los procesos de degradación; el Fe(III) presente y disponible en la disolución aumenta conforme aumenta 
la concentración de STH presentes en la muestra. Se llevaron a cabo también las mismas medidas en presencia de Fe(II) a modo de control.

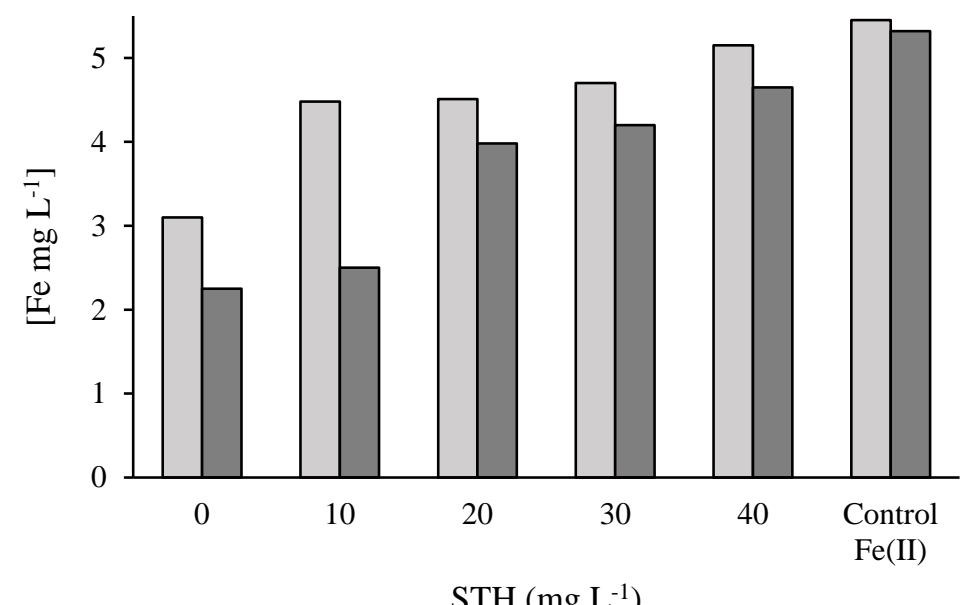

Figura 4.3.3-3. Concentración de hierro total de acuerdo al método de la o-fenantrolina transcurridos 5 minutos (gris claro) y 60 minutos (gris oscuro) a $\mathrm{pH}_{0} 5$, [Fe(III) $]_{0} 5 \mathrm{mg} \mathrm{L}^{-1}$ y diferentes concentraciones de STH 0-40 $\mathrm{mg} \mathrm{L}^{-1}$. Se muestra también la medida de $[\mathrm{Fe}(\mathrm{II})]_{0} 5 \mathrm{mg} \mathrm{L}^{-1} \sin \mathrm{STH}$ a modo de control.

Para finalizar, la Figura 4.3.3-4 muestra la degradación de la CAF en presencia y ausencia de STH para el proceso foto-Fenton. La concentración inicial de STH adicionadas fue de $30 \mathrm{mg} \mathrm{L}^{-1}$ de acuerdo con los resultados obtenidos anteriormente. Se observa que las velocidades de reacción iniciales en ambos casos son similares, pero en el experimento en ausencia de STH, transcurridos 15 minutos la velocidad de degradación cae y se estanca a los 45 minutos, contrariamente a lo que ocurre con la adición de STH. Estos resultados nos estarían revelando la capacidad complejante de estas STH. 


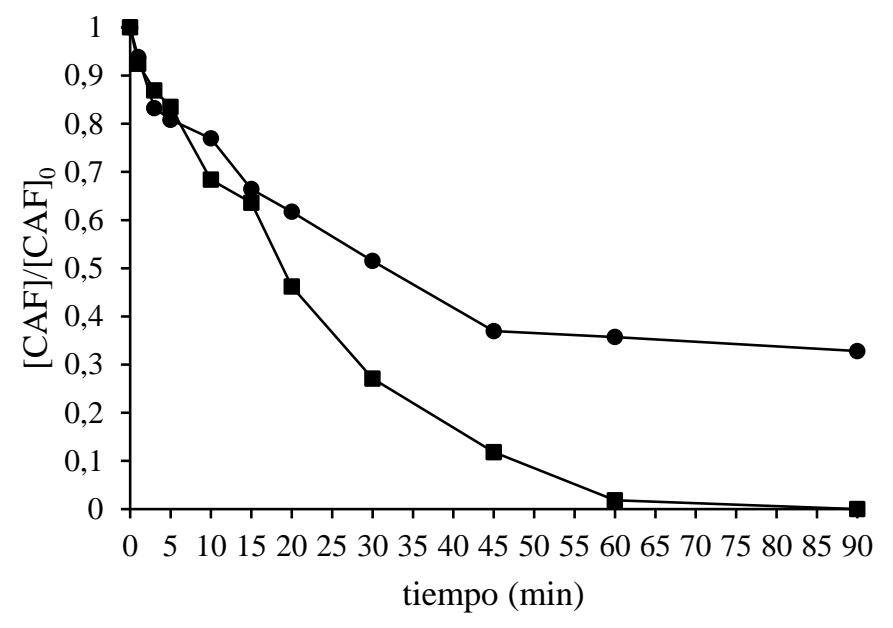

Figura 4.3.3-4. Degradación relativa de la CAF en proceso foto-Fenton en ausencia de STH $(\bullet)$ y con la adición de $30 \mathrm{mg} \mathrm{L}^{-1}$ de $[\mathrm{STH}]_{0}$ (๘) frente al tiempo. Condiciones experimentales: $[\mathrm{CAF}]_{0} 5 \mathrm{mg} \mathrm{L}^{-1}$, $[\mathrm{Fe}(\mathrm{III})]_{0} 5 \mathrm{mg} \mathrm{L}^{-1}$, [ $\left.\mathrm{H}_{2} \mathrm{O}_{2}\right]_{0} 60 \mathrm{mg} \mathrm{L}^{-1}$. 


\subsection{ELIMINACIÓN DE CONSERVANTES COSMÉTICOS (PARABENOS) PRESENTES EN AGUAS RESIDUALES DE LA INDUSTRIA COSMÉTICA POR PROCESO FOTO-FENTON Y EVALUACIÓN DE SU TOXICIDAD}

\subsubsection{Introducción}

Los parabenos son ésteres alifáticos del ácido p-hidroxibenzoico (p-HBA), ampliamente utilizados como conservantes en industria cosmética, farmacéutica y alimentaria (Petric et al., 2021). En la industria cosmética su uso se encuentra regulado por el Reglamento 1223/09 CE, recogidos en el anexo V de dicho Reglamento. Los parabenos se encuentran presentes en gran cantidad de formulaciones cosméticas debido a su estabilidad química en un amplio rango de $\mathrm{pHs}$ (son eficaces entre $\mathrm{pH}$ 4.5-7.5), poseen gran capacidad antimicrobiana y antifúngica y, además, son incoloros, inodoros y tienen bajos costos de producción. La efectividad como conservantes aumenta conforme aumenta la longitud de sus cadenas alifáticas: metilparabeno $(\mathrm{MP})<$ etilparabeno $(\mathrm{EP})<$ propilparabeno $(\mathrm{PP})<$ butilparabeno (BP) < BZP (benzilparabeno) (Figura 4.4.1-1).

Según el Reglamento 1223/09 CE sobre productos cosméticos, pueden utilizarse solos o combinados, pero siempre a una concentración máxima de $0.4 \%$ (de ácido) para ésteres, y $0.8 \%$ (de ácido) para las mezclas de ésteres (Andersen., 2008). Según Pouillot et al., 2006 se encuentran presentes en el 80\% de las formulaciones cosméticas. Actualmente en cosmética solo pueden utilizarse como conservantes el MP, EP y PP, pero en alimentación sí se siguen utilizando el BP y el BZP.
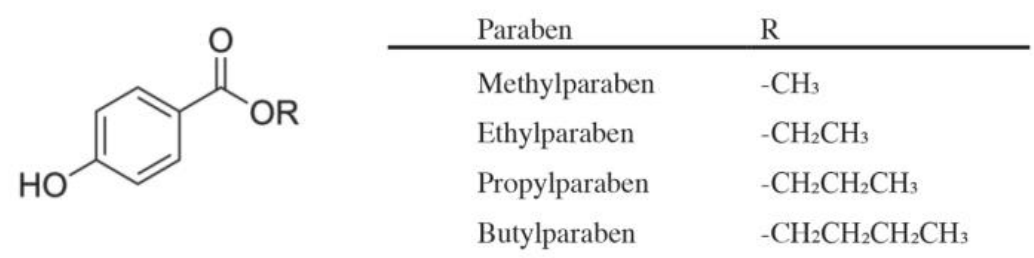

Figura 4.4.1-1. Estructura de los diferentes parabenos (Sheskey et al., 2017).

La creciente preocupación social generada alrededor del uso de estos conservantes radica en el estudio publicado por Darbre et al., 2004 en el cual planteaba una relación entre el uso de desodorantes con parabenos y el cáncer de mama. Anteriormente Routledge et al., 1998; Oishi, 2002a, b ya habían sugerido que los parabenos podían actuar como disruptores endocrinos. La exposición a parabenos puede venir de la alimentación, uso de 
fármacos y del uso de cosméticos, siendo la mayor fuente de exposición en humanos la cosmética (Bledzka et al., 2014; Soni et al., 2005).

Como ya se ha dicho, mediante los tratamientos de agua convencionales no es posible la completa eliminación de los CE y estos son detectados posteriormente en los efluentes de aguas urbanas ya tratadas en concentraciones de $\mu \mathrm{g} \mathrm{L}^{-1}$ y ng L $\mathrm{L}^{-1}$ (Gmurek et al., 2019). Debido al creciente y generalizado uso de PPCPs por parte de la población, la presencia de compuestos contenidas en esas formulaciones, como los parabenos, aparecen en los reservorios de agua y los convierte en un serio problema ambiental a tener en cuenta (Yang et al., 2017).

La concentración de parabenos detectada en el agua de entrada de las EDARs es incluso de $\mathrm{mg} \mathrm{L}^{-1}$ y a la salida después de los diferentes tratamientos sigue siendo considerable (Marta-Sánchez et al., 2018; Gomes et al., 2018a). Se ha detectado la presencia de parabenos en aguas naturales en Japón, Reino Unido, Portugal, Suiza, Bélgica, China, EE. UU. y España entre otros, así como en aguas potables de Alemania, EE. UU. y España (Haman et al., 2015).

La insuficiente eliminación de los parabenos deriva en su acumulación en diferentes organismos acuáticos y representa un serio riesgo ambiental, por lo que es importante el desarrollo de tecnologías de tratamiento eficientes. Los procesos más efectivos para la eliminación de estos contaminantes según la bibliografía se basan en la generación de especies químicas oxidantes con ayuda de radiación ultravioleta (UV), radiación visible (Vis) y ozono (Nakada et al., 2007; Gomes et al., 2017a; Wang et al., 2018).

El presente capítulo tiene como objetivo evaluar la degradación de una mezcla de parabenos (MP, EP, PP, IP y, BZP) mediante aplicación de proceso foto-Fenton en condiciones de pH más cercanas a la neutralidad que el óptimo de 2,8; esto se realizará mediante la adición de diferentes STH. Estás STH, como se ha comentado en capítulos anteriores, se han extraído de diferentes tipos de residuos (oliva, café y de lodo deshidratado del reactor anaerobio de una EDAR). El proceso foto-Fenton se ha llevado a cabo en diferentes condiciones experimentales con la finalidad de buscar el proceso más adecuado, y su evolución se ha estudiado mediante el análisis cromatográfico de los contaminantes y el seguimiento de toxicidad aguda y de actividad endocrina durante los tratamientos realizados en planta piloto. 


\subsubsection{Selección de las STH a adicionar al proceso}

Se ha realizado una primera serie de experimentos a escala de laboratorio con agua destilada para determinar el efecto del $\mathrm{pH}$ y las concentraciones de $\mathrm{H}_{2} \mathrm{O}_{2}$ y $\mathrm{STH}$ en el proceso de oxidación. La concentración inicial de parabenos en la mezcla es de $5 \mathrm{mg} \mathrm{L}^{-1}$ para cada uno de ellos. Se ha tomado muestra a diferentes tiempos de reacción y se han analizado por UHPLC en el menor tiempo posible desde que se recoge la muestra. La Figura 4.4.2-1 presenta la concentración relativa de cada uno de los parabenos vs el tiempo a pH óptimo para el proceso ( $\mathrm{pH}$ 2.8). La velocidad de eliminación difiere de un parabeno a otro, siendo: MP=ET > PP > IP > BZP, lo que está de acuerdo con la longitud de sus cadenas alifáticas.

Antes de empezar con los experimentos foto-Fenton, se realizaron los blancos pertinentes, fotólisis y reacción Fenton a $\mathrm{pH} 2.8$ y 5 para comprobar la degradabilidad de los parabenos. En el caso Fenton a pH 2.8 todos los parabenos son eliminados en un tiempo de 30 minutos, no así a pH 5 donde al cabo de una hora solo se alcanza un $2.6 \%$ de degradación. Se realizan una serie de experimentos foto-Fenton sin la adición de STH a diferentes pHs para conocer el efecto de este factor sobre la degradación de los parabenos. Los experimentos se realizaron en agua destilada y agua del grifo, a pHs 2.8, 5 y 6. Dado que el óptimo para el proceso foto-Fenton es pH 2.8 se observa una rápida degradabilidad de todos los parabenos, habiéndose eliminado el $95 \%$ de estos en agua destilada y el $80 \%$ en agua del grifo a los 5 minutos en ambos casos (Figura 4.4.2-2). A pH 5 se observa que la eliminación es mucho más lenta, debido a la generación de especies no activas del hierro. En este caso se alcanza una degradabilidad del $80 \%$ en 50 minutos con agua destilada y en 60 minutos con agua del grifo. A pH 6 no se observa una buena degradación de los parabenos aun transcurridas dos horas de tratamiento. 


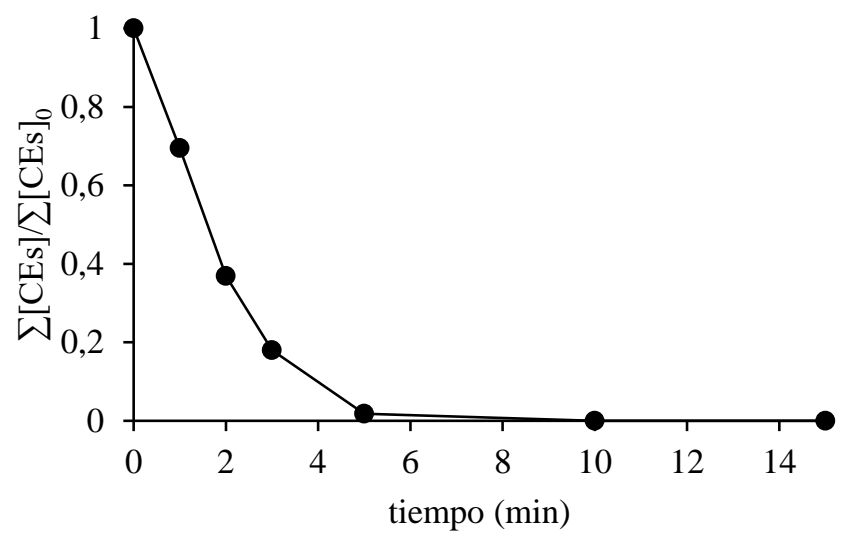

Figura 4.4.2-1. Degradación relativa de los parabenos vs tiempo para el proceso foto-Fenton. Condiciones experimentales: [parabenos] $]_{0} 5 \mathrm{mg} \mathrm{L}^{-1}$ cada uno, [Fe(III) $]_{0} 5 \mathrm{mg} \mathrm{L}^{-1},\left[\mathrm{H}_{2} \mathrm{O}_{2}\right]_{0} 213 \mathrm{mg} \mathrm{L}^{-1}$ y, a pH $\mathrm{pH}_{0} 2.8$. Experimento realizado en agua MQ.
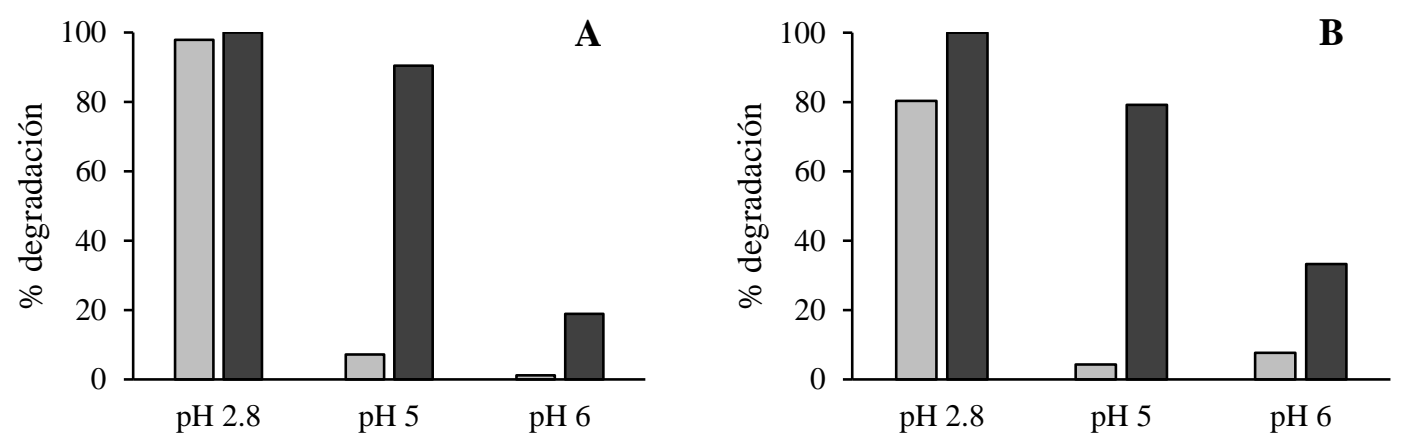

Figura 4.4.2-2. Degradación de la suma de los parabenos a diferentes tiempos de tratamiento vs diferentes pHs $(2.8,5$ y 6$)$ y diferentes matrices de agua. A: agua destilada, B: agua del grifo a los 5 y 60 minutos de tratamiento (gris claro y gris oscuro respectivamente). Condiciones experimentales del proceso fotoFenton: [parabenos $]_{0} 5 \mathrm{mg} \mathrm{L}^{-1}$ cada uno, [Fe (III)] $5 \mathrm{mg} \mathrm{L}^{-1}$ y $\left[\mathrm{H}_{2} \mathrm{O}_{2}\right]_{0} 213 \mathrm{mg} \mathrm{L}^{-1}$.

Con objeto de determinar si existen diferencias de comportamiento estabilizador de hierro en disolución y por tanto de efectividad en la aplicación del proceso foto-Fenton, se han probado tres tipos diferentes de STH provenientes de diferentes tipos de residuos:

- STH extraídas del residuo del café,

- STH extraídas del residuo de la producción del aceite de oliva y,

- STH extraídas de lodos de depuradora.

Previo a la realización de los experimentos foto-Fenton con la adición de las STH, se miedieron las matrices de excitación emisión de las mimas a diferentes concentraciones (20-50 $\mathrm{mg} \mathrm{L}^{-1}$ ) y se analizaron por PARAFAC (Figura 4.4.2-3). 

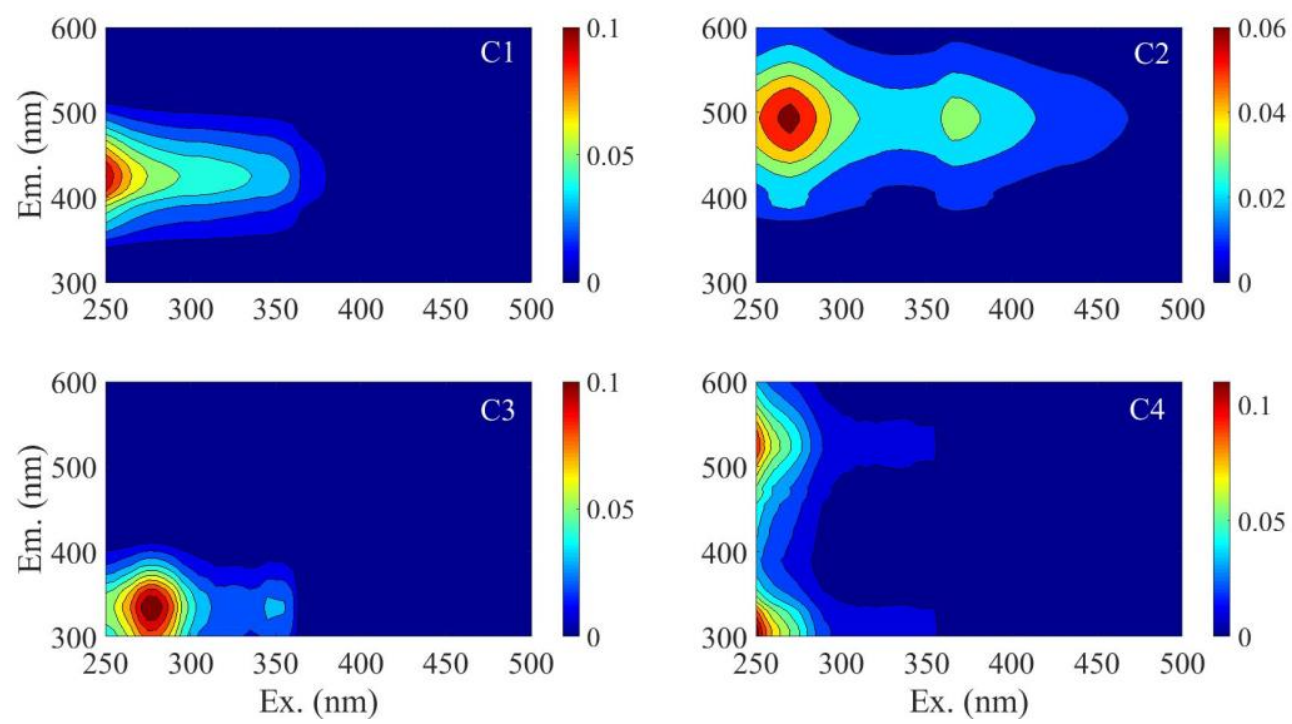

Figura 4.4.2-3. Diferentes componentes obtenidos para el análisis por PARAFAC de las diferentes STH extraídas (residuo de la oliva, café y lodo) a diferentes concentraciones (20-50 mg L $\mathrm{L}^{-1}$ ), de los $\mathrm{AH}$ comerciales de Sigma-Aldrich y de las STH CVT-230 extraídas en Italia. El eje X corresponde a las longitudes d eonda de excitación (250-500 nm) y el eje Y a las longitudes de onda de emisión (300-600 $\mathrm{nm})$.

Del análisis por PARAFAC se obtienen 4 componentes de los cuales los componentes $\mathrm{C} 1$ y C2 correspondes a las señales típicamente asignadas a las sustancias tipo húmicas (237260/400-500 nm y 300-370/400-500 nm Ex/Em). El componente C3 presenta su máximo de Ex/Em entre los 260-300/300-480 nm aproximadamente, lo que puede corresponderse según Yang et al., 2015 con las señales asociadas a proteínas, ácidos tipo húmicos y fúlvicos, y a moléculas tipo triptófano. Teniendo en cuenta el origen de los residuos es coherente que aparezca esta señal en el análisis. Por último, el componente C4 presenta dos regiones destacadas, la comprendida entre los 250-300/300-400 nm de Ex/Em se corresponde con proteínas, triptófano y tirosina, y la región comprendida entre 410600/250-300 nm de Ex/Em con los ácidos tipo húmicos y fúlvicos.

En el set de datos del análisis se incluyeron muestras de ácidos húmicos comerciales (Sigma-Aldrich) y provenientes de Italia (CVT-230), usadas y caracterizadas en anteriores trabajos del grupo de investigación (Gomis et al., 2013; Gomis et al., 2014; Gomis et al., 2015; Caram et al., 2018) para poder comparar el peso de los diferentes componentes en las STH extraídas en la presente tesis con estas conocidas y así determinar cuales son las que van a actuar de forma más eficiente como STH. 


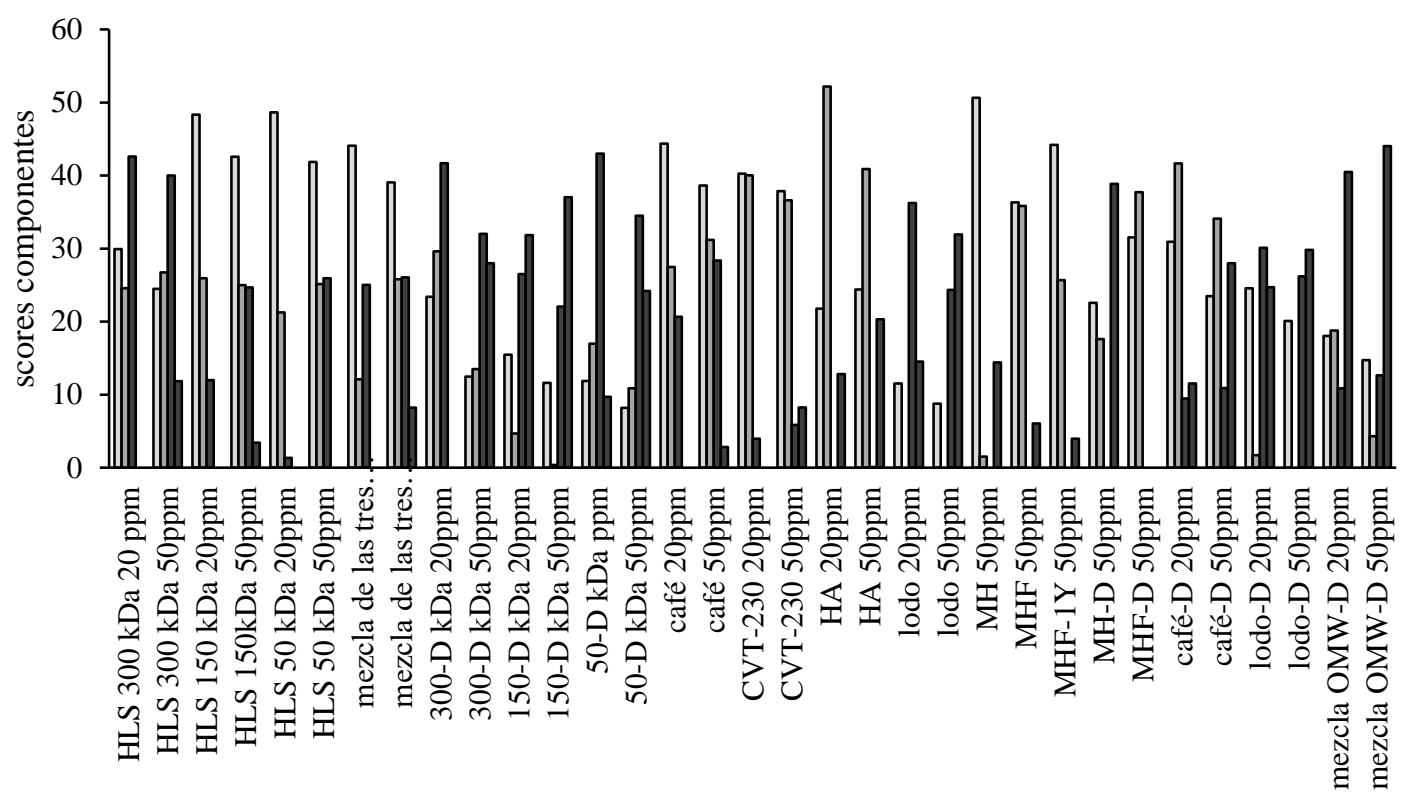

Figura 4.4.2-4. Peso de los diferentes componentes obtenidos por PARAFAC para las diferentes muestras de STH anañizadas. Componente C1 (blanco), componente C2 (gris claro), componente C3 (gris oscuro), componente $\mathrm{C} 4$ (negro).

En la Figura 4.4.2-4 se observa que los componentes correspondientes a las regiones de Ex/Em asociadas a las sustancias tipo húmicas $(\mathrm{C} 1$ y $\mathrm{C} 2)$ tienen más peso en el caso de las STH extraídas del residuo del café, que son los componentes que más peso tienen en el caso de los AH comerciales y del CVT-230. Por lo que de este análisis se puede deducir que a la hora de aplicar estas STH en el proceso oxidativo foto-Fenton las que van a presentar mejores resultados de estabilización del hierro y por tanto de degradación de los contaminantes van a ser las STH extraídas del café. En cualquier caso, se adicionaron los tres tipos de STH al proceso para comprobar los resultados obtenidos.

En todos los casos las condiciones experimentales fueron las mismas: [Fe(III)]o $5 \mathrm{mg} \mathrm{L}^{-1}$, $\left[\mathrm{H}_{2} \mathrm{O}_{2}\right]_{0} 213 \mathrm{mg} \mathrm{L}^{-1} \mathrm{o} 426 \mathrm{mg} \mathrm{L}^{-1}$ y $[\mathrm{STH}]_{0} 20 \mathrm{mg} \mathrm{L}^{-1}$, únicamente se varió el tipo de STH añadida. El tiempo requerido para la eliminación del $60 \%$ de la suma de los parabenos con el uso de las diferentes sustancias y sin ellas se muestra en la Figura 4.4.2-5. El porcentaje de degradación de los parabenos es muy similar en todos los casos, a excepción del uso de las STH extraídas del residuo del café con el doble de la cantidad estequiométrica de peróxido de hidrógeno, donde a la media hora de tratamiento se ha conseguido la degradación del $60 \%$ de la mezcla de contaminantes. Debido a estos resultados, se decide usar este tipo de STH para el resto de los experimentos. 


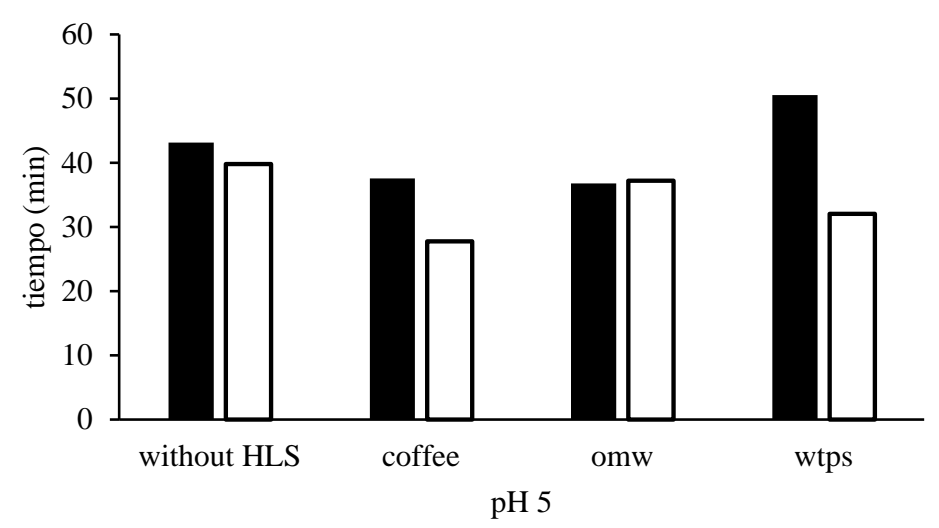

Figura 4.4.2-5. Tiempo necesario para degradar el $60 \%$ de la suma de los parabenos vs diferentes tipos de HLS (residuo del café, residuo de la oliva y lodo de depuradora). Foto-Fenton con agua destilada. Condiciones experimentales: [parabenos $]_{0} 5 \mathrm{mg} \mathrm{L}^{-1}$ cada uno, [Fe (III) $]_{0} 5 \mathrm{mg} \mathrm{L}^{-1},\left[\mathrm{H}_{2} \mathrm{O}_{2}\right]_{0} 213 \mathrm{mg} \mathrm{L}^{-1}$ (a) y $426 \mathrm{mg} \mathrm{L}^{-1}(\square),[\mathrm{STH}]_{0} 20 \mathrm{mg} \mathrm{L}^{-1}, \mathrm{pH}_{0} 5$.

\subsubsection{Toxicidad aguda en organismos acuáticos}

Para conocer cómo puede afectar esta mezcla de parabenos a los organismos acuáticos y saber si es capaz de provocar disrupción endocrina, la reacción se llevó a planta piloto y se realizó a una escala más cercana a la realidad (volumen $5 \mathrm{~L}$ y luz natural) el experimento con STH que mejores resultados de degradación había mostrado a escala de laboratorio (agua del grifo, pH 5 con STH procedentes de café). Se tomaron diferentes muestras para los ensayos de toxicidad: muestra inicial, muestra intermedia (15 minutos t30w) y muestra final (30 minutos t30w). La Figura 4.4.3-1 muestra la degradación de los parabenos bajo estas condiciones. Se consigue la total eliminación de parabenos a los 23 minutos de tratamiento.

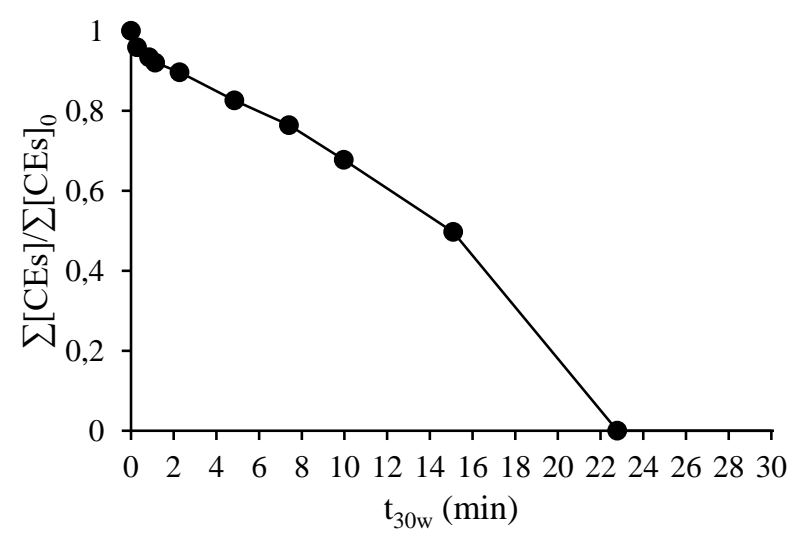

Figura 4.4.3-1. Degradación de la mezcla de parabenos frente al tiempo expresado en $t_{30 \mathrm{w}}(\mathrm{min})$. Condiciones experimentales: [parabenos $]_{0} 5 \mathrm{mg} \mathrm{L}^{-1}$ cada uno, [Fe(III) $]_{0} 5 \mathrm{mg} \mathrm{L}^{-1},\left[\mathrm{H}_{2} \mathrm{O}_{2}\right]_{0} 426 \mathrm{~g} \mathrm{~L}^{-1}$, [STH $]_{0}$ del café $20 \mathrm{mg} \mathrm{L}^{-1}, \mathrm{pH}_{0}$ 5. Experimento realizado con agua MQ. 
El impacto que tiene la presencia de parabenos en agua sobre organismos acuáticos es todavía desconocido, y no existe mucha información disponible sobre los efectos potenciales que estos contaminantes pueden ocasionar (Dobbins et al., 2009; Terasaki et al., 2008). Se considera importante conocer los posibles efectos de estos contaminantes y de sus subproductos de degradación, ya que gran parte de los parabenos usados en cosmética terminan en ecosistemas acuáticos.

Por ello, se realizaron ensayos de toxicidad de diferente naturaleza que nos den información sobre la evolución de este parámetro durante el tratamiento aplicado para la degradación de los parabenos. Para los ensayos de toxicidad se han tomado muestras de diferentes tiempos de tratamiento ( 0 minutos $\mathrm{t}_{30 \mathrm{w}}, 15$ minutos $\mathrm{t}_{30 \mathrm{w}} \mathrm{y} 30$ minutos $\mathrm{t}_{30 \mathrm{w}}$ ), realizados en la planta piloto a un $\mathrm{pH}$ de 5 y se han calculado los valores LID y MID (Tabla 4.4.3-1) para diferentes organismos pertenecientes a diferentes niveles de la cadena trófica (A. fischeri, P. subcapitata y, D. magna). Se ha eliminado el peróxido que pudiera quedar presente en las muestras mediante el método de la catalasa y se han realizado los ensayos toxicológicos en el menor tiempo posible.

Tabla 4.4.3-1. Valores LID y MID obtenidos para las diferentes muestras de agua para cada uno de los organismos acuáticos sobre los que se ha realizado ensayos. Condiciones experimentales: [parabenos] 5 $\mathrm{mg} \mathrm{L}^{-1}$ cada uno, $[\mathrm{Fe}(\mathrm{III})]_{0} 5 \mathrm{mg} \mathrm{L}^{-1},\left[\mathrm{H}_{2} \mathrm{O}_{2}\right]_{0} 426 \mathrm{mg} \mathrm{L}^{-1}$, $[\mathrm{STH}]_{0}$ café $20 \mathrm{mg} \mathrm{L}^{-1}, \mathrm{pH}_{0} 5$. Experimento realizado con agua $\mathrm{MQ}$.

\begin{tabular}{|c|c|c|c|c|c|c|}
\hline & \multicolumn{2}{|c|}{$0 \min t_{30 w}$} & \multicolumn{2}{|c|}{$15 \min t_{30 w}$} & \multicolumn{2}{|c|}{$30 \min t_{30 w}$} \\
\hline & LID & MID & LID & MID & LID & MID \\
\hline $\begin{array}{c}P . \\
\text { subcapitata }\end{array}$ & $1: 16$ & $1: 3.7$ & $1: 8$ & $1: 2.2$ & $1: 16$ & $1: 4.0$ \\
\hline $\begin{array}{l}\text { D. magna } \\
(24 \mathrm{~h})\end{array}$ & $1: 8$ & $1: 3.0$ & $1: 8$ & $1: 4.5$ & $1: 8$ & $1: 1.0$ \\
\hline $\begin{array}{l}\text { D. magna } \\
(48 \mathrm{~h})\end{array}$ & $1: 8$ & $1: 3.8$ & $1: 8$ & $1: 6.2$ & $1: 4$ & $1: 2.0$ \\
\hline A. fischeri & & & & & & \\
\hline
\end{tabular}

Como se observa, la mezcla de parabenos no ha mostrado toxicidad para el organismo $A$. fischeri incluida la muestra inicial. Gmurek et al., 2019 observó una elevada toxicidad para A. fischeri estudiando la misma mezcla de parabenos a una concentración de $10 \mathrm{mg}$ $\mathrm{L}^{-1}$, pero los resultados obtenidos en el presente caso de estudio muestran que la concentración de $5 \mathrm{mg} \mathrm{L}^{-1}$ no afecta a la bioluminiscencia de la bacteria. Una inhibición de la bioluminiscencia (LI) por debajo del $30 \%$ podría considerarse como no toxico (Miralles-Cuevas et al., 2017). Terasaki et al., 2008 concluyó que el organismo A. fischeri 
era más sensible que D. magna a los parabenos, presentando valores de $\mathrm{CE}_{50}$ más bajos, contrario a los resultados obtenidos con la mezcla de parabenos a la concentración estudiada. Los análisis fueron repetidos para confirmar estos resultados y demuestran que el comportamiento de la mezcla de parabenos difiere del comportamiento de cada uno por separado. En esta Tesis se considera interesante realizar el estudio con la mezcla de parabenos de diferente naturaleza ya que sus resultados se asemejarán más a lo que ocurre con unas aguas reales.

Comparando los valores iniciales de LID para D. magna y P. subcapitata (LID 1:8 y 1:16 respectivamente), el alga presenta mayor toxicidad. Kamaya et al., 2006 observaron inhibición en el crecimiento de $P$. subcapitata, causado por la presencia del ácido phidroxibenzoico (un metabolito de los parabenos) a una concentración de $1.37 \mathrm{~g} \mathrm{~L}^{-1}$, mucho más alta que la obtenida en el presente caso de estudio, donde se observa que $P$. subcapitata es el organismo que muestra toxicidad más alta, siendo mayor al final del tratamiento que en tiempos intermedios. Este resultado sugiere que existe un efecto sinérgico entre los diferentes parabenos presentes en la mezcla y sus metabolitos. Teniendo en cuenta que no hay estudios de toxicidad con esta mezcla de parabenos para $P$. subcapitata, este efecto se considera posible.

Respecto al ensayo de toxicidad aguda con el organismo D. magna, se observa que al final del tratamiento, las muestras siguen presentando toxicidad con unos valores MID de 1:1.2 [1:2.5-1:1.3]. Del mismo modo que con los otros organismos estudiados, no existen estudios de toxicidad con esta mezcla para el cladócero. Dobbins et al., 2009 evaluaron la toxicidad de diferentes parabenos para D. magna y $P$. promelas, estableciendo diferentes CL50 para cada parabeno, desde $24.6 \mathrm{mg} \mathrm{L}^{-1}$ para el metilparabeno hasta $4 \mathrm{mg}$ $\mathrm{L}^{-1}$ para el benzilparabeno. Conforme aumenta la lipofilicidad también lo hace la toxicidad.

Se ha determinado que el tiempo de exposición no parece tener un efecto significativo en cuanto a la toxicidad se refiere, es decir, que la toxicidad aguda y el modo de acción en el caso de los parabenos puede determinarse rápidamente (Bazin et al., 2009) no siendo necesarios largos tiempos de exposición.

Los ensayos de toxicidad aguda realizados para los organismos seleccionados revelan que la duración del proceso foto-Fenton en este caso un t30w de 30 minutos no es suficiente para reducir la toxicidad de los parabenos, incluso llegando a aumentar en el caso de $P$. 
subcapitata, probablemente debido a los intermedios clorados que se generan. Los ensayos de toxicidad son importantes en el tratamiento de este tipo de mezclas ya que, aunque los compuestos diana se eliminen, la toxicidad de la disolución puede aumentar debido a los compuestos intermedios (Lincho et al., 2021).

\subsubsection{Ensayo de disrupción endocrina (RYA)}

Teniendo en cuenta que está descrita la posible actividad endocrina de estos compuestos, se considera interesante completar los ensayos de toxicidad con el ensayo RYA.

Diferentes estudios in vitro han demostrado que el MP, EP, PP, BP and BZP son estrogénicos comparados con la hormona esteroidea 17- $\beta$-estradiol (Mizuno et al., 2009; Bazin et al., 2009), y que la respuesta estrogénica aumenta con el tamaño del grupo alquilo (Routledge et al., 1998). Bazin et al., 2009 establecieron y representaron las curvas típicas de dosis-respuesta para el estradiol y los parabenos. Todos los parabenos inducen a una respuesta dependiente de la concentración en las células de levadura.

La actividad estrogénica se expresa en equivalentes de estradiol (EEQs), concentración de estradiol que causa la misma respuesta que la muestra en el ensayo RYA. La muestra inicial ha demostrado ser muy toxica para la cepa de levadura, y la muestra del final del tratamiento moderadamente tóxica (Tabla 4.4.4-1). Observando el factor de dilución Kd, la muestra intermedia ( 15 min $\mathrm{t}_{30 \mathrm{w}}$ ) es menos toxica que la muestra final (30 min $\mathrm{t}_{30 \mathrm{w}}$ ), al igual que ocurre con $P$. subcapitata. En cualquier caso, los resultados obtenidos en el RYA para la mezcla de parabenos se encuentran en el mismo orden de magnitud que los principales disruptores endocrinos usados normalmente, por lo que deben ser tratados como tal. Sería interesante considerar tiempos más cortos de tratamiento en el caso concreto de esta mezcla teniendo en cuenta los resultados obtenidos o, llevar a cabo tratamientos más largos e ir controlando la toxicidad a diferentes tiempos de tratamiento.

Tabla 4.4.4-1. Toxicidad, factor de dilución Kd y actividad estrogénica (EEQs) obtenidas en el ensayo RYA para las diferentes muestras de agua estudiadas. Condiciones experimentales: [parabenos] $]_{0} 5 \mathrm{mg} \mathrm{L}^{-1}$ cada uno, [Fe(III) $]_{0} 5 \mathrm{mg} \mathrm{L}^{-1}$, $\left[\mathrm{H}_{2} \mathrm{O}_{2}\right]_{0} 426 \mathrm{mg} \mathrm{L}^{-1}$, [STH $]_{0} 20 \mathrm{mg} \mathrm{L}^{-1}, \mathrm{pH}_{0} 5$.

\begin{tabular}{cccc}
\hline Muestra & Toxicidad & $\begin{array}{c}\text { Factor de } \\
\text { dilución } \\
\text { Kd }\end{array}$ & $\begin{array}{c}\text { EEQs ng } \\
\mathbf{L}^{-\mathbf{1}}\end{array}$ \\
\hline $\mathbf{0}$ min t30w & Muy toxico & 800 & 57 \\
\hline $\mathbf{1 5}$ min t30w & No toxico & 15 & 1 \\
\hline $\mathbf{3 0}$ min t30w & $\begin{array}{c}\text { Moderadamente } \\
\text { toxico }\end{array}$ & 24 & 2 \\
\hline
\end{tabular}




\subsubsection{Seguimiento de la degradación de los contaminantes por fluorescencia}

Durante el tratamiento realizado en planta piloto, se han tomado muestras a diferentes tiempos y se ha realizado el seguimiento de la degradación y de los posibles cambios químicos que puedan sufrir los contaminantes durante el proceso. El rango de Ex/Em al que se han medido las diferentes muestras ha sido de 250/500 y 300/550 nm respectivamente cada $5 \mathrm{~nm}$. Se han analizado las diferentes matrices obtenidas por PARAFAC testeando los modelos de tres a seis componentes. Se ha elegido como valido el modelo de cuatro componentes de acuerdo con el sentido químico de los compuestos presentes en la mezcla a tratar. En la Figura 4.4.4-1 se muestran los diferentes componentes obtenidos.
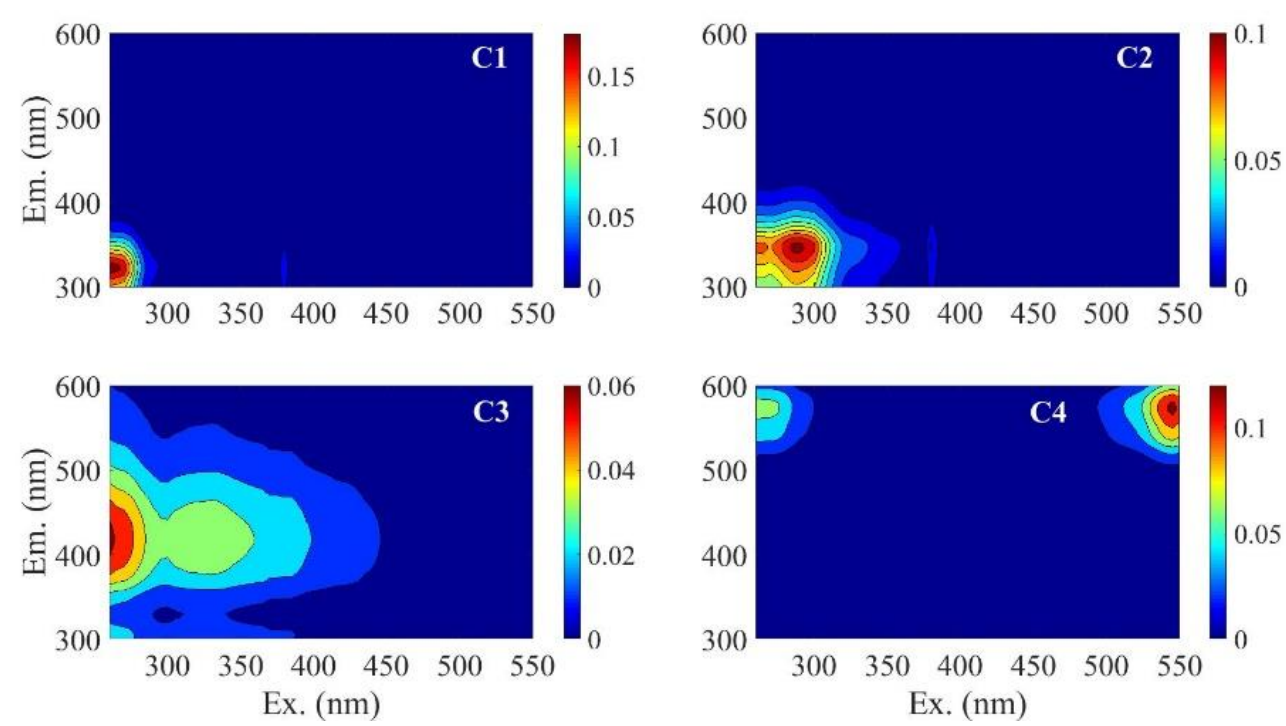

Figura 4.4.4-1. Diferentes componentes presentes en la degradación obtenidos por PARAFAC para el experimento realizado en la planta piloto. Condiciones experimentales: [parabenos] $5 \mathrm{mg} \mathrm{L}^{-1}$ cada uno, $[\mathrm{Fe}(\mathrm{III})]_{0} 5 \mathrm{mg} \mathrm{L}^{-1},\left[\mathrm{H}_{2} \mathrm{O}_{2}\right]_{0} 426 \mathrm{mg} \mathrm{L}^{-1}$, $[\mathrm{STH}]_{0} 20 \mathrm{mg} \mathrm{L}^{-1}, \mathrm{pH}_{0}$ 5. El eje X corresponde a las longitudes d eonda de excitación (250-500 nm) y el eje Y a las longitudes de onda de emisión (300-600 nm).

Si se observa la matriz de Ex/Em obtenida para el tiempo 0 minutos del experimento (Figura 4.4.4-2), puede verse que la región de máxima intensidad corresponde con los componentes $\mathrm{C} 1$ y $\mathrm{C} 2$, por lo que estos dos componentes corresponderían a las EEM de la mezcla de parabenos. El componente C3 corresponde a las sustancias tipo húmicas; éstas presentan un área de máxima intensidad de Ex/Em que se divide en tres regiones 237-260/400-500, 300-370/400-500 y, 290-325/370-430 nm según Yang et al., 2015. En este caso concreto se observa la región de máxima intensidad entre 250-300/300-450 nm Ex/Em y otra con menor intensidad entre 327-375/350-475 nm de Ex/Em. El componente 
C4 podría corresponder a algún intermedio de reacción formado durante el proceso oxidativo.

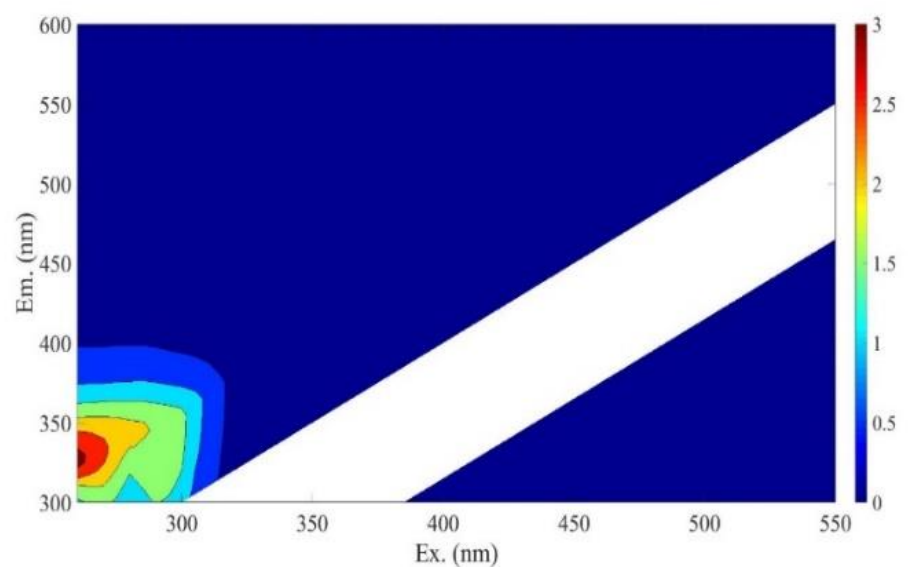

Figura 4.4.4-2. EEM obtenida para el tiempo 0 minutos de tratamiento. Condiciones experimentales: [parabenos $]_{0} 5 \mathrm{mg} \mathrm{L}^{-1}$ cada uno, [Fe(III) $]_{0} 5 \mathrm{mg} \mathrm{L}^{-1},\left[\mathrm{H}_{2} \mathrm{O}_{2}\right]_{0} 426 \mathrm{mg} \mathrm{L}^{-1}$, [STH $]_{0} 20 \mathrm{mg} \mathrm{L}^{-1}, \mathrm{pH}_{0} 5$. El eje X corresponde a las longitudes d eonda de excitación $(250-500 \mathrm{~nm})$ y el eje $\mathrm{Y}$ a las longitudes de onda de emisión (300-600 nm).

Observando la evolución de los diferentes componentes a lo largo del tratamiento, los componentes $\mathrm{C} 1$ y $\mathrm{C} 2$ que corresponderían a la mezcla de parabenos disminuyen conforme avanza el proceso de oxidación, de acuerdo con lo observado durante el proceso oxidativo (Figura 4.4.4-3). Lo mismo ocurre con las STH (componente C3). Como se ha explicado anteriormente (Apartado 1.2.2.3.4.1.6.4) las STH son sensibles a la oxidación y también pueden sufrir degradación. El componente C4 aumenta su intensidad alcanzando el máximo a los 10 minutos y disminuyendo de nuevo con el tiempo. Teniendo en cuenta los resultados de toxicidad anteriores, este componente puede atribuirse a intermedios de reacción. Los ensayos de toxicidad muestran que al final del tratamiento oxidativo no se ha detoxificado la muestra de parabenos. Aunque este componente presente mayor intensidad en la muestra intermedia, es posible que, en el tiempo final, aun teniendo menos intensidad, la muestra sea más tóxica, ya que deben existir otros compuestos intermedios que no posean tanta señal de fluorescencia. 


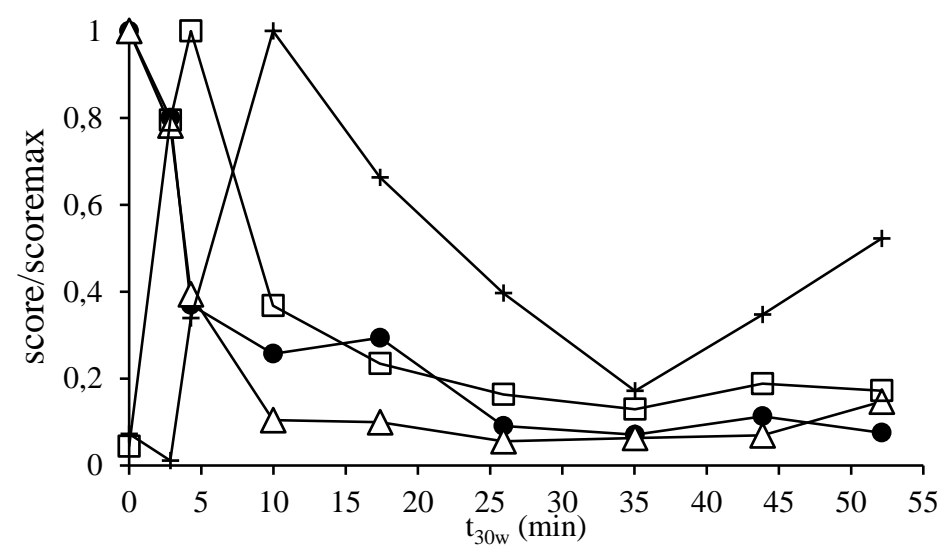

Figura 4.4.4-3. Evolución de los distintos componentes a lo largo del proceso de degradación. Experimento realizado en la planta piloto. Condiciones experimentales: [parabenos $]_{0} 5 \mathrm{mg} \mathrm{L}^{-1}$ cada uno, $[\mathrm{Fe}(\mathrm{III})]_{0} 5 \mathrm{mg}$ $\mathrm{L}^{-1},\left[\mathrm{H}_{2} \mathrm{O}_{2}\right]_{0} 426 \mathrm{mg} \mathrm{L}^{-1},[\mathrm{STH}]_{0} 20 \mathrm{mg} \mathrm{L}^{-1}, \mathrm{pH}_{0} 5 . \mathrm{C} 1(\bullet), \mathrm{C} 2(\Delta), \mathrm{C} 3(\square), \mathrm{C} 4(+)$.

Sería interesante ampliar los estudios sobre los mecanismos de degradación de estos parabenos para relacionar el componente $\mathrm{C} 4$ con los intermedios más probables y con el repunte de toxicidad que se observa en el tratamiento. Esto nos permitiría determinar con mayor precisión el tiempo óptimo de este tratamiento. 
Resultados y discusión 


\subsection{UTILIZACIÓN DE SUSTANCIAS TIPO HÚMICAS PARA LA ELIMINACIÓN DE CONTAMINANTES POR SISTEMA DE MEMBRANAS ACOPLADO A UN PROCESO OXIDATIVO (FOTO-FENTON)}

\subsubsection{Introducción}

El soil washing (lavado de suelos) es una técnica basada en la utilización de tensioactivos para la eliminación de contaminantes en suelos, que considera tanto la capacidad solubilizadora de las micelas formadas por el uso de tensioactivos, como la reducción de la tensión entre estos y las partículas del suelo (Fabbri et al., 2008). Se basa en la separación de los contaminantes diana de la matriz del suelo solubilizándolos en la solución de lavado (Moutsatsou et al., 2006). Posteriormente la solución de lavado ha de someterse a tratamientos químicos o bioquímicos para conseguir eliminar el contaminante lavado.

Para el lavado de suelos se han utilizado tradicionalmente ácidos $\left(\mathrm{HCl}, \mathrm{H}_{2} \mathrm{SO}_{4}, \mathrm{HNO}_{3}\right)$, ácidos orgánicos de bajo peso molecular (cítrico, oxálico) y algunos agentes quelantes sínteticos como el NTA, EDDS, DTPA o el EDTA (Gusiatin et al., 2020), estos últimos debido a su capacidad complejante (Soleimani et al., 2010). Como se ha explicado en capítulos anteriores, las sustancias húmicas $(\mathrm{SH})$ y las sustancias tipo húmicas (STH) poseen capacidad complejante y además han demostrado que debido a su estructura pueden movilizar y neutralizar metales pesados (Huculak-Maczka et al., 2018).

Por otra parte, las STH son moléculas anfifílicas capaces de generar de forma espontánea agregados cuando se encuentran en disolución (Klavins \& Purmalis, 2010), actuando como surfactantes. La formación de estos agregados puede producirse de forma intra e intermolecular (Lippold et al., 2008). Autores como Piccolo et al., 2001; Conte et al., 2005, sugieren que las SH se encuentran en forma de pseudomicelas, pero existen muchos modelos estructurales de la forma que pueden presentar estos agregados.

Las SH se han utilizado en el proceso de soil washing para eliminar metales pesados del suelo (Bi et al., 2019). La concentración micelar crítica (cmc) depende de varios factores como la temperatura, el pH y el origen de las SH. Damian et al., 2019 utilizaron sustancias húmicas para la eliminación de $\mathrm{Cu}$ y $\mathrm{Pb}$ obteniendo buenos resultados y concluyendo que la eficiencia del proceso depende del tiempo de contacto, del ratio suelo:solución, de la concentración de SH y del hecho, que las SH son buenos agentes de lavado cuando el suelo está contaminado con metales pesados y otros contaminantes a altas 
concentraciones. También han demostrado ser útiles para el lavado de hidrocarburos aromáticos y compuestos orgánicos (Conte et al., 2005; Borggaard et al., 2009).

Cuando se descontamina un suelo, hay que considerar también la toxicidad y los cambios que el agente de lavado utilizado puede ocasionar sobre el mismo. El uso de algunos agentes quelantes químicos está cuestionado ya que, presentan toxicidad y si una vez lavado el suelo no se recuperan completamente estos compuestos, pueden ocasionar problemas futuros. Por este motivo, el desarrollo y búsqueda de agentes de lavado alternativos a los tradicionales, que sean biodegradables, que no presentes toxicidad y que sean asequibles está tomando fuerza (Gusiatin et al., 2020).

Con estos antecedentes, se plantea estudiar la interacción de las STH obtenidas en esta tesis con contaminantes emergentes, como por ejemplo el TBZ, cuando se encuentran próximos a su punto de saturación. Se quiere investigar cómo las STH aumentan la solubilidad del contaminante, y en qué medida la capacidad surfactante y de formación de micelas de las STH con el contaminante pueden favorecer su retención en el interior o en la superficie de las micelas.

El objetivo de este capítulo es la posible aplicación de dos procesos acoplados (membranas y fotocatálisis) para la descontaminación de suelos y aguas con una elevada carga de contaminante. Primero se llevará a cabo el proceso de membranas estudiando la selección del tamaño de poro, pH más adecuado y relación TBZ:STH que proporcione mejores resultados. Posteriormente el retentato (RT) obtenido, va a ser tratado por proceso foto-Fenton, en el que se va a comprobar si pueden conseguirse buenos resultados de degradación del contaminante.

\subsubsection{Extracción STH y selección del contaminante}

Las STH utilizadas para los experimentos de soil washing se han extraído de lodos procedentes del reactor anaerobio de EDAR, y la extracción se ha realizado de acuerdo con el procedimiento descrito por García-Ballesteros et al., 2018 (Apartado 4.2.2.). La generación de lodos derivados del tratamiento de aguas va en aumento por lo que el desarrollo de tecnologías y métodos para su aplicación en diferentes procesos y por tanto su revalorización, está tomando fuerza. Las STH extraídas de los lodos de depuradora contienen un $27 \%$ de materia orgánica, de la cual un $91 \%$ son ácidos húmicos (AH) (Gusiatin et al., 2020). 
El contaminante utilizado ha sido el tiabendazol (TBZ), y su selección se basó en el trabajo realizado por Caram et al., 2018 en el que utilizaron unas STH procedentes de residuos sólidos urbanos (CVT-230) y probaron su efectividad como agentes auxiliares en el proceso foto-Fenton a pHs más próximos a la neutralidad, observando que las STH ayudan a aumentar la solubilidad del contaminante y que se produce una interacción entre el contaminante y las STH. Aquí se quiere comprobar si este efecto observado con los residuos italianos (CVT-230), se da también en nuestras STH y puede ser útil para atrapar el contaminante presente en una disolución acuosa y ser retenido en un tratamiento por membranas, de modo que el agua filtrada quede libre del contaminante y se pueda tratar una disolución de menor volumen y mayor concentración de contaminante (el RT).

\subsubsection{Caracterización de las STH}

En primer lugar, se ha medido la tensión superficial de las STH a diferentes concentraciones (5-0.5 $\mathrm{g} \mathrm{L}^{-1}$ ) para comprobar su capacidad de actuar como surfactantes.

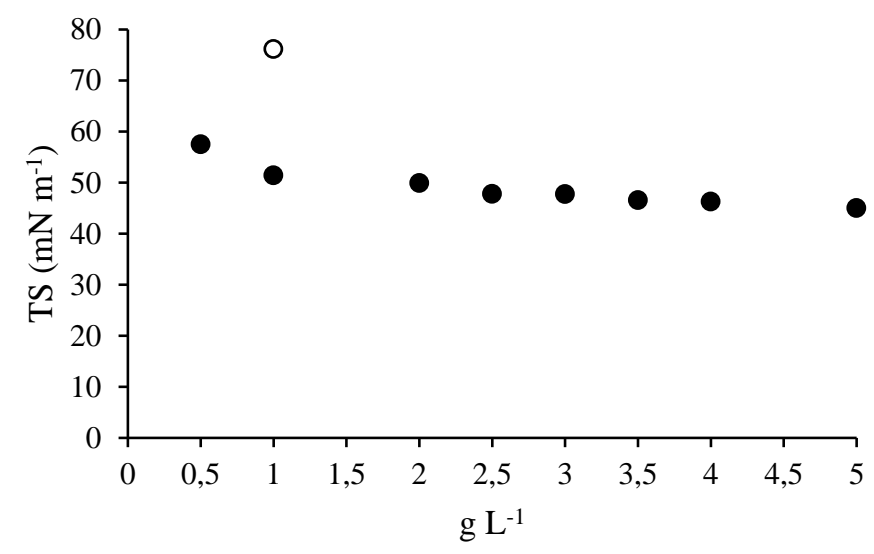

Figura 4.5.3-1. Tensión superficial $\left(\mathrm{mN} \mathrm{m}^{-1}\right)$ para las $\mathrm{STH}$ extraídas de los lodos de EDAR a diferentes concentraciones $(\bullet)$ y para el agua $(\circ)$.

Como se observa en la Figura 4.5.3-1, a cualquiera de las concentraciones seleccionadas, la presencia de STH reduce la tensión superficial respecto al valor de tensión superficial del agua $\left(76.17 \mathrm{mN} \mathrm{m}^{-1}\right)$, por lo que deducimos que estas STH poseen capacidad tensioactiva y van a ser capaces de formar micelas en disolución, atrapando al contaminante, y por tanto aumentando su solubilidad en agua.

Es importante conocer el tamaño medio de las STH, debido a que posteriormente van a ser sometidas a una separación mediante membranas y necesitamos saber si serán capaces de atravesarlas. Este parámetro se mide por dispersión de luz dinámica (DLS). Para ello 
se han preparado disoluciones de $2.5 \mathrm{~g} \mathrm{~L}^{-1}$ a $1 \mathrm{~g} \mathrm{~L}^{-1}$ en agua del grifo (Figura 4.5.3-2), obteniéndose un tamaño medio de partícula de $425.32 \mathrm{~nm}$. Las STH son macromoléculas con capacidad de formar agregados, que pueden romperse y volverse a formar. Se espera que una parte de las STH sí atraviesen la membrana, pero, en cualquier caso, la mayoría permanecerán en el tanque de alimentación.

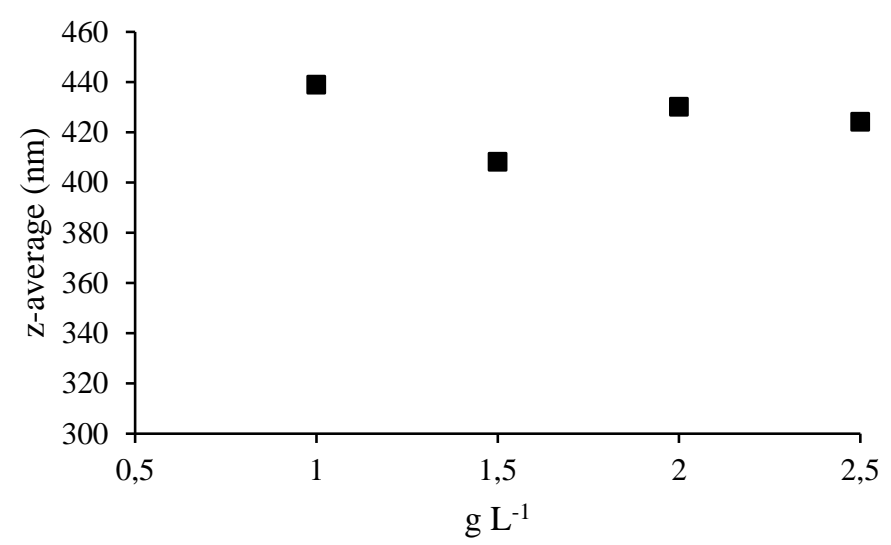

Figura 4.5.3-2. Valores de tamaño medio obtenido (nm) por DLS para diferentes concentraciones de STH

\subsubsection{Selección de la membrana}

El siguiente paso en nuestra investigación es seleccionar un tamaño de poro de membrana; Probamos unas membranas de $50 \mathrm{kDa}$ para realizar experimentos iniciales y determinar si es adecuado para completar la investigación. Se selecciona esta membrana de ultrafiltración debido a que este tipo de membranas separa partículas con tamaños entre alrededor de 0.04 y 0.1 micrometros $(40-100 \mathrm{~nm})$.

Una vez seleccionada la membrana, el siguiente paso es saber si el contaminante queda retenido en la membrana, aunque debido a su peso molecular $201.249 \mathrm{~g} \mathrm{~mol}^{-1}$ no tendría que hacerlo. Las condiciones de operación fueron 2 bares y temperatura ambiente.

Se prepararon disoluciones de TBZ $\left(50 \mathrm{mg} \mathrm{L}^{-1}\right)$. La Figura 4.5.4-1 muestra el paso del TBZ a través de la membrana de $50 \mathrm{kDa}$. Como puede observarse, al cabo de 90 minutos ha atravesado la membrana una cantidad de $73 \mathrm{mg}$ de TBZ, por lo que a partir de aquí sabemos que el TBZ en disolución en ausencia de las STH sí pasa por la membrana. 


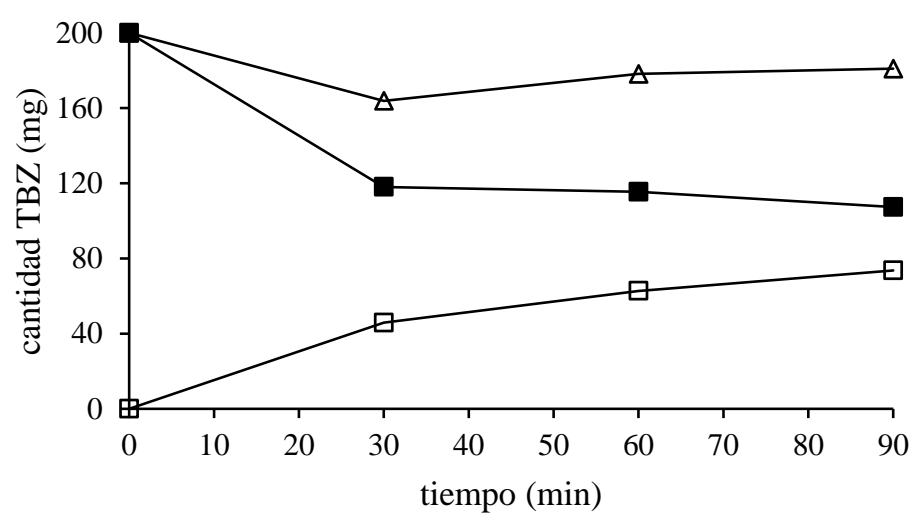

Figura 4.5.4-1. Relación cantidad de TBZ (mg) vs tiempo (min) para el PM (口), RT (•) y la suma de ambos $(\Delta)$. Condiciones experimentales: [TBZ] $]_{0} 50 \mathrm{mg} \mathrm{L}^{-1}, \mathrm{P} 2 \mathrm{bar}, \mathrm{T}^{\mathrm{a}}$ ambiente, membrana de $50 \mathrm{kDa}$.

\subsubsection{Selección de la relación TBZ:HLS}

Para saber si el TBZ era capaz de atravesar la membrana de 50kDa en presencia de las STH y determinar las mejores condiciones de trabajo, se realizaron una serie de pruebas con dos relaciones TBZ:STH y diferentes pHs. Las pruebas se llevaron a cabo en discontinuo, utilizando la membrana cerámica de tamaño de poro $50 \mathrm{kDa}$ y aire a presión ( 2 bar), por lo que no hay recirculación de la muestra y solo se toman muestras inicial y final del RT. La Figura 4.5.5-1 muestra la cantidad total de TBZ (mg) para el retentato (RT, en gris claro) y permeado (PM, en gris oscuro) al final del proceso. Después de un ciclo completo de filtración, vemos que con la relación 1:40 somos capaces de concentrar el tiabendazol, mientras que, con relaciones más bajas, las STH no parecen ser capaces de retener a todo el contaminante formando micelas, por lo que el TBZ atraviesa la membrana sin poderse concentrar.

La duración total de cada proceso de filtrado fue de 6 horas, tomándose muestras intermedias para su análisis por cromatografía liquida, fluorescencia y TOC. Se estudió la relación TBZ:STH 1:20 y 1:40 a pHs: 5, 6 y 7, obteniéndose los mejores resultados con la relación $1: 40$ independientemente del $\mathrm{pH}$. 


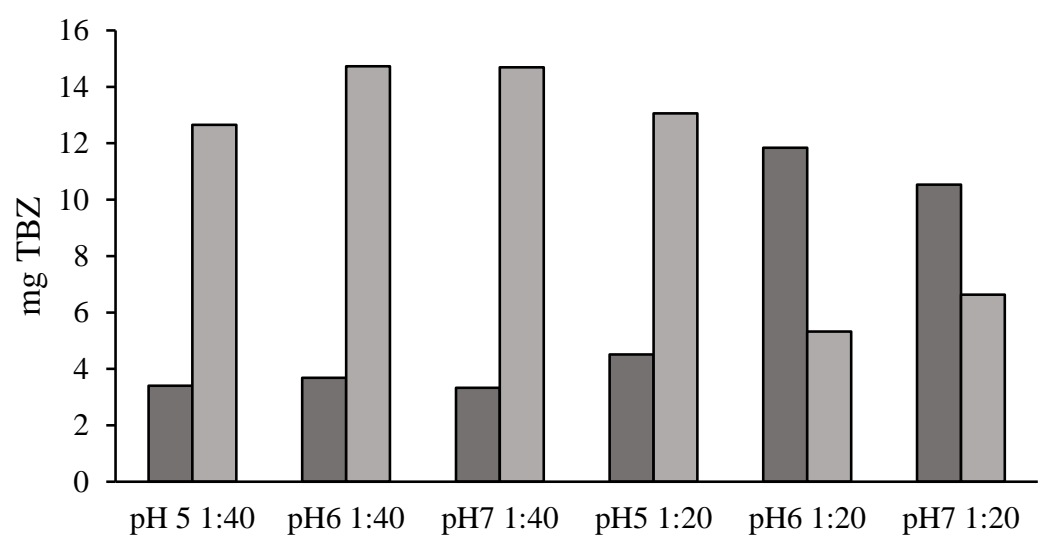

Figura 4.5.5-1. Cantidad de TBZ (mg) presente en el RT (gris claro) y PM (gris oscuro) al final del proceso de membranas (6 horas). [TBZ $]_{0} 50 \mathrm{mg} \mathrm{L}^{-1}$ y $[\mathrm{STH}]_{0} 20$ y $40 \mathrm{~g} \mathrm{~L}^{-1}$.

Al no observarse grandes diferencias de eficacia de retención en los 3 pHs analizados para la relación TBZ:STH 1:40, se decide continuar con las pruebas a $\mathrm{pH} 7$ ya que es el pH más próximo al $\mathrm{pH}$ que va a encontrarse en las aguas contaminadas.

Estos experimentos son realizados en discontinuo, ya que el objetivo principal es determinar la relación de mezcla inicial para formar las micelas. En este sentido, cabe destacar que esta es la principal razón por la cual el balance de materia entre retentato y permeado no suma la cantidad inicial de $25 \mathrm{mg}$, debido a que las micelas al no estar en agitación se van agrupando e incluso algunas precipitan. Para comprobar si el TBZ se queda retenido en los poros de la membrana o formando una torta sobre su superficie debido a la presencia de las STH, se pasa metanol a través de la membrana y se mide el TBZ por UHPLC. Se obtiene una cantidad de $2 \mathrm{mg}$, es decir, un $8 \%$ del total, por lo que aunque una pequeña parte del TBZ pueda quedar retenido en la membrana, el TBZ que falta para cerrar el balance de materia se encontraría dentro de las micelas que forman las STH y que se encuentran en el tanque de alimentación.

\subsubsection{Selección de la presión de trabajo}

Una vez seleccionada la mejor relación TBZ:STH (relación 1:40 y pH 7) se pasa a realizar los experimentos utilizando la bomba y aplicando diferentes presiones de trabajo (2 y 1 bar) y con recirculación del RT. 

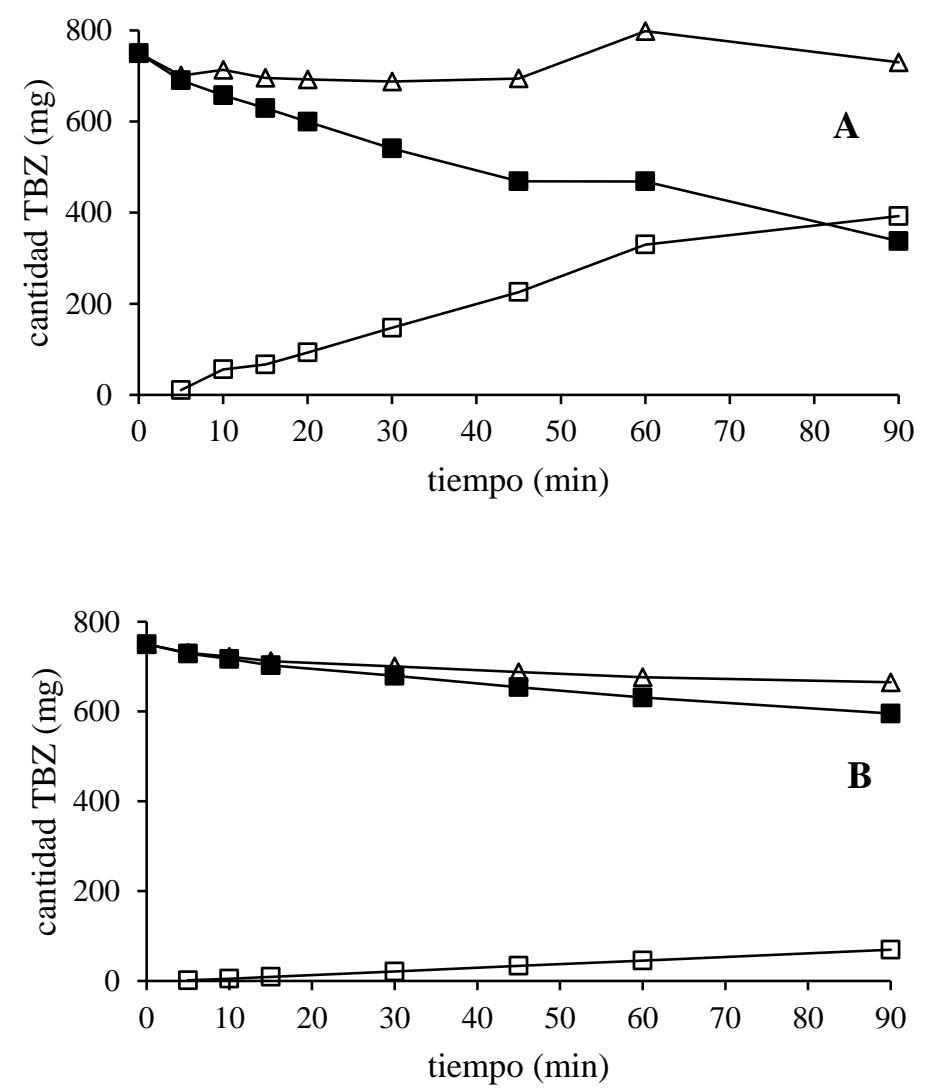

Figura 4.5.6-1. Relación cantidad de TBZ (mg) vs tiempo (min) para el PM (口), RT (•) y la suma de ambos $(\Delta)$. Experimento relación TBZ: STH 1:40, $\mathrm{pH}_{0} 7$ y, (A) 2 bar, (B) 1 bar.

Como se observa en la Figura 4.5.6-1A, a 2 bar de presión y con un tiempo de 90 minutos de duración del proceso de filtrado, no conseguimos la concentración del TBZ (392mg en permeado, superior al $337 \mathrm{mg}$ del permeado). Esto puede ser debido a que la presión de 2 bares influye en el tamaño de las micelas y posiblemente en su rotura al paso a través de los poros de la membrana. Es posible que a medida que se va recirculando la mezcla y debido a la presión, las micelas vayan reduciéndose de tamaño e incluso, liberando el TBZ. Cuando observamos los resultados del experimento realizado a 1 bar de presión, se obtienen resultados mucho más satisfactorios (Figura 4.5.6-1B). En este caso, solo traspasa la membrana un $8.7 \%$ del total del TBZ inicial, aumentándose la concentración de TBZ en el RT.

Con todo lo expuesto, podemos concluir que, a presiones elevadas, las micelas se rompen y pueden liberar el TBZ retenido, facilitando su paso a través de la membrana; en cambio, a menores presiones el contaminante sigue atrapado en su interior, pudiéndose concentrar y alcanzar nuestro objetivo de separar gran cantidad de contaminante. En estos casos, la suma final del TBZ presente en el RT y PM tampoco suma la cantidad total introducida 
en el tanque de alimentación, por lo que de deduce que parte quedará retenido en forma de torta o como parte del fouling de la membrana. Es importante tenerlo en cuenta en un futuro en estudios de limpieza y mantenimiento de las membranas.

De forma complementaria se han realizado ensayos de TOC para corroborar los ensayos anteriores. Al igual que en los resultados mostrados en la Figura 4.5.6-1, solo hay una concentración de TOC significativa cuando se opera a presiones de 1 bar.

La Figura 4.5.6-2 muestra la evolución de la medida del TOC a lo largo del proceso para los dos casos anteriores.
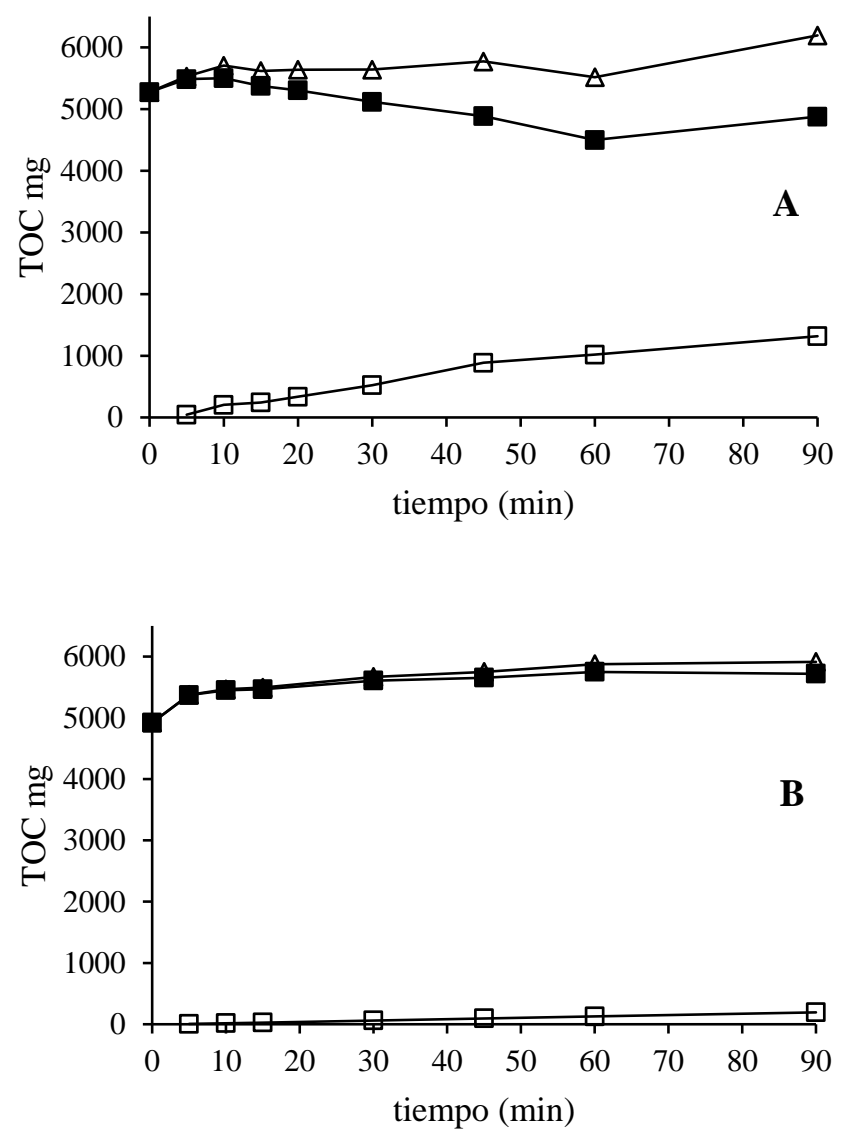

Figura 4.5.6-2. Relación TOC (mg) vs tiempo (min) para el PM ( $\square)$, RT (๘) y la suma de ambos $(\Delta)$. Experimento relación TBZ: STH 1:40, $\mathrm{pH}_{0} 7$ y, P (A) 2 bar, (B) 1 bar.

\subsubsection{Seguimiento del proceso por fluorescencia}

Se considera interesante realizar un análisis de fluorescencia para determinar que especies son las que se observan y si esta técnica analítica puede utilizarse como método de análisis complementario en este caso. 
Los resultados de los experiementos realizados, se han confirmado mediante el uso de espectroscopía de fluorescencia como técnica analítica complementaria. Se han medido las matrices de Ex/Em y los espectros se han analizado por PARAFAC. El barrido de Ex/Em se ha realizado de 250-550 nm y de 300-600 nm cada $5 \mathrm{~nm}$. Dentro del set de datos analizado se han incluido medidas de las STH a 20 y $50 \mathrm{mg} \mathrm{L}^{-1}$ y del TBZ a la concentración utilizada en los procesos de membrana a pH 2.8 y 5. Se ha realizado el analisis de 3 a 6 componentes y se ha validado el modelo para 3 y 4 componentes. Se ha elegido el modelo de 4 componentes (Figura 4.5.7-1) en base al sentido químico del proceso y teniendo en cuenta los resultados obtenidos por Caram et al., 2018.
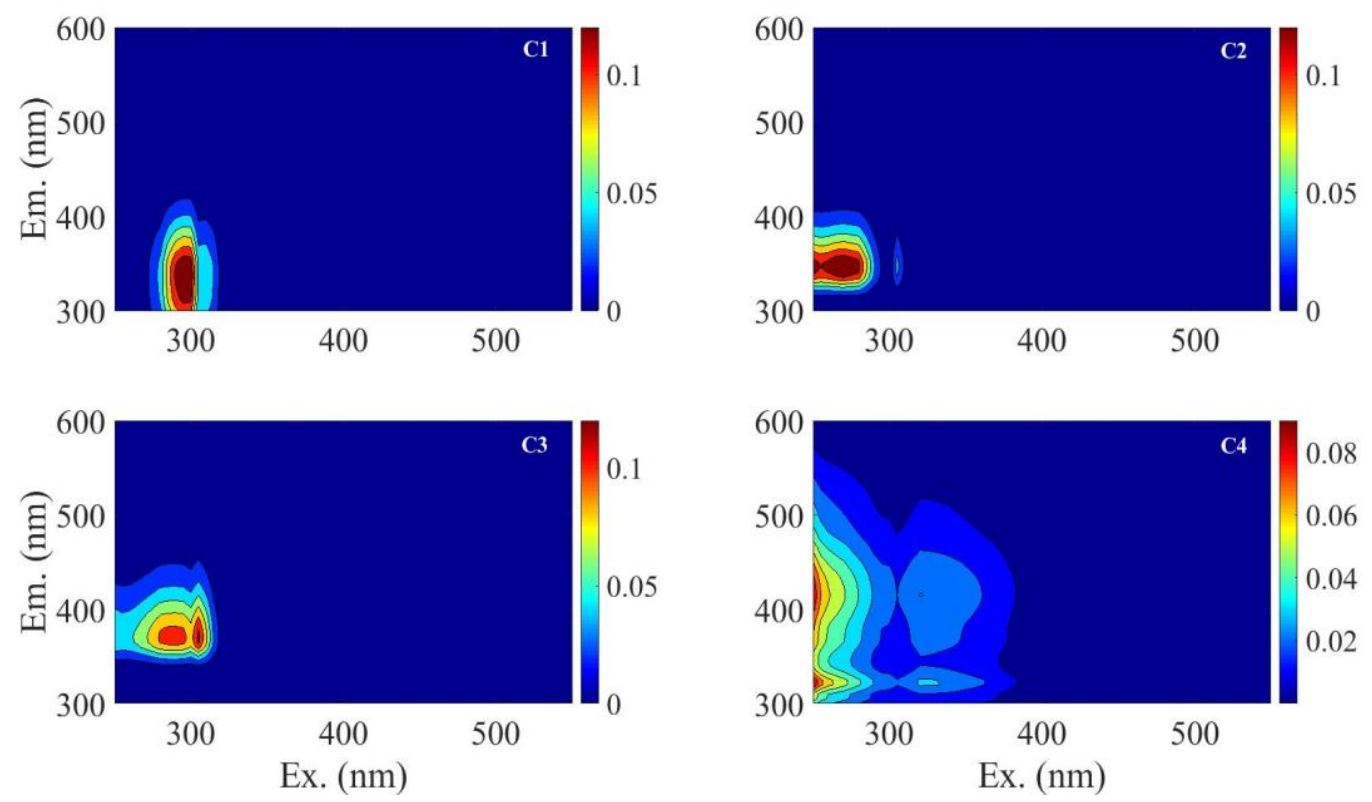

Figura 4.5.7-1. Diferentes componentes obtenidos para el análisis por PARAFAC. Set de datos compuesto por todas las muestras tomadas para el resto de los análisis. Incluye las muestras a diferentes tiempos de los experimentos para selección de la membrana, selección de la relación TBZ:STH y selección de la presión de trabajo, así como disoluciones de TBZ y STH por separado. El eje X corresponde a las longitudes d eonda de excitación (250-500 nm) y el eje Y a las longitudes de onda de emisión (300-600 nm).

El componente C1 y el componente C2 con máximos de Em entre 300-350 y 350 nm respectivamente corresponden a la forma ácida y básica del TBZ de acuerdo con lo obtenido por Caram et al., 2018 en sus experimentos de foto-Fenton con este contaminante. El componente $\mathrm{C} 4$ se encuentra dentro de la región que se atribuye a las STH, Ex/Em 250-370/350-500 nm (Yang et al., 2015). El componente C3 puede atribuirse a la presencia de proteínas, que puede justificarse debido al origen del residuo del que se han extraído las STH (lodos de EDAR), aunque también podría deberse a la 
asociación entre el TBZ y las STH. Los resultados obtenidos están en concordancia con los obtenidos en el estudio de Caram et al., 2018. Validaron el modelo por PARAFAC para 5 componentes. Midieron por fluorescencia disoluciones de TBZ a diferentes pHs en ausencia de STH. Obtuvieron tres factores, de los cuales, dos correspondían a las formas ácido base del TBZ (que se observaban también en las medidas anteriores en presencia de las $\mathrm{STH}$ ) y un tercer componente que aumentaba en torno a $\mathrm{pH} 4.5$ (coincidiendo con el $\mathrm{pK}_{\mathrm{a}}$ del TBZ=4.8) y con la forma básica del TBZ, menos soluble que su forma ácida. Además, en este caso, la banda de dispersión de primer orden de Rayleigh aumentaba, lo que indica la presencia de agregados no solubles. En las muestras en las que había también STH y se encontraban en las mismas condiciones de pH, no se observa este componente, lo que reafirma la idea de una interacción entre el TBZ y las STH de forma que las STH favorecían la solubilidad del TBZ, como también hemos observado nosotros en nuestro experimento de aplicación de soil washing para concentrar el contaminante con nuestras STH.

\subsubsection{Ensayos foto-Fenton del RT obtenido al final del proceso de membranas}

Una vez seleccionadas las mejores condiciones de trabajo (tamaño de poro de la membrana $50 \mathrm{kDa}$, presión de trabajo de 1 bar y relación TBZ:STH (1:40), se procede a oxidar el RT por aplicación de un proceso tipo foto Fenton.

Como la relación TBZ:STH es elevada, las STH se encuentran en alta proporción en la mezcla y es necesario eliminar la parte sedimentada antes de aplicar ningún proceso de oxidación. Este proceso se ensaya de dos modos diferentes, por una parte, el RT se filtra por papel de filtro de laboratorio con tamaño de poro de $12-15 \mu \mathrm{m}$ y en otro experimento, el retentato se deja sedimentar.

Las STH son coloreadas por lo que un exceso de estas puede actuar como filtro interno impidiendo que penetren los fotones en la matriz a tratar. La cantidad de $\mathrm{H}_{2} \mathrm{O}_{2}$ a adicionar en cada uno de los casos se determinó a partir de las respectivas DQO obtenidas, añadiéndose la mitad del valor de DQO, $137.4 \mathrm{mg} \mathrm{L}^{-1}$ y $183 \mathrm{mg} \mathrm{L}^{-1} \mathrm{M}$ para el RT filtrado y sedimentado respectivamente. La concentración de TBZ fue la determinada por cromatografía líquida después del proceso de membranas (44.25 $\mathrm{mg} \mathrm{L}^{-1}$ ) y la concentración de $\mathrm{Fe}(\mathrm{III})$ de $5 \mathrm{mg} \mathrm{\textrm {L } ^ { - 1 }}$. El pH se modificó adicionando $\mathrm{H}_{2} \mathrm{SO}_{4}$ hasta un valor de 5 . 


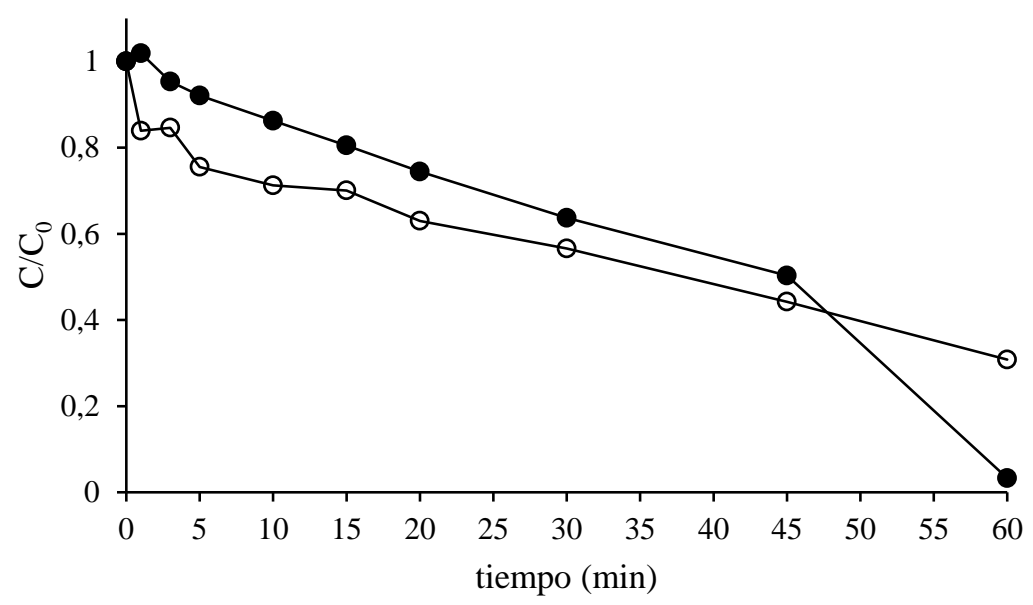

Figura 4.5.8-1. Proceso foto-Fenton del RT obtenido para el proceso de membranas utilizando un tamaño de poro de $50 \mathrm{kDa}, 1$ bar de presión de trabajo y, una relación TBZ:STH 1:40. (•): RT filtrado con papel de filtro, (०): RT sedimentado. Condiciones experimentales: [TBZ] $]_{0} 44.25 \mathrm{mg} \mathrm{L}^{-1}$, [Fe(III) $]_{0} 5 \mathrm{mg} \mathrm{L}^{-1}$, $\left[\mathrm{H}_{2} \mathrm{O}_{2}\right]_{0}(\bullet) 137.4 \mathrm{mg} \mathrm{L}^{-1},(\circ) 183 \mathrm{mg} \mathrm{L}^{-1}, \mathrm{pH}_{0} 5$.

En la Figura 4.5.8-1 se observa que en el caso en que el RT ha sido filtrado (•) con papel de filtro previo al proceso foto-Fenton al cabo de una hora de tratamiento se alcanza un 97\% de degradación del contaminante, mientras que cuando se ha sedimentado (०) se elimina un 70\%. En cualquiera de los dos casos teniendo en cuenta la elevada concentración de TBZ y de STH se obtienen buenos resultados de degradación.

Estos resultados se atribuyeron a la posible interacción entre las STH y el contaminante; se observa que las STH ayudan a aumentar la solubilidad del contaminante debido a que la capacidad surfactante de estas sustancias favorece la reactividad de los contaminantes con las especies oxidantes presentes.

El hecho de que se hayan obtenido mejores resultados de degradación en el caso en el que se ha filtrado el RT puede resultar positivo, ya que podrían recuperarse las STH y utilizarse de nuevo en el proceso. El requisito de reutilización es una de las características para tener en cuenta cuando se realiza el proceso de soil washing. 


\section{CONCLUSIONES}


Conclusiones 
De la presente tesis doctoral se derivan las siguientes conclusiones:

Es posible la extracción de sustancias tipo húmicas de diferentes residuos orgánicos, fomentando la economía circular y la revalorización de residuos. Estas STH pueden adicionarse al proceso foto-Fenton y llevarlo a pHs más próximos a la neutralidad con buenos resultados de degradación.

Aunque el uso de algunas STH aplicadas al proceso foto-Fenton como agentes complejantes del hierro ya ha sido investigada con anterioridad, en esta tesis se obtienen STH procedentes de residuos de distinta naturaleza como son los posos de café y se caracterizan y comparan con otras $\mathrm{STH}$, colaborando de esta forma a la revalorización de otros residuos.

En el presente estudio se profundiza en las propiedades y características de distintas STH (procedentes de alpechín, lodos de EDAR y posos de café), concluyendo que no es necesario ningún proceso de fermentación previo a la extracción de estas sustancias.

Se ha demostrado que la utilización de procesos de membrana para la separación de fracciones con diferentes tamaños de partícula, no se considera un proceso necesario, ya que la eficiencia en el proceso foto-Fenton de unas u otras fracciones es muy similar.

Se ha demostrado que la técnica EPR es un buen método para obtener más información sobre el mecanismo de reacción de la aplicación de STH en proceso foto-Fenton a pHs más neutros. Nos permite tener más conocimiento acerca de uno de sus principales aspectos limitantes, la generación de cantidades adicionales de especies reactivas frente a su capacidad de atrapar estas mismas especies oxidantes reduciendo la eficiencia del proceso.

Se ha observado una buena correlación entre la capacidad de las sustancias STH para generar radicales $\mathrm{OH}$ - y la degradación de contaminantes por proceso tipo Fenton y tipo foto-Fenton. La adición de bajas cantidades de STH conlleva la generación de bajas concentraciones de especies oxidantes, que se manifiestan insuficientes para poder complejar el hierro presente en la disolución, mientras que, cantidades muy elevadas de STH se traduce en una perdida en la eficiencia del proceso debido a la interacción de estas con los radicales generados. 
De los tres residuos orgánicos seleccionados como aditivo para el proceso foto-Fenton (alpechín, café y lodos de EDAR) para el tratamiento de una mezcla de parabenos, el que mejores resultados muestra es el del café. El uso de las STH extraídas del café permite extender el pH del proceso foto-Fenton hasta 5 con buenos resultados de degradación. Los ensayos de toxicidad revelan que, aunque a tiempos cortos de tratamiento se eliminan los compuestos principales, las muestras tratadas siguen presentando toxicidad, especialmente la muestra a tiempo intermedio. Sería interesante considerar menores tiempos de tratamiento para este tipo de mezcla de parabenos bajo las condiciones estudiadas, para evitar la formación de esos intermedios tóxicos derivados de la degradación de parabenos.

Se pone de manifiesto la necesidad de realizar ensayos toxicológicos de manera complementaria sobre organismos pertenecientes a diferentes niveles de la cadena trófica, ya que, sin esta variedad de ensayos, es imposible conocer la detoxificación real de las muestras de agua tratadas.

Algunos aspectos relacionados con la aplicación de las STH en procesos tipo foto-Fenton requieren de mayor investigación, como las condiciones óptimas de operación y el mecanismo de complejación entre el hierro y estas sustancias. Pero, en cualquier caso, las STH extraídas de diferentes tipos de residuo han demostrado ser eficientes en la mejora del proceso foto-Fenton a pHs más neutros.

Por último, las STH (en este caso las de lodo de depuradora) cuando se aplican a un proceso de membranas junto con un contaminante a altas concentraciones han demostrado ser eficaces en la concentración del contaminante en el tanque de alimentación (retentato) y, por tanto, obtención de un menor volumen para poder ser tratado posteriormente por el proceso foto-Fenton. Al usarse membranas de ultrafiltración se está reduciendo el gasto energético derivado del coste de las membranas de nanofiltración y de la presión de trabajo más elevada que sería necesaria en este caso.

Se ha puesto de manifiesto el potencial uso de las STH para diferentes aplicaciones medioambientales, poniendo el foco en la revalorización de residuos y fomento de la economía circular, contribuyendo a crear un futuro más sostenible.

Is possible the isolation of humic like substances from different organic residues, promoting circular economy and waste revalorization. These HLS could be added to 
photo-Fenton process and drive it to circumneutral $\mathrm{pHs}$ achieving good detoxification results.

Although some information about how these HLS can complex iron have been investigated before, in the present work HLS isolated from different sources had been obtained, as from coffee, and had been compared with other HLS, collaborating to other wastes revalorization.

In the present study, further insight is gain in the properties and characteristics of different HLS (olive mill wastes, coffee wastes, and sludge from wastewater treatment plant), concluding that is not necessary any fermentation process before the isolation of the substances.

The use of membrane processes for the separation in different particles sizes, has been demonstrated not to be necessary, because the efficiency of photo-Fenton process is quite similar in the use of one size or another.

EPR technique is a good way to obtain major information related to the reaction mechanism when these HLS are applied to photo-Fenton process at circumneutral pHs. Helps to elucidated one of the major drawbacks of these substances, the quantity of reactive species generates by HLS in comparison with the ability of HLS to catch these reactive species decreasing the efficiency of the process.

Good relationship between the ability of these substances to generate $\mathrm{OH}$ - and pollutants degradation by photo-Fenton process and photo-Fenton like processes was observed. The addition of low quantities of HLS generates few reactive species, been insufficient to complex iron, whereas huge amounts mean a decrease in the process efficiency due to their ability to interact with the reactive species generated.

In the case of parabens removal, three organic residues were selected to add to photoFenton process (olive mill waste, coffee waste, and sludge), and the best results were obtained with coffee. The use of HLS isolated from coffee allows to expand the $\mathrm{pH}$ range to 5 achieving good pollutant removal results. Toxicity bioassays reveals that, although at intermediate treatment times compounds have been removal, at the end of the process samples remain toxic to different organisms. That is why it would be interesting to consider shorter treatment times in the case of this pollutant mixture under the conditions studied, to avoid the formation of toxic byproducts. 
The need to carry out toxicity bioassays on different organisms belonging to different levels of trophic chain has been demonstrated, because without these assays is impossible to know the real samples detoxification.

Some aspects related with the HLS application in photo-Fenton process requires further investigation, as the optimum conditions and the complexing mechanisms between iron and HLS. But, anyway, these HLS isolated had demonstrated to be efficient in pollutant removal at circumneutral $\mathrm{pHs}$.

Finally, HLS isolated from wastewater sludge when are applying to membrane process together with high pollutant concentrations, are efficient reducing the volume that must be treated by photo-Fenton because the pollutant is concentrated in the feed tank. As ultrafiltration membranes were used, energetic cost of the process is decreasing because nanofiltration membranes requires higher pressures to work.

The potential use of the HLS in different environmental applications has been demonstrated, focusing on waste revalorization, and promoting circular economy, contributing to a sustainable future. 


\section{BIBLIOGRAFÍA}


Bibliografía 
Acevedo-Barrios, R., Sabater-Marco, C., Olivero-Verbel, J., 2018. Ecotoxicological assesment of perchlorate using in vitro and in vivo assays. J. Environ Sci Pollut Res. Issue 14, 13697-13708.

Aguer, J-P. \& Richard, C. 1999. Influence of the excitation wavelength on the photoinductive properties of humic substances. Chemosphere. 38(10), 2293-2301.

Ahile, U.J., Wuana, R, A., Itodo, A.U., Sha'Ato, R., Dantas, R.F. 2020. A review on the use of chelating agents as an alternative to promote photo-Fenton at neutral $\mathrm{pH}$ : current trends, knowledge gap, and future studies. Sci. Total Environ. 710, 134872.

Ahile, U.J., Wuana, R.A., Itodo, A.U., Sha'Ato, R., Dantas, R.F. 2020. Stability ofi ron chelates during photo-Fenton process: the role of $\mathrm{pH}$, hydroxyl radical attack and temperature. J. Wat. Proc. Eng. 36, 101320.

Amildon Ricardo, I.; Paiva, V.A.B.; Paniagua, C.E.S.; Trovó, A.G. Chloramphenicol photo-Fenton degradation and toxicity changes in both surface water and a tertiary effluent from a municipal wastewater treatment plant at near-neutral conditions. Chem. Eng. J. 2018, 347, 763-770.

Andersen, F.A. 2008. Final amended report on the safety assessment of methylparaben, ethylparaben, propylparaben, isopropylparaben, butylparaben, isobutylparaben and benzylparaben as used in cosmetic products. Int. J. Toxicol. 27 (4), 1-82.

Andjelkovic, T., Perovic, J., Purenovic, M., Blagojevic, S., Nikolic, R., Andjelkovic, D., Bojic, A. 2006. Spectroscopic and potentiometric studies on derivatized natural humic acid. Anal Sci. 22, 1553-1558.

Antonopoulou, M., Christina, K., Triantafyllos, A., Konstantinou, I. 2021. An overview of homogeneous and heterogeneous photocatalysis applications for the removal of pharmaceutical compounds from real or synthetic hospital wastewaters under lab or pilot scale. Sci. Total Environ. 765, 144163.

Arzate, S., García Sánchez, J.L., Soriano-Molina, P., Casas López, J.L., Campos-Mañas, M.C., Agüera, A., Sánchez Pérez, J.A. 2017. Effect of residence time on micropollutant removal in WWTP secondary effluents by continuous solar photo-Fenton process in raceway pond reactors. Chem. Eng. J. 316, 11141121.

Ateia, M., Ran, J., Fujii, M., Yoshimura, Y. 2017. The relationship between molecular composition and fluorescence properties of humic substances. Int. J. Environ. Sci. Technol. 14, 867-880.

Augugliaro, V., Litter, M., Palmisano, L., Soria, J. The combination of heterogeneous photocatalysis with chemical and physical operations: A tool for improving the photoprocess performance. J. Photochem. Photobiol. C: Photochem. Reviews 7 (2006) 127-144.

Avetta, P., Bella, F., Bianco Prevot, A., Laurenti, E., Montoneri, E., Arques, A., Carlos, L. 2013. Waste cleaning waste: photodegradation of monochlorophenols in the presence of waste-derived photosensitizer. ACS Sustainable Chem. Eng. 1, 1545-1550.

Avetta, P., Berto, S., Bianco Prevot, A., Minella, M., Montoneri, E., Persico, D., Vione, D., Gonzalez, M.C., Mártire, D.O., Carlos, L., Arques, A. 2015. Photoinduced transformation of waste-derived soluble bio-based substances. Chem. Eng. J. 274, 247-255.

Babuponnusami A. and Muthukumar K. 2014. A review on Fenton and improvements to the Fenton process for wastewater treatment. J. Environ. Chem. Eng. 2(1): 557-572.

Barbosa, M.O., Moreira, N.F.F., Ribeiro, A.R., Pereira, M.F.R., Silva, A.M.T. 2016. Occurrence and removal of organic micropollutants: an overview of the watch list of EU Decision 2015/495. Water Res. 94, 257-279.

Bernabeu, A., Vercher, R.F., Santos-Juanes, L., Simón, P.J., Lardín, C., Martínez, M.A., Vicente, J.A., Gónzalez, R., Llosá, C., Arques, A., Amat, A.M. 2011. Solar photocatalysis as a tertiary treatment to remove emerging pollutants from wastewater treatment plant effluents. Catal. Today. 161 (1), 235-240. 
Bi, D., Yuan, G., Wei, J., Xiao, L., Feng, L., Meng, F., Wang, J. 2019. A soluble humic substance for the simultaneous removal of cadmium and arsenic from contaminated soils. Int. J. Environ. Res. and Public Health. 16(24), 4999.

Bianco Prevot, A., Avetta, P., Fabbri, D., Laurenti, E., Marchis, T., Perrone, D.G., Montoneri, E., Boffa, V. 2011. Waste derived bio-organic substances for light induced generation of reactive oxygenated species. ChemSusChem. 4 (1), 85-90.

Bieroza, M., Baker, A., Bridgeman, J., 2009. Relating freshwater organic matter fluorescence to organic carbon removal efficiency in drinking water treatment. J. Sci. Total Environ. 407, 1765-1774.

Boguta, P. \& Sokolowska, Z. 2013. Interactions of humic acids with metals, Interaction of humic acids with metals. Acta. Agroph. Monogr. 2, 1-113.

Boguta, P., D’Orazio, V., Senesi, N., Sokolowska, Z., Szewczuk-Karpisz, K. 2019. Insight into the interaction mechanism of iron ions with soil humic acids. The effect of the $\mathrm{pH}$ and chemical properties of humic acids. J, Environ. Manag. 245, 367-374.

Bokare, A.D. \& Choi, W. 2014. Review of iron-free Fenton-like systems for activating H2O2 in advanced oxidation processes. J. Hazard. Mat. 275, 121-135.

Borggaard, O.K., Hansen, H.C.B., Holm, P.E., Jensen, J.K., Rasmussen, S.B., Sabiene, N., Steponkaite, L., Strobel, B.W. 2009. Experimental assesment of using soluble humic substances for remediation of heavy metal polluted soils. Soil. Sediment Contam. 18, 369-382.

Borja, A., White, M.O., Berdalet, E., Bock, N., Eatock, C., Kristensen, P., Leonard, A., Lloret, J., Pahl, S., Parga, M., Vera Prieto, J., Wuijts, S., Fleming, L.E. 2020. Moving towards an agenda on ocean health and human health in Europe. Front. Mar. Sci. 7, 10

Bro, R \& Kiers, H.A.L. 2003. A new efficient method for determining the number of components in PARAFAC models. J. Chemom. 17,274-286.

Bucheli-Witschel, M \& Egli, T. 2001. Environmental fate and microbial degradation of aminopolycarboxylic acids. FEMS Micro. Rev. 25, 69-106.

Buerge, I.J., Poiger, T., Müller, M.D., Buser, H.D. 2003. Caffeine, an anthropogenic marker for wastewater contamination of surface waters. Environ. Sci. Technol. 37, 691-700.

Buffle, J.A.E. 1977. Humic substances in water and their interaction with minerals ions. Techniq. Sci. Municip. 72, 3-10.

Cáceres, T., Megharaj, M., Naidu, R., 2008. Toxicity and transformation of fenamiphos and its metabolites by two micro algae Pseudokirchneriella subcapitata and Chlorococcum sp. J. Sci Total Environ. 398 (1), 53-59.

Canonica, S., Jans, U., Stemmler, K., Hoigne, J. 1995. Transformation kinetics of phenols in wáter: photosensitization by disolved natural organic material and aromatic ketones. Environ. Sci. Technol. 29(7), 1822-1831.

Caram, B., García-Ballesteros, S., Santos-Juanes, L., Arques, A., García Einschlag, F.S. 2018. Humic-like substances for the treatment of scarcely soluble pollutants by mild photo-Fenton process. Chemosphere. 46, 4732-4740.

Carlos, L., Martire, D.O., Gonzalez, M.C., Gomis, J., Bernabeu, A., Amat, A.M., Arques, A. 2012. Photochemical fate of a mixture of emerging pollutants in the presence of humic substances. Water Res. $46,4732-4740$.

Carra, I.C., García-Sánchez, J.L., Malato, S., Sánchez-Pérez, J.A. 2014. Modelling miropollutant removal by solar photo-Fenton. Global Nest J. 16(3), 445-454. 
Carstea, E.M., Bridgeman, J., Baker, A., Reynolds, D.M. 2016. Fluorescence spectroscopy for wastewater monitoring: a review. Water Res. 95, 205-219.

CE 2000. Directive 2000/60/EC of the European parliament and of the council of 23 October 2000 establishing a framework for community action in the field of water policy. Off. J. Europ. Union. L 327, 172.

CE 2008. Directive 2008/105/EC of the European Parliament and of the council of 16 December 2008 on environmental quality standards in the field of wáter policy, amending and subsequently repealing council directives 82/176/EEC, 53/513/EEC, 84/156/EEC, 84/491/EEC, 86/280/EEC and amending directive 2000/60/EC of the European Parliament and of the council. Off. J. Europ. Union. L 348, 84-97.

CE 2013. Directive 2013/39/EU of the European Parliament and of the council of 12 August 2013 amending directives 2000/60/EC and 2008/105/EC as regards priority substances in the field of water policy. Off. J. Europ. Union. L 226, 1-17.

CE 2018. Commision implementing decisión (EU) 2018/840 of 5 June 2018 establishing a watch list of substances for union-wide monitoring in the field of water policy pursuant to directive 2008/105/EC of the European Parliament and of the council and repealing commission implementing decision (EU) 2015/495 (notified under document C (2018) 3362). Off. J. Europ. Union. L 141, 9-12.

Chen, X., Ma, W., Li, J., Wang, Z., Chen, C., Ji, H., Zhao, J. 2011. Photocatalytic oxidation of organic pollutants catalyzed by an iron complex at biocompatible $\mathrm{pH}$ values using $\mathrm{O}_{2}$ as main oxidant in a Fentonlike reaction. J. Phys. Chem. 115, 4089-4095.

Cieschi, M.T., Polyakov, A.Y., Lebedev, V.A., Volkov, D.S., Pankratov, D.A., Veligzhanin, A.A., Perminova, I.V., Lucena, J.J. 2019. Eco-friendly iron-humic nanofertilizers synthesis for the prevention of iron chlorosis in soyben (Glycine max) grown in calcareous soil. Frontiers in Plant Sci. 10, 413.

Clara, M., Windhofer, G., Hartl, W., Braun, K., Simon, M., Gans, O., Scheffknecht, C., Chovanec, A. 2010. Occurrence of phthalates in surface runoff, untreated and treated wastewater and fate during wastewater treatment. Chemosphere. 78(9), 1078-1084.

Clarizia, L., Russo, D., Di Somma, I., Marotta, R., Andreozzi, R. 2017. Homogeneous photo-Fenton processes at near neutral pH: a review. App. Catal. B: Environ. 209, 358-371.

Coble, P.G. 1996. Characterization of marine and terrestrial DOM in seawater using excitation-emission matriz spectroscopy. Marin. Chem. 54(4), 325-346.

COM/2017/033. Report from the commission to the european parliament, the council, the european economic and social aommitee and the committee of the regions on the implementation of the Circular Economy Action Plan.

COM 2019. Comunicación de la comisión al parlamento europeo, al consejo europeo, al consejo, al comité económico y social europeo y al comité de las regiones El Pacto Verde Europeo. COM/2019/640.

Conte, P., Agretto, A., Spaccini, R., Piccolo, A. 2005. Soil remediation: humic acids as natural surfactants in the washings of highly contaminated soils. Environ. Pollut. 135, 515-522.

Damian, G.E., Micle, V., Sur, I.M. 2019. Mobilization of $\mathrm{Cu}$ and $\mathrm{Pb}$ from multi-metal contaminated soils by dissolved humic substances extracted from leonardite and factors affecting the process. J. Soils Sediment. 19, 2869-2881.

Darbre, P.D., Aljarrah, A., Miller, W.R., Coldham, N.G., Sauer, M.J., Pope, G.S. 2004. Concentrations of parabens in humen breast tumours. J. Appl. Toxicol. 24, 5-13.

David Gara, Pedro M. 2008. Extracción, caracterización de sustancias húmicas y su empleo en procesos fotoquímicos de interés ambiental. Tesis Doctoral. 
Decisión 2013/39/EC on environmental quality standards in the field of water policy. European Community Commission (ECC). Off J Eur Commun (2013) L 226/1, (12.08.2013).

Decisión de ejecución (UE) 2015/495 de la Comisión, de 20 de marzo de 2015, por la que se establece una lista de observación de sustancias a efectos de seguimiento a nivel de la Unión en el ámbito de la política de aguas, de conformidad con la Directiva 2008/105/CE del Parlamento Europeo y del consejo. C(2015) 1756.

De la Cruz, N., Giménez, J., Esplugas, S., Grandjean, D., De Alencastro, L.F., Pulgarín, C. 2012. Degradation of 32 emergent contaminants by UV and neutral photo-Fenton in domestic wastewater effluent previously treated by activated sludge. Water Res. 46(6), 1947-1957.

De Luca, A., Dantas, R.F., Esplugas, S. 2014. Assesment ofi ron chelates efficiency for photo-Fenton at neutral pH. Water Res. 61, 232-242.

De Luca, A., Dantas, R.F., Esplugas, S. 2015. Study of Fe (III)-NTA chelates for applicability in photoFenton at neutral pH. App. Catal. B: Environ. 179, 372-379.

Dias, I. N., Souza, B. S., Pereira, J. H. O. S., Moreira, F. C., Dezotti, M., Boaventura, R. A., Vilar, V. J. P. 2014. Enhancement of the photo-Fenton reaction at near neutral $\mathrm{pH}$ through the use of ferrioxalate complexes: A case study on trimethoprim and sulfamethoxazole antibiotics removal from aqueous solutions. Chemic. Engin. J. 247, 302-313.

Directiva 91/689/CEE of 12 December on hazardous waste. European Economic Community. 1991. Off J Eur Commun, (1991) L377, (31.12.1991).

Directiva 2008/105/CE Environmental Quality Standards in the Field of Water Policy, Amending and Subsequently Repealing Council Directives 82/176/EEC, 83/513/EEC, 84/156/EEC, 84/491/EEC, 86/280/EEC and Amending Directive 2000/60/EC. European Parliament and the Council of the European Union (2008).

Dobbins L. L., Usenko, S., Brain, R.A., Brooks, B.W. 2009. Probabilistic ecological hazard assessment of parabens using Daphnia magna and Pimephales promelas. Environ. Toxicol. Chem. 28-12, 2744-2753.

Dong, W., Jin, Y., Zhou, K., Sun, S.P., Li, Y., Chen, X.D. 2019. Efficient degradation of pharmaceutical micropollutants in water and wastewater by Fe ${ }^{\mathrm{III}}-\mathrm{NTA}$-catalyzed neutral photo-Fenton process. Sci. Total Environ. 688, 513-520.

Duarte, R.M.B.O., Pio, C.A., Duarte, A.C.2005. Spectroscopy study of the water-soluble organic matter isolated from atmospheric aerosols collected under different atmospheric conditions. Anal. Chim. Acta. 530, 7-14.

Duarte, R.M.B.O., Santosa, E.B.H., Pio, C.A., Duarte, A.C., 2007. Comparison of structural features of water-soluble organic matter from atmospheric aerosols with those of aquatic humic substances. Atmos. Environ. 41, 8100-8113.

Dudare, D. \& Klavins, M. 2013. Changes in the humic acid-metal complex forming characteristics depending on the humification degree. Fresenius Environ. Bull. 22, 604-613.

Edzwald, J.K., Tobiason, J.E., 1999. Enhaced coagulation: USA requirements and a broader view. Water Sci. Technol. 40, 63-70.

Ekin, Z. 2019. Integrated use of humic acid and plant growth promoting rhizobacteria to ensure higher potato productivity in sustainable agriculture. Sustainability. 11(12), 3417.

Enev, V., Pospíšilová, L., Klučáková, M., Liptaj, T., Doskočil, L. 2014. Spectral characterization of selected humic substances. Soil \& Water Res. 9, 9-17. 
Ephraim J. H., C. Pettersson, M. Nordén y B. Allard. 1995. Potentiometric titrations of humic substances: Do ionic strength effects depend on the molecular weight? Environ. Sci.Technol. 29: 622 - 628.

Fan, C., Tsui, L., Liao, M.C. 2011. Parathion degradation and its intermediate formation by Fenton process in neutral environment. Chemosphere. 82, 229-236.

Fabbri, D., Bianco Prevot, A., Zelano, V., Ginepro, M., Pramauro, E. 2008. Removal and degradation of aromatic compounds from a highly polluted site by coupling soil washing with photocatalysis. Chemosphere. 71, 56-65.

Fenton, H.J.H. 1894. LXXIII.-Oxidation of tartaric acid in presence of iron. J. Chem. Soc. Trans. 65, 899910.

Flotron, V., Delteil, C., Padellec, Y., Camel, V. 2005. Removal of sorbed polycyclic aromatic hydrocarbons from soil, sludge and sediment samples using the Fenton's reagent process. Chemosphere. 59(10), 14271437.

Francioso, O., Ferrari, E., Saladini, M., Montecchio, D., Gioacchini, P., Ciavatta, C. 2007. TG-DTA, DRIFT and NMR characterisation of humic-like fractions from olive wastes and amended soil. J. Hazard. Mat. 149, 408-417.

Fontmorin, J.M., Burgos Castillo, R.C., Tang, W.Z., Sillanpää, M. 2016. Stability of 5, 5-dimethyl-1pyrroline-N-oxide as a spin-trap for quantification of hydroxil radicals in the Fenton reaction using chemical probes. RSC Adv. 8, 5321-5330.

Fu, L., Huang, T., Wang, S., Wang, X., Su, L., Li, C., Zhao, Y., 2017. Toxicity of 13 different antibiotics towards freshwater green algae Pseudokirchneriella subcapitata and their modes of action. Chemosphere. 168 (Supplement C), 217-222.

García-Ballesteros, S., Mora, M., Vicente, R., Sabater, C., castillo, M.A., Arques, A., Amat, A.M. 2016. Gaining further insight into photo-Fenton treatment of phenolics compounds commonly found in food processing industry. Chem Eng J. 288, 126-136.

García-Ballesteros, S., Constante, M., Vicente, R., Mora, M., Amat, A.M., Arques, A., Carlos, L., García Einschlag, F.S. 2017. Humic-like substances from urban waste as auxiliaries for photo-Fenton treatment: a fluorescence EEM-PARAFAC study. Photochem. Photobiol. Sci. 16, 38-45.

García-Ballesteros, S., Grimalt, J., Berto, S., MInella, M., Laurenti, E., Vicente, R., López-Pérez, M.F., Amat, A.M., Bianco Prevot, A., Arques, A. 2018. A new route for valorisation of oil mil wastes: isolation of humic like substances to be employed in solar-driven processes for pollutant removal. ACS Omega. 3, 13073-13080.

García-Ballesteros, S., Mora, M., Vicente, R., Vercher, R.F., Sabater, C., Castillo, M.A., Amat, A.M., Arques, A. 2019. A new methodology to assess the performance of AOPs in complex samples: application to the degradation of phenolic compounds by $\mathrm{O}_{3}$ and $\mathrm{O}_{3} / \mathrm{UV}-\mathrm{A}-\mathrm{V}$ is. Chemosphere. 222,114-123.

Georgi, A., Schierz, A., Trommler, U., Horwitz, C.P., Collins, T.J., Kopinke, F.D. 2007. Humic acid modified Fenton reagent for enhancement of the working $\mathrm{pH}$ range. Appl. Catal. B: Environ. 72(1-2), 2636.

Gerke, J. 2018. Concepts and misconceptions of humic substances as the stable part of soil organic matter: a review. Agronomy. 8 (5), 76.

Giraldo-Aguirre, A.L.; Serna-Galvis, E.A.; Erazo-Erazo, E.D.; Silva-Agredo, J.; Giraldo-Ospina, H.; Flórez-Acosta, O.A.; Torres-Palma, R.A. Removal of $\beta$-lactam antibiotics from pharmaceutical wastewaters using photo-Fenton process at near-neutral pH. Environ. Sci. Pollut. Res. 2018, 25, 2029320303. 
Gmurek, M., Gomes, J.F., Martins, R.C., Quinta-Ferreira, R.M. 2019. Comparison of radical-driven technologies applied for paraben mixture degradation: mechanism, biodegradability, toxicity, and cost assessment. Environ. Sci. and Polllut. Rs. 26, 37174-37192.

Gojanovich, A.D., Bustos, D.M., Uhart, M., 2016. Differential expression and accumulation of 14-3-3 paralogs in 3T3-L1 preadipocytes and differentiated cells. Biochem Biophys Rep. 7, 106-112.

Gomes, F.E.R., Bernadczyk, K., Gmurek, M., Stelmachowski, M., Zaleska-Medynska, A., Bastos, F.C., Quinta-Ferreira, M.E., Costa, R., Quinta-Ferreira, R.M., Martins, R.C. 2017a. Noble metal-TiO ${ }_{2}$ supported catalyst for the catalytic ozonation of parabens mixtures. Process Saf. Environ. Prot. 111,148-159.

Gomes, F.E.R., Bergo, P.L.S., Trap, M.A., Spadoto, M., Galinaro, C.A., Rodrigues-Filho, E., Leitão, A., Tremiliosi-Filho, G. 2018a. Photolysis of parabens using medium-pressure mercury lamps: toxicity effects in MCF7, Balb/c 3T3 cells and Ceriodhapnia dubia. Chemosphere. 208, 325-334.

Gomis, J., Bianco prevot, A., Montoneri, E., González, M.C., Amat, A.M., Martire, D.O., Arques, A., Carlos, L. 2014. Waste sourced bio-based substances for solar-driven wastewater remediation: photodegradation of emerging pollutants. Chem. Eng. J. 235, 236-243.

Gomis, J., Golçalves, M.G., Vercher, R.F., Sabater, C., Castillo, M.A., Bianco Prevot, A., Amat, A.M., Arques, A. 2015. Determination of photostability, biocompatibility and efficiency as photo-Fenton auxiliaries os three different types of soluble bio-based substances (SBO). Catal. Today. 252, 177-183.

Gomis, J., Carlos, L., Bianco Prevot, A., Teixeira, A.C.S.C., Mora, M., Amat, A.M., Vicente, R., Arques, A. 2015. Bio-based substances from urban waste as auxiliaries for solar photo-Fenton treatment under mild conditions: optimization of operational variables. Catal. Today. 240, 39-45.

Gracia-Lor, J., Sancho, J.V., Serrano, R., Hernández, F. 2012. Occurrence and removal of pharmaceuticals in wastewater treatment plants at the Sapanish Mediterranean área of Valencia. Chemosphere. 87(5), 453462.

Guerard, J.J., Chin, Y.P., Mash, H., Hadad, C.M., 2009. Photochemical fate of sulfadimethoxine in aquaculture waters. Environ Sci Technol. 43 (22), 8587-8592.

Guo, X.X., Liu, H.T., Wu, S.B. 2019. Humic substances developed during organic waste composting: formation mechanisms, structural properties, and agronomic functions. Sci. Total Environ. 662, 501-510.

Gupta, A. \& Garg, A. 2018. Degradation of ciprofloxacin using Fenton's oxidation: Effect of operating parameters, identification of oxidized by-products and toxicity assessment. Chemosphere. 193, 11811188.

Gusiatin, Z.M., Kulikowska, D., Klik, B. 2020. New-generation washing agents in remediation of metalpolluted soils and methods of washing effluent treatment: a review. Int. J. Environ. Res. Public Health. 17,6220 .

Haber, F. \& Weiss, J. 1934. The Catalytic Decomposition of Hydrogen Peroxide by Iron Salts. Proceedings of the Royal Society A, 147.

Haman, C., Dauchy, X., Rosin, C., Munox, J-F. 2015. Occurrence, fate and behaviour of parabens in aquatic environments: a review. Water Res. 68, 1-11.

Hao, Y., Ma, H., Wang, Q., Ge, L., Yang, Y., Zhu, C. 2021. Refractory DOM in industrial wastewater: Formation and selective oxidation of AOPs. Chem. Eng. J. 406, 126857.

Henderson, R.K., Baker, A., Murphy, K.R., Hambly, A., Stuetz, R.M., Khan, S.J. 2009. Fluorescence as a potential monitoring tool for recycled water systems: A review. Water Res. 43, 863-881. 
Her, N., Amy, G., McKight, D., Sohn, J., Yoon, Y., 2003. Characterization of DOM as a function of MW by fluorescence EEM and HPLC-SEC using UVA, DOC, and fluorescence detection. Water Res. 37, 42954303.

Herney-Ramirez, J., Vicente, M.A., Madeira, L.M. 2010. Heterogeneous photo-Fenton oxidation with pillared clay-based catalysts for wastewater treatment: a review. Appl. Catal. B. 98(1), 10-26.

Hirata, H. \& Fujii, H. 2006. Free radicals in living systems: in vivo detection of bioradicals with EPR spectroscopy. Curr. Org. Chem. 10, 521-534.

Hirsch, R., Ternes, T. A., Haberer, K., Kratz, K-L. 1999. Occurrence of antibiotics in the aquatic environment. Sci. Total Envrion. 225, 109-118.

Huang, W., Brigante, M., Wu, F., Hanna, K., Mailhot, G. 2012. Development of a new homogeneous photoFenton process using Fe(III)-EDDS complexes. J. Photochem. Photobiol. A. 239, 17-23.

Huculak-Maczka, M., Hoffmann, J., Hoffmann, K. 2018. Evaluation of the possibilities of using humic acids obtained from lignite in the production of commercial fertilizers. J. Soils Sedim. 18, 2868-2880.

Hudson, N., Baker, A., Reynolds, D. 2007. Fluorescence analysis of dissolved organic matter in natural, waste and and polluted waters- A review. River. Res. Applic. 23,631-649.

Hur J., Williams, M.A., Schlautman, M.A. 2006. Evaluating spectroscopic and chromatographic techniques to resolve dissolved organic matter via end member mixing analysis. 2006. Chemosphere. 63, 384-402.

Ioannou-Ttofa, L., Michael-Kordatou, I., Fattas, S.C., Eusebio, A., Ribeiro, B., Rusan, M., Amer, A.R.B., Zuraiqi, S., Waismand, M., Linder, C., Wiesman, Z., Gilron, J., Fatta-Kassinos, D. 2017. Treatment efficiency and economic feasibility of biological oxidation, membrane filtration and separation processes, and advanced oxidation for the purification and valorization of olive mill wastewater. Water Res. 114, 113.

Jain, B., Singh, A.K., Kim, H., Lichtfouse, E., Sharma, V.K. 2018. Treatment of organic pollutants by homogeneous and heterogeneous Fenton reaction processes. Environ. Chem. Lett. 16(3), 947-967.

Jung, C., Son, H., 2008. The relationship between disinfection by-products formation and characteristics of natural organic matter in raw water. Korean J Chem Eng. 25 (4), 714-720.

Kamaya, Y., Tsuboi, S., Takada, T., Suzuki, K. 2006. Growth stimulation and inhibition effects of 4hydroxybenzoic acid and some related compounds on the freshwater green alga Pseudokirchneriella subcapitata. Environ. Contam. Toxicol. 51,537-541.

Kari, F.G., Hilger, S., Canonica, S. 1995. Determination of the reaction quantum yield for the photochemical degradation of Fe(III)-EDTA: implications for the environmental fate of EDTA in surface waters. Environ. Sci. Technol.29, 1008-1017.

Kari, F. G. \& Giger, W. 1996. Speciation and fate of ethylenediaminetetraacetate (EDTA) in municipal wastewater treatment. Water Res. 3(1), 122-134.

Katsumata, H., Kaneco, S., Suzuki, T., Ohta, K., Yobiko, Y. 2006. Photo-Fenton degradation of alachlor in the presence of citrate solution. J. Photochem. Photobiol. A: Chem. 180(1-2), 38-45.

Katsumata, H., Sada, M., Kaneco, S., Suzuki, T., Ohta, K., Yobiko, Y. 2008. Humic acid degradation in aqueous solution by photo-Fenton process. Chem. Eng. J. 137, 225-230.

Khan, J.A., He, X., Shah, N.S., Khan, H.M., Hapeshi, E., Fatta-Kassinos, D., Dionysiou, D. D. 2014. Kinetic and mechanisms investigation on the photochemical degradation of atrazine with activated $\mathrm{H}_{2} \mathrm{O}_{2}$, $\mathrm{S}_{2} \mathrm{O}_{8}{ }^{2-}$ and $\mathrm{HSO}_{5}{ }^{-}$. Chem. Eng. J. 252, 393-403. 
Klamerth, N., Malato, S., Agüera, A., Fernandez-Alba, A., Mailhot, G. 2012. Treatment of municipal wastewater treatment plant affluents with modified photo-Fenton as a tertiarry treatment for the degradation of micropollutants and desinfection. Environ. Sci. Technol. 46, 2885-2892.

Klavins, M. \& Purmalis, O. 2010. Humic substances as surfactants. Environ. Chem. Lett. 8, 349-354.

Kocot, P., Karocki, A., Stasicka, Z. 2006. Photochemistry of the Fe(III)-EDTA complexes. A mechanistic study. J. Photochem. Photobiol. A. 179, 176-183.

Köck-Schulmeyer, M., Martínez, E., Gajda-Schrantz, K., Ginebreda, A., Navarro, A., López de Alda, M., Barceló, D. 2010. Integrated ecotoxicological and chemical approach for the assessment of pesticide pollution in the Ebro River delta (Spain). J Hydrol. 383(1-2), 73-82.

Kononova, M.M. 1966. Soil organic matter: its nature, its role in soil formation and in soil fertility. Pergamon. Press.

Korshin, G., Chow, C.W.K., Fabris, R., Drikas, M., 2009. Absorbance spectroscopy-based examination of effects of coagulation on the reactivity of fractions of natural organic matter with varying apparent molecular weights. Water Res. 43, 1541-1548.

Kristensen, T.B., Du, L., Nguyen, Q.T., Nøgaard, J.K., Bender Koch, C., Faurskov Nielsen, O., Hallar, A.G., Lowenthal, D.H., Nekat, B., van Pinxteren, D., Herrmann, H., Glasius, M., Kjaergaard, H.G., Bilde, M. 2015. J. Atmos. Chem. 72, 65-80.

Krivácsy, Z., Gelencser, A., Kiss, G., Meszaros, E., Molnar, A., Hoffer, A., Meszaros, T., Sarvari, Z., Temesi, D., Varga, B., Baltensberger, U., Nyeki, S., Weingartner, E. 2001. Study of the chemical character of water soluble organic compounds in fine atmospheric aerosol at the Jungfraujoch. J. Atmos. Che. 39, 235-259.

Kucerik, J., Kovar, J., Pekar, M. 2004. Thermoanalytical investigations of lignite humic acid fractions. J. Therm. Analys. Calorim. 76, 55-65.

Kuster, M., Lopez de Alda, M.J., Hernando, M.D., Petrovic, M., Martin-Alonso, J., Barceló, D. 2008. Analysis and occurrence of pharmaceuticals, estrogens, progestogens and polar pesticides in sewage treatment plant effluents, river water and drinking water in the Llobregat river basin (Barcelona, Spain). J. Hydrol. 358, 112-123.

Lee, C. \& Sedlack, D.L. 2009. A novel homogeneous Fenton-like system with Fe(III)-phosphotungstate for oxidation of organic compounds at neutral pH values. J. Mol. Catal. A: Chem. 311, 1-6.

Legrini O., Oliveros E. and Braun A. M. 1993. Photochemical processes for water treatment. Chem. Reviews 93(2): 671-698.

Li, J., Mailhot, G., Wu, F., Deng, N. 2010. Photochemical efficiency of Fe(III)-EDDS complex: OH radical production and 17 $\beta$-estradiol degradation. J. Photochem. Photobiol. A. 212, 1-7.

Lim, H., Park, S., Yang, J.W., Cho, W., Lim, Y., Park, Y.G., Kwon, D., Kim, H.S. 2018. Remediation of heavy metal-contaminated soils using eco-friendly nano-scale chelators. Membrane Water Treatment. 9(3), 137-146.

Lincho, J., Gomes, J., Martins, R.C. 2021. Paraben compounds-Part II: An overview of advanced oxidation processes for their degradation. Appl. Sci. 11, 3556.

Lipczynska-Kochany, E. \& Kochany, J. 2008. Effect of humic substances on the Fenton treatment at acidic and neutral pH. Chemosphere. 73, 745-750.

Lippold, H., Gottschalch, U., Kupsch, H. 2008. Joint influence of surfactants and humic matter on PAH solubility. Are mixed micelles formed? Chemosphere. 70, 1979-1986. 
Liu, C., Chen, L., Ding, D., Cai, T. 2019. Sulfate radical induced catalytic degradation of metolachlor: efficiency and mechanism. Chem. Eng. J. 368, 606-61.

Liu, S., Lim, M., Fabris, R., Chow, C., Drikas, M., Amal, R. 2010. Comparison of photocatalytic degradation of natural organic matter in two Australian surface waters using multiple analytical techniques. Org. Geochem. 41, 124-129.

Lumbarque, E.C., Araújo, D.S., Klein, T.M., Tiburtius, E.R.L., Argüello, J., Sirtori, C. 2019. Solar photoFenton like process at neutral pH: Fe (III)-EDDS complex formation and optimization of experimental conditions for degradation of pharmaceutical. Catal. Today. 328, 259-266.

Luo, Y., Guo, W., Ngo, H.H., Nghiem, L.D., Hai, F.I., Zhang, J., Liang, S., Wang, X.C. 2014. A review on the occurrence of micropollutants in the aquatic environment and their fate and removal during wastewater treatment. Sci. Tot. Environ. 473-474, 619-641.

Luo, X., Shen, L., Meng, F. 2019. Response of microbial community structures and functions of nitrosifying consortia to biorefractory humic substances. ACS Sustainable Chem. Engin. 7(5), 4744-4754.

MacCarthy P. 2001. The principles of humic substances: An introduction to the first principle. Pág. 19- 30. En: Humic substances. Structures, models and functions. Editado por E. A. Ghabbour y G. Davies. The Royal Society of Chemistry, Gateshead, UK.

Malato, S., Blanco, J., Alarcón, D. C., Maldonado, M. I., Fernández-Ibáñez, P., Gernjak, W. (2007a). Photocatalytic decontamination and disinfection of water with solar collectors. Catal. Today, 122, 137149.

Marques, P., Benites, V., Emoke, B., Santos, A., Hockaday. W., Hatcher., P. 2005. Characterization of humic like substances obtained by chemical oxidation of eucalyptus charcoal. Org. Geochem. 36(11), 14801489.

Marta-Sánchez, A.V., Caldas, S.S., Schneider, A., Cardoso, S.M.V.S., Primel, E.G. 2018. Trace analysis of parabens preservatives in drinking water treatment sludge, treated, and mineral water samples. Environ. Sci. Pollut. Res. 25, 14460-14470.

Matilainen, A., Gjessing, E.T., Lahtinen, T., Hed, L., Bhatnagar, A., Sillanpää, M. 2011. An overview of the methods used in the characterisation of natural organic matter (NOM) in relation to drinking water treatment. Chemosphere. 83 (11), 1431-1442.

McKnight, D.M., Boyer, E.W., Westerhoff, P.K., Doran, P.T., Kulbe, T., Andersen, D.T. 2001. Spectrofluorometric characterization of dissolved organic matter for indication of precursor organic material and aromaticity. Limnol. Oceanogr. 46-1, 38-48.

Meneses, M., Pasqualino, J.C., Castells, F. 2010. Environmental assesment of urban wastewater reuse: treatment alternatives and applications. Chemosphere. 81, 266-272.

Micó, P., García-Ballesteros, S., Mora, M., Vicente, R., Amat, A.M., Arques, A. 2019. EEMlab: a graphical user-friendly interface for fluorimetry experiments based on the drEEM toolbox. Chemo. Intell. Lab. Syst. 188, 6-13.

Miralles-Cuevas, S., Oller, I., Agüera, A., Sánchez Pérez, J.A., Malato, S. 2017. Strategies for reducing cost by using solar photo-Fenton treatment combined with nanofiltration to remove microcontaminants in real municipal effluents: Toxicity and and economic assessment. Chem. Eng. J. 318, 161-170.

Miralles-Cuevas, S., Oller, I., Ruíz-Delgado, A., Cabrera-Reina, A., Cornejo-Ponce, L., Malato, S. 2019. EDDS as complexing agent for enhancing solar advanced oxidation processes in natural water: Effect of iron species and different oxidants. J. Hazard. Mat. 372, 129-136.

Mizuno, H., Hirai, H., Kawai, S., Nishida, T. 2009. Removal of estrogenic activity of iso-butylparaben and $n$-butylparaben by laccase in the presence of 1-hydroxybenzotriazole. Biodegrad. 20,533-539. 
Montoneri, E., Boffa, V., Quagliotto, P., Mendichi, R., Chierotti, M.R., Gobetto, R., Medana, C. 2008. Humic acid-like matter isolated from green urban wastes. Part I: structure and surfactant properties. BioResour. 3(1), 123-141.

Montoneri, E., Savarino, P., Bottigliengo, S., Musso, G., Boffa, V., Bianco Prevot, A., Fabbri, D., Pramauro, E. 2008. HUmic acid-like matter isolated from green urban wastes. Part II: performance in chemical and environmental technologies. BioResour. 3(1), 217-233.

Montoneri, E., mainero, D., Boffa, V., Perrone, D.G. Montoneri, C. 2011. Biochemenergy: a project to turna $\mathrm{n}$ urban wastes treatment plan tinto biorefinery for the production of energy, chemicals and consumer's products with friendly environmental impact. Int. J. Clobal Environ. Issues. 11, 170-196.

Moutsatsou, A., Gregou, M., Matsas, D., Protonotarios, V. 2006. Washing as a remediation technology applicable in soils heavily polluted by mining metallurgical activities. Chemosphere. 63, 1632-1640.

Murray, C.A. \& Parsons, S.A. 2004. Removal of NOM from drinking water: Fenton's and photo-Fenton's processes. Chemosphere. 54, 1017-1023.

Nakada, N., Shinohara, H., Murata, A., Kiri, K., Managaki, S., Sato, N., Takada H. 2007. Removal of selected pharmaceutical and personal care products (PPCPs) and endocrine-disrupting chemicals (EDCs) during sand filtration and ozonation at a municipal sewage treatment plant. Water Res. 41,4373-4382.

Navarro, S., Fenoll, J., Vela, N., Ruiz, E., Navarro, G. 2011. Removal of ten pesticides from leaching water at pilot plant scale by photo-Fenton treatment. Chem. Eng. J. 167(1), 42-49.

Neyens, E \& Baeyens, J. 2003. A review of classic Fenton's peroxidation as an advanced oxidation technique. J. Hazard. Mat. 98, 33-50.

Nie, Y., Qiang, Z., Zhang, H., Ben, W. 2012. Fate and seasonal variation of endocrine-disrupting chemicals in a sewage treatment plant with A/A/O process. Sep. Purif. Technol. 84, 9-15.

Oishi, S. 2002a. Effects of butylparaben on the male reproductive system in rats. Toxicol. Ind. Health. 17 (1), 31-39.

Oishi, S. 2002b. Effects of propylparaben on the male reproductive system. Food Chem. Toxicol. 40 (12), 1807-1813.

Olk, D.C., Bloom, P.R., Perdue, E.M., McKnight, D.M., Chen, Y., Farenhorst, A., Senesi, N., Chin, Y.P., Schmitt-Kopplin, P., Hertkorn, N., Harir, M. 2019. J. Environ. Quality. 48(2), 217-232.

Orama, M., Hyvonen, H., Saarinen, H., Aksela, R. 2002. Complexation of [S,S] and mixed stereoisomers of N,N-ethylenediaminedisuccinic acid (EDDS) with $\mathrm{Fe}(\mathrm{III}), \mathrm{Cu}(\mathrm{II}), \mathrm{Zn}(\mathrm{II})$ and $\mathrm{Mn}$ (II) ions in aqueous solution. J. Chem. Soc. 4644-4648.

Ou, X., Quan, X., Chen, S., Zhang, F., Zhao, Y. 2008. Photocatalytic reaction by Fe(III)-citrate complex and its effect on the photodegradation of atrazine in aqueous solution. J. Photochem. Photobiol. A Chem. 197 (2), 382-388.

Papoutsakis, S., Miralles-Cuevas, S., Oller, I., García Sánchez, J.L., Pulgarín, C., Malato, S. 2015. Microcontaminant degradation in municipal wastewater treatment plant secondary effluent by EDDS assisted photo-Fenton at near-neutral pH: a experimental design approach. Catal. Tod. 252, 61-69.

Peiris, R.H., Hallé, C., Budman, H., Moresoli, C., Peldszus, S., Huck, P.M., Legge, R.L., 2010. Identifying fouling events in a membrane-based drinking water treatment process using principal component analysis of fluorescence excitation-emission matrices. Water Res. 44, 185-194.

Peng, X., Yu, Y., Tang, C., Tan, J., Huang, O., Wang, Z. 2008. Occurrence of steroid estrogens, endocrinedisrupting phenols, and acid pharmaceuticals residues in urban riverine water of the Pearl River Delta, South China. Sci. Total Environ. 397, 158-166. 
Pereira, M.C., Oliveira, L.C.A., Murad, E. 2012. Iron oxide catalysts: Fenton and Fenton-like reactions: a review. Clay. Miner. 47, 285-302.

Pérez, J.A. S., Román Sánchez, I.M., Carra, I., Cabrera Reina, A., Casas López, J.L., Malato, S. Economic evaluation of a combined photo-Fenton/MBR process using pesticides as model pollutant. Factors affecting costs. J. Hazard. Mater. 244-245, 195-203.

Perminova, I.V., Frimmel, F.H., Kudryavtsev, A.V., Kulikova, N.A., Abbt-Braun, G., Hesse, S., Petrosyan, V.S. 2003. Molecular weight characteristics of humic substances from different environments as determined by size exclusion chromatography and their statistical evaluation. Environ. Sci. Technol. 37, 2477-2485.

Petric, Z., Ružić, J., Žuntar, I. 2021. The controversies of parabens- an overview nowadays. Acta Pharm. 71, 17-32.

Petrovic, M., Gonzalez, S., Barceló, D. 2003. Analysis and removal of emerging contaminants in wastewater and drinking water. Trends Analyt. Chem. 22 (10), 685-696.

Peuravori, J., Pihlaja, K., 1997. Molecular size distribution and spectroscopic properties of aquatic humic substances. Anal Chim Acta. 337, 133-149.

Piccolo, A., Conte, P., Cozzolino, A. 2001. Chromatographic and spectrophotometric properties of dissolved humic substances compared with macromolecular polymers. Soil Sci. 166, 174-185.

Piganatello. J.J., Oliveros, E., MacKay, A. 2006. Advanced oxidation processes for organic contaminants destruction based on the Fenton reaction and related chemistry. Crit. Rev. Environ. Sci. Technol. 36, 1-84.

Planas, C., Caixach, J., Santos, F.J., Rivera, J. 1997. Occurrence of pesticides in Spanish surface waters. Analysis by high resolution gas chromatography coupled to mass spectrometry. Chemosphere. 34 (11), 2393-2406.

Pouillot, A., Polla, B.S., Polla, A.S. 2006. Conservateurs en cosmetology mise au point sur les parabenes. J. Méd. Esthét. Chir. Dermatol. 33, 187-196.

Pukalchik, M., Panova, M., Karpukhin, M., Yakimenko, O., Kydralieva, K., Terekhova, V. 2018. Using humic products as amendments to restore $\mathrm{Zn}$ and $\mathrm{Pb}$ polluted soil: a case study using rapid screening phytotest endpoint. J. Soils and Sed. 18(3), 750-761.

Rebhun, M., De Smedt, F., Rwetabula, J. 1996. Dissolved humic substances for remedation of sites contaminated by organic pollutants. Binding-desorption model predictions. Water Res. 30(9), 2027-2038.

Ribeiro, A.R., Nunes, O.C., Pereira, M.F.R., Silva, A.M.T. 2015. An overview on the advanced oxidation processes applied for the treatment of water pollutants defined in the recently launched Directive 2013/39/EU. Environ Int. 75, 33-51.

Richard, C. \& Canonica, S. 2005. Aquatic phototransformation of organic contaminants induced by coloured dissolved natural organic matter. Handbook of Environmental Chemistry, Vol. 2, Part. M. Capítulo 9, 299-323. Editado por O. Hutzinger. Springer-Verlag, Berlín, Alemania.

Rizvi, M.A., Syed, R.M., Khan, B. 2010. Complexation effect on redox potential of iron (III)-iron (II) couple: a simple potentiometric experiment. J. Chem. Educ. 88, 220-222.

Rizzo, L., Meric, S., Kassinos, D., Guida, M., Russo, F., Belgiorno, V. 2009b. Degradation of diclofenac by $\mathrm{TiO}_{2}$ photocatalysis: UV absorbance kinetics and process evaluation through a set of toxicity bioassays. Water Res. 43,979-988.

Roig, A., Cayuela, M.L., Sánchez-Monedero, M.A. 2006. An overview in olive mill wastes and their valorisation methods. Waste Manag. 26, 960-969. 
Romero, J., Gómez, M., Vázquez, M.J. 2004. Determinación de fármacos y productos químicos de cuidado personla (PPCPs) en aguas naturales y residuales. Tec. Cien. Agua. 253, 30-41.

Routledge, E.J., Parker, J., Odum, J., Ashby, J., Sumpter, J.P. 1998. Some alkyl hydroxy benzoate preservatives (parabens) are estrogenic. Toxicol. Appl. Pharmacol. 153, 12-19.

Rutely, C.B.C., Fontmorin, J.M., Tang, W.Z., Dominguez-Benetton, X., Sillanpaa, M. 2018. Towards reliable quantification of hydroxil radicals in the Fenton reaction using chemical probes. RSC Adv 8, 53215330 .

Sadutto, D., Andreu, V., Ilo, T., Akkanen, J., Picó, Y. 2021. Pharmaceutical and personal care products in a Mediterranean coastal wetland: impact of anthropogenic and spatial and environmental risk assessment. Environ. Poll. 271, 116353.

Sakkas, V.A., Lambropoulou, D.A., Albanis, T.A. 2002. Photochemical degradation study of irgarol 1051 in natural waters: influence of humic and fulvic substances on the reaction. J. Photochem. Photobiol. A: Chem. 147, 135-141.

Sánchez-Hernández, J.C., 2006. Earthworm biomarkers in ecological risk assessment. Rev. Environ. Contam. Toxicol. 188, 85-126.

Sannino, F., Spaccini, R., Savy, D., Piccolo, A. 2013. Remediation of highly contaminated soils from an industrial site by employing a combined treatment with exogenous humic substances and oxidative biomimetic catalysis. J. Hazard. Mat. 261, 55-62.

Santos-Juanes, L., Amat, A. M., Arques, A. 2017. Strategies to drive photo-Fenton process at mild conditions for the removal of xenobiotics from aqueous systems. Curr. Org. Chem. 21, 1074-1083.

Schenone, A.V., Conte, L.O., Botta, M.A., Alfano, O.M. 2015. Modeling and optimization of photo-Fenton degradation of 2,4-D using ferroxilate complex and response surface methodology (RSM). J. Environ. Manage. 155, 177-183.

Schmidt, C.K., Fleig, M., Sacher, F., Brauch, H.-J. 2004. Occurrence of aminopolycarboxylates in the aquatic environment of Germany. Environ. Pollut. 131, 107-124.

Schnitzer, M. 1978. Humic Substances: Chemistry and Reactions. Soil Organic Matter Ed: M. Schnitzer and S.U. Khan.

Senka, T., Senta, I., Ahel, M., Gros, M., Petrovic, M., Barceló, D., Müller, J., Knepper, T., Martí, I., Ventura F., Jovancic, P., Jabucar, D. 2008. Occurrence and fate of emerging wastewater contaminats in Western Balkan Region. Sci. Total Environ. 399(1-3), 66-77.

Serra-Clausellas, A., De Angelis, L., Lin, C., Vo, P., Bayati, M., Summer, L., Lei, Z., Amaral, N.B., Bertini, L.M., Mazza, J., Pizzio, L. R., Stripeikis, J.D., Rengifo-Herrera, J.A., Fidalgo de Cortalezzi, M. M. 2018. Abatement of 2, 4-D by $\mathrm{H}_{2} \mathrm{O}_{2}$ solar photolysis and solar photo-Fenton-like process with minute $\mathrm{Fe}(\mathrm{III})$ concentrations. Water Res. 144, 572-580.

Shah, N.S., He, X., Khan, H.M., Khan, J.A., O’Shea, K.E., Boccelli, D.I., Dionysiou, D.D. 2013. Efficient removal of endosulfan from aqueous solution by UV-C/peroxides: a comparative study. J. Hazard. Mater. 263(2), 584-592.

Sheskey, P.J., Cook, W.G., Cable, C.G. 2017. Handbook of Pharmaceutical Excipients, 8th ed., Pharmaceutical Press, London, and American Pharmacists Association, Washington D.C. 2017, pp.130$133,379-382,604-608,803-806$.

Sillanpää, M., Matilainen, A., Lahtinen, T. 2015. Characterization of NOM. IWA Publishing. Natural organic matter in water. Characterization and treatment methods. 17-53. Finland. ElSevier. 
Silva, G.D., Marson, E.O., Batista, L.L., Ueira-Vieira, C., Starling, M.C.V.M., Trovó, A.G. 2021. Contrasting the performance of photo-Fenton at neutral $\mathrm{pH}$ in the presence of different organic ironcomplexes using hydrogen peroxide or persulfate as oxidants for naproxen degradation and removal of antimicrobial activity. Proc. Saf. Environ. Protec. 147, 798-807.

Smith, P.N., Yu, L., McMurry, S.T., Anderson, T.A., 2004. Perchlorate in water, soil, vegetation, and rodents collected from the Las vegas wash, Nevada, USA. Environ Pollut. 132 (1), 121-127.

Solaun, O., Rodríguez, J.G., Menchaca, I., López-García, E., Martínez, E., Zonja, B., Postigo, C., López de Alda, M., Barceló, D., Borja, A., Manzanos, A., Larreta, J. 2021. Contaminants of emerging concern in the Basque coast (N Spain): occurrence and risk assessment for a better monitoring and management decisions. Sci. Tot. Environ. 765, 142765.

Soleimani, M., Hajabbasi, M.A., Afyuni, M., Akbar, S. 2010. Comparison of natural humic substances and synthetic ethylenediaminetetraacetic acid and nitrilotriacetic acid as washing agents of a heavy metalpolluted soil. J. Environ. Qual. 39, 855-862.

Soler, J., García-Ripoll, A., Hayek, N., Miró, P., Vicente, R., Arques, A., Amat, A.M., 2009. Effect of inorganic ions on the solar detoxification of water polluted with pesticides. Water Res. 43, 4441-4450.

Soni, M.G., Carabin, I.G., Burdock, G.A. 2005. Safety assessment of esters of p-hydroxybenzoic acid (parabens). Food Chem. Toxicol. 43 (7), 985-1015.

Soon, A. N. \& Hameed, B. H. 2011. Heterogeneous catalytic treatment of synthetic dyes in aqueous media using Fenton and photo-assisted Fenton process. Desalination. 269(1-3), 1-16.

Soraes, P.A., Batalha, M., Souza, S.M.A.G.U., Boaventura, R.A.R., Vilar, V.J.P. 2015. Enhancement of a solar photo-Fenton reaction with ferric-organic ligands for the treatment of acrylic-textile dyeing wastewater. J. Environ. Manage. 152, 120-131.

Soriano-Molina, P., García Sánchez, J.L., Malato, S., Plaza-Bolaños, P., Agüera, A., Sánchez Pérez, J.A. 2019. On the design and operation of solar photo-Fenton open reactors for the removal of contaminants of emerging concern from WWTP effluents at neutral pH. Appl. Catal. B: Environ. 256, Art. Num. 117801.

Spencer, R.G.M., Bolton, L., Baker, A. 2007. Freeze/thaw and pH effects on fresh water dissolved organic matter fluorescence and absorbance properties from a number of UK locations. Water Res. 41, 2941-2950.

Stedmon, C.A., Markager, S., Bro, R. 2003. Tracing dissolved organic matter in aquatic environments using a new approach to fluorescence spectroscopy. Mar. Chem. 82, 239-254.

Stedmon, C.A. \& Bro, R. 2008. Characterizing dissolved organic matter fluorescence with parallel factor analysis: a tutorial

Steelink, C. 2002. Investigating humic acids in soils. Anal. Chem. 74, 326-333.

Stevenson, F.J. 1982. Nitrogen in agricultural soils. American society of agronomy. Madison, Wisconsin. 940p. 22.

Stevenson, F.J. 1994. Humus Chemistry: Genesys, Composition, Reactions (2nd Edition). John Wiley \& Sons, Inc.

Su, C., Duan, X., Miao, J., Zhong, Y., Zhou, W., Wang, S., Shao, Z. 2017. Mixed conducting perovskite materials as superior catalysts for fast aqueous-phase advanced oxidation: a mechanistic study. ACS Catal. 7, 388-397. 
Sukekava, C., Downes, J., Slagter, H.A., Gerringa, L.J.A., Lagler, L.M. 2018. Determination of the contribution of humic substances to iron complexation in seawater by catalytic cathodic stripping voltammetry. Talanta. 189, 359-364.

Sun, S-P., Zeng, X., Lemley, A.T. 2013. Kinetics and mechanism of carbamazepine degradation by modified Fenton-like reaction with ferric-nitrilotriacetate complexes. J. Hazard. Mat. 252-253, 155-165.

Sutton, R. \& Sposito, G. 2005. Molecular structure in soil humic substances: the new view. Environ. Sci. Technol. 39, 9009-9015.

Tarkwa, J.B., Oturan, N., Acayanka, E., Laminsi, S., Oturan, M.A. 2019. Photo-Fenton oxidation of orange azo dye: process optimization and mineralization mechanism. Environ. Chemistry Letters. 17(1), 473-479.

Terasaki, M., Makino, M., Tatarazako, N. 2008. Acute toxicity of parabens and their chlorinated byproducts with Daphnia magna and Vibrio fischeri bioassays. J. Appl. Toxicol. 29,242-247.

Terzic, S., Senta, I., Ahel, M., Gros, M., Petrovic, M., Barceló, D., Müller, J., Knepper, T., Martí, I., Ventura, F., Jovancic, P., Jabucar, D. 2008. Occurrence and fate of emerging wastewater contaminants in Western Balkan Region. Sci. Total Environ. 399(1-3), 66-77.

Tijani, J., Fatoba, O., Petrik, L.F. 2013. A review of pharmaceuticals and endocrine-disrupting compounds: sources, effects, removal, and detections. Water Air Soil Pollut. 224(11), 1-29.

Thurman E.M., 1985. Organic geochemistry of natural waters. Editado por M. Nijhoff. 516 páginas. Dr W. Junk Publishers, Dordrecht, Holanda.

Tixier, C., Singer, H.P., Oellers, S., Müller, S.R., 2003. Occurrence and fate of carbamazepine, clofibric acid, diclofenac, ibuprofen, ketoprofen, and naproxen in surface waters. Environ Sci. Technol. 37, 10611068 .

Türkay, G.K. \& Kumbur, H. 2019. Investigation of amoxicillin removal from aqueous solution by Fenton and photocatalytic oxidation processes. Kuwait J. Sci. 46 (2), 85-93.

Uyguner C. \& Bekbolet, M. Implementation of spectroscopic parameters for practical monitoring of natural organic matter. Desalination 2005b; 176:47-55.

Valencia, S., Marín, J.M., Restrepo, G., Frimmel, F.H. 2013. Applications of excitation-emission fluorescence matrices and UV/Vis absorption to monitoring the photocatalytic degradation of commercial humic acids. Sci. Total Environ. 442, 207-214.

Visa, M \& Duta, A. 2013. Methyl-orange and cadmium simultaneous removal using fly ash and photoFenton systems. J. Hazard. Mat. 244-245, 773-779.

Waksman, S.A. \& Iyer, K.R.N. 1932. Contribution to our knowledge of the chemical nature and origin of humus: II. The influence of "synthesized" humus compounds and of "natural humus" upon soil microbiological processes. Soil Sci. 34 (1), 71-80.

Walker, C.H., Hopkin, S.P., Sibly, R.M., Peakall, D.B., 2001. Principles of ecotoxicology. $2^{\text {nd }}$ Ed. Taylor and Francis, London.

Wang, L.F., Wang, L.L., Ye, X.D., Li, W.W., Ren, X.M., Sheng, G.P., Yu, H.Q., Wang, X.K. 2013. Coagulation kinetics of humic aggregates in mono- and Di-valent electrolyte solutions. Environ. Sci. Technol. 47, 5042-5049.

Wang, S. \& Wang, J. 2017. Comparative study on sulfamethoxazole degradation by Fenton and Fe(II)activated persulfate process. RSC Adv. 7, 48670-48677.

Wang, Q.; Pang, W.; Mao, Y.; Sun, Q.; Zhang, P.; Ke, Q.; Yu, H.; Dai, C.; Zhao, M. 2019. Study of the degradation of trimethoprim using photo-Fenton oxidation technology. Water. 11, 207. 
Wang, W-L., Wu, Q-Y., Huang, N., Xu, Z.B., Lee, M.Y., Hu, H.Y. 2018. Potential risks from UV/ $\mathrm{H}_{2} \mathrm{O}_{2}$ oxidation and UV photocatalysis: a review of toxic, assimilable, and sensory-unpleasant transformation products. Water Res. 141, 109-125.

Wols, B.A. \& Hofman-Caris, C.H.M. 2012. Review of photochemical reactions constant of organic micropollutants required for UV advanced oxidation processes in water. Water Res. 46(9), 2815-2827.

Wu, Y., Passananti, M., Brigante, M., Dong, W., Mailhot, G. 2014. Fe(III)-EDDS complex in Fenton and photo-Fenton processes: from the radical formation to the degradation of a target compound. Environ. Sci. Pollut. Res. 21, 12154-12162.

Wünsch, U.J., Bro, R., Stedmon, C.A., Wenig, P., Murphy, K.R. 2019. Emerging patterns in the global distribution of dissolved organic matter fluorescence. Anal. Methods. 11,888-893.

Xiao, K., Yu, J., Wang, S., Du, J., Tan, J., Xue, K., Wang, Y., Huang, X. 2020. Relationship between excitation-emission matrix properties and the relative degree of DOM hydrophobicity in wastewater treatment effluents. Chemosphere. 254, 126830.

Xue, X., Hanna, K., Despas, C., Wu, F., Deng, N. 2009. Effect of chelating agent on the oxidation rate of PCP in the magnetite/H2O2 system at neutral pH. J. Mol. Catal. A Chem. 311, 23-35.

Yang, L., Hur, J., Zhuang, W. 2015. Occurrence and behaviors of fluorescence EEM-PARAFAC components in drinking water and wastewater treatment systems and their applications: a review. Environ Sci. Pollu.t Res. 22, 6500-6510.

Yang, Y., Ok, Y.S., Kim, K-H., Kwon, E.E., Tsang, Y.F. 2017. Occurrences and removal of pharmaceutical and personal care products (PPCPs) in drinking water and water/sewage treatment plants: A review. Sci. Total Environ. 596, 303-320.

Yeh C. K. J., Chen W. S., Chen W. Y. 2004. Production of hydroxyl radicals from the decomposition of hydrogen peroxide catalyzed by various iron oxides at $\mathrm{pH}$ 7. Pract. Period. Hazard. Toxic and Radio. Waste Manag. 8(3), 161-165.

Yuan, Z. \& VanBriesen, J.M.2006. The formation of intermediates in EDTA and NTA biodegradation. Environ. Eng. Sci. 23, 533-544.

Zhan, M., Yang, X., Xian, Q., Kong, L. 2006. Photosensitized degradation of bisphenol A involving reactive oxygen species in the presence of humic substances. Chemosphere. 63, 378-386.

Zhang, Y., Klamerth, N., Chelme-Ayala, P., El-Din, M.G. 2016. Comparison of nitriloacetic acid and [S,S]-ethylenediamine- $N, N^{\prime}$-disuccinic acid in UV-Fenton for the treatment of oil sands process-affected water at natural pH. Environ. Sci. Technol. 50, 10535-10544.

Zhang, Y., Dai, M., Yuan, Z. 2018. Methods for the detection of reactive oxygen species. Anal. Met. 10, 4625-4638.

Zhang, M.H., Dong, H., Zhao, L., Wang, D., Meng, D. 2019. A review on Fenton process for organic wastewater treatment based on optimization perspective. Sci. Total. Environ. 670, 110-121.

Zhu, Y., Zhu, R., Xi, Y., Zhu, J., Zhu, G., He, H. 2019a. Strategies for enhancing the heterogeneous Fenton catalytic reactivity: a review. Appl. Catal. B. 255, 117739.

Zingaretti, D., Lombardi, F., Baciocchi, R. 2018. Soluble organic substances extracted from compost as amendments for Fenton-like oxidation of contaminatee sites. Sci. Total Environ. 619-620, 1366-1374. 
Bibliografía 


\section{Estancias y congresos}


Estancias y congresos 


\subsection{Estancias}

En el transcurso de la presente tesis dosctoral, se han realizado dos estancias de investigación en diferentes centros:

1. Estancia de investigación realizada en el Instituto de Investigaciones Fisicoquímicas Teóricas y Aplicadas (INIFTA). La Plata, Argentina. Duración de la estancia: 15-09-2018/15-11-2018

2. Estancia de investigación realizada en LiqTech International A/S. Aalborg, Dinamarca. Duración de la estancia: 01-10-2017/01/12/2017.

\subsection{Congresos}

También se ha asistido a diferentes congresos, tanto nacionales como internacionales, que se citan a continuación:

- 25th International Conference on Advanced Oxidation Technologies for Treatmentof Water, Air and Soil (AOTs-25). Niagara Falls, Canada. Octubre 2019.

$\checkmark$ Novel strategies in iron based processes for wastewater treatment: mild photo-Fenton and ZVI-photo-Fenton combination. 60-60

- 6th European Conference on Environmental Applications of Advanced Oxidation Processes (EAAOP-6). Porotorse, Eslovenia. Junio 2019.

$\checkmark$ Analysis of iron complexing activity in photo-Fenton process of humic substances obtained at different fermentation times of olive mill waste. 473-474.

$\checkmark$ Humic like substances to drive photo-Fenton at mild conditions for parabens removal. 582-583.

$\checkmark$ Isolation of humic-like substances from oil mill wastes to be employed in solar-driven processes for pollutant removal. 155-156.

$\checkmark$ Toxicity assessment of four emerging pollutants contained in 2013/39/EC treated by mild photo-Fenton process. 125-126.

- VII Congreso I+D+i campus de Alcoi. Creando Sinergias. Alcoy, España. Julio 2019. 
Degradación de contaminantes emergentes utilizando sustancias tipo húmicas mediante proceso foto-Fenton a pH próximo a la neutralidad. 89-92.

- VI Congreso I+D+i Campus de Alcoi. Creando Sinergias. Alcoy, España. Julio 2018.

$\checkmark$ Utilización de membranas de UF en la valorización de los residuos procedentes de la producción del aceite de oliva. 141-144.

- XIII Congreso Español de Tratamiento de Aguas (META 2018). León, España. Junio 2018.

$\checkmark$ Comparación de la capacidad complejante de distintas sustancias tipo húmicas obtenidas a partir del alpechín como agentes complejnates en el proceso foto-Fenton. 44-44.

$\checkmark$ Estudio del tamaño molecular de sustancias tipo húmicas procedentes de residuos de la industria olivarera y su efecto sobre procesos foto-Fenton en condiciones suaves de pH. 41-41.

$\checkmark$ Tratamiento mediante procesos de oxidación avanzada y caracterización de aguas residuales provenientes de un centro de atención primaria. 43-43.

- 10th European Meeting on Solar Chemistry and Photocatalysis: Environmental Applications (SPEA10). Almería, España. Junio 2018.

$\checkmark$ Humic like susbtances from olive mill wastes as complexing agent to drive photo-Fenton near neutral pH. 527-528.

$\checkmark$ Steel wood for a combined red-ox process: ZVI reduction and photoFenton oxidation of pentachlorophenol. 546-547.

$\checkmark$ Toxicity assessment of a mixture of emerging compounds treated by photo-Fenton. 548-549.

- V Congreso I+D+i Campus de Alcoi. Creando Sinergias. Alcoy, España. Julio 2017.

$\checkmark$ Eliminación de contaminantes emergentes contenidos en la Directiva 2013/39/CE mediante procesos de oxidación avanzada (AOPs). 71-74. 
- 5th European Conference on Environmental Applications of Advanced Oxidation Processes (EAAOP-5). Praga, República Checa.

$\checkmark$ Study of solar photo-Fenton at different $\mathrm{pH}$ for removal of contaminants of emerging concern. 302-302. 
